\title{
Physiological and Endocrine Factors Contributing to Acyclicity in the Captive Female African Elephant (Loxodonta africana)
}

Tina Lynn Dow

West Virginia University

Follow this and additional works at: https://researchrepository.wvu.edu/etd

\section{Recommended Citation}

Dow, Tina Lynn, "Physiological and Endocrine Factors Contributing to Acyclicity in the Captive Female African Elephant (Loxodonta africana)" (2012). Graduate Theses, Dissertations, and Problem Reports. 4849.

https://researchrepository.wvu.edu/etd/4849

This Dissertation is protected by copyright and/or related rights. It has been brought to you by the The Research Repository @ WVU with permission from the rights-holder(s). You are free to use this Dissertation in any way that is permitted by the copyright and related rights legislation that applies to your use. For other uses you must obtain permission from the rights-holder(s) directly, unless additional rights are indicated by a Creative Commons license in the record and/ or on the work itself. This Dissertation has been accepted for inclusion in WVU Graduate Theses, Dissertations, and Problem Reports collection by an authorized administrator of The Research Repository @ WVU.

For more information, please contact researchrepository@mail.wvu.edu. 


\title{
Physiological and Endocrine Factors Contributing to Acyclicity in the Captive Female African Elephant (Loxodonta africana)
}

\section{Tina Lynn Dow}

\author{
Dissertation submitted to the \\ Davis College of Agriculture, Forestry, and Consumer Sciences \\ at West Virginia University \\ in partial fulfillment of the requirements \\ for the degree of \\ Doctor of Philosophy \\ in \\ Reproductive Physiology \\ Robert A. Dailey, Ph.D., Chair \\ Philip Keeting, Ph.D. \\ Stan Hileman, Ph. D \\ Gene Felton, Ph.D. \\ Ida Holásková, Ph.D. \\ Janine L. Brown, Ph.D.
}

Division of Animal and Nutritional Sciences

Morgantown, West Virginia

2012

Keywords: gonadal dysfunction, ovary, granulosa cell, prolactin, anti-Müllerian hormone 
Physiological and Endocrine Factors Contributing to Acyclicity in the Captive Female African Elephant (Loxodonta africana)

Tina Lynn Dow

\begin{abstract}
Currently, the captive African elephant population in North America is not self-sustaining. An increase in acyclicity has been documented among post-pubertal females of all ages. Due to ethical issues and cost, importation of new animals is not feasible at this time; therefore, it is imperative that all post-pubertal females within zoological facilities be reproductively viable. The main objectives of these projects were to assess the reproductive status of the captive population and to identify contributing factors to acyclicity. In addition, prevention and treatment protocols were to be designed to promote reproductive proficiency in all reproductiveage females to avert the population collapse that has been predicted.
\end{abstract}

\title{
Experiment 1
}

A written survey assessed reproductive status of female Asian and African elephants in AZA/SSP facilities in 2008, and data were compared to surveys conducted in 2002 and 2005. Results showed ovarian acyclicity rates across the surveys remained unchanged for Asian (13.3, 10.9 and 11.1\%) and African (22.1, 31.2 and 30.5\%) elephants, respectively ( $\mathrm{P}>0.05)$, but were higher overall for African compared to Asian elephants $(\mathrm{P}<0.05)$. In 2008, the percentages of Asian and African elephants with irregular cycles (14.3 and 15.8\%) and irregular + no cycles (25.4 and 46.4\%) was similar to 2005 (7.6 and 11.8\%; 18.5 and 43.0\%), but were increased compared to 2002 (2.6 and 5.2\%; 16.0 and 27.3\%), respectively $(\mathrm{P}<0.05)$. For both species, ovarian acyclicity increased with age $(\mathrm{P}<0.05)$. Reproductive tract pathologies did not account for the majority of acyclicity, although rates were higher in noncycling females $(\mathrm{P}<0.05)$. Bull presence was associated with increased cyclicity rates $(\mathrm{P}<0.05)$ for Asian $(92.5$ versus 58.3\%) and African (64.9 versus 57.8\%) elephants compared to females at facilities with no male, respectively. Cyclicity rates were higher for Asian (86.8 versus 65.2\%) and African (67.9 versus $56.7 \%)$ elephants managed in free compared to protected contact programs $(\mathrm{P}<0.05)$, respectively. Geographical facility location had no effect on cyclicity ( $\mathrm{P}>0.05)$. In summary, incidence of ovarian cycle problems continues to predominantly affect African elephants. Although percentages of acyclicity did not increase between 2005 and 2008, 42.2\% Asian and $30.2 \%$ African females were no longer being hormonally monitored; thus, reproductive cycle abnormalities could be worse than current data suggest.

\section{Experiment 2}

This paper described anti-Müllerian hormone (AMH) secretion in Asian and African elephants of different age groups and reproductive status. Overall mean concentrations did not differ ( $\mathrm{P}>0.05)$ between species, but were markedly higher in male than female Asian (31.01 \pm 4.22 $\mathrm{ng} / \mathrm{mL}, 0.19 \pm 0.02 \mathrm{ng} / \mathrm{mL})$ and African (40.27 $\pm 3.18 \mathrm{ng} / \mathrm{mL}, 0.17 \pm 0.04 \mathrm{ng} / \mathrm{mL})$ elephants, respectively. Anti-Müllerian hormone secretion was not related to ovarian cyclicity status (cycling vs. noncycling) $(\mathrm{P}>0.05)$, but was higher in prepubertal $(0.40 \pm 0.10 \mathrm{ng} / \mathrm{mL})$ compared 
to reproductive age (8-35 years old; $0.18 \pm 0.04 \mathrm{ng} / \mathrm{mL}$ ) and aged ( $\geq 36$ years old; $0.16 \pm 0.03$ $\mathrm{ng} / \mathrm{mL})$ females $(\mathrm{P}<0.05)$. In males, AMH secretion was not affected by musth status, but was age-related $(\mathrm{P}<0.05)$, with concentrations being higher in prepubertal $(49.08 \pm 6.11 \mathrm{ng} / \mathrm{mL})$ as compared to aged ( $\geq 36$ years old) $(22.27 \pm 5.82 \mathrm{ng} / \mathrm{mL})$ bulls; concentrations in mature bulls (835 years of age) $(37.01 \pm 3.17 \mathrm{ng} / \mathrm{mL})$ were similar to prepubertal and older bulls $(\mathrm{P}>0.05)$. We concluded that circulating AMH concentrations in elephants were similar between species and not affected by reproductive status; however, concentrations were significantly higher in males than females, and were elevated in younger animals. The diagnostic value of AMH to assess fertility status of individual elephants remains to be determined.

\section{Experiment 3}

Currently, reproductive age (11-35 years old) female African elephants (Loxodonta africana) in U.S. zoos are experiencing high rates of ovarian cycle problems (>40\%) and low reproductive success. Previously, one-third of acyclic females exhibited hyperprolactinemia, a likely cause of ovarian dysfunction. This follow-up study examined the current state of hyperprolactinemia in African elephants and found the incidence has increased significantly to 71\%. Circulating serum progestagens and prolactin were analyzed in 31 normal cycling, 13 irregular cycling, and 31 acyclic elephants for a 12-month period. In acyclic females, overall mean prolactin concentration differed from cycling females $(\mathrm{P}<0.05)$, with concentration being either higher $(n=22 ; 54.90 \pm 13.31 \mathrm{ng} / \mathrm{mL})$ or lower $(n=9 ; 6.47 \pm 1.73 \mathrm{ng} / \mathrm{mL})$ than normal. No temporal patterns of prolactin secretion were evident in elephants that lacked progestagen cycles. In cycling females, higher concentrations of prolactin were observed during nonluteal (34.38 \pm 1.77 and $32.75 \pm 2.61 \mathrm{ng} / \mathrm{mL})$ than luteal $(10.51 \pm 0.30$ and $9.67 \pm 0.42 \mathrm{ng} / \mathrm{mL})$ phases for normal and irregular females, respectively. Overall prolactin means did not differ $(\mathrm{P}>0.05)$ between normal $(16.11 \pm 2.89 \mathrm{ng} / \mathrm{mL})$ and irregular $(15.03 \pm 4.17 \mathrm{ng} / \mathrm{mL})$ cycling females. Of most concern was that over two-thirds of acyclic females now are hyperprolactinemic, a dramatic increase from the one-third observed 7 years earlier. Furthermore, females of reproductive age constituted $45 \%$ of elephants with hyperprolactinemia. Until the cause of this problem is identified and/or a treatment is developed, reproductive rates will remain suboptimal and the population non-sustaining.

\section{Experiment 4}

Perturbations in serum prolactin concentration have been identified as a common symptom among captive acyclic African elephants. In the human, hyperprolactinemia and prolactin deficiencies are significant causes of amenorrhea. Pituitary prolactin is held under constant inhibition by a hypothalamic derived neurotransmitter, dopamine; thus, regulation via exogenous treatment with antagonists or agonists has been successful in reinitiating normal ovarian cycles. Oral administrations of Cabergoline (dopamine agonist; $n=4$ ) and domperidone (dopamine antagonist; $n=4$ ) were studied as possible treatments for hyperprolactinemia or prolactin deficiency, respectively. Changes in serum prolactin and progestagen concentrations in response to treatment were evaluated to determine if regulation of prolactin synthesis can reinitiate normal estrous cyclicity. Overall mean prolactin concentration decreased $(\mathrm{P}=0.01)$ in cabergoline treated females $(32.22 \pm 14.75 \mathrm{ng} / \mathrm{mL})$ when compared to controls $(77.53 \pm 0.96 \mathrm{ng} / \mathrm{mL})$. Overall mean progestagen concentrations increased $(\mathrm{P}<0.05)$ in treated females $(0.15 \pm 0.01$ 
$\mathrm{ng} / \mathrm{mL}$ ). In contrast, control hyperprolactinemic females maintained mean baseline progestagen concentration $(0.07 \pm 0.01 \mathrm{ng} / \mathrm{mL})$. Overall mean prolactin concentration increased $(\mathrm{P}=0.005)$ during times of domperidone treatment $(21.77 \pm 3.69 \mathrm{ng} / \mathrm{mL})$ when compared to controls $(5.77 \pm$ $0.46 \mathrm{ng} / \mathrm{mL}$ ). Overall mean serum progestagen concentration was not significantly different in the treated group $(0.11 \pm 0.01 \mathrm{ng} / \mathrm{mL})$ when compared to controls $(0.07 \pm 0.01 \mathrm{ng} / \mathrm{mL})$. In conclusion, prolactin synthesis can be regulated with either a dopamine agonist or antagonist resulting in a decrease or increase in serum prolactin concentration, respectively. Although serum progestagen concentration increased in response to Cabergoline treatment, whether estrous cyclicity sufficient for successful breeding was reinitiated could not be determined. 


\section{Table of Contents}

$\begin{array}{lll}\text { Abstract } & \text { ii }\end{array}$

Table of Contents $\quad$ V

List of Tables $\quad$ ix

List of Figures $\quad$ xi

Acknowledgements $\quad$ xvi

$\begin{array}{ll}\text { Review of Literature } & 1\end{array}$

$\begin{array}{ll}\text { Natural History } & 1\end{array}$

$\begin{array}{lr}\text { Social Structure } & 1\end{array}$

Communication 3

Diet $\quad 4$

Reproduction

$\begin{array}{ll}\text { Puberty } & 5\end{array}$

$\begin{array}{ll}\text { Estrous Cycle: Captive Population } & 7\end{array}$

$\begin{array}{ll}\text { Follicular Phase } & 7\end{array}$

$\begin{array}{ll}\text { Luteal Phase } & 13\end{array}$

$\begin{array}{ll}\text { Reproductive Abnormalities } & 15\end{array}$

$\begin{array}{lr}\text { Estrous Acyclicity } & 15\end{array}$

$\begin{array}{lr}\text { Housing and Management } & 16\end{array}$

$\begin{array}{ll}\text { Dietary Insufficiencies } & 17\end{array}$

$\begin{array}{lr}\text { Hyperprolactinemia } & 18\end{array}$

$\begin{array}{ll}\text { Prolactin Deficiencies } & 20\end{array}$ 
Results of the Third Reproductive Assessment Survey of North American Asian (Elephas maximus) and African (Loxodonta africana) Female Elephants

Abstract

Introduction

Results

Discussion

Conclusions

References

Tables

Influence of Age and Gender on Secretion of Anti-Müllerian Hormone in Asian (Elephas maximus) and African (Loxodonta africana) Elephants

Abstract

Introduction 
$\begin{array}{ll}\text { Materials and Methods } & 60\end{array}$

$\begin{array}{ll}\text { Results } & 62\end{array}$

$\begin{array}{ll}\text { Discussion } & 63\end{array}$

$\begin{array}{ll}\text { Conclusions } & 67\end{array}$

$\begin{array}{ll}\text { References } & 69\end{array}$

$\begin{array}{ll}\text { Tables and Figures } & 75\end{array}$

Evidence of Hyperprolactinemia as a Growing Cause of Infertility in Female Zoo African

$\begin{array}{ll}\text { (Loxodonta africana) Elephants } & 79\end{array}$

$\begin{array}{lc}\text { Abstract } & 80 \\ \text { Introduction } & 81 \\ \text { Materials and Methods } & 83 \\ \text { Results } & 85 \\ \text { Discussion } & 87 \\ \text { References } & 94 \\ \text { Tables and Figures } & 101\end{array}$

Determining the Efficacy of Domeridone and Cabergoline for Treating Ovarian Acyclicity in Captive female African (Loxodonta africana) Elephants 108

$\begin{array}{ll}\text { Abstract } & 109\end{array}$

$\begin{array}{ll}\text { Introduction } & 110\end{array}$

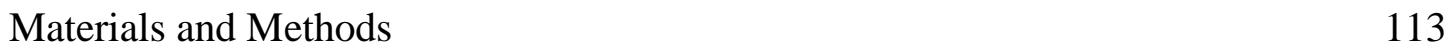

$\begin{array}{ll}\text { Results } & 116\end{array}$ 
Discussion

References

Figures

Summary and Conclusion

Literature Cited

Apendix I

189

Vita

205 


\section{List of Tables}

\section{Experiment 1}

Table 1. Response rates and cyclicity status results of the 2008 Reproductive Assessment Survey for female Asian and African elephants in North America

Table 2. Number and age distributions of Asian elephant females exhibiting normal ovarian cycles, no ovarian cycles, or irregular cycles in the SSP population in North America based on 2008 Reproductive Assessment Survey results

Table 3. Number and age distribution of African elephant females exhibiting normal ovarian cycles, no ovarian cycles, or irregular cycles in the SSP population in North America based on 2008 Reproductive Assessment Survey results

Table 4. Numbers of Asian elephant females evaluated by transrectal ultrasonography and categorized based on both normal and abnormal urogenital tract morphology within ovarian cyclicity status categories

Table 5. Numbers of African elephant females evaluated by transrectal ultrasonography and categorized based on normal and abnormal urogenital tract morphology within ovarian cyclicity status categories 
Table 6. Comparison of results between the 2002, 2005, and 2008 reproductive assessment surveys for the SSP population of Asian and African elephants. Data from 2002 and 2005 surveys were from Brown et al. (2004) and Proctor et al. (2010)

Experiment 2

Table 7. Overall mean ( \pm SEM) serum AMH concentrations in postpubertal male and female Asian and African elephants 76

Table 8. Mean ( \pm SEM) serum AMH concentrations in cycling and acyclic female and musth and nonmusth male Asian and African elephants

Table 9. Mean ( \pm SEM) serum AMH concentrations in female and male Asian and African elephants across age categories

\section{Experiment 3}

Table 10. Circulating serum prolactin concentrations (mean \pm SEM) in normal cycling, irregular cycling, and acyclic female African elephants during the estrous cycle, and for the 1-year study period 


\section{List of Figures}

\section{Literature Review}

Figure 1. Summary of possible contributing factors to acyclicity in the captive female African elephant, and their investigation thus far.

\section{Experiment 2}

Figure 2. Profile of serum AMH concentrations over a 20-year period in an older female Asian elephant (age 42 - 62 years of age). Regression analysis showed a significant decrease in AMH concentration over time $(* \mathrm{P}<0.05)$.

\section{Experiment 3}

Figure 3. Representative profile of serum progestagen and prolactin concentrations for a normal cycling female elephant.

Figure 4. Representative profiles of serum progestagen and prolactin concentrations for three representative irregular cycling female elephants.

Figure 5. Representative profiles of serum progestagen and prolactin concentrations for three representative irregular cycling female elephants.

Figure 6. Representative profiles of serum progestagen and prolactin concentrations for three representative irregular cycling female elephants. 
Figure 7. Representative profile of serum progestagen and prolactin concentrations for an acyclic female elephant with high prolactin concentrations.

106

Figure 8. Representative profile of serum progestagen and prolactin concentrations for an acyclic female elephant with low prolactin concentrations.

107

\section{Experiment 4}

Figure 9. Serum prolactin concentrations in all Cabergoline treated $(\mathrm{n}=4)$ and control $(\mathrm{n}=4)$ hyperprolactinemic, acyclic female African elephants.

Figure 10. Serum progestagen concentrations in all Cabergoline treated $(n=4)$ and control $(n=4)$ hyperprolactinemic, acyclic female African elephants.

Figure 11. Serum prolactin concentrations in all domperidone treated $(n=4)$ and control $(n=4)$ prolactin deficient, acyclic female African elephants. Black areas designate treatment times (Week 0-3; 12-15; 24-27; 36-39; and 48-51).

Figure 12. Serum progestagen concentrations in all domperidone treated $(n=4)$ and control $(n=4)$ prolactin deficient, acyclic female African elephants. Black areas designate treatment times (Week 0-3; 12-15; 24-27; 36-39; and 48-51). 
Figure 13. Serum progestagen and prolactin concentrations in a single normal cycling female African elephant. [Reprinted with permission from Dow and Brown (2012).]

\section{Appendix I.}

Figure 14. Elephant 1. Serum progestagen and prolactin concentrations in an domperidone treated prolactin deficient acyclic female African elephant.

Figure 15. Elephant 2. Serum progestagen and prolactin concentrations in an domperidone treated prolactin deficient acyclic female African elephant.

Figure 16. Elephant 3. Serum progestagen and prolactin concentrations in an domperidone treated prolactin deficient acyclic female African elephant.

Figure 17. Elephant 4. Serum progestagen and prolactin concentrations in an domperidone treated prolactin deficient acyclic female African elephant.

Figure 18. Elephant 5. Serum progestagen and prolactin concentrations in an domperidone control prolactin deficient acyclic female African elephant.

Figure 19. Elephant 6. Serum progestagen and prolactin concentrations in an domperidone control prolactin deficient acyclic female African elephant. 
Figure 20. Elephant 7. Serum progestagen and prolactin concentrations in an domperidone control prolactin deficient acyclic female African elephant.

Figure 21. Elephant 8. Serum progestagen and prolactin concentrations in an domperidone control prolactin deficient acyclic female African elephant.

Figure 22. Elephant 9. Serum progestagen and prolactin concentrations in a Cabergoline treated hyperprolactinemic acyclic female African elephant.

Figure 23. Elephant 10. Serum progestagen and prolactin concentrations in a Cabergoline treated hyperprolactinemic acyclic female African elephant.

Figure 24. Elephant 11. Serum progestagen and prolactin concentrations in a Cabergoline treated hyperprolactinemic acyclic female African elephant.

Figure 25. Elephant 12. Serum progestagen and prolactin concentrations in a Cabergoline treated hyperprolactinemic acyclic female African elephant.

Figure 26. Elephant 13. Serum progestagen and prolactin concentrations in a Cabergoline control hyperprolactinemic acyclic female African elephant.

Figure 27. Elephant 14. Serum progestagen and prolactin concentrations in a Cabergoline control hyperprolactinemic acyclic female African elephant. 
Figure 28. Elephant 15. Serum progestagen and prolactin concentrations in a Cabergoline control hyperprolactinemic acyclic female African elephant.

Figure 29. Elephant 16. Serum progestagen and prolactin concentrations in a Cabergoline control hyperprolactinemic acyclic female African elephant. 


\section{$\underline{\text { Acknowledgements }}$}

I would like to thank Drs. Robert Dailey, Phil Keeting, Stan Hileman, Gene Felton, Ida Holásková, and Janine Brown not only for serving on my committee, but for their support, guidance, and contributions to my research. I would especially like to thank Dr. Dailey for instilling in me good scientific values and teaching me to look at life as if there is no "box." Even when I doubted myself he continued to believe in me. I am the person and scientist I am today because of him. I would like to thank Dr. Keith Inskeep for his knowledge, support, and encouragement; his door was always open and for that I will be forever grateful. In addition, Dr. Ida Holásková has not only served as a committee member, but has also been a great friend and confidant.

Without the support and participation of zoological facilities, Elephant Taxonomy Advisory Group (TAG), Elephant Managers Association (EMA), and the Association of Zoos and Aquariums (AZA) my research would not have been possible. Having worked at a zoological facility for a number of years before graduate school, I know all too well that there are never enough hours in the day. Therefore, I am appreciative to everyone who took time out of an already busy day to fill out surveys, collect and ship blood samples, answer emails, and administer medication to elephants for my projects. I was always greeted with warm smiles and kind words by all facilities I was fortunate enough to work with.

A great deal of thanks is owed to those individuals who have and continue to inspire me. I am forever indebted to Jennifer Warmbold, Ginny, Alice, and Kate. Thank you so much for allowing me to be part of the herd and to experience life through the eyes of an elephant. I would like to thank Dr. Elizabeth Freeman for giving me the compass to find my way on this journey. Elizabeth has been an incredible role model and grounding point. There has never been 
a time when I have needed her that she has not been there to answer questions or to give encouragement. I can say with the utmost sincerity that I hope I can be half the scientist and woman that she is. In addition, Nicole Parker, Olivia Parker, Devett Parker, and Natalia PradoOviedo have been helpful inside and outside of the lab as colleagues and dear friends. I thank them all very much for all the knowledge they have instilled in me, for sharing the triumps and failures with encouragement and humor, and for always reminding me what is most important in life.

Last, but definitely not least, I would like to thank my unwavering support system, “The Golden Trifecta." I cannot begin to find the words to thank my husband, Andrew. Always the first to congratulate me on a job well-done or to wipe my tears and encourage me to try again, I could not have accomplished any of this without him. In addition, I am so grateful for the unconditional love and support from our four-legged children, Chase and Marley. No matter how long and tedious the day, all was made right with the world by wagging tails and cold noses. Finally, I would like to thank all my family and friends who have supported me throughout the years. Your kind words have meant more to me then you will ever know. 


\section{Literature Review}

\section{Natural History}

\section{Social Structure}

Wild female African elephants live in a fission-fusion matriarchal society involving four tiers of social interactions: cow-calf units, family groups, kinship/bond groups, and clans. Cow-calf pairs are the most basic unit that make up the family group consisting of mothers, daughters, sisters, aunts, and immature males (Douglas-Hamilton, 1975; Moss and Poole, 1983; Wittemyer et al., 2007). Typically, the largest female assumes the role of the matriarch of a herd, which is composed of a family group of cow-calf units; all individuals within a family group are genetically related. The matriarch’s job entails coordinating protection of the herd, finding valuable resources, and contributing genetically (Douglas-Hamilton, 1975; Dublin, 1983; Poole and Moss, 1989; McComb et al., 2001). Herd sizes vary according to available resources, with an average size in most African countries ranging from five to fifteen adult females (cows) and their offspring (calves). Herds consisting of over 100 individuals have been documented; however, if a family group gets too big for the available resources; mature females will leave and form smaller family groups. The newly formed family groups will stay in close contact with their maternal herd for their entire life forming what is termed a kinship/bond group. Bond groups consist of multiple family groups that share a home range. Kinship/bond groups are important as they function to aid in group defenses and allomothering, which allows for young, nulliparous females to learn how to care for young and enables nursing mothers sufficient time to forage (Douglas-Hamilton, 1975; Moss and Poole, 1983; Lee, 1987). Furthermore, elephants are known to congregate into clans. Elephant clans consist of 
family and bond groups of unrelated elephants that share territory intermittently, i.e., watering holes and food browsing areas. An elephant family group’s home range can stretch for 10-20 kilometers during the wet season with documented daily migrations during drought reaching 200 kilometers (Rodgers and Elders, 1977; Douglas-Hamilton, 1998).

The life of the adult male (bull) is in stark contrast to its female counterpart. As young bulls reach sexual maturity, they begin to spend more time at the edge of the herd, gradually leaving for hours or days at a time. Eventually, days become weeks and around the age of 14 years the sub-adult male leaves his family group (Douglas-Hamilton, 1975). While males live primarily solitary lives, they frequently form loose associations with other males called bachelor herds. Males in bachelor herds forage together, work cooperatively in group defense behaviors, and spar with one another (Poole, 1987). Males usually stay in bachelor herds until they have matured to an age where they experience musth, a state of heightened sexual arousal. Regardless, bull society, much like within family groups, has a dominance hierarchy within a given territory with the musth bull becoming the dominant figure (Hall-Martin, 1987; Poole, 1989). Musth is an annual episode of sexual excitement for male elephants that is comparable to rut in male ungulates (Poole, 1987). During periods of musth, which usually lasts 1-3 months depending on individual fitness, bulls only interact with breeding cows or other musth bulls. Only the most dominant males will be allowed to interact with a herd, and be permitted to breed with females in standing heat or estrus. Fights over breeding opportunities between musth bulls can last from minutes to hours and, although rare, can end in death. Usually the older bulls, forty to fifty years of age, do most of the breeding (Poole and Moss, 1981; Poole, 1987). 


\section{Communication}

Elephants communicate in a multitude of ways. When in close proximity to one another elephants can communicate tactilely and visually through touch and body posturing (Kahl and Santiapillai, 2004). Because of their social structure, elephants need to communicate over great distances to warn family, kinship/bond group, or clan members about impending danger or to signal musth males during times of breeding opportunities. Elephants are able to transmit messages over a distance of approximately 10 kilometers vocally via infrasound and chemically through pheromones secreted in urine and temporal gland secretion (Poole et al., 1984; Payne et al., 1986; Langbauer et al., 1989; Rasmussen and Schulte, 1998).

Communication via subsonic vocalizations and chemical signals becomes very important during breeding times when females have to convey their physiological status to potential suitors (Poole and Moss, 1989). Mature male elephants in their twenties will annually experience a period of musth (Poole and Moss, 1981). During this time the male will focus all of his energy on fighting other musth bulls for breeding opportunities with estrus females, breeding, and mate guarding. A male has to be of a specific age and body condition to go into musth; thus, the fit, strong mature bulls are preferred to father offspring (Poole, 1989). Notably, a bull does not have to be in musth to be fertile; however, musth gives the bull the advantage when fighting off other dominant bulls and attracting females (Hildebrandt et al., 2000b). The musth bulls communicate to other males and females by constantly dribbling urine, which contains pheromones, in addition to the steroids and pheromones being secreted from temporal glands (Poole and Moss, 1981; Poole, 1987). Specifically, the composition of the temporal gland secretion shifts from predominantly dihydrotestosterone (DHT) to testosterone (Jainudeen et al., 1972; Rasmussen et al., 1984; Hall-Martin, 1987; Rasmussen et al., 1996). As shown in studies with captive elephants, cows with no previous exposure to bulls 
exhibit an increased state of excitation while investigating temporal gland secretion from a musth bull when compared to a non-musth male (Schulte and Rasmussen, 1999). Furthermore, the concentration of circulating testosterone found in blood serum and temporal gland secretion can increase from $0.04-0.46 \mathrm{ng} / \mathrm{ml}$ and $0.05-0.50 \mathrm{ng} / \mathrm{ml}$ in non-musth bulls to $150 \mathrm{ng} / \mathrm{ml}$ and $\geq 300 \mathrm{ng} / \mathrm{ml}$ during musth, respectively (Poole and Moss, 1981; Hall-Martin, 1987; Poole, 1987; Poole, 1989; Rasmussen et al., 1996; Ganswindt et al., 2005a and 2005b). Exposure to musth bulls could be necessary to stimulate normal ovarian cyclicity; however, that has yet to be determined.

\section{Diet}

An adult elephant can consume between 68 to $91 \mathrm{~kg}$ or $1.5-1.9 \%$ of its body mass daily. Individual variations of daily dry matter intake are dependent on dry matter digestibility and animal characteristics: age, reproductive status, gender, and activity level (Clauss et al., 2003a). Wild elephants are described as browsers and have been documented to consume more than 400 different plant species daily during the wet season. However, even though they appear to be generalized eaters, elephants actually have a very specific diet (Dougall and Sheldrike, 1964; McCullagh, 1969; Buss, 1990), wherein grasses are the most prevalent food item (Field, 1976; Chaika, 1996). Having a monogastric digestive system, with an enlarged pouch at the beginning of the large intestine called a cecum that allows for microbial fermentation of fibrous diets, elephants have to eat almost constantly to fuel their large bodies (Dierenfeld, 1994). Elephants, in general, display low diet digestibility compared to other herbivores with similar diets. Dry matter digestibility in captive African elephants ranged from $22 \%$ to $39 \%$ when fed mixed grasses hay to exceeding $62 \%$ when fed alfalfa hay 
(Roehrs et al., 1989). Field studies that utilized lignin ratio technique as an internal marker suggested average dry matter digestibility of $30 \%$ to $45 \%$ for free-ranging wild elephants (Dierenfeld, 1994).

Overall, the diet of the elephant contains $8-10 \%$ crude protein with slight fluctuations in protein content in plants during dry versus wet seasons (Lindsay, 1994). Certainly, when foodstuffs are plentiful the elephant consumes more dry matter and subsequently more protein; however, the elephant will adjust its diet accordingly. Sub-Saharan trees contain high concentrations of protein binding soluble condensed tannins. During the wet season, elephants not only ingest more protein rich plants, but also add more bark and leaves from tannin rich trees to increase crude fiber content in the diet, which subsequently balances the diet ensuring daily protein content remains at $10-12 \%$ throughout the year (McCullagh, 1969). In addition, 1.2-1.8\% lipid, 43-62\% fiber, as well as vitamins and minerals via consumption of twigs, bark, and even soil are considered the dietary norm (McCullagh, 1973; Sukamar, 2003). In contrast, captive elephants are fed daily diets of approximately $8-10 \%$ crude fiber and $\geq 30 \%$ crude protein consisting of highly digestible grain pellets and mixed-grasses hay (Hatt and Clauss, 2006; Masuri, 2007).

\section{$\underline{\text { Reproduction }}$}

\section{Puberty}

Puberty in wild female elephants occurs between 8 to15 years of age. Puberty for the female is defined as the time of first estrus (Perry, 1953; Sukumar, 1994). If successful, the estrus will be accompanied by a fertile mating with a male and after a 22 month gestation, a healthy calf (Hodges, 1998). Considering that elephants have a long lifespan and survive up to 70 years in the wild, some 
females reproduce well into their 50s; thus, they can have a reproductive lifespan of $\geq 40$ years (Laws 1969; Whitehouse and Hall-Martin, 2000; Moss, 2001). In general, wild elephants are either pregnant or in lactational anestrous (Hall-Martin, 1987) with an average calving interval of 4-6 years (Moss and Poole, 1983). Data collected from culled elephants in Kruger National Park, South Africa between 1975 and 1995 showed that reproductive success declines sharply as females age, specifically around the age of 50 (Freeman et al., 2009b). Ovarian morphological data collected from culled wild females in African game parks also suggested that females $\geq 50$ years of age have nearly exhausted follicular reserves (Perry, 1953; Laws, 1969). Moreover, at this time in an elephant's life she is taking on more of an alloparenting role, spending more time helping rear calves within the family (Douglas-Hamilton, 1975; Lee, 1987; Wittemyer et al., 2007). Similar data from culling have shown rare cases of wild cows that have never had calves and appear to experience reproductive tract pathologies including endometrial, uterine, and/or ovarian cysts (Freeman et al., 2009b).

In contrast, captive elephants reach puberty at a significantly earlier age with the majority of females having obtained maturity (first estrus) at 7 years of age (Brown, 2000). In one case, an Asian female elephant was impregnated at the age of two and gave birth at age four (Keele et al., 2007). Currently, only 38.9\% of all captive reproductive age African females in North America have a breeding history either via live cover by a bull or artificial insemination, with less than half of those individuals successfully conceiving and able to carry calves full term (Olson, 2008). Furthermore, the majority of captive cows that have never experienced pregnancy seem to exhibit higher incidences of reproductive tract pathologies and abnormal estrous cyclicity that appears to have progressively worsened over the last six years (Brown, 2000; Brown et al., 2004a; Hermes et al., 2004; Proctor et al., 2009). 


\section{Estrous Cycle: Captive Population}

The captive female elephant exhibits a long spontaneous estrous cycle that is 14-16 weeks in length consisting of a 4-6 week follicular phase and 8-10 week luteal phase; approximately 3-4 estrous cycles per year (Plotka et al., 1988; Hodges, 1998; Brown, 2000). The elephant’s estrous cycle is at least three times longer in duration when compared to other species: the horse, sheep, cattle, and guinea pig (all 16-21 days), rat (4-5 days), and menstrual cycle of the primate (28 days) (Draincourt et al., 1993). The elephant is a monovular, non-seasonal breeder, regardless of habitat or environment, i.e., wild or captive (Short, 1966; Hildebrandt et al., 1996; 2000a; Hermes et al., 2000; Schulte et al., 2000). However, in wild populations, more breeding and calving has been documented during the rainy season when resources are most abundant (Douglas-Hamilton, 1975; Moss and Poole, 1989). Unlike the homosexual behaviors observed in cattle such as females mounting estrus females, the female elephant does not show any outward signs of estrus or heat (Katz and McDonald, 1992). Thus, hormone profiles assayed from urine, feces, and/or blood collection are necessary to monitor ovarian cyclicity. In wild populations the bull elephant is able to detect estrus via pheromones excreted in urine and temporal gland secretion using only the vomeronasal organ located in the roof of his mouth (Rasmussen, 1998; Rasmussen and Schulte, 1998; Bagley et al., 2006).

\section{Follicular Phase}

At the onset of the 4-6 week follicular phase, follicle stimulating hormone (FSH) is the dominant reproductive hormone in circulation (Brown et al., 1999a; 2004b). Follicle stimulating hormone is a glycoprotein that is synthesized and secreted by gonadotrophic cells in the anterior pituitary in response to pulsatile secretion of hypothalamic gonadotropin-releasing hormone $(\mathrm{GnRH})$ 
(Phifer et al., 1973) and granulosa cell derived activin (Bilezikjian et al., 2004). Follicle stimulating hormone targets a specific G-protein coupled transmembrane receptor found on granulosa cell membranes in developing preantral follicles (Richards, 1980; Funkenstein et al., 1984). Important for selection, growth, and development of follicles, FSH also acts at the granulosa cell to convert testosterone from theca interna cells into estradiol $\left(\mathrm{E}_{2}\right)$ by increasing the activity of the aromatase enzyme (Fitzpatrick and Richards, 1991). Although not yet proven in the elephant, it is thought that like in other species, estradiol enters the vascular circulation transported by sex-hormone binding globulin to target estradiol- $\alpha$ receptors $(E R \alpha)$ in the arcuate nucleus of the hypothalamus allowing for the negative feedback regulation of tonic GnRH secretion and subsequent luteinizing hormone (LH) synthesis and secretion by gonadotrophic cells in the anterior pituitary (Goodman et al., 1980). Since GnRH neurons do not express ER $\alpha$, it is hypothesized estradiol works indirectly through other neurotransmitters to inhibit GnRH neurons (Lehman and Karsch, 1993; Lehman et al., 1993). A possible candidate for local control of GnRH release is kisspeptin (kiss-1); kiss-1 neurons express ER $\alpha$ (Franceschini et al., 2006). In the sheep (Pompolo et al., 2006), primate (Silverman et al., 1977), and rodent (Clarkson and Herbison, 2006) GnRH neurons are found in close apposition to projections from kiss-1 neurons. Moreover, GnRH neurons express the kiss-1 receptor, GPR-54 (Clarkson et al., 2008). Kisspeptin has been shown to increase GnRH secretion during the estrous cycle thereby increasing FSH and LH secretion (Pompolo et al., 2006); binding of estradiol to kiss-1 neurons inhibits synthesis and secretion of kiss- 1 and subsequent GnRH secretion and pituitary gonadotropins (Pielecka-Fortuna et al., 2008). In addition, kiss-1 may also act directly or indirectly on intermediary $\gamma$-aminobutyric acid (GABA) releasing neurons to regulate GnRH secretion (Pielecka-Fortuna et al., 2008; Zhang et al., 2009). 
As the follicular phase progresses, FSH from the anterior pituitary decreases from its peak concentration of approximately $25 \mathrm{ng} / \mathrm{ml}$ to a baseline of $6 \mathrm{ng} / \mathrm{ml}$ just before the ovulatory LH surge (Brown et al., 1991; Brown et al., 1999a; Brown et al., 2004b). As seen in other species, secretion of inhibin, produced by granulosa cells of the growing follicles, follows an inverse pattern to that of FSH, and along with estradiol begins to suppress FSH (Brown et al., 1991). Inhibin, a heterodimeric glycoprotein and member of the transforming growth factor- $\beta$ family (TGF- $\beta$ ), acts at the pituitary level through serine-threonine receptors on gonadotrophic cells to selectively suppress synthesis of the FSH $\beta$ unit (Vale et al., 1990). In addition, inhibins have been shown to exert an antagonistic effect by competing with activins. Activins are members of the TGF- $\beta$ family that are both stimulatory to and stimulated by FSH (Bilezikjian et al., 2006).

In addition to the secretion of estradiol and activin, the developing follicles also produce antimüllerian hormone $(\mathrm{AMH})$. Like activin, $\mathrm{AMH}$ is a member of the TGF- $\beta$ family; $\mathrm{AMH}$ is produced in primary, secondary, and small antral follicles in the post-pubertal ovary by granulosa cells (Buarends et al., 1995). Similar to inhibin, AMH participates in primary follicle formation during folliculogenesis by inhibiting excessive primordial follicular recruitment by FSH (Lee and Donahoe 1993; Durlinger et al., 1999). Currently, AMH is used as a marker of fertility in women (Weenen et al., 2004), cattle (Ireland et al., 2008) and mice (Kevenaar et al., 2006), with circulating concentration being positively correlated with the number of morphologically healthy oocytes within the follicular reserve (Ficicioglu et al., 2006; Visser et al., 2006). Clinically, tests for AMH commonly are used to estimate the onset of menopause in women, a state of reproductive cycle cessation due to ovarian follicle depletion (Rock and Bartlett, 1937; van Rooij et al., 2002; van Rooij et al., 2005). To date, $\mathrm{AMH}$ in the elephant has not been investigated. 
During the time when FSH and activin begin to decrease and estradiol and inhibin increase, the first of two waves of follicular development is observed, along with subsequent estradiol and LH surges (Hermes et al., 2000; Leuders et al., 2010). Although not completely understood, the elephant experiences two LH surges during the follicular phase, 19-21 days apart, unlike the single LH surge that is seen in all other mammalian species (Kapustin et al., 1996; Brown et al., 1999). The first LH surge occurs 10-20 days after the drop in luteal progestagens and does not result in ovulation; however, without this first LH surge ovulation during the second LH surge does not occur (Hermes et al., 2000). During both anovulatory and ovulatory LH surges, concentrations of urinary estrogens and serum LH reach about $8 \mathrm{ng} / \mathrm{mg}$ and $13 \mathrm{ng} / \mathrm{ml}$, respectfully; thus, both surges are qualitatively and quantitatively similar (Brown et al., 1999; Brown et al., 2004b). Although not completely understood, the two LH surges could serve an evolutionary purpose because of the social structure of the wild elephant. In the Asian elephant, a urinary pheromone, (Z)-7-dodecenyl acetate (Z7-12: Ac) has been detected immediately after the anovulatory LH surge (Rasmussen, 2001). This pheromone may be detected kilometers away by prospective males, allowing them approximately 21 days to locate females that will soon be in estrus (Rasmussen, 2001). Such pheromones secreted in the urine of the African elephant are yet to be identified.

Specifically for the African elephant, but not the Asian, the protein hormone prolactin secreted from lactotrophic cells in the anterior pituitary is increased during the time of follicular development (Brown and Lehnhardt, 1997). Prolactin is involved in a variety of biological processes, most notably mammary gland development during mid to late gestation and postpartum lactation (Rillema, 1994 and 1998). Prolactin release is under constant inhibitory control by dopamine released from tubero-infundibular dopamine (TIDA) neurons in the arcuate nucleus of the hypothalamus (Ben-Jonathan, 1994). Prolactin has been found to participate in a variety of 
physiological processes; several mechanisms of action for prolactin are of particular interest in regards to reproduction and are dependent on species and stage of estrous cycle (Freeman et al., 2000). In the rodent, prolactin is the main luteotropic hormone to ensure pregnancy survival via maintenance of progesterone secretion from the corpus luteum (CL) by decreasing the progesterone metabolizing enzyme 20 $\alpha$-hydroxysteroid dehydrogenase (Lamprecht et al., 1969; Bast and Melampy, 1972; Morishige and Rothchild, 1974). Additionally, at the ovarian level, prolactin has anti-atretic properties in preovulatory follicles in cattle (Lebedeva et al., 1998). In the African, but not the Asian elephant, prolactin is shown to increase in a cyclic pattern during the follicular phase of the estrous cycle (Brown et al., 2004; Yamamoto et al., 2010). Thus, in the African elephant, prolactin could participate in follicular selection and development.

Prolactin secretion is under both positive and negative regulation. Hypothalamic dopamine acts on specific membrane bound receptors, dopamine 2 (D2) receptors, on lactotrophs in the anterior pituitary to inhibit prolactin synthesis by decreasing intracellular cyclic adenosine monophosphate (cAMP), which is necessary for prolactin mRNA synthesis (Vallar and Meldolesi, 1989).

Additionally, melatonin from the pineal gland has also been identified as a prolactin inhibitory factor. Working through a different physiological system than dopamine, melatonin acts to decrease the synthesis of a prolactin-stimulating factor, namely vasoactive intestinal polypeptide (VIP) (Kamberi et al., 1971; Nicosia et al., 1983).

Vasoactive intestinal polypeptide in the brain is synthesized in and secreted from two distinct areas, the hypothalamus and lactotrophs in the anterior pituitary. Acting to stimulate prolactin mRNA synthesis by enhancing adenyl cyclase and subsequently cAMP, directly at the lactotroph and/or indirectly through deactivation of TIDA neurons, VIP works in concert with other prolactinstimulating factors (Ajika et al., 1972; Meites et al., 1972; Ben-Jonathan et al., 2008). Estrogen acts on the hypothalamus to decrease dopaminergic tone and directly on lactotrophs to increase 
thyrotropin-releasing hormone (TRH) receptors and on D2 receptors to block the dopamine-induced decrease in cAMP. In addition, TRH is known to increase prolactin production via direct stimulation by calcium or the subsequent phosphorylation of proteins through a calmodulin-dependent protein kinase (Tashjian et al., 1971; Geras et al., 1982). Furthermore, corticotrophin-releasing hormone (CRH) has also been shown to stimulate prolactin secretion (Sar and Meites, 1968). Bechart and colleagues (1999) found a negative correlation of progestagen and cortisol and a positive correlation between prolactin and cortisol in the female African elephant. Moreover, an increase in circulating cortisol concentration has been observed in non-cycling, hyperprolactinemic female African elephants (Brown et al., 2004b). However, in the human, cortisol has a suppressive effect on the prolactin gene and synthesis of prolactin (Molitch, 2009).

The first follicular wave yields 2-4 small follicles that grow to approximately $10 \mathrm{~mm}$ in diameter before becoming atretic; no dominant follicle is observed during the first wave in the cycling, non-pregnant African female elephant (Hermes et al., 2000). Two days before ovulation a single antral follicle, $\geq 20 \mathrm{~mm}$ in diameter, derived from the second follicular wave will be the only structure on the active ovary (Hermes et al., 2000; Leuders et al., 2010). Ovulation occurs between 18 and 24 hours after the ovulatory estrogen peak and subsequent LH surge. In contrast to the negative feedback that estradiol exerts on tonic GnRH secretion during follicular development, the estradiol surge resulting in ovulation works through the hypothalamic surge center in a positive feedback loop; this mechanism is thought to work via a kiss-1 mediation of glutamate stimulation on GnRH neurons (Smith et al., 2006). Interestingly, progestagens begin to rise one to three days before the ovulatory LH surge (Kapustin et al., 1996; Brown et al., 1999). Although the rise in progestagen concentration is considered a normally occurring event in both Asian and African elephants, physiologically it is not yet understood. 


\section{Luteal Phase}

After ovulation of the dominant follicle, concentrations of progestagens and FSH begin to increase, with FSH lagging behind progestagens by approximately one week (Brown et al., 1999a; 2004b). Increases in hormone concentrations occur regardless if the cow is pregnant or not, followed by normal estrous cycle profiles for approximately eight weeks (Brown and Lehnhardt, 1995), after

which progestagen concentration will begin to decrease. However, if there is maternal recognition of pregnancy then the CL will not regress and progestagen concentration will increase and remain between $1.0 \mathrm{ng} / \mathrm{ml}$ to $1.5 \mathrm{ng} / \mathrm{ml}$ for the remainder of the 22 month gestation (Brown and Lehnhardt, 1995).

The 8-10 week luteal phase of the elephant is dominated by progestagens produced by the CL. Unlike other eutherian mammals, the major circulating progestagen in the elephant is not progesterone, but rather its 5- $\alpha$ reduced metabolites, $5 \alpha$-pregnane-3, 20-dione (5 -DHP) and $5 \alpha$ -

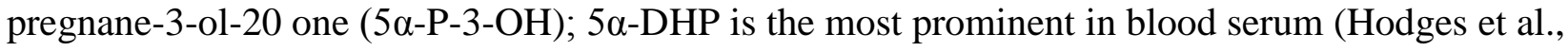
1997; Schwarzenberg et al., 1997). In circulation, 5 -DHP follows a biphasic pattern, rising to a concentration of 0.8-1.1 ng/ml midluteal and is maintained for approximately eight weeks before falling to a baseline concentration of $\leq 0.08 \mathrm{ng} / \mathrm{ml}$ (Carden et al., 1998).

During the luteal phase, concentrations of FSH increase allowing for recruitment and growth of follicles to occur, as well as participation in the production of estrogen via aromatase activation (Brown et al., 1999a; 2004b). In the elephant, FSH increases during the same time that progestagen is at its highest concentration; FSH reaches a plateau which is held at a constant concentration until dropping prior to ovulation. In other monovular species such as horse (Bergfelt et al., 1991), cattle (Kaneko et al., 1995), and primates (Schneyer et al., 2000; Zeleznik, 2001), FSH is shown to increase 
in spikes preceding each follicular wave, dropping to baseline concentration directly afterward (Ginther et al., 2001). Interestingly, waves of follicular development are only observed during the follicular phase after progestagen has decreased to baseline concentrations (Hermes et al., 2000). As the luteal phase progresses, the CL begins to slowly regress and, thus, new estrogen producing follicles are developing in two follicular waves (Hermes et al., 2000). Unless pregnancy is established, this dynamic environment of the ovary sets the stage for the follicular phase and subsequent ovulation.

The luteolytic mechanism in the elephant has not yet been characterized. In domestic animal species as well as primates and humans, prostaglandin $\mathrm{F}_{2} \alpha\left(\mathrm{PGF}_{2} \alpha\right)$ is the primary luteolytic hormone initiating luteal regression. During the follicular phase, estradiol causes upregulation of endometrial oxytocin receptors and progesterone during the luteal phase increases phospholipid stores and synthesis of the enzyme prostaglandin synthase; both mechanisms support production of luteolytic $\mathrm{PGF}_{2} \alpha$ (Pate and Townson, 1994). In the cow (Thatcher et al., 1976), sheep (McCracken et al., 1972), and pig (Moeljonoet et al., 1977), pulsatile secretion of posterior pituitary oxytocin acts on the uterine endometrium to stimulate the synthesis and pulsatile secretion of $\mathrm{PGF}_{2} \alpha$; a finite store of oxytocin in the CL acts to amplify $\mathrm{PGF}_{2} \alpha$ pulses from the uterus (McCracken et al., 1999). Luteolytic concentration of $\mathrm{PGF}_{2} \alpha$ is transported to the ovary via a vascular countercurrent exchange mechanism consisting of the utero-ovarian vein and ovarian artery (Ginther, 1974). In addition to increasing oxytocin release, $\mathrm{PGF}_{2} \alpha$ binds at the ovary to specific receptors on the plasma membrane of luteal cells (Fried et al., 1969). Prostaglandin $F_{2} \alpha$ causes ischemia (Niswender et al., 1976), activates protein kinase C to inhibit progestagen synthesis (Lahav et al., 1976; Davis et al., 1987), stimulates an influx of immune cells (Webb et al., 2002) and increases intracellular calcium (Dorflinger et al., 1984). These actions result in apoptosis of luteal cells and ultimately regression of 
the CL. Day of luteolysis is species specific (Diaz et al., 2007). However, Gross and colleagues (1991) showed that administration of intramuscular injections of $80-125 \mathrm{mg} \mathrm{PGF}_{2} \alpha$ to cycling female elephants 25, 30, 45, and 60 days post estrus failed to initiate luteolysis. Circulating serum progestagen concentration decreased in one female four days after injection on day 60 of treatment; however, luteal regression normally begins on day 60. Although it was concluded that PGF2 $\alpha$ was incapable of inducing luteolysis at this dose regimen for the female elephant, dose, number of injections per animal per day, and route of injection play key roles in initiation of lyses of luteal cells in other species. Therefore, further studies regarding the role of PGF2 $\alpha$ in luteolysis in the elephant are necessary.

\section{Reproductive Abnormalities}

\section{Estrous Acyclicity}

As documented by Brown et al., (2004a; 2004b) captive elephants in North America experience ovarian inactivity, wherein the circulating progestagen concentration is held at baseline. This phenomenon, termed acyclicity, has been observed in captive African and Asian elephants in North America, as well as in European zoological facilities (Brown et al., 2004b; Oerke et al., 1999). Acyclicity occurs specifically in older Asian elephants $\geq 40$ years of age but throughout the postpubertal reproductive life of the African elephant; $\geq 11$ years of age and older. Within North American zoological facilities, approximately 11\% of Asian and 31\% of African elephants are acyclic, with an additional 11\% of Asian and 13\% of African elephants exhibiting irregular estrous cyclicity (Proctor et al., 2010). In addition, Hildebrandt and colleagues (2000) found that, ultrasonographically, the vagina of acyclic cows shows an advanced dormant appearance wherein the 
vaginal mucosa is hyperechogenic. Interestingly, this condition seems to be reversible (Brown et al., 2004b; Schulte et al., 2000).

\section{Housing and Management}

Housing conditions and management practices play a deciding role not only in longevity, but also in reproductive success for other captive species. In captivity, the black rhinoceros (Diceros biconis) exhibits high mortality and inconsistent reproductive rates. The captive population has not been able to sustain itself without replacements from the wild (Smith and Reed, 1992). Furthermore, mortality in this species has been positively correlated with time spent on exhibit in public access areas, breeding success has been positively correlated with exhibit size, and zoological facilities housing more than one female have seen a decrease in reproductive success (Carlstead et al., 1999a). Furthermore, parallels exist between captive African elephants and black rhinoceros wherein both captive populations are not self sustaining, with a failure of more than one-third of the captive population to breed, long-birth intervals among multiparous females, and in most cases death rates exceeding birth rates (Carlstead et al., 1999a and 1999b). For example, since 1999, there have been 37 recorded African elephant births and 42 deaths in North American at Association of Zoos and Aquariums (AZA) accredited zoological facilities. Of the 37 births, 14 (37\%) calves have already died from disease and trauma related incidences (Olson, 2009). Miller-Schroeder and Paterson (1989) found that enclosure volume, enclosure complexity, and availability of privacy were positively correlated with breeding success in Western lowland gorillas (Gorilla gorilla gorilla). Comparably, large enclosures and multiple nest boxes are important factors in successful reproduction in the red panda (Ailurus fulgens) (Roberts, 1989). Clouded leopards (Neofelis 
nebulosa) experience increases in circulating cortisol concentrations in accordance to enclosure height, degree of exposure to the public and/or predators, and type of keeper interactions (Wielebnowski et al., 2002). Additionally, female cheetah (Acinonyx jubatus) housed together experience ovarian suppression and display more behaviors indicative of potential distress; i.e. stereotypic pacing and increased aggression (Brown et al., 1996). The findings of these studies reaffirm that zoos should manage captive species according to natural history and natural social conditions whenever possible.

\section{Dietary Insufficiencies}

Although captive elephants are free of dietary pressures seen in wild conspecifics, cases of life threatening vitamin, mineral, and nutritional deficiencies within captive populations are frequently documented. Reports of mineral deficiency diseases include rickets (Ensley et al., 1994), zinc deficiency associated with foot and skin lesions (Schmidt, 1989), and vitamin E deficiencies (Dierenfeld and Dolensek, 1988). In addition, obesity is an increasing problem in captive zoo elephants thought to be due to a combination of an overly digestible diet and a lack of physical activity; captive female African elephants are 27\% heavier than wild females of the same age (Ange et al., 2001). Not only does obesity have negative ramifications on animal care resulting in atherosclerosis (Clauss et al., 2003b) and gastrointestinal problems (Salzert, 1976; Rüedi, 1995), but also obesity could be directly correlated to estrous acyclicity. In human beings, obesity has been linked to gonadal dysfunction, infertility, miscarriage, poor pregnancy outcome, impaired fetal wellbeing, cancer of the breast and uterus, and polycystic ovarian syndrome, in addition to diabetes mellitus (Norman and Clark, 1998). Body weight has been shown to have an inverted "U” effect on 
reproduction; wherein low or high body mass contributes to infertility, menstrual disorders, and poor reproductive outcome (Correa and Jacoby, 1978). Moreover, Freeman and colleagues (2009a) found females with a larger body index were more susceptible to acyclicity.

\section{Hyperprolactinemia}

In 2004, Brown and colleagues completed a comprehensive study to determine if specific hormonal imbalances were causative factors to ovarian acyclicity. Out of 10 hormones [LH, FSH, prolactin, thyroid stimulating hormone (TSH), estradiol, free and total triiodide thyronine (T3), free and total thyroxin (T4), and cortisol] that were assayed, significant differences were found in circulating concentrations of estradiol, FSH, and prolactin in acyclic compared to normal cycling females. Of particular interest, hyperprolactinemia was detected in one-third (11/33) of acyclic African female elephants. In addition, for hyperprolactinemic females, estradiol was significantly increased, FSH was significantly decreased and cortisol was increased, though not significant. Comparably, Bechert and colleagues (1999) found a positive correlation between prolactin and cortisol, and a negative correlation between progestagens and cortisol in female elephants. Although prolactin is much needed during times of pregnancy and lactation to stimulate mammary development and milk protein synthesis, continuously elevated concentrations of the hormone during the menstrual cycle in human beings can contribute to infertility (Biller, 1999).

Hyperprolactinemia is one of the primary causes of amenorrhea and anovulation in the human (Yu et al., 1981; Jones, 1989). Although hyperprolactinemia has been associated with sleep apnea, anorexia, protein ingestion, hypoglycemia, stress, chest wall stimulation, and trauma (Woolf, 1986; Jones, 1989; Biller et al., 1996), the three main causative factors of hyperprolactinemia resulting in 
infertility in the human are physiological (pregnancy and lactation); pharmacological (antiinflammatories, analgesics, and $\mathrm{H}_{2}$ inhibitors); and pathological (pituitary prolactinomas) (Mah and Webster, 2002). High concentration of prolactin in pregnant or nursing individuals acts at the hypothalamus to increase sensitivity to estrogen, which subsequently suppresses the GnRH/LH pulse generator causing lactational amenorrhea (McNeilly, 2001). In addition, increases in serum prolactin can also act via receptors on dopaminergic neurons resulting in an increase in dopamine release (Moore and Demarest, 1982.). Dopamine not only acts to inhibit anterior pituitary prolactin synthesis and secretion, but also decreases gonadotropin synthesis and secretion indirectly by suppressing GnRH secretion in the hypothalamus causing gonadal dysfunction (Rolland and Corbey, 1977). In the human, a variety of pharmaceuticals either work as receptor antagonists to remove dopamine inhibition or directly stimulate prolactin secretion, both of which result in a dramatic increase in prolactin secretion (La Torre and Falorni, 2007). Regardless of causative pathway, an increase in prolactin secretion would cause an increase in dopamine resulting in suppression of GnRH. Prolactinomas account for $25-30 \%$ of functioning pituitary tumors and are a major contributor to hyperprolactinemia (Webster and Scanlon, 1997). Not only could tumors in the pituitary cause an abnormal increase in prolactin secretion and subsequent dopamine release, but tumor presence could physically block the secretion of gonadotropins thereby compromising estrous cyclicity (Mah and Webster, 2002). Likewise, tumor growth could result in release of other pituitary derived hormones causing perturbations in the hypothalamic-pituitary-ovarian/adrenal axis resulting in infertility (Webster and Scanlon, 1997). Adenoma in a Western lowland gorilla (Gorilla gorilla gorilla) has been shown to cause hyperprolactinemia resulting in gonadal dysfunction (Chatfield et al., 2006). Furthermore, pharmacologically-induced hyperprolactinemia in the rat caused a decrease in core body temperature, increase in circulating corticosterone and a decrease in pituitary adrenocorticotropic hormone (ACTH) (Drago and Amir, 1984; Drago et al., 1989). Although 
prolactin concentration during pregnancy and lactation in elephants has been studied (McNeilly et al., 1983; Brown and Lehnhardt, 1997), the contribution of pharmaceuticals and pituitary tumors on hyperprolactinemia in the elephant is yet to be investigated.

\section{Prolactin Deficiency}

Prolactin deficiency has been associated with menstrual disorders, delayed puberty, infertility, and subfertility in humans (Martikainen et al., 1989; Falk, 1992; Mukherjee et al., 2003; Van Aken and Lamberts, 2005). Although the mechanism of action remains unknown, in the majority of prolactin deficient cases, the actual deficiency is a secondary condition to general anterior pituitary dysfunction (Toledano et al., 2007). The clinical signs of prolactin deficiency are dependent on the extent of the deficiency and may be non-specific. In humans, prolactin deficiency often occurs in conjunction with other pituitary hormone deficiencies, head injury, infections, and parasellar or infiltrative disease (Roberts and Ladenson, 2004; Van Aken and Lamberts, 2005). In addition, several pharmaceuticals, i.e., pyridoxine, hydergine, and diuretics, have been identified as inhibitors of prolactin synthesis (Yazigi et al., 1997).

It is well documented that prolactin deficiency in the horse via Tall Fescue Toxicosis has been directly linked to numerous reproductive problems such as extended gestation periods, abortion, increased incidences of stillborns and dystocia, and decreased lactation (Cross et al., 1999). Tall fescue infected with an endophytic fungus, Neotyphodium coenophialium, contains ergot alkaloids that act as a dopamine D2 receptor agonist (Oliver, 1997). Such agonists have a direct inhibitory effect on lactotroph cells in the anterior pituitary suppressing prolactin synthesis (Macleod and Lehmeyer, 1974). Supplementation in mares (Evans et al., 1999) and heifers (Evans et al., 2003) with dopamine D2 receptor antagonist domperidone has been successful to counteract the deleterious 
effects on reproduction during ergot alkaloid ingestion. Interpretation of these data suggests reinitiation of prolactin synthesis may be needed for normal reproductive function.

In a 1988 study using human in vitro fertilization patients, treatment with the dopamine agonist bromocriptine after ovarian hyperstimulation resulted in decreased serum and follicular fluid prolactin, increased serum estradiol, accelerated ovarian follicle growth, decreased luteal phase progesterone concentration, and subsequently shortened luteal phase length, thus, suggesting that induced hypoprolactinemia interferes with ovarian function (Kauppila et al., 1988). Furthermore, prolactin has gonadotropic activity (Doppler, 1994; Wise and Maurer, 1994; Lebedeva et al., 1998) and has been implicated in the regulation of ovarian function in a number of species (Gaytan et al., 1997; Clarke and Cummings, 1989). Prolactin increases during the follicular phase of the estrous cycle in response to positive feedback action of follicular estrogens on the pituitary lactotroph cells (Lawson et al., 1993) and acts on specific ovarian receptors to regulate follicular activity (Besognet et al., 1996; Besognet et al., 1997). In addition, healthy follicles contain significantly higher follicular fluid prolactin concentrations than atretic ones (Lebedeva et al. 1998). Follicular fluid prolactin is believed to be involved in angiogenesis and the stimulation of ovarian epithelial cells, both of which are important for follicular formation of corpora lutea (Castilla et al., 2010). Prolactin in conjunction with gonadotropins and estradiol, aids in the process of oocyte maturation by inhibiting the degeneration of surface epithelial cells and the disruption of connective tissue in the follicle wall. Thus, high preovulatory concentrations of prolactin may be important to the process of follicular growth, oocyte maturation and ovulation (Yoshimura et al., 1991). 


\section{Interactions with Herd Members}

Certainly, interaction with herd mates could play a role in reproductive acyclicity. In a variety of species, including gray wolves (Canis lupus) (Packard et al., 1985), cheetah (Acinonyx jubatus) (Wielebnowski et al., 2002), dwarf mongoose (Helogale parvula) (Creel et al., 1992), African wild dog (Lycaon pictus) (Creel et al., 1997), black-backed jackal (Canis mesomelas) (Creel and Creel, 1991), naked mole-rats (Heterocephalus glaber) (Faulkes et al., 1990; Smith et al., 1997), saddle-back tamarin (Saguinus fuscicollis) (Epple and Katz, 1984), and marmoset monkey (Callithrax jacchus) (Abbott, 1984) estrus suppression is a common occurrence wherein the dominant female will suppress reproductive cyclicity in subordinates via direct contact, vocal or chemical cues.

In wild elephant herds, during times of drought when resources are sparse, the matriarch may actually suppress reproduction in younger subordinate females (Sikes, 1971; Dublin, 1983). For the elephant, the role of dominance status of captive females has recently been investigated by Proctor and colleagues (2010b). Utilizing behavioral surveys completed by elephant keepers, observations, and endocrine data, investigators suggested that the cow that assumes the matriarchal role among captive family groups experiences an increase in reproductive acyclicity. It is hypothesized that because captive groups consist of non-related females continuously moved to different facilities throughout their lives, which is in direct contrast to wild herds, much more energy is spent maintaining peace among herd mates, and maintaining dominant status (Freeman et al., 2009a and 2010). In wild conspecifics, more female to female competition has been observed during times when resources are limited, whether those resources be food, water, or mates (Schulte et al., 2000; Slade et al., 2003; Archie et al, 2006). 


\section{Stress}

Suppression of reproduction in subordinates could possibly be accomplished via stressmediated alteration to the hypothalamic-pituitary-adrenal (HPA) or hypothalamic-pituitary-ovarian (HPO) axis, thus resulting in ovarian inactivity. Reproduction in the nonpregnant female is dependent on a carefully synchronized sequence of endocrine events. Adrenal-produced cortisol secreted during times of stress is a known suppressor of GnRH from the hypothalamus (Ringstrom and Shwartz, 1987). Increased glucocorticoid secretion near the onset of estrus in the cow, ewe, and sow can block the ovulatory surge in LH and ovarian steroidogenesis (Essawy et al., 1989), suppress $\mathrm{PGF}_{2 \alpha}$ subsequently prolonging the estrous cycle in ruminants (Abilay et al., 1975; Liptrap, 1993), and retard follicular development at the time of emergence of the ovulatory cohort in the sow (Liptrap, 1970; Barb et al., 1982). During the normal estrous cycle, GnRH from the hypothalamus acts at the pituitary level to initiate the secretion of gonadotropins, FSH and LH. Once in circulation, FSH and LH target granulosa and thecal cells, respectively, in the developing follicle. If GnRH is suppressed via cortisol, then FSH and LH are also subsequently suppressed, not only blocking ovulation but also follicle selection and development (Moberg, 1985). Blood cortisol analysis has proven useful as an indicator of stress under a variety of conditions wherein not all events were considered negative (Elridge et al., 1976; Line et al., 1987; Reinhardt et al., 1990). However, cortisol clearly is not sensitive to every type of stressor, and considerable intra-animal variability in biological responses exists. 


\section{Environmental Factors}

Environmental changes deviating from the norm are also factors that can cause alterations in ovarian activity. For a variety of mammalian species, multiple environmental factors play key roles in reproduction, such as resource availability, ambient temperature, rainfall, day/night cycle, and social cues (Bronson, 1985). Although the elephant is not a classical seasonal breeder, whereby breeding cyclicity and subsequent receptivity is initiated by photoperiod, breeding activity increases in the wild African elephant during times of increased rainfall when resources are most abundant (Asdell, 1964; Sadleir, 1969). One particular study investigating if environment played a role in reproductive cyclicity in three captive African cows in Rhode Island, North America, showed a positive correlation of acyclicity with time spent indoors. Importantly, the most time spent indoors was during the winter (Schulte et al, 2000). Moreover, data from the North American African Elephant Studbook and 2005 Reproductive Assessment Survey show, regardless of time of year or location of facility, elephants remain cyclic and are capable of breeding 365 days a year (Olsen, 2009; Proctor et al., 2010a).

\section{Age}

Reproductive cessationincreasing with age is common among long-lived species. As a female continues to cycle, follicles are selected for development either resulting in atresia or ovulation. Throughout a female’s reproductive lifespan, follicular reserves are continually reduced until finally not enough follicles remain to produce the necessary hormones to support cyclicity (Richardson et al., 1987). The elephant in the wild spends her post-pubertal life either pregnant or in lactational 
anestrous. With a 22 month gestation and a four to six year calving interval, a cow that lives well into her 50s could have only 10 breeding opportunities throughout her entire life time. Wild cows well into their 50s, have successfully given birth to healthy calves; however, there are also cows that seem to stop showing signs of estrus as early as her 40s (Laws et al., 1969; Hall-Martin, 1987; Whitehouse and Hall-Martin, 2000; Moss, 2001). The latter is thought not to be due to a known depletion of her follicular reserves, but instead due to the grandmother hypothesis (Hawkes et al., 1998; Alvarez, 2000; Hawkes, 2004). Rather than continue to use energy reserves to give birth herself, older females are known to care for other calves in the herd. This kind of nurturing allows the calf's mother to conserve her energy ensuring that she remains healthy and able to produce milk of the highest nutrient content to maintain good calf health. Furthermore, this kind of aid from older females can enable other mothers to wean offspring sooner thus increasing reproductive rates (Hawkes, 2004). In contrast, elephants in captivity do not have the breeding opportunities that their wild counterparts experience. Data collected from a recent reproductive assessment survey showed that only $45.9 \%$ of Asian and 42.6\% of African elephants in North America have either experienced a natural breeding via direct contact with a bull or breeding via artificial insemination. Moreover, of those cows with breeding histories, $61.5 \%$ of Asian and $76.6 \%$ of African cows became pregnant and 68.7\% of Asian and 39.1\% of African females delivered a live calf (Olsen, 2009; Proctor et al., 2010a). With a 16 week estrous cycle, captive cows can have approximately three cycles per year. Although the average lifespan of a captive elephant is much shorter than wild females, 29.8 years compared to 56.0 years, captive elephants with no breeding history could cycle at least 60 times in their lifespan, a six-fold increase (Clubb et al., 2008 and 2009; Olsen, 2009). It is possible the constant cyclicity could lead to a premature cessation of estrous cycles due to earlier threshold follicle depletion. 


\section{Reproductive Tract Pathologies}

Over the last 10 years, incidences of reproductive tract pathologies such as tumors and polyps, cysts, and endometrial disease appear to be increasing in captive African female elephants (Hermes et al., 2004). As of 2008, 37.5\% (27/72) of captive reproductive age female African elephants monitored in North America via transrectal ultrasonography were affected with at least one reproductive tract pathology (Proctor et al., 2010a). In comparison, data from wild culled African elephants revealed that reproductive tract pathologies in general only occurred in 3.3\% (18 out of 552) reproductive age females. Furthermore, only 9.4\% $(n=112)$ of reproductive age females appeared to be experiencing a loss of ovarian activity as determined by a lack of structures on the ovary, i.e., follicle(s) of any stage of development or CL. Interestingly, only one female, a 58-yearold cow, had never calved (Freeman et al., 2009b).

Tumors and polyps in the reproductive tract can be detrimental to reproductive success. The anatomy of the female elephant is unique wherein the urogenital tract opening is located on the abdomen between the rear legs; total tract length is approximately 12 feet (Balke et al., 1988). Obstruction of the tract in the vestibule, vagina, cervix, or uterus by a benign tumor could cause pain and discomfort during mating or act as a physical barrier preventing sperm from traveling into the oviduct for ovum fertilization (Hildebrandt et al., 2000a). Furthermore, passage of the blastocyst from the oviduct into the uterine body could be compromised, as well as implantation and placentation (Perry, 1974). Although such pathologies have never been found in the African elephant, Asian elephants experience benign smooth muscle fibroid tumors known as uterine leiomyomas (Hildebrandt et al., 2000a). Growth factors and steroid hormones play a key role in the development of leiomyomas (Marsh and Bulun, 2006). First described in 1793 by Baillie, uterine leiomyomas are the most common mass found in women in a clinical setting, becoming more prevalent with age and 
reproductive experience; $40 \%$ of woman over 40 years of age experience leiomyomas (Buttram, 1986). Montali and colleagues (1997) found similar results in aged, nulliparous female Asian elephants. Although uterine fibroids are estrogen and progestagen dependent, individuals suffering from this pathology do not always experience abnormal circulating concentration of steroid hormones (Hildebrandt and Göritz, 1995). However, fibroids contain an increased number of receptors for estrogen and progesterone (Marsh and Bulun, 2006).

Despite extensive research regarding ovarian cysts, an exact etiology remains unknown. In the human, polycystic ovarian syndrome (PCOS) is one of the most common endocrine disorders compromising fertility. Woman with PCOS exhibit abnormally high circulating androgen concentration and peripheral insulin resistance; there has also been a link to obesity (Ehrmann, 2005). Although a treatment protocol for PCOS including weight loss, exogenous hormone therapy via birth control pills, aromatase inhibitors, LH analogs, and Metformin, a hypoglycemia-inducing drug that increases insulin sensitivity, has shown success in regaining fertility, no definitive treatment has been agreed upon (Badawy and Elnashar, 2011). In cattle, cystic ovarian disease involves follicular cysts, luteinized follicular cysts, or cystic CL (Roberts, 1971; Bierschwal et al., 1975). Furthermore, abnormal estrous behavior from perturbations within the endocrine environment results in either constant estrus or anestrus (Casida et al., 1944; Garm, 1949). Treatment in this species is most often accomplished through exogenous administration of GnRH. A study by Cantley and colleagues (1975) showed that approximately 80\% of cystic cows treated with GnRH recovered and resumed cyclicity within 23 days. Ovarian cysts are observed in approximately 15\% of captive African elephants, but are rarely observed in their wild counterparts with a documented incidence of $<1 \%$ in data collected from natural deaths and culls (Hildebrandt et al., 2004; Freeman et al., 2009b). 
Treatment with exogenous GnRH of one African female, 23 years of age, presenting a reoccurring ovarian cyst did not elicit a response (Brown et al., 1999b).

In the rhesus monkey (macaca mulatta) (Zuckerman, 1937), Boer goat (capra hircus) (Radi, 2005), Vietnamese pot-bellied pig (Sus scrofa) (Harmon et al., 2004), domestic dog (Canis familiaris) (Bosschere et al., 2000), and peri-menopausal human (Takreem et al., 2009), cystic endometrial hyperplasia (CEH), a progressive degenerative disorder of the endometrium, has been observed to impair fertility. In Asian and African elephants CEH has been shown to occur more frequently and be more prevalent in aged, nulliparous females. Moreover, CEH lesions are severe and associated with polyps (Agnew et al., 2004). Unlike other species with CEH, elephants are unique in that affected individuals have a normal hormonal environment; therefore, $\mathrm{CEH}$ is not due to exogenous phytoestrogens or ovarian estrogen-secreting cysts or tumors as in the sow, cow and ewe (Kennedy et al., 1998, Agnew et al., 2004). Regardless, persistent CEH can cause infertility by preventing implantation or fertilization. Similar to the carnivore, the elephant placenta is endotheliochorial and zonary with uniform number and thickness of endometrial glands (Mossman, 1987). In the carnivore, size, number, and secretory function of endometrial glands are under estrogenic and progestational influence, respectively (Ambrósio et al., 2011). Cyclicity i.e., progressive proliferation and prolonged secretory activity by the uterus, without pregnancy interference can result in chronic proliferative changes in the endometrium. Interestingly, uterine glandular hyperplasia in the adult mouse, rabbit and pig is caused by hyperprolactinemia (Chilton et al., 1988; Young et al., 1989; Kelly et al., 1997). 


\section{Statement of Problem}

In a 2000 report, State of the North American African Elephant Population and Projection for the Future, Olsen and Wiese concluded that "the current population may be able to become selfsustaining without the need of future importations only if reproduction and juvenile survivorship increase significantly by 2010.” Currently, the North American captive population of African elephants is not self-sustaining (Proctor et al., 2010a). Since 1999, there have been 37 documented births (14 of which have already died) and 42 deaths; infant mortality, including infanticide continues to increase (Clubb et al., 2008 and 2009; Olson, 2009). Moreover, data from the most recent Reproductive Assessment Survey has shown estrous cycle abnormalities, as well as reproductive tract pathologies continue to plague captive African elephants (Proctor at el., 2010a). Ten years ago there was a growing concern among captive elephant managers that some of the behavioral problems demonstrated by North American elephants are directly attributed to a lack of social learning and a strong matriarchal figure. Captive "herds" consist of approximately two to three, same-aged animals with no resemblance of the complex fission-fusion society that wild elephants have evolved (Olson and Wiese, 2000). Therefore, the present studies are conducted to assess the frequency and demographics of acyclic captive females, identify factors contributing to acyclicity, and development of protocoles to restore estrous cyclicity in acyclic individuals. Although a substantial amount of data has been gathered to help identify those factors contributing to acyclicity in this species, there are a number of possible causes that are yet to be investigated (Figure 1). 


\section{Possible Contributing Factors to Acyclicity in Captive Female African Elephants (Loxodonta africana)}

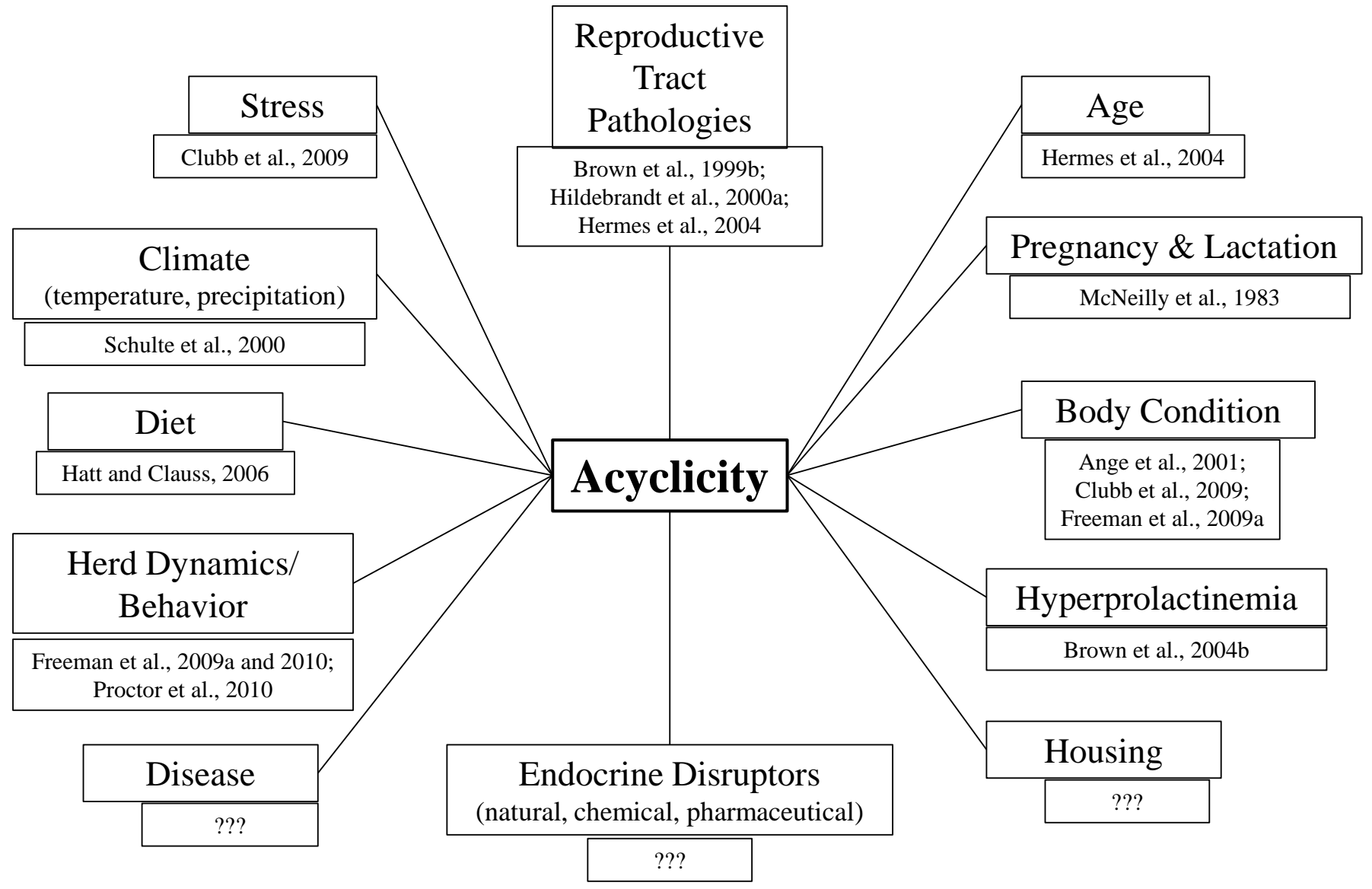

Figure. 1.

??? denotes no published work regarding topic 
Results of the Third Reproductive Assessment Survey of North American Asian (Elephas maximus) and African (Loxodonta africana) Female Elephants

Dow TL ${ }^{\mathrm{A}, \mathrm{B}}$, Holásková, $\mathrm{I}^{\mathrm{B}}$ and Brown JL ${ }^{\mathrm{A}}$

Zoo Biology 2011 29:1-13

${ }^{\text {A }}$ Center for Species Survival, Smithsonian Conservation Biology Institute, Smithsonian National Zoological Park, Front Royal, Virginia

${ }^{\mathrm{B}}$ West Virginia University, Division of Animal and Nutritional Sciences, Morgantown, West Virginia 


\begin{abstract}
A written survey assessed reproductive status of female Asian and African elephants in AZA/SSP facilities in 2008, and data were compared to surveys conducted in 2002 and 2005. Results showed ovarian acyclicity rates across the surveys remained unchanged for Asian (13.3, 10.9 and 11.1\%) and African (22.1, 31.2 and 30.5\%) elephants, respectively ( $\mathrm{P}>0.05)$, but were higher overall for African compared to Asian elephants $(\mathrm{P}<0.05)$. In 2008, the percentages of Asian and African elephants with irregular cycles (14.3 and 15.8\%) and irregular + no cycles (25.4 and 46.4\%) was similar to 2005 (7.6 and 11.8\%; 18.5 and 43.0\%), but were increased compared to 2002 (2.6 and 5.2\%; 16.0 and 27.3\%), respectively $(\mathrm{P}<0.05)$. For both species, ovarian acyclicity increased with age $(\mathrm{P}<0.05)$.

Reproductive tract pathologies did not account for the majority of acyclicity, although rates were higher in noncycling females $(\mathrm{P}<0.05)$. Bull presence was associated with increased cyclicity rates $(\mathrm{P}<0.05)$ for Asian (92.5 versus 58.3\%) and African (64.9 versus 57.8\%) elephants compared to females at facilities with no male, respectively. Cyclicity rates were higher for Asian (86.8 versus 65.2\%) and African (67.9 versus 56.7\%) elephants managed in free compared to protected contact programs $(\mathrm{P}<0.05)$, respectively. Geographical facility location had no effect on cyclicity $(\mathrm{P}>0.05)$. In summary, incidence of ovarian cycle problems continues to predominantly affect African elephants. Although percentages of acyclicity did not increase between 2005 and 2008, 42.2\% Asian and 30.2\% African females were no longer being hormonally monitored; thus, reproductive cycle abnormalities could be worse than current data suggest.
\end{abstract}

Keywords: ovarian cyclicity, hormones, reproduction, acyclicity, ultrasound, progestagens 


\section{Introduction}

North American populations of elephants continue to be non-self-sustaining. Studbook data show that in the last 10 years (1998-2008), Asian (Elephas maximus) and African (Loxodonta africana) elephants averaged 4.0 and 3.7 births compared to 6.0 and 4.0 deaths per year, respectively. Of the 77 calves born during this time, only 41 (53.2\%) are currently still living [Keele et al., 2007; Olson, 2008]. Furthermore, at present, 68.1\% of Asian and 30.3\% of African elephant populations are considered post-reproductive; i.e., $\geq 35$ years old. It has been hypothesized that if reproductive rates are not increased significantly, the North American elephant populations will become demographically extinct within a few decades [Olsen and Wiese, 2000; Faust et al., 2006; Wiese and Willis, 2006].

To address this problem, the Association of Zoos and Aquariums (AZA) Elephant Taxon Advisory Group (TAG)/Species Survival Plan (SSP) takes steps to ensure females between 11 and 35 years of age are given every opportunity to breed. Hormone profiling services, specifically for progestagens in frequent blood, urine, and/or fecal samples are provided by several laboratories in the U.S., including the Smithsonian Conservation Biology Institute (SCBI). Data from these laboratories have been instrumental in assessing elephant fertility status for TAG/SSP breeding recommendations, in addition to exposing a range of ovarian cycle problems, from irregular to chronically acyclic [Brown et al., 1991; Brown, 2000; Schulte et al., 2000]. To document changes in reproductive health, written survey data are being collected by our laboratory about every 3 years. The first was conducted in 2002 [Brown et al., 2004], with a follow up survey in 2005 [Proctor et al., 2010]. These surveys document: 1) how many females in the captive population are being hormonally monitored; 2) rates of ovarian cyclicity problems; 3) changes in the cyclicity status of individual females; 4) what types of reproductive tract pathologies exist; and 5) relationships between age, reproductive tract pathologies and ovarian problems. A comparison of the 2002 and 2005 surveys was 
discouraging because it showed a significant increase in ovarian and reproductive tract pathologies within a 3-year period, particularly in African elephants (30.7\% to $41.1 \%$ and $19.6 \%$ to $28.6 \%$, respectively) [Proctor et al., 2010]. The objective of this third survey was to determine if further changes in the SSP populations have occurred. Additionally, a range of new variables including management style, breeding history, male presence and facility location were analyzed to ascertain possible contributions to estrous cyclicity status.

\section{Materials and Methods}

Written surveys were sent to all 76 AZA elephant-holding facilities in 2008, similar to previous studies [Brown et al., 2004; Proctor et al., 2010]. Survey questions included those on herd dynamics and demographics, facility location and climate, management system, reproductive cyclicity status, transrectal reproductive tract ultrasound data, and breeding history over the past 15 years. Hormone cyclicity status referred to progestagen data subsequent to the survey completed in 2005 (i.e., a 3-year period). Ovarian cyclicity data were only used if a female had been assessed for at least 1 year. Animal age refers to the age in 2008. Pregnant cows (2 Asian and 2 African) were excluded from the survey results and analyses.

\section{$\underline{\text { Statistical Analysis }}$}

Effect of categorical variables on cyclicity status, such as species (Asian, African), management (free contact, protected contact, both), female social status within the herd (dominant, middle, subordinate, variable), reproductive tract pathologies (undetermined, pathologies present, normal morphology), presence of male in facility (yes, no), type of breeding (natural, artificial insemination - AI, both, none), geographical location (average winter temperature below $3.9^{\circ} \mathrm{C}$, between 4.4 and $9.4^{\circ} \mathrm{C}$, between 10 and $15^{\circ} \mathrm{C}$, and above $15.6^{\circ} \mathrm{C}$ ), years at a given facility, and age 
were determined using PROC GLM of Statistical Analyses System, version 9.1.3 (SAS Institute Inc., Cary, NC, 2004). Each of the variables was analyzed individually, then as the interaction within species. Last, an overall model to predict cyclicity status was determined using all categorical data. PROC ANOVA was used to determine the means and standard deviations for each variable and the interactions. Significance was set at $\mathrm{P}<0.05$. All data are presented as means $\pm \mathrm{SEM}$.

\section{Results}

Seventy-five of the 76 facilities in the Elephant SSP program participated in the 2008 survey. Of those, 29 housed Asian elephants, 37 housed African elephants, and 9 housed both species. There were 109 Asian and 136 African female elephants surveyed. Overall survey results are presented in Table 1. A higher percentage of African than Asian elephants were monitored for reproductive cyclicity via progestagen assessments $(\mathrm{P}<0.05)$. Of those females, African elephants exhibited a higher rate of ovarian acyclicity as compared to Asian elephants $(\mathrm{P}<0.05)$. Additionally, African females also experienced more irregular ovarian cyclic activity than did Asian females $(\mathrm{P}<0.05)$ (Table 1).

The age range for the captive female Asian elephant population was 1-68 years, with an average age of $34.5 \pm 1.4$ years. The age of captive female African elephants ranged from 1-53 years, with an average age of $28.1 \pm 0.9$ years. Overall, the African population was younger than the Asian population $(\mathrm{P}<0.05)$. For both species, rates of acyclicity increased with age $(\mathrm{P}<0.05)$. Reproductive cyclicity status data for both species as a function of age are summarized in Tables 2 and 3. Most acyclicity in postpubertal Asian elephants was observed in the older age group, those aged $>36$ years (Table 2). For African elephants, acyclicity was observed in cows as young as 21 years of age, with the majority of acyclic females found in the 26-30 age category (Table 3). The 
vast majority (86.2\%, 25 out of 29) of acyclic African elephants were between the ages of 26 and 40 years.

Reproductive tract ultrasound assessments were conducted on 56.9\% (62 out of 109) of the Asian and 46.3\% (63 out of 136) of the African SSP elephants (Tables 4 and 5, respectively). There were a number of females (7 Asian and 3 African) that had ultrasound results, but no corresponding hormone data. For Asian elephants, 53.2\% (33 out of 62) of females being hormonally monitored had normal tract morphology. Twenty-nine Asian elephants exhibited at least one reproductive tract pathology, but there was no difference $(\mathrm{P}>0.05)$ between females with tract pathologies that cycled normally $(n=16)$ compared to individuals that exhibited irregular or no cyclicity $(n=9)$ (Table 4). For African elephants, $71.4 \%$ (45 out of 63) of those monitored had normal tract morphologies. Eighteen African females possessed at least one reproductive tract pathology; more females with tract pathologies exhibited irregular or no cyclicity $(n=11)$ compared to those that cycled normally $(n=$ 5) $(\mathrm{P}<0.05)$ (Table 5). Overall, reproductive tract pathologies were observed in Asian females $\geq 15$ years of age and African females $\geq 21$ years of age (data not shown). The most prominent tract pathologies were uterine cysts/tumors (31.1\%) and other pathologies, i.e., idiopathic lesions, leiomyomas, etc., (17.2\%) for Asian (Tables 4), and vaginal cysts/tumors (22.2\%) and other pathologies (27.8\%) for African (Table 5) elephants.

Breeding histories over the previous 15 years were obtained for 50 Asian elephants. Of 29 AIs reported, 10 resulted in a pregnancy. Of these, three were aborted, one fetus died in utero, four resulted in live births, and two pregnancies were pending at the time of the survey. For 127 natural matings, 46 were unsuccessful, four resulted in abortions, three were stillbirths, one fetus died in utero, 34 resulted in live births, and four pregnancies were pending. Likewise, over the last 15 years, Fifty-eight African females had 174 breeding opportunities; 63 by AI and 111 by natural mating. Of the AIs, 47 were unsuccessful, two resulted in stillbirths, two fetuses died in utero, there were eight 
live births, and four were pregnant. For the 111 natural matings, 96 were unsuccessful, two fetuses died in utero, there were 11 live births, and two pregnancies were pending. Conception rates for AI (34.4\% versus $25.4 \%$ ) and natural matings (29.9\% versus $13.5 \%)$ were higher $(\mathrm{P}<0.05)$ in Asian than African elephants, respectively. Overall conception rates for Asian and African elephants were $30.8 \%$ and $17.8 \%$, respectively. Females with breeding histories, whether successful or not, had a higher rate of cyclicity (>75\%) when compared to those females that had not been bred (51\%) $(\mathrm{P}<0.05)$.

Of the 75 SSP facilities surveyed, there were 25 African $(n=15$ zoos) and 27 Asian $(n=15$ zoos) bull elephants aged $<1$ to 45 years. A total of 124 females (67 African; 57 Asian) were housed at a facility with a mature male, $\geq 15$ years of age, compared to 69 African and 52 Asian elephants that were not. For postpubertal Asian and African elephants, respectively, there was a higher ovarian cyclicity rate (92.5\% and 64.9\%) among individuals housed at a zoo with a bull $(\mathrm{P}<0.05)$, as compared to those zoos with no male (58.3\% and 57.8\%), whether there was direct contact or not. For both species, geographic location and average daily winter temperature did not affect cyclicity status in female elephants $(\mathrm{P}>0.05)$.

There were three types of management systems reported in the survey: free contact $(n=13$ Asian, 13 African facilities); protected contact ( $\mathrm{n}=16$ Asian, 25 African), and a combination of both ( $\mathrm{n}=4$ Asian, 4 African). Numbers of elephants managed using a combination of both were low; however, ovarian cyclicity rates were highest at those facilities (93.1\% of Asian and 70.0\% of African females cycled normally) when compared to those in protected contact only (65.2\% for Asian and 56.7\% for African) $(\mathrm{P}<0.05)$. In facilities that used only free contact management, 86.8\% of Asian and 67.9\% of African females cycled normally, which was higher than that for elephants in protected contact $(\mathrm{P}<0.05)$. 
A total of 163 out of 236 female elephants ( $=64$ Asian, 99 African) had both hormonal and herd social status data. Elephants were characterized as having dominant, middle, subordinate, or variable status according to keeper staff rankings. The majority of both Asian (50.1\%) and African (51.3\%) females were considered to be of middle status within the herd hierarchy. For both species there were no significant differences between herd status groups and ovarian cyclic activity (data not shown).

An overall comparison of selected results between the 2002, 2005 and 2008 surveys is shown in Table 6; significant differences among the three surveys are highlighted. There was a decrease in the number of Asian elephants monitored in 2008 when compared to $2005(\mathrm{P}<0.05)$ due to older individuals no longer being monitored. The percentage of Asian elephants with irregular cycles in 2008 was similar to that in 2005, but increased since $2002(\mathrm{P}<0.05)$. Likewise, there was no change in the percentage of African elephants with irregular cycles between the 2005 and 2008 surveys ( $\mathrm{P}>0.05)$, but there was an increase between 2002 and $2008(\mathrm{P}<0.05)$. When acyclicity and irregular cycling data were combined, the overall percentage of postpubertal individuals with abnormal reproductive cycles was stable for Asian elephants, but increased for African females between 2002 and 2005 ( $\mathrm{P}<0.05)$, with no further change in $2008(\mathrm{P}>0.05)$.

Between 2005 and 2008, nine Asian and 38 African females were new to the survey. Of those, only two Asian females were being monitored with none cycling; 17 African females were monitored with 13 listed as cycling. Of the returning females, 12 Asian and 10 African females not monitored in 2005 were in 2008, with 1 and 4 females found to be not cycling, respectively. Several females switched cyclicity status between the 2005 and 2008 surveys. For Asian elephants, one irregular cycling female began to cycle normally (age 38 years), one switched from irregular cycling to acyclic (age 42 years), seven cycling females became irregular (ages 28, 33, 36, 38, 40, and 50 years), four cycling females became acyclic (ages 28, 37, and 41 years), and eight acyclic and two 
irregular cycling females were no longer monitored. For African elephants, although two new females were being monitored, overall 26 fewer elephants had hormonal data in 2008 than in 2005. Two irregular cycling females became acyclic (both 28 years old), two irregular cycling females started cycling normally (ages 23 and 28 years), four acyclic females were irregular (ages 30, 38 and 39 years), two acyclic females switched to normal cyclicity (ages 22 and 25 years), 10 previously cycling females were acyclic (ages 24 to 49 years), and seven acyclic and three irregular females (ages $\geq 30$ years) were no longer being hormonally monitored.

There was no difference in the percentage of individuals being monitored via transrectal ultrasonography between Asian and African elephants, with only 50.2\% of the total SSP population having previously been examined. For the 2008 survey, there was a decrease in the number of reproductive age Asian females that were ultrasounded $(\mathrm{P}<0.05)$ when compared to 2002 and 2005; however the total number was similar. For African elephants, the number of reproductive age females in the population with ultrasound data remained unchanged across all three surveys, although they represented a smaller portion of the population in 2008 than in 2002 and 2005.

\section{Discussion}

Supporting the results observed in 2002 and 2005, the 2008 survey showed that ovarian acyclicity and reproductive tract pathologies continue to be a threat to the reproductive health status of North American SSP populations of African and Asian elephants. Compared to 2002 data, there was a $16.2 \%$ and $3.4 \%$ increase in tract pathologies, and a $9.4 \%$ and $19.1 \%$ increase in cyclicity abnormalities in Asian and African elephants, respectively, in 2008. Ovarian cycle abnormalities and reproductive tract pathologies are thus a continuing problem for both elephant species; however, the African elephant appears to be more susceptible to fertility problems. When comparing the number of reproductive age African females that were either acyclic or cycling irregularly, it appears that 
rates were stable between 2005 and 2008. However, closer evaluation of individual elephants indicates this may not be the case. Of the 32 cows in 2005 with ovarian cycle abnormalities, 10 currently are no longer being monitored and six are now deceased. Furthermore, most of the 30 reproductive aged females reported as not cycling normally in 2008 have either switched from cycling to noncycling or are new individuals to the survey. According to the recent age pyramid for SSP African elephants [Olson, 2008], 103 females are < 35 years of age (i.e., considered potentially reproductive). Of these, 73 ( 70.1\%) are hormonally monitored, with only 41 (32.3\%) cycling normally. Thus, acyclicity continues to be a major concern for this species, significantly reducing the breeding population.

It was originally believed that elephant females were either cyclic or acyclic [Brown, 2000], but now many Asian and African cows have been shown to alter between periods of normal cyclicity and irregular or acyclicity during the prime reproductive years (11-35 years of age). Research over the past 10 years have investigated possible causative factors for abnormal cyclicity, such as seasonality [Bechart et al., 1999], herd rank and time spent outdoors [Schulte et al., 2000], and behavioral influences of herd mates [Freeman et al., 2004, 2009, 2010]. Wild elephants are generally not considered seasonal breeders, although fluctuations in estrus activity can occur during times of climate change, i.e., drought and monsoon seasons [Douglas-Hamilton 1975; Moss 1983]. Increased bouts of temporary ovarian inactivity have been reported in African elephants during winter months when time spent indoors is increased [Schulte et al., 2000]. However, we found no differences $(\mathrm{P}>0.05)$ in overall ovarian cyclicity rates in either species with respect to facility location, i.e., seasonal changes in temperature or precipitation. These findings confirm an earlier study that showed no significant effect of facility location or climate on rates of ovarian acyclicity in zoo African elephants [Freeman et al., 2009]. 
Transrectal ultrasonography techniques have become instrumental in monitoring reproductive tract health [Hildebrandt et al., 2003]. Currently, nearly half of the Asian and African populations had an ultrasound examination conducted within the last 3 years. Of those, the majority exhibited one or more of the following tract pathologies: ovarian, uterine, and vaginal cysts and/or tumors. According to new data in 2008, more than half of all Asian and African cows with documented tract pathologies had no previous breeding history either through natural mating or AI. Other studies have shown that nulliparous cows $>30$ years of age have increased incidences of reproductive tract pathologies, termed asymmetric reproductive aging [Hildebrandt et al., 2000; Hermes et al., 2004]. Older, nonreproductive African elephants are prone to developing endometrial hyperplasia [Hildebrandt et al., 1997, 2000], whereas Asian elephants develop uterine leiomyomas [Hildebrandt and Göritz, 1995; Hildebrandt et al., 2006], not unlike that observed in the present study. Overall, individuals that experienced one or more breeding opportunities within the past 15 years cycled at a rate $24.1 \%$ higher when compared to cows that had not been bred. More than likely, these results reflect the biased selection of cycling females for breeding opportunities, which is now a requirement of the Elephant TAG/SSP before a recommendation is approved.

A decade ago, Olsen and Wiese hypothesized that if reproductive rates were not increased 9fold, there would be few elephants in zoos by 2050 [Olson and Wiese, 2000]. Although 2008 survey data showed that reproductive rates have increased, pregnancy loss and infant mortality also are higher. Currently, only one-third of female Asian elephants are between 11 and 35 years of age [Keele, 2007]. Of those, two-thirds had been given breeding opportunities, but less than one-third conceived and carried a calf to full term [Doyle et al., 1999]. By contrast, almost three-fourths of the African elephant population is between the ages of 11 and 35. Still, less than half had been bred, either naturally or by AI, and only $10.0 \%$ actually conceived. Infant mortality, excluding stillborns, over the last 10 years has claimed 1.7 juveniles per year for both species [Olson 2008]. Thus, not 
only are low reproductive rates contributing to decreasing captive populations, but calf loss continues to be a problem [Olson, 2008; Saragusty et al., 2009].

We speculated that the presence of a bull elephant might have a stimulatory effect on the female estrous cycle, via chemical, visual, or auditory stimulation. This prediction was supported by the 2008 survey data that showed the presence of a bull at a facility, whether in direct contact with cows or not, significantly increased rates of estrous cyclicity by $37.0 \%$ in Asian and $10.9 \%$ in African females. Male effects, both direct and indirect, on estrous cyclicity have been demonstrated in other species. For example, in the female gray short-tailed opossum exposure to non-volatile male pheromones in scent marks stimulated body growth, follicular development and estrous behavior [Harder and Jackson, 2003]. Similarly, in cattle, indirect and direct bull exposure accelerated the onset of puberty in heifers by 74 days [Kinder et al., 1994]. And the presence of a male Angora goat shortened the seasonal anestrous period in females by at least one estrous cycle [Shelton, 1960]. In elephants, chemical signals mediate intersexual and intrasexual interactions associated with reproduction in both Asian and African elephants [Rasmussen and Schulte, 1998]. Bulls exude chemical pheromonal signals from several orifices: the facial temporal gland, urine and breathe [Rasmussen, 1998]. Asian elephant females are responsive to the urinary pheromone, frontalin, depending on estrous state, and are most responsive during the follicular phase [Rasmussen and Greenwood, 2003]. Still, there were a number of facilities with cycling females that did not house a bull, and vice versa, so this is not an absolute requirement.

It has been previously shown that captive females who hold dominant herd status are more prone to be acyclic [Freeman et al., 2004; Freeman et al., 2010]. But according to the 2008 survey data, the majority of acyclic Asian and African elephants were ranked in the middle category. With the current survey, herd status data was based on keeper rankings only, whereas work done by Freeman and colleagues use more intensive behavioral and multi-question survey evaluation 
approaches. Thus, the lack of a relationship between social dominance and ovarian acyclicity in this study could be methodological. Alternatively, given the large number of African females, throughout all age categories, no longer being monitored, it is possible that more dominant, acyclic females no longer are being included in survey data.

The impact of management style on ovarian activity also was investigated, which at present consists of free contact, protected contact, or a combination of both. For both species, ovarian cyclicity was higher in females housed in free or a combination of both free and protected contact when compared to protected contact only. There was an average increase in the rate of ovarian cyclicity of 24.9\% for Asian and 12.5\% for African elephants when individuals were in a management program that incorporated direct human contact. Elephants are a very tactile animal, and touching herd mates is a way of communication and reinforcing social bonds [Sukumar, 2003]. Thus, positive hands-on interactions in free contact could provide an enriching experience, both mental and physical, for the elephants [Kahl and Santiapillai, 2004; Brown et al., 2008].

In summary, these data support efforts by the TAG/SSP to require SSP facilities to continually monitor all reproductive aged females for reproductive tract health and hormone activity [Keele and Ediger, 1997-2002]. This most recent survey showed that ovarian acyclicity, along with reproductive tract pathologies, is evident among all postpubertal age groups for both African and Asian elephants. Although overall rates of ovarian acyclicity did not change between 2005 and 2008, irregular cycles continued to increase, and in many females represent the transition from a cyclic to an acyclic state. Geographical location of a facility was not found to contribute to ovarian acyclicity, whereas management style, male presence, breeding opportunities, age and presence of tract pathologies all had significant influences on estrous cyclicity status in female elephants. There continues to be a species difference in the types and degree of reproductive problems, with African elephants apparently being more susceptible to factors affecting ovarian activity compared to Asian 
females. To ensure a healthy elephant population in North America, elephants must be selfsustaining. Continual longitudinal monitoring of ovarian steroids can identify changes in the reproductive potential of the captive population, as well as in individual elephants. Now that we know significant problems continue to exist, additional studies (i.e., diet, endocrine, physiological, etc.) are planned to identify what are the contributing factors that inhibit ovarian function.

\section{Conclusions}

1. In 2008, 95/136 (69.8\%) and 62/109 (56.9\%) African elephants, and 63/109 (57.8\%) and 63/136 (46.3\%) Asian elephants were being monitored for hormone and ultrasound data, respectively.

2. Of those being hormonally monitored, acyclicity appears throughout all age groups of postpubertal African elephants, but most prevalent in older Asian elephants > 35 years of age. Currently $46.4 \%$ of African and $25.4 \%$ of Asian cows in SSP facilities experience some form of ovarian cycle abnormality.

3. Reproductive tract pathologies such as ovarian, uterine, and vaginal cysts and/or tumors continue to be observed in both Asian and African cows of all ages, with a 37.0\% and 7.0\% increase in reproductive tract pathologies, respectively, over the last 6 years.

4. Management style, male presence, breeding opportunities, age and presence of tract pathologies significantly impacted long-term reproductive health status in female elephants.

\section{Acknowledgments}

The authors thank all zoological facilities that completed this reproductive assessment survey. We are grateful to those facilities that continue to monitor elephants via hormone profiles and ultrasonography regardless of age and reproductive status. We also thank Nicole Parker for conducting most of the endocrine analyses, and Dr. Elizabeth W. Freeman and Dr. Robert A. Dailey 
for support and guidance. Additionally, we thank Karen Lewis (Oregon Zoo) and Mike Keele (Oregon Zoo) for assistance in contacting zoological facilities and encouraging them to participate in our survey. 


\section{References}

Bechert US, Swanson L, Wasser SK, Hess DL, Stormshak F. 1999. Serum prolactin concentrations in captive female African elephants (Loxodonta africana): Potential effects of season and steroid hormone interactions. Gen Comp Endocrinol 114:269-278.

Brown JL, Citino SB, Bush M, Lehnhardt J, Phillips LG. 1991. Cyclic patterns of luteinizing hormone, follicle-stimulating hormone, inhibin, and progesterone secretion in the Asian elephant (Elephas maximus). J Zoo Wildl Med 1:49-57.

Brown JL. 2000. Reproductive endocrine monitoring of elephants: An essential tool for assisting captive management. Zoo Biol 19:347-68.

Brown JL, Olson D, Keele M, Freeman EW. 2004. Survey of the reproductive status of Asian and African elephants in North America. Zoo Biol 23:309-21.

Brown JL, Wielebnowski N, Cheeran J. 2008. Challenges with identifying and evaluating pain, distress and suffering in elephants. In: Wemmer C, Christen C, editors. Elephants and Ethics. Baltimore (MD): John Hopkins University Press. p 121-148.

Douglas-Hamilton I. 1975. On the Ecology and Behaviour of the African Elephant. [dissertation]. Oxford: University of Oxford.

Doyle C, York B, Whitely A. 1999. A survey of Asian elephant births from 1962-1998. J Elephant Managers Assoc 10:146-148.

Faust LJ, Thompson SD, Earnhardt JM. 2006. Is reversing the decline of Asian elephants in North American zoos possible? An individual-based modeling approach. Zoo Biol 25:201-218.

Freeman EW, Weiss E, Brown JL. 2004. Examination of the impact of physical and behavioral factors on ovarian cyclicity status in captive Asian and African elephants. Zoo Biol 23:431448. 
Freeman EW, Guagnano G, Olsen D, Keele M, Brown JL. 2009. Social factors influence ovarian acyclicity in captive African elephants (Loxodonta africana). Zoo Biol 28:1-15.

Freeman EW, Schulte BA, Brown JL. 2010. Investigating the impact of rank and ovarian activity on the social behavior of captive female African elephants. Zoo Biol 29:154-167.

Harder JD, Jackson LM. 2003. Male pheromone stimulates ovarian follicular development and body growth in juvenile female opossums (Monodelphis domestica). Reprod Bio Endocrinol 1:2130.

Hermes R, Hildebrandt TB, Göritz F. 2004. Reproductive problems directly attributable to long-term captivity-asymmetric reproductive aging. Anim Reprod Sci 82-83:49-60.

Hildebrandt TB, Göritz F. 1995. Transrectal ultrasonography for ovary and pregnancy in Indian elephant. Verh ber Erkrg Zootiere 37:261-68.

Hildebrandt TB, Göritz F, Pratt NC, Schmitt DL, Lehnhardt J, Hermes R, Quandt S, Raath J, West G, Montali RJ. 1997. Assessment of health and reproductive status in African and Asian elephants by transrectal ultrasonography. Proc Am Assoc Zoo Vet annual meeting, October 2630, Houston, TX. p 207-212.

Hildebrandt TB, Göritz F, Pratt NC, Brown JL, Montali RJ, Schmitt DL, Fritsch G, Hermes R. 2000. Ultrasonography of the urogenital tract in elephants (Loxodonta africana and Elephas maximus): An important tool for assessing female reproductive function. Zoo Biol 19:321-32.

Hildebrandt TB, Brown JL, Hermes R, Goeritz F. 2003. Ultrasound for the analysis of reproductive function in wildlife. In: Wildt DE, Holt WV, Pickard AR, Roger JC, editors. Reproduction and Integrated Conservation Science, London: Zoological Society of London. p 166-182.

Hildebrandt TB, Goritz F, Hermes R, Reid C, Denhard M, Brown JL. 2006. Aspects of the reproductive biology and breeding management of Asian and African elephants. Int Zoo Yb 40:20-40. 
Kahl MP, Santiapillai C. 2004. A glossary of elephant terms. Gajah 23:1-36.

Keele M, editor. 2007. Asian elephant North American regional studbook. Portland, OR: Oregon Zoo.

Keele M, Ediger ND-E, editors. 1997-2002. AZA elephant master plan. AZA publication number 1999 10285.zooe. Portland, OR: Oregon Zoo.

Kinder JE, Roberson MS, Wolfe MW, Stampf TT. 1994. Management factors affecting puberty in the heifer. In: Fields MJ, Sands R, editors. Factors Affecting Calf Crops. Boca Raton (FL): CRC Press, Inc. p 69-89.

Moss CJ. 1983. Oestrous behavior and female choice in the African elephant. Behaviour 100:167196.

Olson DJ, editor. 2008. African elephant North American regional studbook. Indianapolis, IN: Indianapolis Zoo.

Olson D, Wiese RJ. 2000. State of the North American African elephant population and predictions for the future. Zoo Biol 19:311-20.

Proctor CM, Freeman EW, Brown JL. 2010. Results of a second survey to assess the reproductive status of female Asian and African elephants in North America. Zoo Biol 29:127-139.

Rasmussen LEL. 1998. Chemical communication: an integral part of functional Asian elephant (Elephas maximus) society. Ecoscience 5:410-426.

Rasmussen LEL, Schulte BA. 1998. Chemical signals in the reproduction of Asian (Elephas maximus) and African (Loxodonta africana) elephants. Anim Reprod Sci 53:19-34.

Rasmussen LEL, Greenwood DR. 2003. Frontalin: a chemical message of musth in Asian elephants (Elephas maximus). Chem Senses 28:433-446.

Saragusty J, Hermes J, Göritz F, Schmitt DL, Hildebrandt TB. 2009. Skewed birth sex ratio and premature mortality in elephants. Anim Reprod Sci 115:247-254. 
Schulte BA, Feldman E, Lambert R, Oliver R, Hess DL. 2000. Temporary ovarian inactivity in elephants: relationship to status and time outside. Physiol Behav 71:123-31.

Shelton M. 1960. Influence of the presence of a male goat on the initiation of estrous cycling and ovulation of Angora does. J Anim Sci 19:368-375.

Sukumar R. 2003. The Living Elephants: Evolution, Ecology, Behavior, and Conservation. Oxford, UK: Oxford University Press. 125-152 p.

Wiese RJ, Willis K. 2006. Population management of zoo elephants. Int Zoo Yb 40:80-87. 
TABLE 1. Response rates and cyclicity status results of the 2008 Reproductive Assessment Survey for female Asian and African elephants in North America. Data are for the SSP populations.

\begin{tabular}{|c|c|c|c|c|}
\hline & \multicolumn{2}{|c|}{ Asian } & \multicolumn{2}{|c|}{ African } \\
\hline & $\mathrm{N}$ & Percent & $\mathrm{N}$ & Percent \\
\hline Studbook Population & 220 & & 190 & \\
\hline SSP Population & 114 & & 136 & \\
\hline Surveys Returned & 109 & 95.6 & 136 & 100 \\
\hline No. Monitored ${ }^{1}$ & 68 & $62.4^{\mathrm{a}}$ & 105 & $77.2^{\mathrm{b}}$ \\
\hline Unknown + Not Monitored & 46 & $40.4^{\mathrm{a}}$ & 31 & $22.8^{\mathrm{b}}$ \\
\hline \multicolumn{5}{|l|}{ Cyclicity Status } \\
\hline Cycling $^{2}$ & 47 & $69.1^{\mathrm{a}}$ & 51 & $48.6^{\mathrm{b}}$ \\
\hline Irregular $^{2}$ & 9 & 13.2 & 15 & 14.3 \\
\hline Not Cycling ${ }^{2}$ & 7 & $10.3^{\mathrm{a}}$ & 29 & $27.6^{\mathrm{b}}$ \\
\hline Immature & 5 & 7.4 & 10 & 9.5 \\
\hline
\end{tabular}

Unknown = no survey returned

${ }^{1}$ Based on surveys returned from SSP facilities.

${ }^{2}$ Numbers based on those monitored hormonally, and excludes females $\leq 10$ years of age.

${ }^{\mathrm{a}, \mathrm{b}}$ Superscripts denote significant difference $(\mathrm{P}<0.05)$ in cyclicity status between species 
TABLE 2. Numbers and age distributions of Asian elephant females exhibiting normal ovarian cycles, no ovarian cycles, or irregular cycles in the SSP population in North America based on 2008 Reproductive Assessment Survey results.

\begin{tabular}{lcccccccc}
\hline & \multicolumn{7}{c}{ Age of Asian Females in 2008 (years) } \\
\cline { 2 - 8 } & 0 to 10 & 11 to 15 & 16 to 20 & 21 to 25 & 26 to 30 & 31 to 35 & 36 to 40 & $>40$ \\
\hline Total & 5 & 9 & 4 & 9 & 6 & 15 & 26 & 35 \\
Surveys Returned & 5 & 9 & 4 & 9 & 6 & 14 & 26 & 34 \\
No. Monitored $^{\text {a }}$ & 5 & 9 & 4 & 9 & 6 & 10 & 12 & 13 \\
No. Cycling & 0 & 9 & 4 & 9 & 4 & 7 & 5 & 9 \\
No. Not Cycling & 5 & 0 & 0 & 0 & 1 & 1 & 3 & 2 \\
\% Not Cycling & 100 & 0 & 0 & 0 & 16.7 & 10 & 25 & 15.4 \\
No. Irregular & 0 & 0 & 0 & 0 & 1 & 2 & 4 & 2 \\
No. Unknown \& NM & 0 & 0 & 0 & 0 & 0 & 5 & 14 & 22 \\
\% Unknown \& NM & 0 & 0 & 0 & 0 & 0 & 33.3 & 53.8 & 62.8 \\
\hline
\end{tabular}

Unknown = no survey returned, NM = not monitored hormonally.

${ }^{a}$ Based on surveys returned for SSP facilities.

${ }^{\mathrm{b}}$ Percentages based on those monitored hormonally. 
TABLE 3. Numbers and age distributions of African elephant females exhibiting normal ovarian cycles, no ovarian cycles, or irregular cycles in the SSP population in North America based on 2008 Reproductive Assessment Survey results.

\begin{tabular}{lcccccccc}
\hline & \multicolumn{7}{c}{ Age of African Females in 2008 (years) } \\
\cline { 2 - 8 } & 0 to 10 & 11 to 15 & 16 to 20 & 21 to 25 & 26 to 30 & 31 to 35 & 36 to 40 & $>40$ \\
\hline Total & 10 & 0 & 9 & 23 & 44 & 17 & 26 & 7 \\
Surveys Returned & 10 & 0 & 9 & 22 & 42 & 17 & 26 & 7 \\
No. Monitored & 10 & 0 & 8 & 18 & 36 & 12 & 18 & 3 \\
No. Cycling & 0 & 0 & 8 & 13 & 21 & 4 & 4 & 1 \\
No. Not Cycling & 10 & 0 & 0 & 2 & 11 & 7 & 7 & 2 \\
\% Not Cycling & 100 & 0 & 0 & 11.1 & 30.6 & 58.3 & 38.9 & 66.7 \\
No. Irregular & 0 & 0 & 0 & 3 & 4 & 1 & 7 & 0 \\
No. Unknown \& NM & 0 & 0 & 1 & 5 & 8 & 5 & 8 & 4 \\
\% Unknown \& NM & 0 & 0 & 11.1 & 21.7 & 18.2 & 29.4 & 30.8 & 57.1 \\
\hline
\end{tabular}

Unknown = no survey returned, NM = not monitored hormonally.

${ }^{a}$ Based on surveys returned for SSP facilities.

${ }^{\mathrm{b}}$ Percentages based on those monitored hormonally. 
TABLE 4. Numbers of Asian elephants evaluated by transrectal

ultrasound, and categorized based on normal and abnormal urogenital tract morphology within ovarian cyclicity status categories

\begin{tabular}{lcccc}
\hline & \multicolumn{4}{c}{ Asian } \\
\cline { 2 - 5 } Category & Cycling & Noncycling & Irregular & Not Monitored \\
\hline Normal & $27^{\mathrm{a}}$ & $0^{\mathrm{b}}$ & $3^{\mathrm{b}}$ & 3 \\
OC & 1 & & 1 & 1 \\
UT c/t & 6 & 1 & & 1 \\
VA c/t & 4 & & 1 & \\
OC, UT c/t, VA c/t & & & 2 & 1 \\
UT c/t, VA c/t & 1 & & 1 & \\
OP & 1 & 2 & & 1 \\
OC, OP & 1 & & & \\
UT c/t, OP & 2 & 1 & & \\
UT c/t, VA c/t, OP & & & & \\
\hline
\end{tabular}

$\mathrm{NM}=$ Not monitored hormonally, OC $=$ Ovarian Cysts, UT c/t $=$ Uterine

Cysts/Tumors, VA c/t $=$ Vaginal Cysts/Tumors, $\mathrm{OP}=$ Other Pathologies

${ }^{\mathrm{a}, \mathrm{b}}$ Different superscripts are significantly different within species $(\mathrm{P}<0.05)$ for normal pathology verses cycling or noncycling females 
TABLE 5. Numbers of African elephants evaluated by transrectal ultrasound, and categorized based on normal and abnormal urogenital tract morphology within ovarian cyclicity status categories

\begin{tabular}{lcccc}
\hline & \multicolumn{3}{c}{ African } \\
\cline { 2 - 5 } Category & Cycling & Noncycling & Irregular & Not Monitored \\
\hline Normal & $31^{\mathrm{a}}$ & $7^{\mathrm{b}}$ & $6^{\mathrm{b}}$ & 1 \\
OC & & 1 & & 1 \\
UT c/t & 1 & 2 & 1 & \\
VA c/t & 2 & 1 & & \\
OC, UT c/t & & 1 & & \\
UT c/t, VA c/t & & 1 & & \\
OP & 2 & 2 & & \\
OC, OP & & 1 & & \\
OC, VA c/t & & & & \\
\hline
\end{tabular}

$\mathrm{NM}=$ Not monitored hormonally, OC = Ovarian Cysts, UT c/t = Uterine

Cysts/Tumors, VA c/t $=$ Vaginal Cysts/Tumors, $\mathrm{OP}=$ Other Pathologies

${ }^{\mathrm{a}, \mathrm{b}}$ Different superscripts are significantly different within species $(\mathrm{P}<0.05)$ for normal pathology verses cycling or noncycling females 
TABLE 6. Comparison of results between the 2002, 2005, and 2008 reproductive assessment surveys for the SSP population of Asian and African elephants. Data from 2002 and 2005 surveys were from Brown et al. [2004] and Proctor et al. [2010], respectively.

\begin{tabular}{|c|c|c|c|c|c|c|}
\hline & \multicolumn{3}{|c|}{ Asian } & \multicolumn{3}{|c|}{ African } \\
\hline & 2002 & 2005 & 2008 & 2002 & 2005 & 2008 \\
\hline No. of Females & 131 & 116 & 109 & 114 & 128 & 136 \\
\hline No. of Adult Females Monitored (\%) & $75(57.3)^{\mathrm{a}}$ & $92(79.3)^{\mathrm{b}}$ & $63(57.8)^{\mathrm{a}}$ & $77(67.5)^{\mathrm{a}}$ & $93(72.7)^{\mathrm{b}}$ & $95(69.8)^{\mathrm{ab}}$ \\
\hline Not Cycling (\%) ${ }^{3}$ & $10(13.3)$ & $10(10.9)$ & $7(11.1)$ & $17(22.1)$ & $29(31.2)$ & $29(30.5)$ \\
\hline Irregular Cycling (\%) $)^{3}$ & $2(2.6)^{\mathrm{a}}$ & $7(7.6)^{\mathrm{ab}}$ & $9(14.3)^{b}$ & $4(5.2)^{\mathrm{a}}$ & $11(11.8)^{\mathrm{b}}$ & $15(15.8)^{\mathrm{b}}$ \\
\hline Not Cycling + Irregular Cycling (\%) ${ }^{3}$ & $12(16.0)$ & $17(18.5)$ & $16(25.4)$ & $21(27.3)^{\mathrm{a}}$ & $40(43.0)^{\mathrm{b}}$ & $44(46.4)^{\mathrm{b}}$ \\
\hline Females with U/S Data $(\%)^{2}$ & $70(53.4)$ & $69(59.5)$ & $57(52.3)$ & $50(43.9)$ & $66(51.6)$ & $62(45.6)$ \\
\hline No. of Reproductive Age Females (\%) ${ }^{1}$ & $68(51.9)^{\mathrm{a}}$ & $57(49.1)^{\mathrm{a}}$ & $43(39.4)^{\mathrm{b}}$ & $94(82.5)$ & $96(75.0)$ & $93(68.4)$ \\
\hline No. Monitored (\%) ${ }^{1}$ & $46(67.6)$ & $49(86.0)$ & $38(88.4)$ & $64(68.1)$ & $75(78.1)$ & $73(78.5)$ \\
\hline No. Not Cycling (\%) ${ }^{1}$ & $6(13.0)$ & $4(8.2)$ & $2(5.3)$ & $15(23.4)^{\mathrm{a}}$ & $24(32.0)^{\mathrm{b}}$ & $22(30.1)^{\mathrm{ab}}$ \\
\hline No. Irregular Cycling (\%) ${ }^{1}$ & $2(4.3)$ & $4(8.2)$ & $3(7.9)$ & $4(6.3)$ & $8(10.7)$ & $8(11.0)$ \\
\hline Not Cycling + Irregular Cycling (\%) ${ }^{1}$ & $8(17.3)$ & $8(16.4)$ & $5(13.2)$ & $19(29.7)^{\mathrm{a}}$ & $32(42.7)^{\mathrm{b}}$ & $30(41.1)^{\mathrm{ab}}$ \\
\hline No. of Females New to Survey $(\%)^{2}$ & & $6(5.2)$ & $9(8.3)$ & & $6(4.7)$ & $38(27.9)$ \\
\hline No. of New Females Monitored (\%) & & $5(83.3)$ & $2(22.2)$ & & $2(33.3)$ & $17(44.7)$ \\
\hline No. of New Females Cycling (\%) & & & $0(0.0)$ & & & $13(76.5)$ \\
\hline No. of Returning Females Now Monitored (\%) & & $21(22.8)$ & $12(17.6)$ & & $14(15.1)$ & $10(9.5)$ \\
\hline
\end{tabular}

${ }^{1}$ Reproductive age $=11-35$ years of age as established by the SSP.

${ }^{2}$ Percentage of population total.

${ }^{3}$ Includes all age groups except for immature/prepubertal females

${ }^{\mathrm{a}, \mathrm{b}}$ Superscripts denote significantly different from 2002, 2005 and 2008 survey data $(\mathrm{P}<0.05)$. 
Influence of age and gender on secretion of anti-Müllerian hormone in Asian (Elephas maximus) and African (Loxodonta africana) elephants

T. L. Dow ${ }^{\mathrm{a}, \mathrm{c}}, \mathrm{W}$. Roudebush $^{\mathrm{b}}$, F. N. Parker ${ }^{\mathrm{a}}$ and J. L. Brown ${ }^{\mathrm{a}}$

Theriogenology 2011 75:620-627

${ }^{a}$ Center for Species Survival, Smithsonian Conservation Biology Institute, National Zoological Park, Front Royal, Virginia 22623, United States

${ }^{\mathrm{b}}$ Charleston Southern University, Charleston, South Carolina 29406, United States

${ }^{c}$ West Virginia University, Division of Animal and Nutritional Sciences, Morgantown, WestVirginia 26505, United States 


\begin{abstract}
This paper described anti-Müllerian hormone (AMH) secretion in Asian and African elephants of different age groups and reproductive status. Overall mean concentrations did not differ $(\mathrm{P}>0.05)$ between species, but were markedly higher in male than female Asian (31.01 $\pm 4.22 \mathrm{ng} / \mathrm{mL}, 0.19 \pm$ $0.02 \mathrm{ng} / \mathrm{mL})$ and African (40.27 $\pm 3.18 \mathrm{ng} / \mathrm{mL}, 0.17 \pm 0.04 \mathrm{ng} / \mathrm{mL})$ elephants, respectively. AntiMüllerian hormone secretion was not related to ovarian cyclicity status (cycling vs. noncycling) ( $\mathrm{P}>0.05)$, but was higher in prepubertal $(0.40 \pm 0.10 \mathrm{ng} / \mathrm{mL})$ compared to reproductive age (8-35 years old; $0.18 \pm 0.04 \mathrm{ng} / \mathrm{mL})$ and aged $(\geq 36$ years old; $0.16 \pm 0.03 \mathrm{ng} / \mathrm{mL})$ females $(\mathrm{P}<0.05)$. In males, AMH secretion was not affected by musth status, but was age-related $(\mathrm{P}<0.05)$, with concentrations being higher in prepubertal (49.08 $\pm 6.11 \mathrm{ng} / \mathrm{mL})$ as compared to aged ( $\geq 36$ years old) $(22.27 \pm 5.82 \mathrm{ng} / \mathrm{mL})$ bulls; concentrations in mature bulls (8-35 years of age) $(37.01 \pm 3.17 \mathrm{ng} / \mathrm{mL})$ were similar to prepubertal and older bulls $(\mathrm{P}>0.05)$. We concluded that circulating AMH concentrations in elephants were similar between species and not affected by reproductive status; however, concentrations were significantly higher in males than females, and were elevated in younger animals. The diagnostic value of AMH to assess fertility status of individual elephants remains to be determined.
\end{abstract}

Keywords: anti-Müllerian hormone, ovary, granulosa cell, follicle, spermatogenesis 


\section{Introduction}

Elephant populations in western zoos are not self-sustaining and reproductive rates are low. One problem is that some females do not exhibit normal ovarian cycles. In successive surveys, a marked increase in overall rates of acyclic and irregular cycling activity has been observed, from $27 \%$ to $43 \%$ in African and 16\% to 24\% in Asian cows between 2002 and 2008, respectively [1,2]. To create selfsustaining populations in the U.S., it has been estimated that a total of six female calves per species must be produced annually [3,4]. This will not be possible if the rates of abnormal ovarian activity continue to increase, and makes it imperative to identify causes of ovarian cycle problems.

Anti-Müllerian hormone (AMH), also known as Müllerian inhibiting Substance, (MIS), is a dimeric glycoprotein hormone in the transforming growth factor- $\beta$ (TGF- $\beta$ ) family. In the female, $\mathrm{AMH}$ is produced by granulosa cells in the postpuberal ovary, with expression being highest in the preantral and small antral follicles [5]. Anti-Müllerian hormone participates in primary follicle formation during folliculogenesis by inhibiting excessive follicular recruitment by follicle stimulating hormone (FSH) [6,7]. Recently, AMH has been used as a marker of fertility in women [8], cows [9] and mice [10], with circulating concentration being correlated with the number of morphologically healthy oocytes within the follicular reserve [11,12]. Clinically, tests for AMH commonly are used to determine the onset of menopause in women, a state of reproductive cycle cessation due to ovarian follicle depletion [13-15].

The cause of ovarian acyclicity in captive elephants is not known. However, in the wild, females experience few ovarian cycles in their lifetime; most are either lactating (lactational anestrous) or pregnant [16]. By contrast, the majority of captive females exhibit up to four cycles per year, and do so continuously [17]. Ovarian function is dependent on the presence of primordial follicles that develop into antral follicles during the estrous cycle [18]. In the elephant, the follicular phase is 
characterized by two follicular waves that occur approximately 20 days apart. Many follicles are recruited into development, but only one ovulates $[19,20]$. In women, the number of ovarian follicles eventually is exhausted and at that point reproduction ceases, the female enters menopause and stops cycling [21]. It is not possible to quantify the number of small follicles in elephants by ultrasound procedures; thus, an alternative method is needed to determine if acyclicity is related to follicle depletion. Changes in AMH over time could specify whether captive elephants experience depletion in ovarian follicle numbers as they age. This information is important so that management options can be optimized for individual elephants. If the ovaries no longer contain a pool of healthy oocytes, then hormonal or other therapies for treating acyclicity would be ineffective. But elephants with functional follicles would be good candidates for treatment. What we lack is a valid test for determining ovarian functional status in elephants.

Reproductive failure in captive elephants is not just a problem among females. Male elephant infertility has been related to low libido and decreased semen quality [22,23]. Measurement of testosterone generally is not a reliable marker of fertility in Asian or African species [24,25]. Semen quality varies considerably in ejaculates between and within bulls, and it is not clear if these differences are due to the collection method or some physiological problem [26]. In other species, AMH is secreted by Sertoli cells during embryonic development, and along with testosterone from the Leydig cells, it is responsible for regression of the Müllerian ducts and formation of the male reproductive tract [6]. In men, Sertoli cells continue to produce AMH after reproductive tract differentiation, but concentrations decrease gradually after puberty to nadir levels [27]. Measurements of AMH in serum and seminal plasma have been used as a marker for spermatogenic function in men $[28,29]$. Thus, screening for AMH could be a first step in identifying reproductively sound elephants for reproductive breeding programs. If AMH secretion is found to be correlated with reproductive status or age, then it might be useful as a marker of fertility in male and/or female 
elephants. The objectives of this study were to: 1) validate an AMH ELISA for Asian and African elephants; 2) establish baseline concentrations for males and females of both species; and 3) investigate whether concentrations change with respect to age or gonadal functional status.

\section{Materials and methods}

\subsection{Animals}

Serum samples from Asian ( $\mathrm{n}=21$ male, 20 female) and African ( $\mathrm{n}=20$ male, 41 female) elephants were used to assess AMH, progesterone (females) and testosterone (males) concentrations. Blood samples were collected from either the saphenous vein in a rear leg or an ear vein by the zoo veterinarian or elephant staff as part of the standard husbandry routine. Weekly samples over a 1year period were used for progestagen and testosterone analyses to assess reproductive status. Females who exhibited progestagen concentrations of $0.05 \mathrm{ng} / \mathrm{mL}$ for at least a 1 -year period were deemed acyclic, while those whose progestagens showed normal cyclic patterns were categorized as cycling [24]. Based on criteria established by Brown et al. [25], males exhibiting testosterone concentrations $>30 \mathrm{ng} / \mathrm{mL}$ were considered in musth, whereas those with $<30 \mathrm{ng} / \mathrm{mL}$ testosterone were categorized as non-musth. This project was approved by the National Zoo’s Animal Care and Use Committee (NZP-IACUC \# 09-04) and by individual zoological facilities where elephants were housed. Yearly serum samples from each elephant were used for AMH analysis. In addition, yearly samples were evaluated in one female over a 20-year period, between the ages of 42 and 62, and monthly samples were analyzed in one 17-year old bull over a 1-year span to investigate changes in AMH concentration over time within an individual. 


\subsection{Serum hormone analyses}

For females, concentrations of serum progestagens were quantified using a validated solid-phase $\mathrm{I}^{125}$ progesterone radioimmunoassay (RIA) (Seimens Medical Diagnostic Solutions, Costa Mesa, CA) [30]. For males, concentrations of testosterone were quantified using a validated solid-phase $\mathrm{I}^{125}$ testosterone RIA (Seimens Medical Diagnostic Solutions, Costa Mesa, CA) [31,1]. Assay sensitivities were $0.03 \mathrm{ng} / \mathrm{mL}$ and $0.05 \mathrm{ng} / \mathrm{mL}$ for the progesterone and testosterone RIAs, respectively. For both assays, intra-assay and inter-assay CV were $<10 \%$ and $<15 \%$, respectively.

A human MIS/AMH enzyme immunoassay (EIA) (DSL-10-14400, Beckman Coulter, Inc., Brea, CA) was used to measure AMH concentrations. The two-site EIA is specific for AMH and does not crossreact with other members of the TGF- $\beta$ family, including TGF- $\beta$, activin, or inhibin A and B [10]. Assay sensitivity was $0.006 \mathrm{ng} / \mathrm{mL}$, and the intra-assay and inter-assay CVs were $3.4 \%$ and 6.5\%, respectively. The assay was validated for elephant serum by demonstrating parallelism between serial dilutions of elephant serum (neat, 1:2 - 1:64) and the AMH standard curve. Additionally, serum from castrates were utilized as a control and found to contain little to no AMH concentrations compared to intact animals.

\subsection{Statistical analysis}

Statistical analyses were performed using SAS (SAS Institute, Inc. Cary, NC). First, PROC MIXED of ANOVA was used to determine the effect of species, age, gender, and reproductive status within gender on AMH concentrations. After the significant effect of gender was determined, a second PROC MIXED of ANOVA was used for males and females separately to test the affects of 
species, age, and reproductive status on AMH concentrations. In cases where the null hypothesis was rejected, Tukey-Kramer post hoc test was used to determine significant differences between groups. Specifically, AMH concentration was compared between males and females, and then within gender, comparison was done between species. Next, AMH was compared between two categories of reproductive status (cycling vs. acyclic in females; musth vs. non-musth in males). Lastly, for both males and females, AMH concentration was compared in three age categories: prepubertal $(\leq 7$ years of age), reproductive age (8-35 years of age) and aged $(\geq 36$ years of age) for females; prepubertal $(\leq$ 7 years of age), mature (8-35 years of age), aged ( $\geq 36$ years old) for male elephants. Age categories for male and female captive elephants were based on hormonal and ultrasound data, and breeding management recommendations $[24,31,20,32]$. Data are presented as means \pm SEM. Differences were considered significant if $\mathrm{P}<0.05$.

\section{Results}

Table 1 summarizes overall mean serum AMH concentrations in postpubertal male and female elephants. Concentrations varied more between than within individuals $(\mathrm{P}<0.05)$. Within gender, there were no differences in AMH concentrations between Asian and African elephants, $(\mathrm{P}>0.05)$. However, concentrations in bull elephants were more than 100 times higher than those observed in females $(\mathrm{P}<0.05)$, with the exception of the four castrated males where AMH concentrations were essentially undetectable. Because no species differences were found, AMH data were combined for subsequent reproductive status and age analyses (Tables 2 and 3, respectively). Among pubertal females, AMH concentrations did not differ with ovarian cyclicity status (i.e., cycling or noncycling; $\mathrm{P}>0.05$ ) (Table 2). Similarly, AMH secretion was not affected by musth status in bulls ( $\mathrm{P}>0.05)$. Among age categories, AMH concentrations in prepubertal females ( $\leq 7$ years old) were more than 
double those of reproductive (8-35 years old) $(\mathrm{P}=0.013)$ and older ( $\geq 36$ years old) aged females $(\mathrm{P}<0.05)$ (Table 3). All females in the prepubertal category were not cycling. Concentrations of AMH within a 20-year span in one Asian female (from 42-62 years of age) were relatively constant between 42 and 58 years of age (mean, $0.26 \pm 0.01 \mathrm{ng} / \mathrm{mL}$ ) and then decreased from $0.22 \mathrm{ng} / \mathrm{mL}$ to $0.07 \mathrm{ng} / \mathrm{mL}$ between the ages of 58 and 62 (Figure 1). This female also stopped cycling at approximately 61 years of age. Among bull age categories, AMH concentration were higher $(\mathrm{P}<0.05)$ in prepubertal ( $\leq 7$ years old) than aged $(\geq 36$ years $)$ males, but were not different from those of mature males (11-35 years) $(\mathrm{P}>0.05)$. Concentrations of $\mathrm{AMH}$ did not differ between the mature and aged males ( $\mathrm{P}>0.05)$ (Table 3). Testosterone secretion was higher in musth (38.71 \pm 5.00 $\mathrm{ng} / \mathrm{mL})$ than in non-musth $(31.12 \pm 3.45 \mathrm{ng} / \mathrm{mL})$ males, but there was no correlation between serum $\mathrm{AMH}$ and testosterone concentrations ( $\mathrm{r}=0.23$; $\mathrm{P}>0.05)$. Anti-Müllerian hormone concentrations were consistent within one 17-year old male elephant over a 1-year period (22.07 $\pm 0.62 \mathrm{ng} / \mathrm{mL})$, during which time he experienced a 4-week musth period (Data not shown).

\section{Discussion}

Previous studies in cattle [9], humans [8] and mice [10] show that AMH secretory patterns do not necessitate intensive longitudinal sampling. Within age categories, concentrations are relatively constant within an individual and are not affected by stage of the estrous cycle [9]. Thus, for this study yearly samples were analyzed and divided into discrete age categories for analysis, as well as into groups according to reproductive status. We inferred that concentrations of circulating AMH were similar between Asian and African elephants; however, for both species, concentrations were markedly higher in males than females, and there was a significant decline in concentrations as a function of age. 
Anti-Müllerian hormone concentrations in human, mouse, and bovine females are shown to be directly correlated with antral follicle number. As the follicular pool is depleted, AMH concentrations decrease accordingly $[34,10,9]$. As a result, AMH is used as a marker of fertility and an early detection test for menopause [8]. In women, circulating AMH concentrations analyzed using the same assay are undetectable prepubertally, but increase to $3.8 \pm 1.2 \mathrm{ng} / \mathrm{mL}$ after puberty [35]. Similarly, in the female mouse, AMH concentration peak at puberty ( $29 \mathrm{ng} / \mathrm{mL})$; followed by a decline to $5 \mathrm{ng} / \mathrm{mL}$ by 16 months of age as follicles are depleted [10]. In cattle, AMH concentrations of $~ 100 \mathrm{ng} / \mathrm{mL}$ are reported in prepubertal cows, which then decrease with age [36,9]. Although much lower concentrations of AMH were detected in female elephants, the temporal profiles appeared to be similar; with concentration being highest in younger animals $(\sim 0.60 \mathrm{ng} / \mathrm{mL})$ compared to those in the older age categories $(\sim 0.17 \mathrm{ng} / \mathrm{mL})$.

One reason for conducting this study was to determine if follicle depletion normally occurs in elephants, and if it is related to the lack of normal ovarian cyclicity observed in many captive elephants [17,2]. Elephants in the wild can give birth into their 50's, and many reproduce up to their death $[37,16,38]$. However, they experience comparatively fewer cycles compared to captive females. An elephant female probably loses 20 or more eggs each cycle as multiple follicles grow before one is selected to ovulate [20]. Elephants do not reproduce well in zoos, in part because many females do not cycle normally [1]. A potentially significant finding is that abnormal cycles occur more in females $\geq 26$ years of age [2]. Though by no means geriatric, data have suggested that acyclic females may be experiencing premature reproductive aging and loss of functional follicles, similar to menopause in humans [21]. In this study, AMH concentrations were not correlated with ovarian cyclicity status. Therefore, our interpretation was that acyclicity in elephants is not caused by a premature decline in the number of viable ovarian follicles. Longitudinal data from one older Asian female (from 42 - 62 years of age) showed there may be a natural decline in AMH concentration 
over time in long-lived individuals and as reproductive cyclicity ceases. Unfortunately, very little data exists on females in captivity older than 40 years of age, so data on only one female may not be representative of all older elephants.

In the male, Sertoli cell derived AMH plays a key role in sex differentiation in utero causing the regression of the müllerian ducts in the male fetus [39]. Postnatally, AMH concentrations measured in the blood vary by age and species. This proved to be true for elephants, where mean AMH concentrations in prepubertal males ( $\sim 50 \mathrm{ng} / \mathrm{mL}$ ) were highest before puberty and declined significantly with age to about $20 \mathrm{ng} / \mathrm{mL}$ for bulls $\geq 36$ years of age. Postnatal AMH concentrations in men peak at 80-100 $\mathrm{ng} / \mathrm{mL}$, but then decline after puberty to concentrations less than $5 \mathrm{ng} / \mathrm{mL}$ [40,41]. In cattle, AMH concentrations fall significantly from over $700 \mathrm{ng} / \mathrm{mL}$ prepubertally to less than $200 \mathrm{ng} / \mathrm{mL}$ after puberty [36]. In the male mouse, AMH concentrations average $~ 160 \mathrm{ng} / \mathrm{mL}$ prepubertally, then decrease in a pattern similar to that observed in the human to $<2 \mathrm{ng} / \mathrm{mL}$ postpubertally [41].

In the elephant, there was a significant gender difference in AMH secretion, with concentrations being more than 100-fold higher in males than females. Interestingly, a similar gender difference in AMH concentrations has been reported for cattle [36] and West Indian manatees [43]. In the prepubertal male bovine, mean AMH concentrations at birth are more than $700 \mathrm{ng} / \mathrm{mL}$ in contrast to $120 \mathrm{ng} / \mathrm{mL}$ in the female [36]. In the male West Indian Manatee, the gender difference was even more dramatic; mean AMH concentration in males was $\sim 500 \mathrm{ng} / \mathrm{mL} \mathrm{ng} / \mathrm{ml}$ compared to only 0.08 $\mathrm{ng} / \mathrm{mL}$ in the females [43]. Such vast comparative differences in AMH secretion suggest Sertoli cell functional capacity may differ across species, as they are considered the major source of AMH in males [6]. The absence of AMH immunoactivity in castrated bulls further confirms the testicular source of this hormone in elephants. 
In human and mouse [44,41] and bovine [36] males, serum AMH and testosterone concentrations are shown to be inversely correlated during development. The post-pubertal elephant experiences an annual state of heightened sexual behavior and aggression called musth [45], which is associated with marked elevations in testosterone production. However, in this study, there were no differences in AMH concentrations between non-musth and musth males despite the dramatic testosterone difference, and no correlation among all individuals between AMH and testosterone concentrations. Therefore, AMH does not appear to be a good indicator of testicular steroidogenic activity in the bull elephant. Whether AMH assessments could be used to assess general fertility in bull elephants, however, remains to be determined.

Preliminary results from this study looked promising for AMH to be a potentially valid test for assessing at least pubertal changes in gonadal function, and possibly other reproductive factors. Reproductive tract pathologies such as ovarian cysts and tumors are common in a variety of species [46,47], and do occur in elephants [23]. Serum AMH concentrations are shown to be markedly elevated in insulin resistant patients with polycystic ovarian syndrome, and decrease after treatment with Metaformin (Bristol-Myers Squib, New York), an anti-diabetic drug that helps suppress hepatic glucose production and increases insulin sensitivity [48]. Until transrectal reproductive tract ultrasound examinations become routine, many pathologies undoubtedly go undetected in elephants. Early variations in granulosa cell derived AMH could be a useful marker for disease detection and progression in the ovaries, as well as determining treatment options. For the male, AMH may play a biological role during spermatogenesis. It is well known that there are certain physiological conditions that decrease both quality and quantity of sperm in a male, including those related to sickness and disease [49]. Inflammatory immune responses could illicit an increase in temperature, interstitial fluid, and pressure that indirectly or directly compromises spermatogenesis, resulting in temporary infertility [50]. Thus, we might expect to see decreases in circulating AMH concentration 
during times when a male is sick, stressed or injured [29]. Moreover, in men, seminal plasma antiMüllerian hormone are shown to be lower in individuals suffering from infertility, when compared to fertile counterparts [51]. Although no correlation between serum AMH and testosterone concentration was found in the elephants of this study, in men AMH is shown to be positively correlated with testicular volumes, sperm concentration [52] and semen volume [53]. More longitudinal sampling within the same individuals and over longer periods of time might reveal relationships not evident in this study.

\section{Conclusions}

In summary, serum AMH concentrations in male and female Asian and African elephants have been compared across age categories and between elephants of different reproductive status. From these data, we conclude there were no differences in mean AMH concentration between elephant species. However, overall mean AMH concentrations were markedly higher in males than females. Anti-Müllerian hormone concentrations were highest in prepubertal individuals of both genders, and decreased with age. However, AMH concentrations were not correlated with reproductive cyclicity status in female elephants, so the observation of high rates of ovarian inactivity in the captive population are likely not related to a loss of ovarian follicles. Only a limited number of males were evaluated in this study, and all were considered healthy. The lack of a difference in AMH secretion between musth and non-musth bulls suggests that Sertoli cell function is not appreciably altered in that regard. However, more work is needed to determine the diagnostic value of AMH measurements in assessing overall fertility status of mature bull elephants, especially in relation to physical or psychological changes in health status. 


\section{Acknowledgments}

The authors thank Beckman-Coulter Inc. for an in-kind donation of the AMH kits, as well as Jose Lopez for technical support. We are grateful to all zoological facilities that provided samples for this project: Albuquerque Biological Park; Buttonwoods Zoo; Caldwell Zoo; Denver Zoo; Dickerson Park Zoo; Fresno Chaffee Zoo; Gladys Porter Zoo; Indianapolis Zoo; Jacksonville Zoo and Gardens;

Knoxville Zoological Gardens; Little Rock Zoo; Maryland Zoo in Baltimore; Miami Metro Zoo; Milwaukee County Zoo; Nashville Zoo; National Zoological Park; North Carolina Zoo; Oregon Zoo; Philadelphia Zoo; Phoenix Zoo; Pittsburgh Zoo and PPG Aquarium; Reid Park Zoo; Riverbanks Zoo; Roger Williams Park Zoo; Sedgwick County Zoo; Seneca Park Zoo; Tampa’s Lowry Park Zoo; Tulsa Zoo and Living Museum; Utah’s Hogle Zoo; Virginia Zoo; Wildlife Safari; and Woodland Park Zoo, Seattle. Additionally, we thank the Elephant TAG for their endorsement of this project, Dr. Elizabeth

Freeman, Dr. Robert A. Dailey, and Coralie Munro for support and guidance, and Dr. Ida Holásková for help with statistical analysis. 


\section{References}

[1] Brown JL, Walker SL, Moeller T. Comparative endocrinology of cycling and noncycling Asian (Elephas maximus) and African (Loxodonta africana) elephants. Gen Comp Endocrinol 2004;136:360-370.

[2] Proctor CM, Freeman EW, Brown JL. Results of a Second Survey to Assess the Reproductive Status of Female Asian and African Elephants in North America . Zoo Biol 2010;29:127-139.

[3] Olson D, Wiese RJ. State of the North American African elephant population and projections for the future. Zoo Biol 2000;19:311-320.

[4] Faust LJ, Thompson SD, Earnhardt JM. Is reversing the decline of Asian elephants in North American zoos possible? An individulal-based modeling approach. Zoo Biol 2006;25:201218.

[5] Baarends WM, Uilenbroek JT, Kramer P, Hoogerbrugge JW, van Leeuwen EC, Themmen AP, Grootegoed JA. Anti-Müllerian hormone and anti-Müllerian hormone type II receptor messenger ribonucleic acid expression in rat ovaries during post-natal development, estrous cycle, and gonadotropin-induced follicle growth. Endocrinol 1995;136:4951-4962.

[6] Lee MM, Donahoe PK. Müllerian inhibiting substance: a gonadal hormone with multiple functions. Endocr Rev 1993;14:152-164.

[7] Durlinger AL, Kramer P, Karels B, de Jong FH, Uilenbroek JT, Grootegoed JA, et al. Control of primordial follicle recruitment by anti-Müllerian hormone in the mouse ovary. Endocrinol 1999;140:5789-96.

[8] Weenen C, Laven J, Von Bergh A, Cranfield M, Groome N, Visser J, et al. Anti-Müllerian hormone expression pattern in the human ovary: potential implications for initial and cyclic follicle recruitment. Mol Hum Reprod 2004;10:77-83. 
[9] Ireland JLH, Scheetz D, Jimenez-Krassel F, Themmen APN, Ward F, Lonergan P,et al. Antral follicle count reliably predicts number of morphologically healthy oocytes and follicles in ovaries of young adult cattle. Biol Reprod 2008;79:1219-1225.

[10] Kevenaar ME, Meerasahib MF, Kramer P, van de Lang-Born BM, de Jong FH, Groome NP, et al. Serum anti-Müllerian hormone levels reflect the size of the primordial follicle pool in mice. Endocrinol 2006;147:3228-34.

[11] Ficicioglu C, Kutlu T, Baglam E, Bakacak Z. Early follicular anti-Müllerian hormone as an indicator of follicular reserve. Fertil Steril 2006;85:592-596.

[12] Visser J, de Jonh F, Laven J, Themmen A. Anti-Müllerian hormone: A new marker for ovarian function. Reprod 2006;131:1-9.

[13] Rock J, Bartlett MK. Biopsy studies of the human endometrium: criteria of dating and information about amenorrhea, menorrhagia, and time of ovulation. J Am Med Assoc 1937;108:2002-2028.

[14] van Rooij IA, Broekmans FJ, te Velde ER, Fauser BC, Bancsi LF, de Jong FH, et al. Serum anti-Müllerian hormone levels: a novel measure of ovarian reserve. Hum Reprod 2002;17:3065-71.

[15] van Rooij IA, Broekmans FJ, Scheffer GJ, Looman CW, Habbema JD, de Jong FH, et al. Serum anti-Müllerian hormone levels best reflect the reproductive decline with age in normal women with proven fertility: a longitudinal study. Fertil Steril 2005;4:979-87.

[16] Moss CJ. The demography of an African elephant (Loxodonta africana) population in Amboseli, Kenya. J Zool 2001;255:145-156.

[17] Brown JL. Reproductive Endocrinology. In: Biology, Medicine, and Surgery of Elephants. Fowler ME, Mikota SK (Eds.), Blackwell Publishing, 2006, pp. 377-387. 
[18] Fortune JE, Rivera GM, Yang MY. Follicular development: the role of the follicular microenvironment in selection of the dominant follicle. Anim Reprod Sci 2004;82:109-126

[19] Hermes R, Olson D, Göritz F, Brown JL, Schmitt DL, Hagen D, et al. Ultrasonography of the Estrous Cycle in Female African Elephants (Loxodonta africana). Zoo Biol 200;19:369-382.

[20] Hildebrandt TB. Reproductive and Diagnostic Ultrasonography. In: Biology, Medicine, and Surgery of Elephants. Fowler ME, Mikota SK (Eds.), Blackwell Publishing, 2006, pp. 357376.

[21] Udoff LC, Adashi EY. Menopause. In: Encyclopedia of Reproduction. Knobil E, Neill JD (Eds.), Academic Press, 1998, pp. 183-188.

[22] Schmitt DL, Hildebrandt TB. Manual collection and characterization of semen from Asian elephants (Elephas maximus). Anim Reprod Sci 1998;53:309-314.

[23] Hildebrandt TB, Hermes R, Pratt NC, Fritisch G, Blottner S, Schmitt DL, et al. Ultrasonography of the urogenital tract in elephants (Loxodonta africana and Elephas maximus): an important tool for assessing male reproductive function. Zoo Biol 2000;19:333345.

[24] Brown JL. Reproductive endocrine monitoring of elephants: An essential tool for assisting captive management. Zoo Biol 2000;19:347-367.

[25] Brown JL, Somerville M, Riddle HS, Keele M, Duer CK, Freeman EW. Comparative endocrinology of testicular, adrenal, and thyroid function in captive Asian and African elephant bulls. Gen Comp Endocrinol 2007;151:153-162.

[26] Kiso W. Dissertation: Motility and morphology of thawed cryopreserved semen in the African and Asian elephant. Personal communication. 
[27] Teixeira J, Maheswaran S, Donahoe PK. Müllerian inhibiting substance: an instructive developmental hormone with diagnostic and possible therapeutic applications. Endocr Rev 2001;22:657-674.

[28] Fujisawa M, Yamsaki T, Okada H, Kamidono S. The significance of anti-müllerian hormone concentration in seminal plasma for spermatogenesis. Hum Reprod 2002;17:968-970.

[29] Josso N, Picard JY, Rey R, Clemente N. Testicular anti-Müllerian hormone: history, genetics, regulation and clinical application. Pediatr Endocrinol Rev 2006;3:347-358.

[30] Brown JL, Lehnhardt J. Serum and Urinary Hormones During Pregnancy and the Peri- and postpartum Period in an Asian Elephant (Elephas maximus). Zoo Biol 1995;14:555-564.

[31] Brown JL, Bush M, Wildt DE, Raath JR, de Vos V, Howard JG. Effects of GnRH analogues on Pituitary-Testicular Function in Free-Ranging African Elephants (Loxodonta africana). J Reprod Fertil 1993;99:627-634.

[32] Association of Zoos and Aquariums (AZA). Reproduction. In: Standards for Elephant Management and Care. AZA, 2003, pp. 6.

[33] Schmitt D. Reproductive System. In: Biology, Medicine, and Surgery of Elephants. Fowler ME, Mikota SK (Eds.), Blackwell Publishing, 2006, pp. 347-356.

[34] Fanchin R, Schonauer LM, Righini C, Guibourdenche J, Frydman R, Taieb J. Serum antiMüllerian hormone is more strongly related to ovarian follicular status than serum inhibin-B, estradiol, FSH and LH on day 3. Hum Reprod 2003;18:323-327.

[35] LaMarca A, Stabile G, Carducci Artensisio A, Volpe A. Serum anti-Müllerian hormone throughout the human menstrual cycle. Hum Reprod 2006;21:3103-3107.

[36] Rota A, Ballarin C, Vigier B, Cozzi B, Rey R. Age dependent changes in plasma anti-müllerian hormone concentrations in the bovine male, female, and freemartin from birth to puberty: 
relationship between testosterone production and influence on sex differentiation. Gen Comp Endocrinol 2002;129:39-44.

[37] Smuts GL. Reproduction and population characteristics of elephants in Kruger National Park. J S Afr Wildl Mgmt Assoc 1975;5:1-10.

[38] Freeman EW, Whyte I, Brown JL. Reproductive evaluation of elephants culled in Kruger National Park, South Africa between 1975 and 1995. Af J Ecology 2009;47:192-201.

[39] Jost A. Problems of fetal endocrinology: the gonadal and hypophyseal hormones. Recent Prog Horm Res 1953;8:379-418.

[40] Lee MM, Donahoe PK, Hasegawa T, Silverman B, Crist GB, Best S, et al. Müllerian inhibiting substance in humans: normal levels from infancy to adulthood. J Clin Endocrinol Metab 1996;81:571-576.

[41] Rey RA, Belville C, Nihoul-Fékété C, Michel-Calemard L, Forest MG, Lahlou N, et al. Evaluation of gonadal function in 107 intersex patients by means of serum anti-Müllerian hormone measurement. J Clin Endocrinol Metab 1999;84:627-631.

[42] Al-Attar L, Noël K, Dutertre M, Belville C, Forest MG, Burgoyne PS, et al. Hormonal and cellular regulation of sertoli cell anti-Müllerian hormone production in the postnatal mouse. $\mathrm{J}$ Clin Invest 1997;100:1335-134

[43] Roudebush WE, Wetzel DL, Breuel KF, Reynolds JE. Validation of an anti-Müllerian hormone (AMH) ELISA for use in an endangered marine mammal, the West Indian Manatee (Trichechus manatus). Bio Reprod 2009;81:214.

[44] Rey R, Josso N. Regulation of testicular anti-müllerian hormone secretion. Eur J Endocrinol 1996;135:144-152.

[45] Sukumar R. The Living Elephants. Oxford University Press, Inc., 2003. 
[46] Kesler DJ, Garverick HA. O Ovarian cysts in Dairy cattle: a review. J Anim Sci 1982;55:114759.

[47] Bosu WTK, Sequin BE. Reproductive System. In: The Merck Veterinary Manual. Aiello SA, Mays A (Eds.), Merck and Company, Inc., 1998, pp. 977-1048.

[48] Piltonen T, Morin-Papunen L, Koinvunen R, Perheentupa A, Ruokonen A, Tapanainen JS. Serum anti-Müllerian hormone levels remain high until late reproductive age and decrease during metaformin therapy in patients with polycystic ovarian syndrome. Hum Reprod 2005;20:1820-1826.

[49] Carlson E, Giwercman A, Keiding N. Evidence for decreasing quality of semen during the past 50 years. BMJ 1992;305:609-13.

[50] Carlson E, Andersson AM, Peterson JH, Skakkebaek NE. History of febrile illness and variation in semen quality. Hum Reprod 2003;18:2089-2092.

[51] Zalata AA, Hassan AH, Nada HA, Bragais FM, Agarwal A, Mostafa T. Follicle-stimulating hormone receptor polymorphism and seminal anti-Müllerian hormone in fertile and infertile men. Andrologia 2008;40:392-397.

[52] Tüttelmann F, Dykstra N, Themmen APN, Visser JA, Nieschlag E, Simoni M. Anti-müllerian hormone in men with normal and reduced sperm concentration and men with maldescended testes. Fertil Steril 2009;91:1812-1819.

[53] Appasamy M, Muttukrishna S, Pizzey AR, Groome NP, Serhal P, Jauniaux E. Relationship between male reproductive hormones, sperm DNA damage and markers of oxidative stress in infertility. Reprod Biomed Online 2007;14:159-165. 


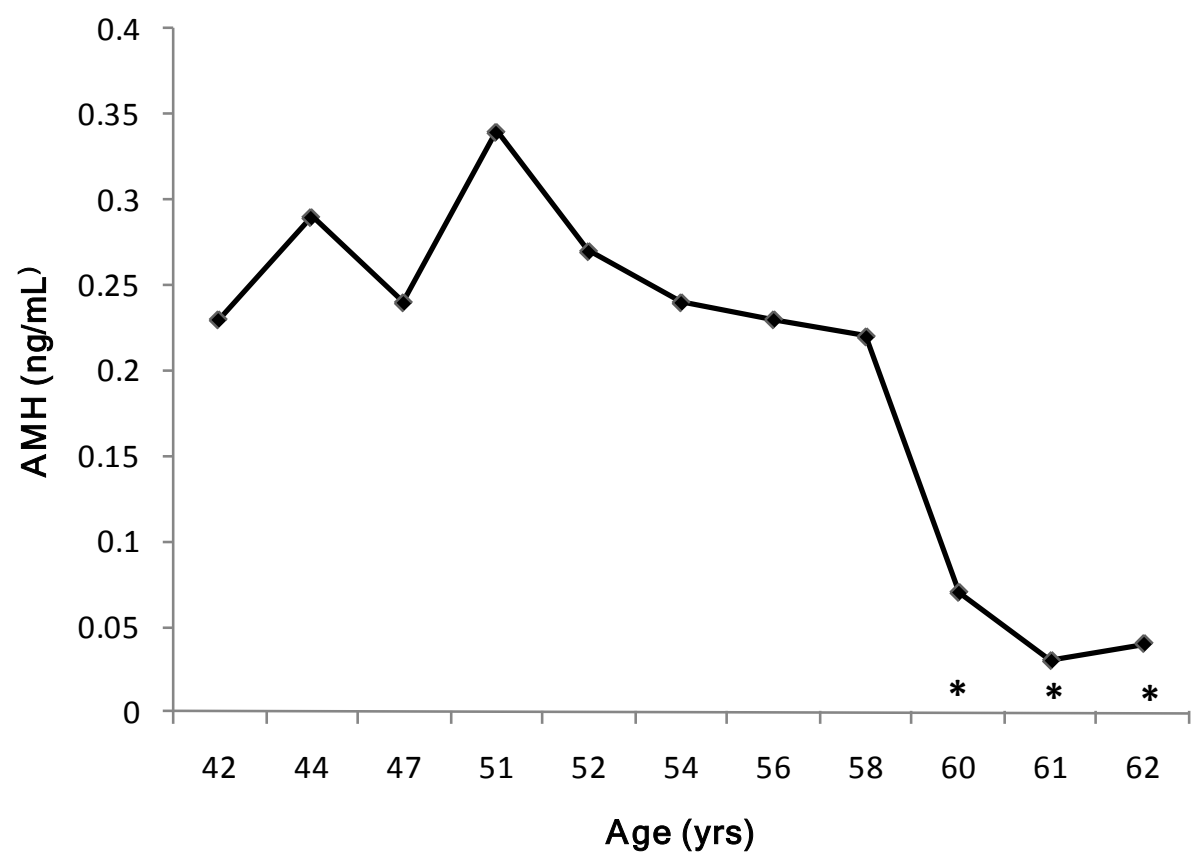

Figure 1. Profile of serum AMH concentrations over a 20-year period in an older female Asian elephant (age $42-62$ years of age). Regression analysis showed a significant decrease in AMH concentration overtime. 
Table 1. Overall mean $( \pm$ SEM) serum AMH concentrations in postpubertal male and female Asian and African elephants.

\begin{tabular}{lcccccc}
\hline Species & Gender & Elephants & $\begin{array}{c}\text { Serum } \\
\text { samples }\end{array}$ & $\begin{array}{c}\text { Mean AMH } \\
(\mathrm{ng} / \mathrm{ml})\end{array}$ & $\begin{array}{c}\text { AMH range } \\
(\mathrm{ng} / \mathrm{ml})\end{array}$ & $\begin{array}{c}\text { Mean AMH } \\
\text { within gender } \\
(\mathrm{ng} / \mathrm{ml})\end{array}$ \\
\hline Asian & Female & $\mathrm{n}=18$ & $\mathrm{n}=18$ & $0.19 \pm 0.02$ & $0.06-0.34$ & $0.18 \pm 0.03^{\mathrm{a}}$ \\
African & Female & $\mathrm{n}=41$ & $\mathrm{n}=46$ & $0.17 \pm 0.04$ & $0.04-1.43$ & \\
Asian & Male & $\mathrm{n}=20$ & $\mathrm{n}=29$ & $40.27 \pm 3.18$ & $4.94-62.53$ & $35.64 \pm 3.70^{\mathrm{b}}$ \\
African & Male & $\mathrm{n}=18$ & $\mathrm{n}=32$ & $31.01 \pm 4.22$ & $0.75-74.14$ & \\
& Castrate & $\mathrm{n}=2$ & $\mathrm{n}=4$ & $0.002 \pm 0.001$ & $0.000-0.004$ & $0.002 \pm 0.001^{\mathrm{c}}$ \\
\hline
\end{tabular}

${ }^{\mathrm{a}, \mathrm{b}, \mathrm{c}}$ Mean values with different superscripts are significantly different $(\mathrm{P}<0.05)$. 
Table 2. Mean ( \pm SEM) serum AMH concentrations cycling and acyclic female and musth and nonmusth male Asian and African elephants.

\begin{tabular}{lcccc}
\hline $\begin{array}{c}\text { Reproductive } \\
\text { status }\end{array}$ & Elephants & $\begin{array}{c}\text { Serum } \\
\text { samples }\end{array}$ & $\begin{array}{c}\text { Mean AMH } \\
(\mathrm{ng} / \mathrm{mL})\end{array}$ & $\begin{array}{c}\text { AMH range } \\
(\mathrm{ng} / \mathrm{mL})\end{array}$ \\
\hline Cycling & $\mathrm{n}=15$ & $\mathrm{n}=16$ & $0.24 \pm 0.08$ & $0.06-1.43$ \\
Acyclic & $\mathrm{n}=30$ & $\mathrm{n}=33$ & $0.16 \pm 0.02$ & $0.05-0.76$ \\
& & & & \\
Non-musth & $\mathrm{n}=14$ & $\mathrm{n}=38$ & $31.12 \pm 3.45$ & $0.75-62.53$ \\
Musth & $\mathrm{n}=14$ & $\mathrm{n}=15$ & $38.71 \pm 5.00$ & $4.94-60.76$ \\
\hline
\end{tabular}


Table 3. Mean ( \pm SEM) serum AMH concentrations in female and male Asian and African elephants across age categories.

\begin{tabular}{llccc}
\hline \multicolumn{1}{c}{ Age category } & Elephants & $\begin{array}{c}\text { Serum } \\
\text { samples }\end{array}$ & $\begin{array}{c}\text { Mean AMH } \\
(\mathrm{ng} / \mathrm{mL})\end{array}$ & $\begin{array}{c}\text { AMH range } \\
(\mathrm{ng} / \mathrm{mL})\end{array}$ \\
\cline { 1 - 3 } \multicolumn{1}{c}{ Females } & & & & \\
Prepubertal $^{1}$ & $\mathrm{n}=2$ & $\mathrm{n}=5$ & $0.59 \pm 0.30^{\mathrm{a}}$ & $0.05-1.55$ \\
Reproductive age $^{2}$ & $\mathrm{n}=20$ & $\mathrm{n}=31$ & $0.18 \pm 0.04^{\mathrm{b}}$ & $0.05-1.43$ \\
Aged $^{3}$ & $\mathrm{n}=11$ & $\mathrm{n}=28$ & $0.17 \pm 0.03^{\mathrm{b}}$ & $0.04-0.76$ \\
\cline { 1 - 3 } Males & & & & \\
Prepubertal $^{1}$ & $\mathrm{n}=3$ & $\mathrm{n}=9$ & $49.08 \pm 6.11^{\mathrm{a}}$ & $17.5-74.14$ \\
Mature $^{2}$ & $\mathrm{n}=12$ & $\mathrm{n}=38$ & $37.01 \pm 3.17^{\mathrm{a}, \mathrm{b}}$ & $0.75-62.53$ \\
Aged $^{3}$ & $\mathrm{n}=5$ & $\mathrm{n}=14$ & $22.27 \pm 5.82^{\mathrm{b}}$ & $1.58-54.45$ \\
\hline
\end{tabular}

${ }^{\mathrm{a}, \mathrm{b}}$ Different superscripts designate significant differences in AMH concentrations among the age categories $(\mathrm{P}<0.05)$ within each gender.

$1 \leq 7$ years of age

${ }^{2} 8-35$ years of age

${ }^{3} \geq 36$ years of age 
Evidence that Hyperprolactinemia is Associated with Ovarian Acyclicity in Female Zoo African Elephants

Dow $\mathrm{TL}^{\mathrm{A}, \mathrm{B}}$, Brown $\mathrm{JL}^{\mathrm{A}}$

Reproduction, Fertility and Development 2012. In Press

${ }^{\text {A }}$ Smithsonian Conservation Biology Institute, Smithsonian National Zoological Park, 1500 Remount

Road, Front Royal, Virginia, USA

${ }^{\text {B }}$ West Virginia University, Division of Animal and Nutritional Sciences, P.O. Box 6108, Morgantown, West Virginia, USA 


\section{ABSTRACT}

Currently, reproductive age (11-35 years old) female African elephants (Loxodonta africana) in U.S. zoos are experiencing high rates of ovarian cycle problems (>40\%) and low reproductive success. Previously, our laboratory found one-third of acyclic females exhibited hyperprolactinemia, a likely cause of ovarian dysfunction. This follow-up study examined the current state of hyperprolactinemia in African elephants and found the problem has increased significantly to $71 \%$. Circulating serum progestagens and prolactin were analyzed in 31 normal cycling, 13 irregular cycling, and 31 acyclic elephants for a 12-month period. In acyclic females, overall mean prolactin concentration differed from cycling females $(\mathrm{P}<0.05)$, with concentration being either higher $(\mathrm{n}=22 ; 54.90 \pm 13.31 \mathrm{ng} / \mathrm{mL})$ or lower ( $\mathrm{n}=9 ; 6.47 \pm 1.73 \mathrm{ng} / \mathrm{mL}$ ) than normal. No temporal patterns of prolactin secretion were evident in elephants that lacked progestagen cycles. In cycling females, prolactin was secreted in a cyclic manner, with higher concentrations observed during nonluteal (34.38 \pm 1.77 and $32.75 \pm 2.61$ $\mathrm{ng} / \mathrm{mL})$ than luteal $(10.51 \pm 0.30$ and $9.67 \pm 0.42 \mathrm{ng} / \mathrm{mL})$ phases for normal and irregular females, respectively. Overall prolactin means did not differ $(\mathrm{P}>0.05)$ between normal $(16.11 \pm 2.89 \mathrm{ng} / \mathrm{mL})$ and irregular $(15.03 \pm 4.17 \mathrm{ng} / \mathrm{mL})$ cycling females. Of most concern was that over two-thirds of acyclic females now are hyperprolactinemic, a dramatic increase from the one-third observed 7 years earlier. Furthermore, females of reproductive age constituted $45 \%$ of elephants with hyperprolactinemia. Until the cause of this problem is identified and/or a treatment is developed, reproductive rates will remain suboptimal and the population non-sustaining.

Keywords: ovarian cyclicity, progestagens, gonadal dysfunction 


\section{Introduction}

At present, $41.1 \%$ of post-pubertal African female elephants in North America experience estrous cycle abnormalities, such as irregular or no ovarian activity (Dow et al., 2011). Individuals that do not cycle exhibit baseline concentrations of progestagens and are considered infertile (Brown and Lehnhardt, 1997; Brown, 2000). One significant endocrine finding associated with abnormal ovarian activity is high circulating prolactin concentrations; i.e., hyperprolactinemia (Brown et al., 2004a; Meyer et al., 2004). In 2004, we completed a comprehensive study to determine if specific hormonal imbalances were causative factors to ovarian acyclicity (Brown et al., 2004a). Of the 10 hormones examined [luteinizing hormone (LH), follicle stimulating hormone (FSH), prolactin, thyroid stimulating hormone (TSH), estradiol, free and total triiodide thyronine $\left(\mathrm{T}_{3}\right)$, free and total thyroxin $\left(\mathrm{T}_{4}\right)$, and cortisol], only prolactin differed and was significantly elevated in one-third (11/33) of acyclic females.

Prolactin is a single-chain peptide hormone involved in a variety of biological processes, most notably mammary gland development and lactation (Li et al., 1987; Li et al., 1989; Rillema, 1994;

Rillema, 1998). Secreted by the anterior pituitary gland, prolactin is under constant inhibitory control by dopamine released from tubero-infundiular dopamine (TIDA) neurons in the arcuate nucleus of the hypothalamus Ben-Jonathan, 1994). This hormone participates in a variety of physiological processes important to reproduction (Freeman et al., 2000). It is the main luteotropic hormone during gestation, supporting luteal progesterone secretion by decreasing the progesterone metabolizing enzyme 20 $\alpha$-hydroxysteroid dehydrogenase (Lamprecht et al., 1969; Bast and Melampy, 1972; Morishige and Rothchild, 1974), and is anti-atretic at the preovulatory follicle level by decreasing intracellular calcium concentration (Lebedeva et al., 1998). In African, but not Asian elephants, prolactin increases in a cyclic pattern during the nonluteal phase of the estrous cycle (Brown et al., 2004a; Yamamoto et al., 2010), and is presumed to be important for facilitating follicle selection and 
development similar to that described in other species (Yoshimura et al., 1989; Larsen et al., 1990; Yoshimura et al., 1991; Li et al., 2011).

Except for high levels of prolactin during pregnancy and lactation, hyperprolactinemia is a pathologic condition at any age and a primary cause of amenorrhea and anovulation in several species (Yu et al., 1981; Jones, 1989; Bachelot and Binart, 2007). In general, the negative effects of chronic elevated prolactin secretion on reproductive function involve inhibition of hypothalamic GnRH release and subsequent suppression of pituitary LH and FSH secretion, resulting in anovulation (Bachelot and Binart, 2007). Temporary hyperprolactin secretion has been linked to sleep apnea, anorexia, protein ingestion, hypoglycemia, stress, chest wall stimulation, and trauma (Jones, 1989; Woolf et al., 1986; Billings et al., 2002). However, longer-term hyperprolactinemia-induced infertility is generally associated with pituitary prolactinomas (Mah and Webster, 2002). Any physiological or pharmacological process that disrupts dopamine secretion or interferes with the delivery of dopamine to the portal vessels can cause hyperprolactinemia (Bachelot and Binart, 2007). The etiology of hyperprolactinemia in elephants has yet to be established, but preliminary data showing a dopamine agonist (cabergoline) and antagonist (domperidone) affects prolactin secretion (Ball and Brown, 2006; Brown, unpubl. data) suggests it is under dopamine control similar to other species.

The main objective of this study was to compare prolactin secretory patterns between cycling and noncycling female African elephants, and determine if the percentage of acyclic females experiencing hyperprolactinemia had changed since the last endocrine study published in 2004 (Brown et al., 2004a). We also assessed prolactin secretion in irregular cycling females, as it is now clear that a number of elephants do not clearly fall into cycling or noncycling categories. The eventual goal is to better understand the role of prolactin in normal and abnormal ovarian function, 
and to develop management or pharmaceutical strategies to mitigate cyclicity problems in captive African elephants.

\section{Materials and Methods}

Animals and Sample Collections

Weekly serum samples from cyclic $(n=31)$, irregular cycling $(n=13)$, and acyclic $(n=31)$ postpubertal African female elephants were collected from an ear vein or saphenous vein in a rear leg for 12 months for progestagen and prolactin analyses. Females that exhibited sustained progestagen concentrations of $<0.1 \mathrm{ng} / \mathrm{mL}$ for at least a 1-year period prior to this study were considered acyclic. Normal cycling females were those that experienced consistent estrous cycles consisting of 4-6 week nonluteal and an 8-10 luteal phases (Brown, 2000). As previously characterized by Brown and colleagues (Brown et al., 2004b), irregular cycling females were those that exhibited extended nonluteal phases ( $>9$ weeks) or shortened luteal phases ( $<6$ weeks), and/or the presence of marked, inconsistent serum progestagen concentration during nonluteal or luteal phases as compared to those of normal cycling females. As defined by Prado-Oviedo (2011), elephants with constant prolactin concentrations $\geq 30 \mathrm{ng} / \mathrm{ml}$ were considered hyperprolactinemic. This project was approved by the National Zoo’s Animal Care and Use Committee and by individual zoological facilities where elephants were housed.

\section{Hormone Analysis}

Serum prolactin was measured by heterologous ${ }^{125}$ I double-antibody radioimmunoassay (RIA) as previously described (Brown and Lehnhardt, 1997; Brown et al., 2004a). All assays were conducted using a PBS-BSA buffer system [0.01 $\mathrm{M} \mathrm{PO}_{4}, 0.5 \%$ BSA, 2mM ethylenediaminetetraacetic acid (EDTA), $0.9 \% \mathrm{NaCl}$, and $0.01 \%$ thimerosal, $\mathrm{pH}$ 7.6), with the 
exception of second antibody where BSA was omitted. An anti-human prolactin antiserum (NIDDKanti-hPRL-3) and ovine I ${ }^{125}$ prolactin label and standards (NIDDK-oPRL-I-2) were employed. The assay was incubated at room temperature over a 3-day period. Assay sensitivity (based on $90 \%$ of maximum binding) was $1.0 \mathrm{ng} / \mathrm{ml}$ with intra- and inter-assay CV $<10 \%$ and $<15 \%$, respectively.

In contrast to most mammals, the major circulating luteal steroid in the elephant is not progesterone, but $5 \alpha$-reduced pregnanes (Hodges, 1998). Serum was analyzed using a solid-phase $I^{125}$ progesterone RIA (Seimens Medical Diagnostic Solutions, Costa Mesa, CA) that has been validated for quantifying progestagens in elephant serum (Brown et al., 1991). Sensitivity (based on $90 \%$ of maximum binding) was $0.03 \mathrm{ng} / \mathrm{mL}$ and intra- and inter-assay CV were $<10 \%$ and $<15 \%$, respectively.

\section{Data Analysis}

Statistical analyses were performed using SAS (SAS Institute, Inc. Cary, NC). PROC GLM of ANOVA for fixed-effects was used to determine overall differences in mean prolactin concentrations for a one-year period between normal cycling, irregular cycling, and acyclic elephants. Estrous cycle length was based on serum progestagen concentration and calculated as the number of days from the first increase in serum progestagens until the next rise (Brown et al., 1999). Prolactin peak and baseline concentrations were determined for each individual by an iterative process in which high values were excluded if they exceeded the mean plus 2 standard deviations (Brown et al., 1999). The highest concentration within a group of elevated samples was considered a peak, and baseline values were those remaining after all high values had been excluded. For normal and irregular cycling females, overall mean prolactin concentration during the nonluteal and luteal phases of the estrous cycle were averaged compared. PROC MIXED of ANOVA for repeated measures was used to determine differences in mean prolactin concentration between individual estrous cycles 
within each individual for normal and irregular cycling elephants. In cases where the null hypothesis (no statistical differences among cyclicity groups) was rejected, Tukey-Kramer post hoc test was used to determine significant differences among groups. Correlation analysis was used to determine the relationship between prolactin and progestagens within normally cycling and irregular cycling females. Data are presented as means \pm SEM. Differences were considered significant at $\mathrm{P}<0.05$.

\section{Results}

Cycling elephants exhibited $4.2 \pm 1.2$ estrous cycles over the 1-year study period (11 \pm 0.4 weeks; range, 9 - 13 weeks). Irregular cycling elephants exhibited $2.4 \pm 0.9$ estrous cycles over the same time period (18 \pm 1.2 weeks; range $1-26$ weeks). There was no clear progestagen pattern for irregular females; 30.7\% (4 of 13) had prolonged nonluteal phases (22.1 \pm 1.1 weeks; range, 18 - 26 weeks), 23.1\% (3 of 13) had short nonluteal phases (1.9 \pm 0.8 weeks; range, 1 - 3 weeks ), 23.1\% (3 of 13) had long luteal phases (12.3 \pm 1.1 weeks; range, $12-14$ weeks), and $23.1 \%$ (3 of 13) had short luteal phases ( $3.7 \pm 0.9$ weeks; range, $3-5$ weeks). Serum prolactin data in normal cycling, irregular cycling, and acyclic elephants are summarized in Table 1. In both cycling groups, prolactin concentration was about three times higher during nonluteal phases as compared to the luteal phase $(\mathrm{P}<0.05)$. Overall mean concentration throughout the estrous cycle also was not different between normal and irregular cycling females $(\mathrm{P}<0.05)$. By contrast, acyclic females exhibited higher prolactin concentrations on average over the 1-year period than cycling elephants $(\mathrm{P}<0.05)$, at levels that were similar to nonluteal phase concentrations in cycling females $(\mathrm{P}>0.05)$. Prolactin data in acyclic females were further separated into 'high' ( $\mathrm{n}=22$ of 31; 71\%) and 'low' ( $\mathrm{n}=9$; 29\%) categories, with the concentration in the 'high' group being nearly 4-fold greater than those during the estrous cycle in cycling females $(\mathrm{P}<0.05)$. By contrast, concentration in the 'low' category were 
less than half of the overall estrous cycle or 1-year means, similar to those observed during the luteal phase of cycling individuals $(\mathrm{P}<0.05)$.

Figures 1-4 illustrate representative profiles of serum progestagens and prolactin in normal, irregular and noncycling female elephants, respectively. For normal cycling females, serum prolactin concentrations followed a recurring pattern, with concentrations being higher during the nonluteal phase (Fig. 1). In general, prolactin started to increase as the progestagens were returning to baseline, peaked during the mid-nonluteal phase point, and then steadily declined to baseline as progestagens rose during the subsequent luteal phase. On average, prolactin concentration peaked at $29.27 \pm 3.68$ $\mathrm{ng} / \mathrm{ml}$ and progestagens at around $0.60 \pm 0.21 \mathrm{ng} / \mathrm{ml}$ during their respective phases in the cycle. Prolactin secretion in the irregular cycling females generally followed a similar pattern with concentration highest during periods of low progestagens (Fig. 2A). In Figure 2A, two successive waves of elevated prolactin of approximately equal duration were observed during a long nonluteal period that lasted 17 weeks. Between these two waves, prolactin was at baseline for $\sim 4$ weeks. Prolactin concentration was again low for about 5 weeks before a subsequent, normal duration (9 week) luteal phase, but with relatively low overall progestagen concentration. In the next cycle, prolactin was increased throughout the following, extremely short ( 1 week) nonluteal phase. In Figure 2B, two successive waves of elevated prolactin were observed during a long nonluteal period that lasted at least 20 weeks; progestagens were at baseline concentration at the start of the monitoring period, and although monitoring began during the first wave of elevated prolactin, it appears overall mean concentration during this wave was higher than those subsequent. A total of three complete waves of elevated prolactin were observed in this individual, all of equal duration and overall mean concentration. During the long nonluteal phase at the beginning of sampling, a biphasic pattern of secretion was observed. After that, a normal 14-week cycle was observed, consisting of a 9-week luteal and 5-week nonluteal phase, followed by a comparatively long cycle $\sim 24$ weeks in 
duration; 13-week luteal and 11-week nonluteal phases. Again, prolactin was higher during nonluteal periods, but the increase started towards the end of the nonluteal phase in the middle cycle and right as progestagens were returning to baseline at the end of the luteal phase in the last cycle. In Figure 2C, two luteal periods were observed during the monitoring period, with peak progestagen concentration of 0.38 and $0.46 \mathrm{ng} / \mathrm{ml}$. Two successive waves of elevated prolactin of equal duration were observed during the long, 34-week nonluteal period between these two luteal phases. Overall mean prolactin concentration was higher in the first $(20.83 \pm 4.9 \mathrm{ng} / \mathrm{mL})$ compared to the second wave $(10.62 \pm 6.6 \mathrm{ng} / \mathrm{mL})$. Overall, for irregular cycling females, prolactin increased up to 2 weeks before to about 2 weeks after the start of a nonluteal phase. In addition, during periods of extended nonluteal phases where progestagens were maintained at baseline concentration, more than one biphasic elevation in prolactin was observed in 6 of 13 females (11 cycles). Figure 3 represents a typical pattern observed in hyperprolactinemic elephants, with prolactin concentration consistently elevated and showing little variation, and progestagens remaining at baseline. In Figure 4, both serum prolactin and progestagen concentrations were at low, baseline concentrations with no cyclic patterns observed. Serum prolactin and progestagen concentration generally remained at or below $6.0 \mathrm{ng} / \mathrm{ml}$ and $0.10 \mathrm{ng} / \mathrm{ml}$, respectively.

\section{Discussion}

Ovarian cycle problems in female African elephants have been well documented for over a decade, yet the etiology remains unknown. This study examined one suspected cause of ovarian acyclicity in elephants: hyperprolactinemia (Brown et al., 2004a) and found that significant perturbations in circulating prolactin concentrations are observed only in acyclic females. Even more importantly, the proportion of females with hyperprolactinemia appears to have significantly increased over the past 7 years. The females in this study represented 60\% (31 of 51), 100\% (31 of 
31) and 100\% (13 of 13) of the normal cycling, irregular cycling, and acyclic female African elephants, respectively, recently identified in a recent Elephant Species Survival Plan (SSP) reproductive assessment survey (Dow et al., 2011). Hyperprolactinemia was observed in $71 \%$ of acyclic females in this study, but in only 37\% (11 of 30) of noncycling elephants in 2004 (Brown et al., 2004a). Perhaps related, rates of ovarian cycle problems also have increased over this time period, from 22\% in 2004 (Brown et al., 2004b) to 41\% in 2011 (Dow et al., 2011). Of the 30 acyclic females from the 2004 study, 5 are deceased, 9 are no longer monitored, and 16 are still acyclic. Of the 16 acyclic females, 4 previously hyperprolactinemic individuals are still hyperprolactinemic and 14 females previously with normal prolactin concentration are now hyperprolactinemic (Brown et al., 2004a; Dow et al., 2011, Dow, unpubl. data). In both endocrine studies, $100 \%$ of the acyclic elephants identified in SSP surveys were represented (Brown et al., 2004a, present study), so there was not a selective bias towards hyperprolactinemic elephants. Cause and effect has not been established because these two studies focused on only two 1-year periods of time; however, the concomitant increase in ovarian problems and rates of hyperprolactinemia is strongly suggestive of a physiological link between the two.

In women, hyperprolactinemia is a known primary cause of infertility, and has a diverse pathophysiology (Yu et al., 1981; Jones, 1989). Prolactinomas account for 25-30\% of functioning pituitary tumors and are a major contributor to hyperprolactinemia (Webster et al., 1997). In some cases, tumor presence can physically block the secretion of gonadotropins, thereby compromising estrous cyclicity (Webster et al., 1997). There are numerous other conditions not associated with pituitary tumors that can result in hyper prolactin secretion, such as sleep disorders, tuberculosis, trauma and renal failure (Mah and Webster, 2002), although none are suspected to be a problem in our study animals based on veterinary records. A variety of pharmaceuticals also have been shown to either remove dopamine inhibition or directly stimulate prolactin secretion to cause an increase in 
prolactin secretion (La Torre and Falorni, 2007). These agents include neuroleptics: phenothiazines, haloperidol; antihypertensives: calcium-channel blockers, methyldopa; psychotropic agents: tricyclic antidepressants; and anti-ulcer agents: H2 antagonists (La Torre and Falorni, 2007). But again, we have no evidence that any of the elephants in this study were exposed to prolactin-inducing chemical agents.

In addition to physiological and pharmacological effects, several endocrine factors have been identified as stimulants of prolactin synthesis: vasoactive intestinal polypeptide (VIP) (Nicosia et al., 1983), thyrotropin-releasing hormone (TRH) (Tashjian et al., 1971) and estradiol (Lieberman et al., 1978). VIP in the brain is synthesized and secreted in two distinct areas, the hypothalamus and within lactotrophs in the anterior pituitary. One action of VIP is to stimulate prolactin mRNA synthesis by enhancing adenyl cyclase and subsequent cAMP directly at the lactotroph, and/or indirectly through deactivation of the tubero-infundibular dopamine system (Ajika et al., 1972; Meites et al., 1972; Ben-Jonathan et al., 2008). Hypothalamic and lactotroph derived VIP has been shown to increase prolactin synthesis during the same time dopamine is exerting an inhibitory effect (Ben-Jonathan et al., 2008). It is possible that a secondary effect of acyclicity in elephants is an increase in dopaminergic tone, resulting in elevated prolactin synthesis and suppression of hypothalamic GnRH. Neither dopamine nor VIP have been evaluated in African or Asian elephants, but given the obvious problem of hyperprolactinemia-related problems in the African species, such investigations appear to be warranted.

Estradiol is a known stimulator of prolactin secretion working both directly and indirectly at the anterior pituitary to increase prolactin synthesis and secretion (Lieberman et al., 1978). Estrogens act at the hypothalamus to decrease dopaminergic tone and on lactotroph cells to increase TRH receptors and block the dopamine inhibiting decrease in cAMP at dopamine 2 receptors (BenJonathan, 1994). TRH can increase prolactin production via direct stimulation by calcium or the 
subsequent phosphorylation of proteins through a calmodulin-dependent protein kinase (Tashjian et al., 1971). A TRH challenge in a female African elephant resulted in an increase in serum prolactin concentrations (Bechert, 1998). However, in the 2004 study of Brown and colleagues (Brown et al., 2004a), serum estradiol did not appear to be a contributing factor to hyperprolactinemia in noncycling African elephants. Thus, because the stimulatory effect of TRH on lactotrophs is mediated through estradiol, it is unlikely that TRH is a likely candidate for prolactin synthesis and secretion (Yamamoto et al., 2010; Prado-Oviedo, 2011). Finally, in women, obesity has been linked with amenorrhea and an increase in dopamine secretion (Doknic et al., 2002), and there is some evidence this may be the case for elephants. Captive African elephants are reported to be $27 \%$ heavier than their wild counterparts (Ange et al., 2001), and a study by Freeman et al. (Freeman et al., 2009) found ovarian acyclicity was associated with a higher body mass index in zoo females. In addition, European zoos housing African elephants are experiencing similar problems (Clubb et al., 2009). A study presently underway to correlate body weight and condition scores, subcutaneous fat deposits and serum nutritional biomarkers with ovarian-pituitary function may shed light on these putative relationships.

In African elephants, prolactin appears to participate in normal follicular development because concentrations increase during the nonluteal or follicular phase of the estrous cycle and reach maximum levels immediately preceding ovulation (Bechert et al., 1999; Brown et al., 2004a). In other species, prolactin regulates follicular development by altering gonadatropin actions at both the hypothalamic-pituitary and ovarian level, resulting in decreases in preantral and antral follicle numbers (Larsen et al., 1990), cAMP levels and steroidogenic function (Gitay-Goren, 1989), and aromatase activity (Tsai-Morris, 1983). Elephants are unique in that during the nonluteal phase they exhibit two quantitatively similar LH surges approximately 21 days apart, which correspond with two discrete follicular waves (Hermes et al., 2000; Lueders et al., 2010); only the second LH surge 
induces ovulation (Brown et al., 1999; Hodges, 1998). Prolactin has been shown to decrease plasminogen and metalloprotease concentrations within preovulatory follicles (Yoshimura et al., 1989; Yoshimura et al., 1990; Yoshimura et al., 1992), both of which play pivotal roles in the degradation of tissue at the apex of an ovulatory follicle, facilitating follicle rupture and subsequent extrusion of the oocyte (Smith et al., 1999). By decreasing enzymes involved in ovulation, increases in prolactin during the early nonluteal phase of the elephant cycle may function to prevent ovulation at the first LH surge. Prolactin then decreases immediately before ovulation (Brown et al., 2004a), possibly resulting in an increase in plasminogen and metaloprotease activity that allows ovulation to occur. By contrast, the Asian elephant also exhibits two LH surges, but no cyclic pattern of prolactin secretion (Brown and Lehnhardt, 1997). It may be significant then, that hyperprolactinemia is only observed in African elephants; prolactin may not play a significant role in controlling ovarian function in the Asian species (Brown et al., 2004a).

Increases in prolactin secretion during the nonluteal phase were observed in both normal and irregular cycling females. However, temporal patterns were more distinct in normal cycling elephants, with a stronger negative relationship existing between the two hormones $(r=-0.8)$ compared to irregular cycling females $(r=-0.6)$. Similar to progestagens, prolactin secretion patterns for the latter were in fact irregular. Unlike in normal cycling individuals where prolactin was elevated during the nonluteal phase until just before the ovulatory LH surge, in irregular cycling females increases in prolactin were observed anywhere from two weeks before to about two weeks after the start of the nonluteal phase, in some cases carrying over into the next luteal phase. In some irregular females experiencing prolonged nonluteal periods, more than one increase in prolactin was observed. This finding suggests that prolactin follows a somewhat regular pattern of secretion during periods of low progestagens, with each wave lasting approximately 8-10 weeks, similar to the single wave observed in normal cycling females. 
While over two-thirds of acyclic elephant females exhibited hyperprolactinemia in this study, we also observed acyclic female elephants with consistently low circulating serum prolactin concentrations and no cyclic temporal profiles. It is possible that in these females, a lack of estradiol from growing follicles is responsible for reduced prolactin secretion. With no follicular development, estrogens would not reach a threshold concentration to increase prolactin. Thus, low prolactin concentrations might be a consequence of acyclicity and not a contributing factor. However, if the problem is an increase in dopaminergic tone, constantly low prolactin secretion would result in the lack of a cyclical profile. As previously mentioned, in other species prolactin participates in a variety of regulatory mechanisms during the estrous cycle, both stimulatory and inhibitory (Tsai-Morris et al., 1983; Gitay-Goren et al., 1989; Yoshimura et al., 1989; Zadworney et al., 1989; Larsen et al., 1990; Martel et al., 1990; Matsuyama et al., 1990; Yoshimura et al., 1990; Yoshimura et al., 1991; Yoshimura et al., 1992; Smith et al., 1999). Assuming prolactin plays a stimulatory role in follicular development and ovulation in African elephants, its suppression could result in the types of ovarian dysfunction observed in females with low prolactin.

In summary, prolactin secretory patterns in acyclic verses normal and irregular cycling female African elephants are significantly altered. Although the exact mechanism of prolactin action in elephants is still unclear, it appears that perturbations in prolactin synthesis, either too much or too little, may be directly or indirectly involved in gonadal dysfunction. Most importantly, the frequency of hyperprolactinemia appears to have dramatically increased and is now observed in $71 \%$ of acyclic females, up from the 37\% in 2004 (Brown et al., 2004a). The next step is to determine if a loss in cyclical prolactin secretion during the nonluteal phase precedes acyclicity acting as a causative factor or if constant low prolactin synthesis is a consequence of the acyclic state. Because our captive African elephant population is not self-sustaining, it is imperative to have all reproductive-aged females cycling. One potential treatment option involves the use of cabergoline, a dopamine receptor 
agonist that has been shown to temporarily decrease circulating prolactin concentration in hyperprolactinemic elephants (Ball and Brown, 2006). A trial is now underway to determine if longterm cabergoline treatment (at least 1 year) will permit resumption of ovarian activity, similar to that observed in women (Dekkers et al., 2010). By identifying causative factors of acyclicity, we hope to develop proper courses of treatment to mitigate ovarian cycle problems in reproductive-age female elephants, and prevent the population crash predicted for this species in zoos (Faust et al., 2006).

\section{Acknowledments}

The authors thank Dr. Robert A. Dailey, and Coralie Munro for support and guidance, Natalia Prado-Oviedo and Nicole Parker for endocrine lab support, Dr. Ida Holásková for help with statistical analysis, and Andrew Dow for data entry and technical support. We are grateful to A. F. Parlow for supplying prolactin antibody for iodination. In addition, we give special thanks to the following zoological facilities that provided samples for this project: Caldwell Zoo; Cheyenne Mountain Zoo; Cleveland Metroparks Zoo; The Dallas Zoo; Disney’s Animal Kingdom Park; Indianapolis Zoo; Jacksonville Zoo and Gardens; The Kansas City Zoo; Knoxville Zoo; Lee Richardson Zoo; Lion Country Safari Park; The Maryland Zoo in Baltimore; The Memphis Zoo; Montgomery Zoo; Nashville Zoo at Grassmere; North Carolina Zoo; Omaha’s Henry Doorly Zoo; Philadelphia Zoo; Pittsburgh Zoo \& PPG Aquarium; Redwood Six Flags Discovery Kingdom; Riverbanks Zoo and Garden; Roger Williams Park Zoo; Sedgwick County Zoo; Seneca Park Zoo; Tampa’s Lowry Park Zoo; The Toledo Zoo; Utah’s Hogle Zoo; Virginia Zoo in Norfolk; Wildlife Safari; Woodland Park Zoo; Zoo Atlanta; and Zoo Miami. 


\section{References}

Ajika, K., Krulich, L., Fawcett, C.P., and McCann, S.M. (1972). Effects of estrogen on plasma and pituitary gonadotropins and prolactin, and on hypothalamic releasing and inhibiting factors. Neuroendocrinology 9, 304-315.

Ange, K., Crissey, S.D., Doyle, C., Lance, K., and Hintz, H. (2001). A survey of African (Loxodonta africana) and Asian (Elephas maximus) elephant diets and measured body dimensions compared to their estimated nutrient requirements. In 'Proceedings of the Association of Zoos and Aquariums Nutritional Advisory Group’. pp. 5-14. (Association of Zoos and Aquariums Nutritional Advisory Group: USA.)

Bachelot, A., and Binart, N. (2007). Reproductive role of prolactin. Reproduction 113, 361-369.

Ball, R., and Brown, J.L. (2006). Preliminary results of a cabergoline trial in captive elephants with hyperprolactinemia. In 'Proceedings, International Elephant Conservation and Research Symposium, Coppenhagen, 21 October 2006’. p. 9. (International Elephant Foundation: USA.)

Bast, J.D., and Melampy, R.M. (1972). Luteinizing hormone, prolactin and ovarian 20 $\alpha-$ hydroxysteroid dehydrogenase levels during pregnancy and pseudopregnancy in the rat. Endocrinology 91, 1499-1505.

Bechert, U.S. (1998). Factors affecting prolactin secretion in the African elephant. Ph.D. Thesis, Oregon State University: Corvallis, Oregon.

Bechert, U.S., Swanson, L., Wasser, S.K., Hess, D.L., and Stormshak, F. (1999). Serum prolactin concentrations in the captive female African elephant (Loxodonta africana): potential effects of season and steroid hormone interactions. Gen. Comp. Endocrinol. 114, 269-278. 
Ben-Jonathan N. (1994). Regulation of prolactin secretion. In 'The Pituitary Gland'. (Ed. H. Imura.) pp. 261-283. (Raven Press: New York.)

Ben-Jonathan, N., LaPensee, C.R., and LaPensee, E.W. (2008). What can we learn from rodents about prolactin in humans? Endocrinol. Rev. 29, 1-41.

Billings, H.J.., Viguie, C., Karsch, F.J., Goodman, R.L., Connors, J.M., and Anderson, G.M. (2002). Temporal requirements of thyroid hormones for seasonal changes in LH secretion. Endocrinology 143, 2618-2625.

Brown, J.L., Citino, S.B., Bush, M., Lehnhardt, J., and Phillips, L.G. (1991). Cyclic patterns of luteinizing hormone, follicle-stimulating hormone, inhibin, and progesterone secretion in the Asian elephant (Elephas maximus). J. Zoo. Wildl. Med. 1, 49-57.

Brown, J.L., and Lehnhardt, J. (1997). Secretory patterns of serum prolactin in Asian (Elephas maximus) and African (Loxodonta africana) elephants during different reproductive states: comparison with concentrations in a noncycling African elephant. Zoo Biol. 16, 149-159.

Brown, J.L., Schmitt, D.L., Bellum, A., Graham, L.H., and Lehnhardt, J. (1999). Hormone secretion in the Asian elephant (Elephas maximus): Characterization of ovulatory and anovulatory luteinizing hormone surges. Bio. Reprod. 61, 1294-1299.

Brown, J.L. (2000). Reproductive endocrine monitoring of elephants: An essential tool for assisting captive management. Zoo Biol. 19, 347-368.

Brown, J.L., Walker, S.L., and Moeller, T. (2004a). Comparative endocrinology of cycling and noncycling Asian (Elephas maximus) and African (Loxodonta africana) elephants. Gen. Comp. Endocrinol. 136, 360-370.

Brown, J.L., Olson, D., Keele, M., and Freeman, E.W. (2004b). Survey of the reproductive status of Asian and African elephants in North America. Zoo Biol. 23, 309-321. 
Chatfield, A., Zhang, L., Ramey, J., Bowsher, T., Loskutoff, N., and O’Neill, K. (2006). Resolution of hyperprolactinemia in western lowland gorilla (gorilla gorilla gorilla). J. Zoo. Wildl. Med. 37, 565-566.

Clubb, R., Rowcliffe, M., Lee, P., Mar, K.U., Moss, C., and Mason, G.J. (2009). Fecundity and population viability in female zoo elephants: problems and possible solutions. Anim. Welf. 114, 237-247.

Dekkers, O.M., Lagro, J., Burman, P., Jørgensen, J.O., Romijn, J.A., and Pereira, A.M. (2010). Recurrence of hyperprolactinemia after withdraw of dopamine agonists: systemic review and meta-analysis. J. Clin. Endocrinol. Metab. 95, 43-51.

Doknic, M., Pekic, S., Zarkovic, M., Medic-Stojanoska, M., Dieguez, C., Casanueva, F., and Popovic, V. (2002). Dopaminergic tone and obesity: an insight from prolactinomas treated with bromocriptine. Eur. J. Endocrinol. 147, 77-84.

Dow, T.L., Holásková, I., and Brown, J.L. (2011). Results of the third reproductive assessment survey of North American Asian (Elephas maximus) and African (Loxodonta africana) female elephants. Zoo Biol. 29, 1-13.

Faust, L.J., Thompson, S.D., and Earnhardt, J.M. (2006). Is reversing the decline of Asian elephants in North American zoos possible? An individual-based modeling approach. Zoo Biol. 25, 201218.

Freeman, E.W., Guangnano, G., Olson, D., Keele, M., and Brown, J.L. (2009). Social factors influence ovarian acyclicity in captive African elephants (Loxodonta africana). Zoo Biol. 2009; 28, 1-15.

Freeman, M.E., Kanyicska, B., Lerant, A., and Nagy, G. (2000). Prolactin: structure, function and regulation of secretion. Physiol. Rev. 80, 1523-1631. 
Geras, E., Rebecchi, M.J., and Gershengorn, M.C. (1982). Evidence that stimulation of thyrotropin and prolactin secretion by thyrotropin-releasing hormone occur via different calciummediated mechanisms: studies with verapamil. Endocrinology 110:901-906.

Gitay-Goren, H., Lindenbaum, E.S., and Kraiem, Z. (1989). Effects of prolactin on steroidogenesis and cAMP accumulation in rat luteal cell cultures. Mol. Cell. Endocrinol. 65, 195-201.

Hermes, R., Olson, D., Goeritz, F., Brown, J.L., Schmitt, D.L., Hagan, D., Peterson, J.S., Fritsch, G., and Hildebrandt, T.B. (2000). Ultrasonography of the sexual cycle in female African elephants (Loxodonta africana). Zoo. Biol. 19, 369-382.

Hodges, J.K. (1998). Endocrinology of the ovarian cycle and pregnancy in the Asian (Elephas maximus) and African (Loxodonta africana) elephant. Anim. Reprod. Sci. 19, 3-18.

Jones, E.E. (1989). Hyperprolactinemia and female infertility. J. Reprod. Med. 34, 117-126. Lamprecht, S.A., Lindner, H.R., and Strauss, J.F. (1969). Induction of 20 $\alpha$-hydroxysteroid dehydrogenase in rat corpora lutea by pharmacological blockage of pituitary prolactin secretion. Biochim. Biophys. Acta. 187, 133-143.

Larsen, J.L., Bhana, A., and Odell, W.D. (1990). Prolactin inhibition of pregnant mare’s serum stimulated follicle development in the rat ovary. Endocrinol. Res. 16, 449-459.

La Torre, D., and Falorni, A. (2007). Pharmacological causes of hyperprolactinemia. Ther. Clin. Risk Manage. 3, 929-951.

Lebedeva, I.Y., Denisenko, V.U., Leebedeva, V.A., and Kuzmina, T.I. (1998). Prolactin in follicular fluid and intracellular store calcium in follicular cells are related to morphological signs of ovarian follicle atresia in cows: work in progress. Theriogenology 49, 509-519.

Li, C.H., Chung, D., Bewley, T.A., and Cabrera, C.M. (1987). Elephant prolactin: isolation and characterization. Int. J. Peptide Protein Res. 29, 472-477. 
Li, C.H., Oosthuizen, M.M.J., and Chung, D. (1989). Primary Structure of elephant pituitary prolactin. Int. J. Peptide Protein Res. 33, 67-69.

Li, W.L., Liu, Y., Yu, Y.C., Huang, Y.M., Liang, S.D., and Shi, Z.D. (2011). Prolactin plays a stimulatory role in ovarian follicular development and egg laying in chicken hens. Domest. Anim. Endocrinol. 41, 57-66.

Lieberman, M.E., Maurer, R.A., and Gorski, J. (1978). Estrogen control of prolactin synthesis in vitro. Proc. Natl. Acad. Sci. U. S. A. 75, 5946-5949.

Lueders, I., Niemuller, C., Gray, C., Rich, P., and Hildebrandt, T. (2010). Luteogenesis during the estrous cycle in Asian elephants (Elephas maximus). Reproduction 140, 777-786.

Mah, P.M., and Webster, J. (2002). Hyperprolactinemia: etiology, diagnosis, and management. Semin. Reprod. Med. 20, 365-373.

Martel, C., Labrie, C., Couët, J., Dupont, E., Trudel, C., Luu-The, V., Takahashi, M., Pelletier, G., and Labrie, F. (1990). Effects of human chorionic gonadotropin (hCG) and prolactin (PRL) on 3 beta-hydroxy-5-ene-steroid dehydrogenase/delta 5-delta 4 isomerase (3beta-HSD) expression and activity in the rat ovary. Mol. Cell. Endocrinol. 72:R7-13.

Matsuyama, S., Shiota, K., and Takahashi, M. (1990). Possible role of transforming growth factorbeta as a mediator of luteotropic action of prolactin in rat luteal cell cultures. Endocrinology 127, 1561-1567.

Meites, J., Lu, K.H., Wuttke, W., Welsch, C.W., Nagasawa, H., and Quadri, S.K. (1972). Recent studies on functions and control of prolactin secretion in rats. Recent Prog. Horm. Res. 28, 471-526.

Meyer, J., Ball, R., and Brown, J.L. (2004) Why are so many elephants in captivity not cycling? Evidence of an association between ovarian inactivity and hyperprolactinemia. JEMA. 15, 915.

Morishige, W.K., and Rothchild, I. (1974). Temporal aspects of regulation of corpus luteum function by luteinizing hormone, prolactin, and placental luteotropin during the first half of pregnancy in the rat. Endocrinology 95, 260-274. 
Nicosia, S., Olivia, D., Giannattasio, G., and Spada, A. (1983). The role of vasoactive intestinal polypeptide (VIP) as a hypothalamic neurohormone. J. Endocrinol. Invest. 6, 235-240.

Prado-Oviedo, N. (2011). Role of estrogens in hyperprolactinemia: Induced acyclicity in African female elephants. MS. Thesis, American University:Washington, DC.

Rillema, J.A. (1994). Development of the mammary gland and lactation. Trends Endocrinol. Metab. 5, 149-154.

Rillema, J.A. (1998). Actions of prolactin. In 'Encyclopedia of Reproduction’, Vol. 4, 3rd edn. (Eds. E. Knobil and J. Neill.) pp. 39-43. (Academic Press: London.)

Smith, M.F., McIntush, E.W., Ricke, W.A., Kojima, F.N., and Smith, G.W. (1999). Regulation of ovarian extracellular matrix remodeling by metalloproteases and their tissue inhibitors: effects on follicular development, ovulation, and luteal function. J. Reprod. Fertil. Suppl. 54, 367381.

Tashjian, A.H., Barowsky, N.J., and Jensen, D.K. (1971). Thyrotropin-releasing hormone: direct evidence for stimulation of prolactin production by pituitary cells in culture. Biochem. Biophys. Res. Commun. 43, 516-523.

Tsai-Morris, C.H., Ghosh, M., Hirshfield, A.N., Wise, P.M., and Brodie, A.M. (1983). Inhibition of ovarian aromatase by prolactin in vivo. Biol. Reprod. 29, 342-346.

Webster, J., and Scanlon, M.F. (1997). Prolactinomas. In ‘Clinical Endocrine Oncology’. (Eds. R. Sheaves, P.J. Jenkins, J.A. Wass.) pp. 189-194. (Blackwell Science: Oxford, UK.)

Woolf, P.D. (1986). Differential diagnosis of hyperprolactinemia: physiological and pharmacological factors. In 'Prolactinomas: Contemporary Issues in Endocrinology and Metabolism', Vol 2. (Eds .J.M. Olefsky and R.J. Robbins.) pp. 43-65. (Churchill Livingstone: New York.) Yamamoto, Y., Yamamoto, T., Watanabe, G., Yuto, N., Keio, M., Narushima, E., Katayanagi, M., Nakao, R., Morikubo, S., Sakurai, Y., Kaneko, M., Kaewmanee, S., and Taya, K. (2010). 
Prolactin secretion and ovarian function in cycling and non-cycling African female elephants (Loxodonta africana). J. Vet. Med. Sci. 72, 845-852.

Yoshimura, Y., Tada, S., Oda, T., Nakamura, Y., Maruyama, K., Ichikawa, F., Ebihara, T., Hirota, Y., Sawada, T., and Kawakami, S. (1989). Direct inhibitory ovarian effects of prolactin in the process of ovulation. Nippon Sanka Fujinka Gakhai Zasshi. 41, 83-89.

Yoshimura, Y., Maruyana, K., Shiraki, M., Kawakami, S., Fukushima, M., and Nakamura, Y. (1990). Prolactin inhibits plaminogen activator activity in the preovulatory follicles. Endocrinology 126, 631-636.

Yoshimura, Y., Nakamura, Y., Yamada, H., Ando, M., Ubukata, Y., Oda, T., and Suzuki, M. (1991). Possible contribution of prolactin in the process of ovulation and oocyte maturation. Horm. Res. 35, 22-32.

Yoshimura, Y., Nakamura, Y., Oda, T., Ando, M., Ubukata, Y., Koyama, N., Karube, M., and Yamada, H. (1992). Effects of prolactin on ovarian plasmin generation in the process of ovulation. Biol. Reprod. 46, 322-327.

Yu, M.C., Gerkins, V.R., Henderson, B.E., Brown, J.B., and Pike, M.C. (1981). Elevated levels of prolactin in nulliparous women. Br. J. Cancer. 43, 826-831.

Zadworney, D., Shimada, K., Ishida, H., and Sato, K. (1989). Gonadotropin-stimulated estradiol production in small ovarian follicles of the hen is suppressed by physiological concentrations of prolactin in vitro. Gen. Comp. Endocrinol. 74, 468-473. 
TABLE 1. Circulating serum prolactin concentrations (mean $\pm S E M)$ in normal cycling, irregular cycling, and acyclic female African elephants during the estrous cycle, and for the 1-year study period.

\begin{tabular}{|c|c|c|c|c|c|c|c|}
\hline \multirow[b]{2}{*}{ Group } & \multirow[b]{2}{*}{$\begin{array}{l}\text { Mean Age } \\
\text { (years) }\end{array}$} & \multirow[b]{2}{*}{$\begin{array}{l}\text { Age Range } \\
\text { (years) }\end{array}$} & \multirow[b]{2}{*}{$\begin{array}{l}\text { No. of } \\
\text { Elephants }\end{array}$} & \multicolumn{4}{|c|}{ Overall Mean Prolactin Concentrations (ng/ml) } \\
\hline & & & & $\begin{array}{l}\text { Nonluteal } \\
\text { Phase }\end{array}$ & Luteal Phase & $\begin{array}{l}\text { Estrous } \\
\text { Cycle }\end{array}$ & 1-year period \\
\hline Normal Cycling & 29.1 & $16-39$ & $\mathrm{n}=31$ & $34.38 \pm 1.77^{\mathrm{a}}$ & $10.51 \pm 0.30^{b}$ & $16.10 \pm 0.40$ & $16.11 \pm 2.89^{\mathrm{a}}$ \\
\hline Irregular Cycling & 34.5 & $23-48$ & $\mathrm{n}=13$ & $32.75 \pm 2.61^{\mathrm{a}}$ & $9.67 \pm 0.42^{b}$ & $15.03 \pm 0.57$ & $15.03 \pm 4.17^{\mathrm{a}}$ \\
\hline Acyclic & 35.4 & 26.53 & $\mathrm{n}=31$ & N/A & N/A & N/A & $33.03 \pm 5.93^{b}$ \\
\hline $\begin{array}{c}\text { High } \\
\text { Prolactin }\end{array}$ & 36.4 & $28-53$ & $\mathrm{n}=22$ & N/A & N/A & N/A & $\begin{array}{c}64.90 \pm \\
13.31^{*}\end{array}$ \\
\hline Low Prolactin & 32.9 & $26-45$ & $\mathrm{n}=9$ & N/A & N/A & N/A & $6.47 \pm 1.73^{*}$ \\
\hline
\end{tabular}

${ }^{\mathrm{a}, \mathrm{b}}$ Within column, means without a common superscript significantly differed $(\mathrm{P}<0.05)$ for normal cycling, irregular cycling, and acyclic females over a 1-year period or between nonluteal and luteal phases for normal cycling and irregular cycling females

${ }^{*}$ Values with asterisk subscripts were not included in statistical analysis 


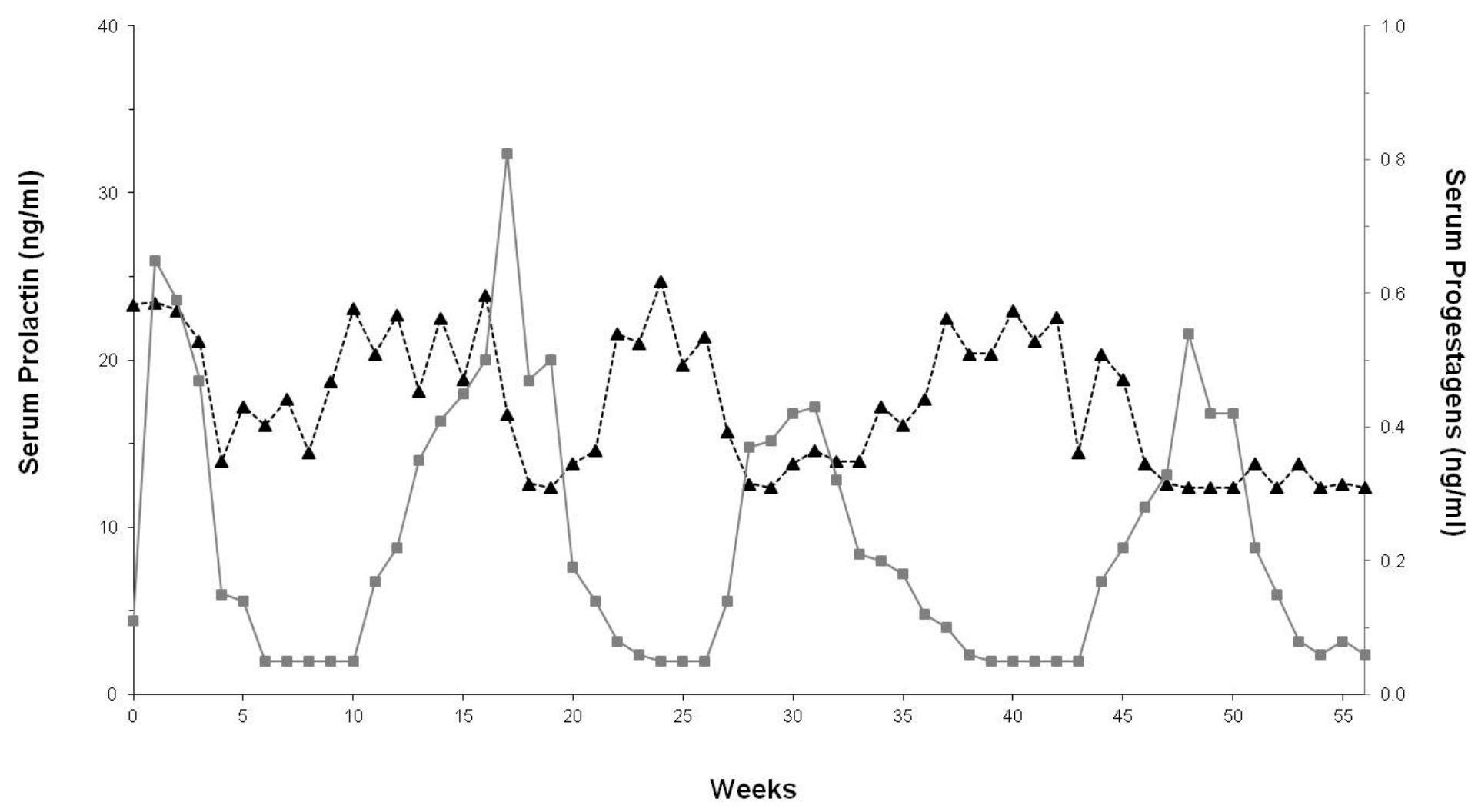

Figure 1. Representative profile of serum progestagen and prolactin concentrations for a normal cycling female elephant. 


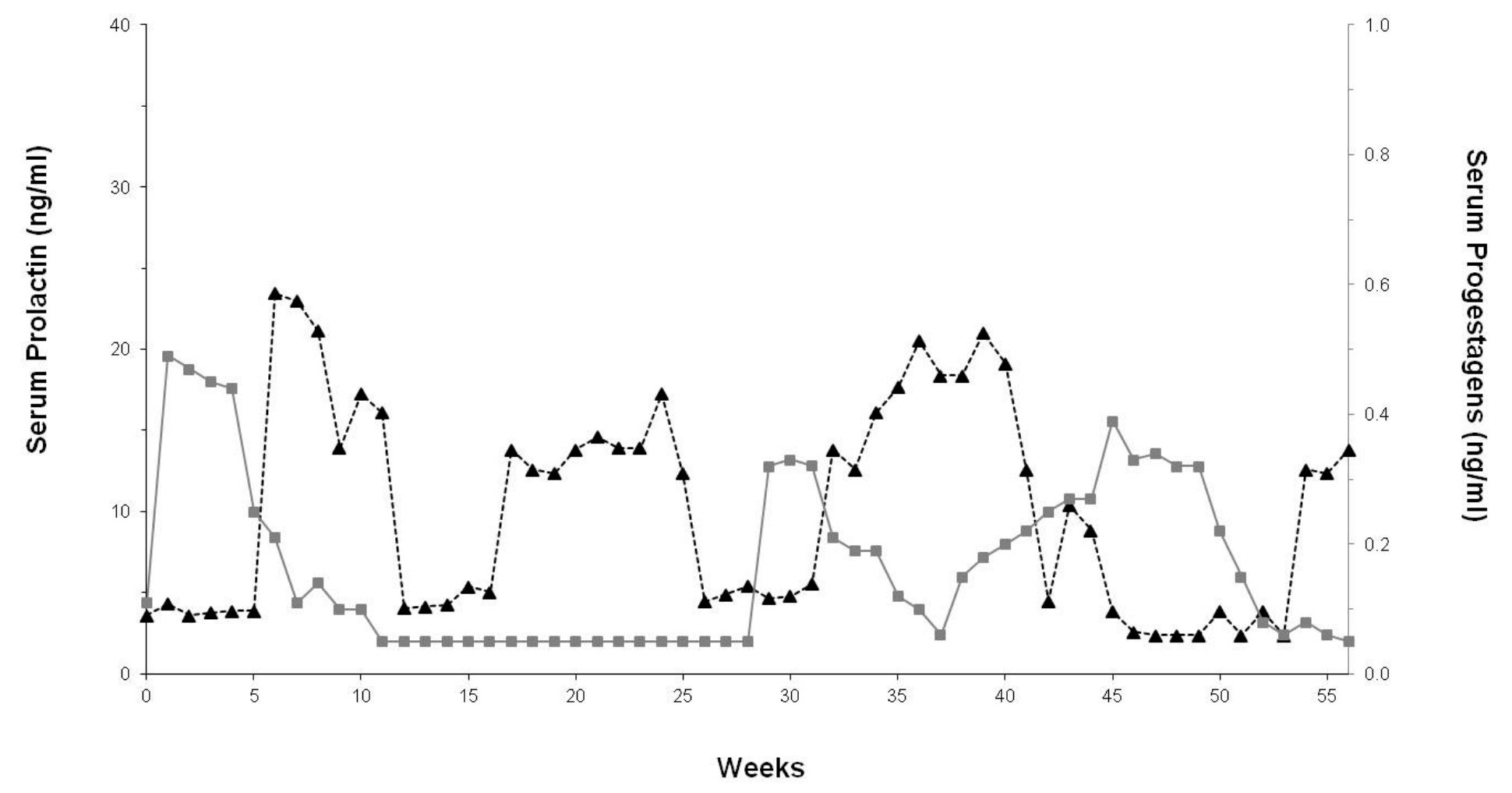

Figure 2A. Representative profiles of serum progestagen and prolactin concentrations for three representative irregular cycling female elephants. 


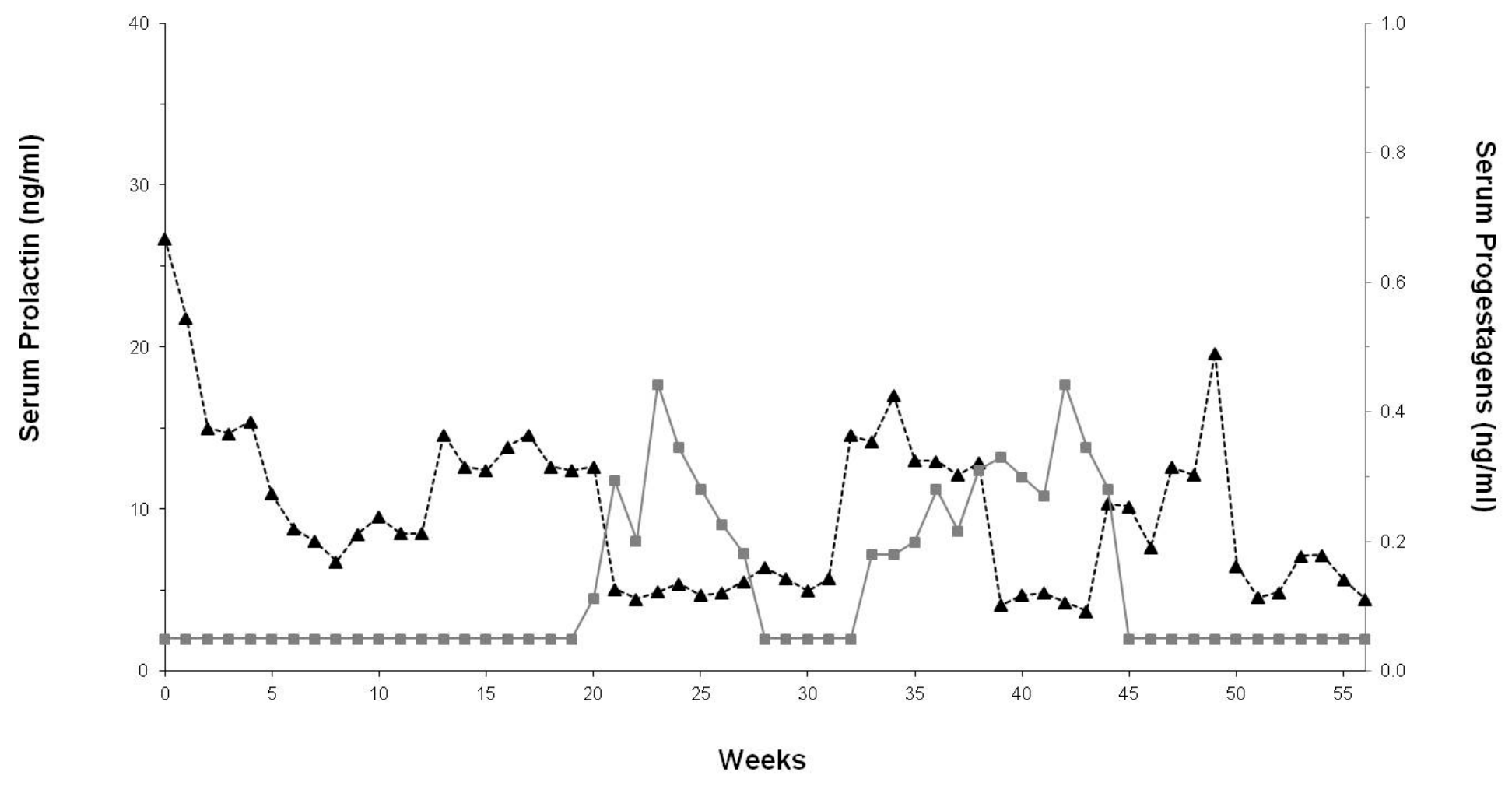

Figure 2B. Representative profiles of serum progestagen and prolactin concentrations for three representative irregular cycling female elephants. 


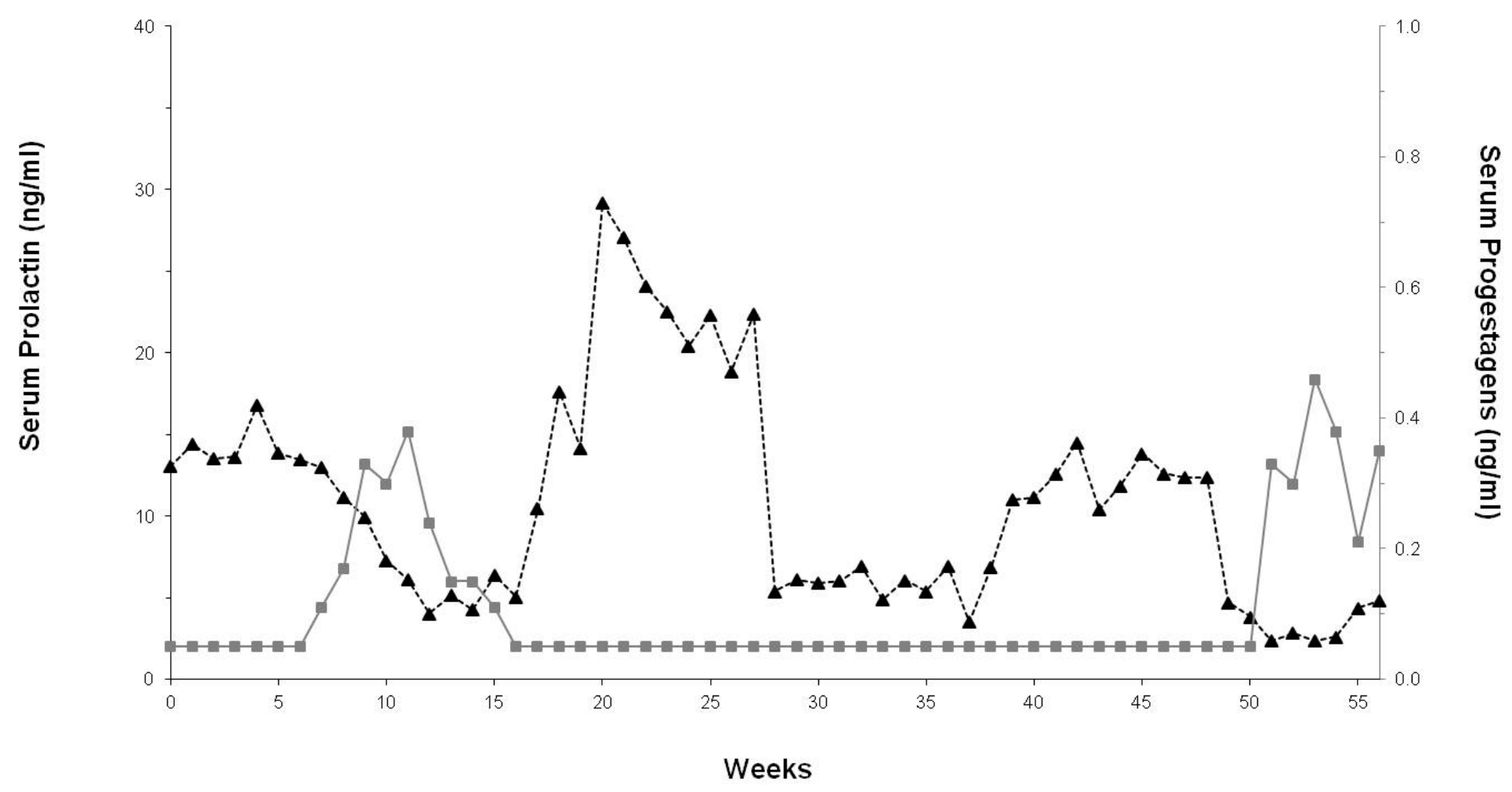

Figure 2C. Representative profiles of serum progestagen and prolactin concentrations for three representative irregular cycling female elephants. 


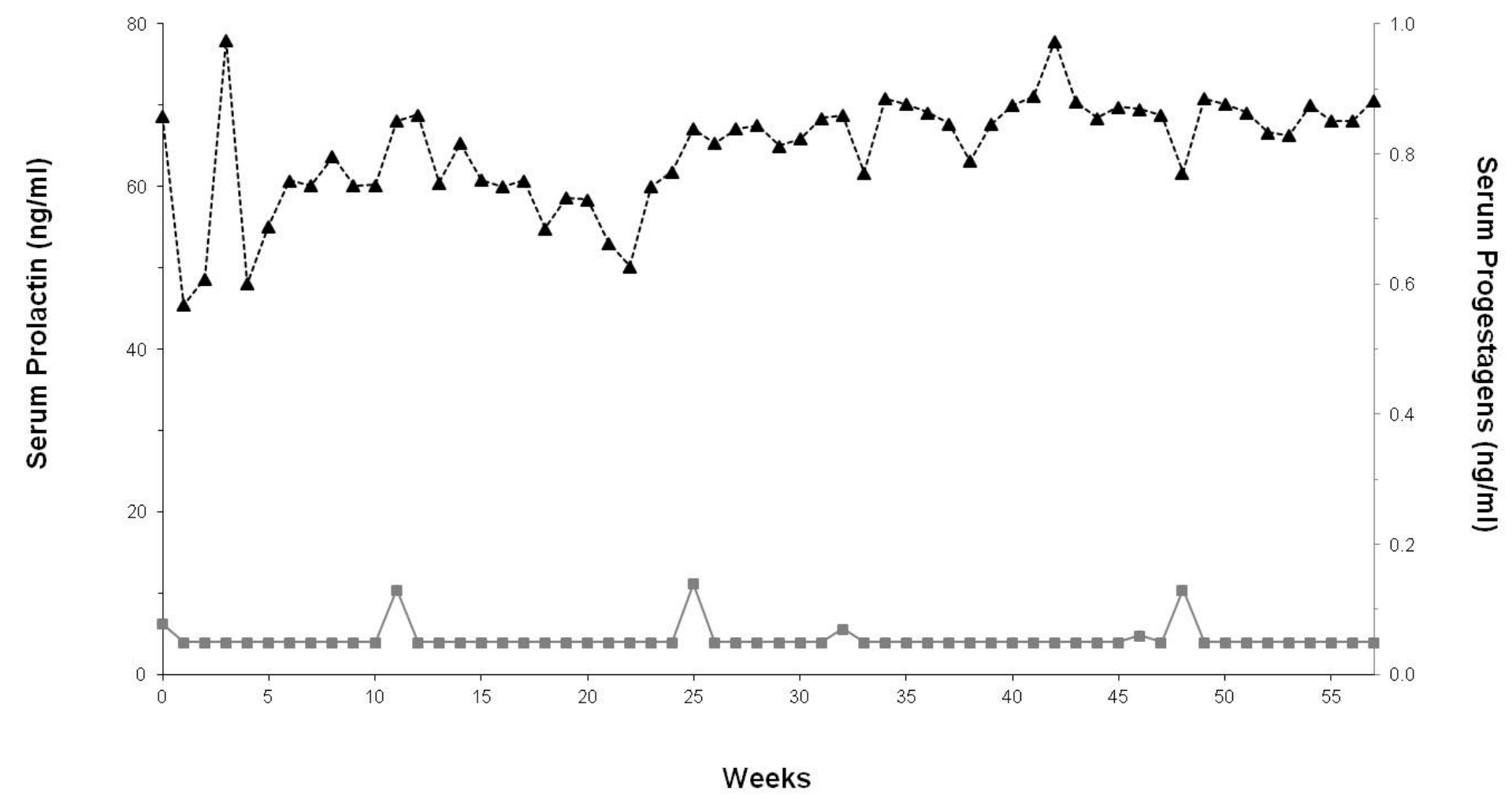

Figure 3. Representative profile of serum progestagen and prolactin concentrations for an acyclic female elephant with high prolactin concentrations. 


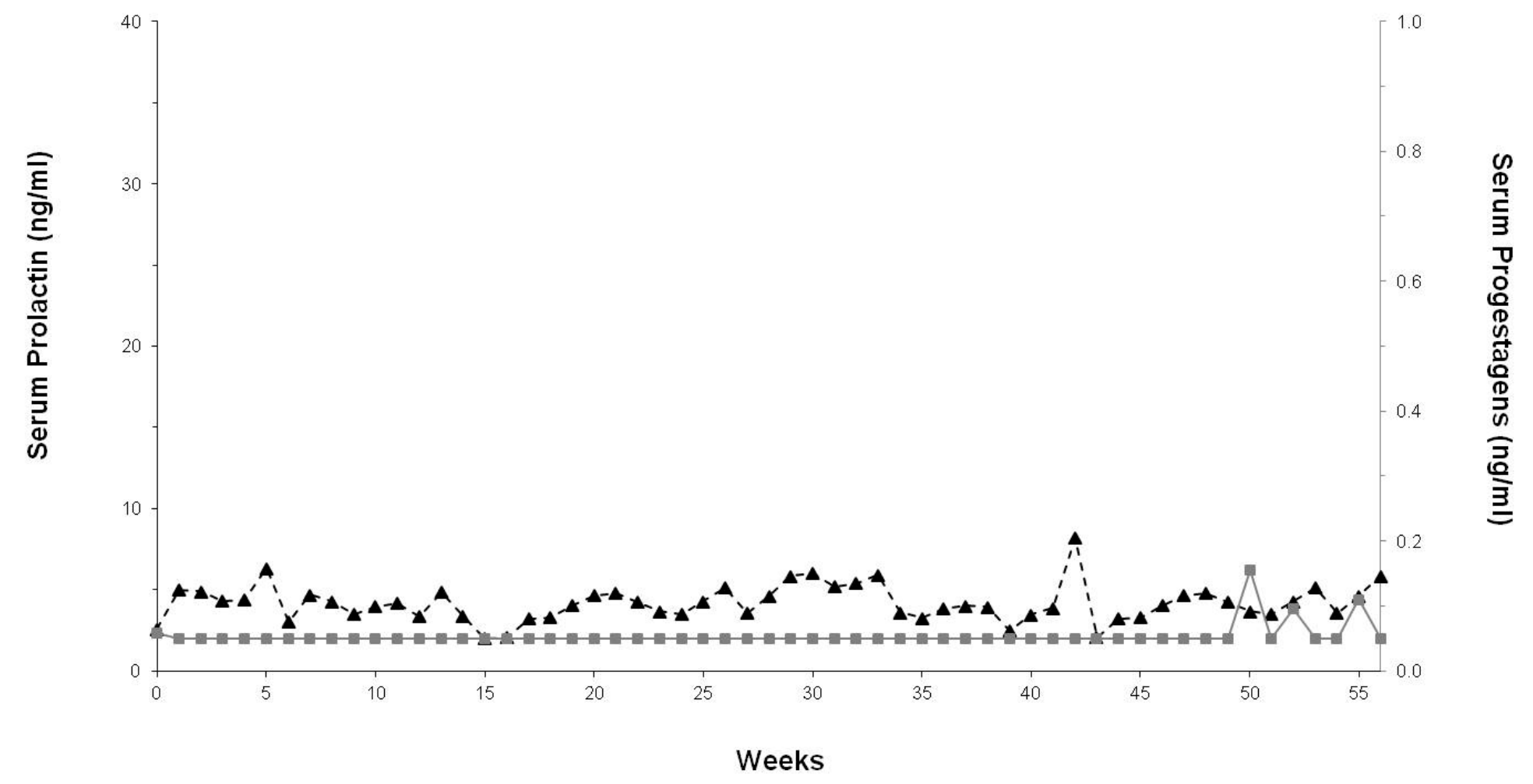

Figure 4. Representative profile of serum progestagen and prolactin concentrations for an acyclic female elephant with low prolactin concentrations. 
Determining the efficacy of cabergoline and domperidone for treating ovarian acyclicity in African elephants (Loxodonta africana).

Dow $\mathrm{TL}^{1,2}$ and Brown $\mathrm{JL}^{1}$

${ }^{1}$ Smithsonian Conservation Biology Institute, Smithsonian National Zoological Park, Front Royal, Virginia

${ }^{2}$ West Virginia University, Division of Animal and Nutritional Sciences, Morgantown, West Virginia 


\section{Abstract}

Perturbations in serum prolactin concentration have been identified as a common symptom among captive acyclic African elephants. In the human, hyperprolactinemia and prolactin deficiencies are significant causes of amenorrhea. Pituitary prolactin is held under constant inhibition by a hypothalamic derived neurotransmitter, dopamine; thus, regulation via exogenous treatment with antagonists or agonists has been successful in reinitiating normal ovarian cycles. Oral administrations of Cabergoline (dopamine agonist; $\mathrm{n}=4$ ) and domperidone (dopamine antagonist; $\mathrm{n}=4$ ) were studied as possible treatments for hyperprolactinemia or prolactin deficiency, respectively. Changes in serum prolactin and progestagen concentrations in response to treatment were evaluated to determine if regulation of prolactin synthesis can reinitiate normal estrous cyclicity. Overall mean prolactin concentration decreased $(\mathrm{P}=0.01)$ in cabergoline treated females $(32.22 \pm 14.75 \mathrm{ng} / \mathrm{mL})$ when compared to controls $(77.53 \pm 0.96 \mathrm{ng} / \mathrm{mL})$. Overall mean progestagen concentrations increased $(\mathrm{P}<0.05)$ in treated females $(0.15 \pm 0.01 \mathrm{ng} / \mathrm{mL})$. In contrast, control hyperprolactinemic females maintained mean baseline progestagen concentration $(0.07 \pm 0.01 \mathrm{ng} / \mathrm{mL})$. Overall mean prolactin concentration increased $(\mathrm{P}=0.005)$ during times of domperidone treatment $(21.77 \pm 3.69$ $\mathrm{ng} / \mathrm{mL}$ ) when compared to controls ( $5.77 \pm 0.46 \mathrm{ng} / \mathrm{mL}$ ). Overall mean serum progestagen concentration was not significantly different in the treated group $(0.11 \pm 0.01 \mathrm{ng} / \mathrm{mL})$ when compared to controls $(0.07 \pm 0.01 \mathrm{ng} / \mathrm{mL})$. In conclusion, prolactin synthesis can be regulated with either a dopamine agonist or antagonist resulting in a decrease or increase in serum prolactin concentration, respectively. Although serum progestagen concentration increased in response to Cabergoline treatment, whether estrous cyclicity sufficient for successful breeding was reinitiated could not be determined.

Keywords: ovarian cyclicity, prolactin, domperidone, acyclicity, progestagens 


\section{Introduction}

Over the last 10 years, incidence of irregular or a lack of estrous cyclicity have increased in reproductive age (11-35 years) female African elephants in North American zoos (Brown et al., 2004; Proctor et al., 2010; Dow et al., 2011). At present, 46.4\% of post-pubertal captive African elephants in North American zoos experience estrous cycle abnormalities (Dow et al., 2011). In a 2004 study, Brown and colleagues found significant differences in circulating prolactin concentrations between cycling and noncycling females; 25\% of all acyclic females African elephants were hyperprolactinemic. More recently, our lab investigated differences in circulating concentrations of serum prolactin were found among normal cycling, irregularly cycling, and acyclic individuals, with all acyclic females experiencing perturbations in prolactin secretion (Dow and Brown, In Review). Hormonal analysis revealed that $71 \%$ of all acyclic females were hyperprolactinemic; a dramatic increase from 25\% just 7 years earlier (Brown et al., 2004; Dow and Brown, 2012). Interestingly, the same study showed the remaining 29\% of acyclic individuals experience abnormal prolactin secretion profiles wherein circulating prolactin concentration is low and secreted in a constant rather than cyclical pattern (Dow and Brown, In Review). Under normal circumstances, prolactin is an important hormone during pregnancy for mammary gland development and subsequent milk production (Neill and Nagy, 1994). During the estrous cycle, it increases during the follicular phase in many species, including African, but not Asian, elephants, and is believed to be involved in follicular development (Brown and Lehnhardt, 1997; Brown et al., 2004). However, chronically elevated or deficient prolactin concentrations cause luteal insufficiency and infertility (Mah and Webster, 2002; Benson, 2008).

Hyperprolactinemia is a primary cause of amenorrhea and anovulation in the human (Yu et al., 1981; Jones, 1989). The three main causative factors of hyperprolactinemia resulting in infertility in the human have been identified as either physiological (pregnancy and lactation); pharmacological 
(anti-inflammatories, analgesics, and $\mathrm{H}_{2}$ inhibitors); and pathological (pituitary prolactinomas) (Mah and Webster, 2002). High concentration of prolactin in pregnant or nursing individuals acts at the hypothalamus to increase sensitivity to estrogen, which subsequently suppresses the gonadatropinreleasing hormone/lutenizing hormone $(\mathrm{GnRH} / \mathrm{LH})$ pulse generator causing lactational amenorrhea (McNeilly, 2001). Furthermore, increases in serum prolactin increase dopamine release from dopaminergic neurons (Moore and Demarest, 1982). Dopamine not only acts to inhibit anterior pituitary prolactin synthesis and secretion but also decreases GnRH secretion resulting in gonadal dysfunction (Rolland and Corbey, 1977). Regardless of the cause or mechanism, an increase in prolactin secretion would cause an increase in dopamine resulting in suppression of GnRH.

Although the mechanisms of action are not entirely clear, prolactin deficiency has been associated with menstrual disorders, delayed puberty, infertility, and subfertility in humans (Martikainen et al., 1989; Falk, 1992; Mukherjee et al., 2003; Van Aken and Lamberts, 2005). The clinical signs of prolactin deficiency are dependent on the extent of the deficiency and may be nonspecific; in humans, prolactin deficiency often occurs in conjunction with other pituitary hormone deficiencies (Roberts and Ladenson, 2004; Van Aken and Lamberts, 2005). In a 1988 study, in vitro fertilization patients receiving bromocriptine, a dopamine agonist, after ovarian hyperstimulation experienced a decrease in serum and follicular fluid prolactin, increased serum estradiol, accelerated ovarian follicle growth, decreased in luteal phase progesterone concentration, and subsequent shortened luteal phase length (Kauppila et al., 1988), suggesting induced hypoprolactinemia interferes with ovarian function. Furthermore, prolactin has gonadotropic activity (Doppler, 1994; Wise and Maurer, 1994; Lebedeva et al., 1998) and has been implicated in the regulation of ovarian function in a number of species (Gaytan et al., 1997; Clarke and Cummings, 1989). Prolactin increases during the follicular phase of the estrous cycle in response to positive feedback action of follicular estrogens on the pituitary lactotroph cells (Lawson et al., 1993) and acts on specific ovarian 
receptors to regulate follicular activity (Besognet et al., 1996; Besognet et al., 1997). In addition, healthy follicles contain higher follicular fluid prolactin concentrations than atretic ones (Lebedeva et al. 1998). Follicular fluid prolactin is believed to be involved in angiogenesis and the stimulation of ovarian epithelial cells, both actions are important for follicular development and formation of corpora lutea (Castilla et al., 2010). By inhibiting the degeneration of surface epithelial cells and the disruption of connective tissue in the follicle wall, prolactin, in conjunction with gonadotropins and estradiol, aids in the process of oocyte maturation. Thus, high preovulatory concentrations of prolactin could be important to the process of follicular growth, oocyte maturation and ovulation in humans (Yoshimura et al., 1991).

The main objectives of this study were to determine the effectiveness of domperidone and cabergoline to initiate cyclic prolactin secretion and treat hyperprolactinemia, respectively and, thereby, restore cyclicity in captive African elephants. From a scientific standpoint, this study will provide valuable new scholarly knowledge on the mechanistic control of prolactin secretion in African elephants, as well as its role in ovarian follicular development and function. This information is important for maximizing the breeding success of zoo elephants, and would reduce the need to import animals from range countries to supplement captive populations. The cyclic regimen of oral domperidone administration was hypothesized to result in an increase in circulating prolactin concentrations, and an oral administration of cabergoline would decrease circulating prolactin concentration, thereby facilitating follicular development and subsequent ovulation resulting in progestagen synthesis. 


\section{Materials and methods}

Animals and sample collections

Sixteen postpubertal, acyclic female elephants ranging from 24 to 43 years of age and housed in zoological facilities in North America were divided into two groups according to circulating serum prolactin concentration. Acyclic hyperprolactinemic and prolactin-deficient females had a constant mean serum prolactin concentration of $\geq 30 \mathrm{ng} / \mathrm{mL}$ (Prado-Oviedo, 2011) and $\leq 10 \mathrm{ng} / \mathrm{mL}$ (Dow and Brown, 2012), respectively. Regardless of serum prolactin concentration, females that exhibited sustained serum progestagen concentration $\leq 0.10 \mathrm{ng} / \mathrm{mL}$ for at least a one-year period prior to this study were considered acyclic (Brown, 2000).

\section{Experiment 1}

Hyperprolactinemic, acyclic female elephants $(n=8)$ were randomly assigned to one of two treatment groups: oral administration of 2 mg Cabergoline (Dostinex@, Pfizer Inc., New York, New York) encapsulated in clear vegetarian capsules derived from hydroxypropyl methylcellulose (Capsuline, Inc., Pompano Beach, Florida) with dextrose $(n=4)$ or placebo (dextrose capsule), each given twice weekly for 12 months $(n=4)$.

\section{Experiment 2}

Prolactin deficient, acyclic females $(n=8)$ were randomly assigned to one of two treatment groups: consisting of 2 g/day of domperidone (Equidone ${ }^{\circledR}$ oral gel; Equi-Tox Pharma, Inc., Central, South Carolina) $(n=4)$ or 2 g/day vehicle $(n=4)$ each for four weeks, followed by eight weeks of no

treatment. Each 12 week regimen was repeated for 12 months. In accordance to the dosing schedule, domperidone was administered on week 0-3; 12-15; 24-27; 36-39; and 48-51. 
Doses were determined via previously unpublished preliminary studies and with manufacture input. Weekly blood samples were collected by venipuncture of an ear or saphenous vein by facility staff for progestagen and prolactin analysis. This project was approved by the National Zoo's Animal Care and Use Committee and by individual zoological facilities where elephants were housed.

\section{Hormone Iodination}

Highly purified prolactin (NIDDK-oPrRL-I-2) (A.F. Parlow, Torrance, California) was iodinated using chloramine-T. For each iodination, $5 \mu \mathrm{g}$ of hormone (in $20 \mu \mathrm{l}$ of $0.5 \mathrm{M} \mathrm{NaPO}_{4}, \mathrm{pH}$ 7.6) was incubated with $1 \mathrm{mCi}$ carrier-free $\mathrm{Na}^{-125} \mathrm{I}(10 \mu \mathrm{l})$ for 1 minute in the presence of $2.5 \mu \mathrm{g}$ chloramine- $\mathrm{T}\left(10 \mu \mathrm{l}\right.$ in $0.05 \mathrm{M} \mathrm{NaPO}_{4}, \mathrm{pH}$ 7.6). The reaction was stopped with sodium metabisulfite (10 $\mu$ g in $10 \mu \mathrm{l}$ of $0.05 \mathrm{M} \mathrm{NaPO}_{4}$, $\mathrm{pH}$ 7.6) and labeled hormone separated from free ${ }^{125} \mathrm{I}$ using anionexchange chromatography (AG 2-X8, 100-200 mesh, chloride form; BioRad Laboratories, Melville, NY). Columns ( 1 x $5 \mathrm{~cm})$ were prepared by equilibrating resin in $0.05 \mathrm{M} \mathrm{NaPO}_{4}(\mathrm{pH}$ 7.6) followed by successive elution with $2 \mathrm{ml}$ each $0.5 \mathrm{M}, 0.05 \mathrm{M}$ with 5\% bovine serum albumin (BSA) and 0.05 $\mathrm{M} \mathrm{NaPO}_{4}(\mathrm{pH}$ 7.6). The iodination reaction mixture was layered onto the column, and labeled hormone was eluted with $2 \mathrm{ml}$ of $0.05 \mathrm{M} \mathrm{NaPO}_{4}$ into a tube containing $1 \mathrm{ml}$ phosphate-buffered saline (PBS) with 0.1\% BSA (pH 7.4) (Brown and Lehnhardt, 1997).

\section{Hormone Analysis}

Serum prolactin was measured by heterologous ${ }^{125}$ I double-antibody radioimmunoassay (RIA) (Brown and Lehnhardt, 1997; Brown et al., 2004). All assays were conducted using a PBS-BSA buffer system [0.01 $\mathrm{M} \mathrm{PO}_{4}, 0.5 \% \mathrm{BSA}, 2 \mathrm{mM}$ ethylenediaminetetraacetic acid (EDTA), $0.9 \% \mathrm{NaCl}$, and $0.01 \%$ thimerosal, $\mathrm{pH}$ 7.6), with the exception of secondary antibody where BSA was omitted. 
An anti-human prolactin antiserum (NIDDK-anti-hPRL-3) and ovine ${ }^{125}$ I prolactin label and standards (NIDDK-oPRL-I-2) were employed. The assay was incubated at room temperature over a 3-day period. Assay sensitivity (based on $90 \%$ of maximum binding) was $1.0 \mathrm{ng} / \mathrm{ml}$ with intra- and inter-assay $\mathrm{CV}<10 \%$ and $<15 \%$, respectively.

Unlike most mammals, the major circulating luteal steroid in the elephant is not progesterone, but

$5 \alpha$-reduced pregnanes (Hodges, 1998). Serum was analyzed using a solid-phase ${ }^{125}$ I progesterone RIA (Seimens Medical Diagnostic Solutions, Costa Mesa, CA) that has been validated for quantifying progestagens in elephant serum (Brown et al., 1991). Sensitivity (based on 90\% of maximum binding) was $0.03 \mathrm{ng} / \mathrm{mL}$ and intra- and inter-assay $\mathrm{CV}$ were $<10 \%$ and $<15 \%$, respectively.

\section{Data Analysis}

Statistical analyses were performed using SAS (SAS Institute, Inc. Cary, NC). Continuous data for prolactin and progestagen concentrations were analyzed using the repeated-measures analysis of variance (ANOVA) of the PROC MIXED procedure of SAS, version 9.1.3 (SAS Institute, Inc., Cary, NC, 2004). Prolactin peak and baseline concentrations were determined for each individual by an iterative process in which high values were excluded if they exceeded the mean plus 2 standard deviations (Brown et al., 1999). The highest concentration within a group of elevated samples was considered a peak, and baseline values were those remaining after all high values had been excluded. Although the same statistical analyses were used for both experiments, data where not combined and experiments were analyzed separately. Data are presented as mean \pm SEM. Differences were considered significant at $\mathrm{P}<0.05$. 


\section{Results}

\section{Experiment 1}

Serum prolactin concentration was significantly different $(\mathrm{P}=0.01)$ for the Cabergoline treated group when compared to the controls (Figure 1). In addition to an effect due to treatment there was also a significant effect of time $(\mathrm{P}=0.001)$ and interaction of treatment by time $(\mathrm{P}=$ 0.0006) for treated compared to controls. Prolactin concentration began to decrease from an overall mean concentration of $>80.00 \mathrm{ng} / \mathrm{mL}$ within the first week of Cabergoline administration in the treated group and remained lowered at a mean of $32.22 \pm 14.75 \mathrm{ng} / \mathrm{mL}$ for the remainder of the treatment. For control females, mean overall serum prolactin concentration was maintained constantly at $77.53 \pm 0.96 \mathrm{ng} / \mathrm{mL}$. Overall mean serum progestagen concentration was different for the treated group $(0.15 \pm 0.01 \mathrm{ng} / \mathrm{mL})$ when compared to controls $(0.07 \pm 0.01 \mathrm{ng} / \mathrm{mL})(\mathrm{P}<0.05)$. For reference, prolactin and progestagen profiles of a normal cycling elephant have been included (Figure 5). Individual elephant profiles can be found in Appendix I.

\section{Experiment 2}

Serum prolactin concentration was significantly different $(P=0.005)$ for the domperidone treated group when compared to the controls (Figure 3). On average, prolactin concentration increased either during or within three weeks after domperidone administration and returned to baseline during the eight weeks without domperidone. Overall mean serum prolactin concentration for treated females was $21.77 \pm 3.69 \mathrm{ng} / \mathrm{mL}$ compared to $5.77 \pm 0.46 \mathrm{ng} / \mathrm{mL}$ in controls. Moreover, overall mean peak prolactin concentration in response to domperidone treatment was $40.09 \mathrm{ng} / \mathrm{mL}$ (range 14.00-80.00 ng/mL); no peaks were observed in control females. Overall mean serum progestagen concentration was not significantly different in the treated group $(0.11 \pm 0.01 \mathrm{ng} / \mathrm{mL})$ 
when compared to controls $(0.07 \pm 0.01 \mathrm{ng} / \mathrm{mL})$. Individual elephant profiles can be found in Appendix I.

\section{Discussion}

Infertility due to ovarian cyclicity abnormalities in post-pubertal captive female African elephants in North America has increased by 19.1\% in the last 10 years (Dow et al., 2011). Recently, perturbations in normal prolactin secretion have been identified as a common factor in these same acyclic individuals (Dow and Brown, In Press). The purpose of this study was to investigate whether serum prolactin concentration could be regulated with oral administration of either a dopamine agonist or antagonist. The hyperprolactinemic, acyclic females in this study treated with cabergoline experienced an overall significant decrease in serum prolactin concentration and increase in serum progestagen concentration in response to treatment. Prolactin deficient, acyclic individuals responded to domperidone treatment with significant increases in overall serum prolactin concentration but not serum progestagen concentration during times of drug administration. These experiments are likely the first time a dopamine agonist (cabergoline) and antagonist (domperidone) have been used in the African elephants to control prolactin secretion.

Cabergoline, a long-acting D2 receptor agonist, acts directly to stimulate dopamine receptors on pituitary lactotroph cells causing an inhibition in prolactin synthesis and secretion (Di Salle et al., 1982). Oral administration in hyperprolactinemic human patients has been shown to effectively reduce serum prolactin concentrations by approximately 50\% with few adverse side effects (Ferrari et al., 1992; Pontiroli et al., 1987). Furthermore, in a western lowland gorilla (Gorilla gorilla gorilla), Cabergoline was effective treatment for hyperprolactinemia and resulted in the resumption of ovarian activity and a successful conception and birth (Chatfield et al., 2006). Cabergoline has been used to significantly reduce the size of pituitary tumors and adenomas by reducing lactotroph cell size with a 
rapid involution of rough endoplasmic reticulum and Golgi apparatus (Nissim et al., 1982;

Rengachary et al., 1982; Tindall et al., 1982; Landolt et al., 1985), and subsequently decreased prolactin secretion (Melis et al., 1989).

For the cabergoline treated females, three out of four elephants responded with a significant decrease in overall serum prolactin concentration, which was maintained throughout treatment period. The individual that did not respond to treatment had a mean overall prolactin concentration of $73.92 \mathrm{ng} / \mathrm{mL}$ compared to the18.32 $\pm 6.91 \mathrm{ng} / \mathrm{mL}$ in other females. Possibly another exogenous or endogenous factor was overriding the agonistic effect of cabergoline for this individual female. In the human, a variety of pharmaceuticals have been shown to act to either remove dopamine inhibition or directly stimulate prolactin secretion, both of which allow for a dramatic increase in prolactin secretion (La Torre and Falorni, 2007). In addition, prolactinomas account for $25-30 \%$ of functioning pituitary tumors and are a major contributor to hyperprolactinemia (Webster and Scanlon, 1997). Not only could tumors in the pituitary cause an abnormal increase in prolactin secretion and subsequent dopamine release, but tumor presence could physically block the secretion of gonadotropins, thereby compromising estrous cyclicity (Mah and Webster, 2002). Likewise, tumor growth could result in release of other pituitary derived hormones causing for perturbations in the hypothalamic-pituitaryovarian/adrenal axis resulting in infertility (Webster and Scanlon, 1997). Adenoma in a Western lowland gorilla has been shown to cause hyperprolactinemia resulting in gonadal dysfunction (Chatfield et al., 2006). Unfortunately, the contribution of pharmaceuticals and pituitary tumors on hyperprolactinemia in the elephant is yet to be investigated.

Interestingly, although one female did not respond to cabergoline treatment with a decrease in overall mean prolactin secretion, she did experience an increase in overall serum progestagen concentration. Peak progestagen concentrations were $0.24,0.28$, and 0.19 with durations of 7 weeks, 7 weeks, and 12 weeks, respectively, for each luteal phase. Although mean overall prolactin 
concentration in this female remained at $73.92 \mathrm{ng} / \mathrm{mL}$ the range for concentration during treatment was 13.02-80.00 ng/mL. Possibly prolactin concentration decreased just long enough to allow for brief increases in progestagen concentrations. In normal cycling females, maximum luteal concentration of immunoreactive progestins has been documented as $0.25-0.90 \mathrm{ng} / \mathrm{mL}$ (Plotka et al., 1988; Kapustin et al., 1996). For this experiment, changes on the ovary via follicle development or luteal structure presence were not monitored ultrasonographically. Six to eight luteal structures of both nonovulatory and ovulatory nature are present on the ovary during each estrous cycle (Hanks and Short, 1972; Smith and Buss, 1975; de Villiers et al., 1989; Hodges et al., 1997). In addition, the ovarian cyclicity for the African elephant have previously been defined ultrasonographically (Hermes et al., 2000; Hildebrandt et al., 2000). However, no correlations in reference to luteal structure size, age, appearance, and progestagen content has been established (Hodges, 1998). Likely progestagen synthesis was of adrenal rather than ovarian origin. In the human, pregnanediol was found in the urine of ovariectomized, but not ovariectomized and adrenalectomized patients (Klopper et al., 1957). Comparably, progesterone was isolated in adrenal venous blood 10-100 times greater than in arterial blood sampled at the same time in sheep, cattle, and pigs (Balfour et al., 1957). Therefore, estrous cyclicity may not have been actually reinitiated and progestagen biosynthesis was not occurring in ovarian as opposed to adrenal tissue.

Domperidone is a specific dopamine 2 (D2) receptor antagonist that inhibits dopamine action at the pituitary level and induces significant and prolonged ( $>24 \mathrm{~h}$ ) increases in prolactin secretion (Redmond et al., 1992). Domperidone does not cross the blood brain barrier and, therefore, does not elicit neuroleptic side effects like other D2 receptor antagonists (Strickland et al., 1994). Domperidone has been shown to increase prolactin secretion in a variety of species, including the horse (Brendemuehl and Cross, 2000); camel (Almaw et al., 2000); heifer (Jones et al., 2003); and dog (Gómez-Ochoa et al., 2009). Increasing prolactin has been beneficial to equine reproduction, 
including improving follicular development, increasing ovulation and conception rates, and preventing problems associated with dystocias and poor milk production (Cross, 1997). Furthermore, mares treated with domperidone during seasonal anestrous developed follicles that were functionally normal (Brendemuehl and Cross, 2000). For this experiment, all females treated with domperidone experienced significant increases in overall serum prolactin concentration in response to treatment. Oral administration of domperidone was given for four weeks followed by eight weeks of no treatment for five treatment cycles; thus, one treatment cycle equaled 12 weeks. Out of 20 total treatment cycles (five treatment cycles per elephant with four elephants being treated), prolactin concentration increased during the four week period domperidone was being administered for 13 treatment cycles, within three weeks of treatment for four treatment cycles, at least three weeks before treatment for two treatment cycles, and failed to respond for only one cycle.

In addition, like seen in the cabergoline treated females, maximum peak luteal progestagen concentration was within a normal range during treatment. Importantly all treated and control females were acyclic for at least one year prior to this experiment. In a seasonal breeding animal like the horse, during the transition out of the anestrous period the mare does not ovulate during the first estrous cycle and therefore serum progesterone concentrations remain lower than normal until after the second estrous cycle (Oxender et al., 1977). In the sheep, progesterone is required to prime the hypothalamus during the transition from anestrous into estrous for normal hypothalamic-pituitary function to occur (Caraty and Skinner, 1999). Although the elephant is not a seasonal breeder, periods of acyclicity may be similar to anestrous periods in those seasonal breeding species, and thus similar mechanisms may be behind the transition into resumption of estrous cyclicity.

In summary, these experiments demonstrate that overall serum prolactin concentration can be regulated by oral administration of cabergoline or domperidone in acyclic hyperprolactinemic or prolactin-deficient female African elephants, respectively. However, it is unlikely that ovarian 
cyclicity was reinititated. Currently, the North American captive African elephant population is not self-sustaining, thus it is crucial that all reproductive-aged females have normal estrous cyclicity. Although we now have potential treatment protocols for these types of acyclic females, we have nonetheless failed to define the mechanisms of action behind what causes these conditions. Moreover, it is yet to be determined if acyclicity is caused by or causes perturbations in prolactin synthesis. It is our ultimate goal with our current and future work to not only develop treatment protocols to mitigate ovarian cycle problems, but also to identify factors contributing to acyclicity and thus prevent the predicted population crash for this species in zoos (Olson and Wiese, 2000; Faust et al., 2006).

\section{Acknowledgments}

The authors thank Equi-Tox, Inc. and Pfizer, Inc., for in-kind donations of Equidone and Cabergoline, respectively. In addition, we thank, Dr. Robert A. Dailey for guidance, Nicole Parker for assistance with endocrine analysis, Natalia Prado-Oviedo for help with prolactin iodinations, and

Dr. Ida Holásková for statistical analysis support. We are grateful to all elephant and veterinary staff at the following zoological facilities: Indianapolis Zoo; Jacksonville Zoo and Garden; Kansas City Zoo; Lee Richardson Zoo; Memphis Zoo; Nashville Zoo at Grassmere; Pittsburgh Zoo \& PPG Aquarium; Sedgwick County Zoo; Seneca Park Zoo; Virginia Zoo; and Zoo Miami. 


\section{References}

Almaw G, Molla B. 2000. Prevalence and etiology of mastitis in camels (camelus dromodarius) in Eastern Ethiopia. J Camel Pract Res. 7:97-100.

Balfour WE, Comline RS, Short RV. 1957. Secretion of progesterone by the adrenal gland. Nature. 180:1480-1481.

Benson CT. 2008. Prolactin deficiency. http://www.emedicine.com/med/topics1914.htm.

Besognet B, Hansen BS, Daels PF. 1996. Dopaminergic regulation of gonadotrophin secretion in seasonally anoestrous mares. J Reprod Fertil. 108:55-61.

Besognet B, Hansen BS, Daels PF. 1997. Induction of reproductive function in anestrous mares using a dopamine antagonist. Theriogenology 47:467-480.

Brendemuehl JP, Cross DL. 2000. Influence of the dopamine antagonist domperidone on the vernal transition in seasonally anoestrous mares. J. Reprod. Fertil., Suppl. 56:185-193.

Brown JL, Citino SC, Bush M, Lehnhardt J, Phillips LG. 1991. Cyclic patterns of luteinizing hormone, follicle-stimulation hormone, inhibin, and progesterone secretion in the Asian elephant (Elephas maximus). J Zoo Wildl Med. 22:49-57.

Brown JL, Lehnhardt J. 1997. Secretory patterns of serum prolactin in Asian (Elephas maximus) and African (Loxodonta africana) elephants during different reproductive states: comparison with concentrations in a noncycling African elephant. Zoo Biol. 16:149-159.

Brown JL, Schmitt DL, Bellum A, Graham LH, Lehnhardt J. 1999. Hormone secretion in the Asian elephant (Elephas maximus): Characterization of ovulatory and anovulatory luteinizing hormone surges. Bio Reprod. 61:1294-1299.

Brown JL. 2000. Reproductive endocrine monitoring of elephants: An essential tool for assisting captive management. Zoo Biol 19:347-68. 
Brown JL, Walker SL, Moeller T. 2004. Comparative endocrinology of cycling and noncycling Asian (Elephas maximus) and African (Loxodonta africana) elephants. Gen Comp Endocrinol 136:360-370.

Caraty A, Skinner DC. 1999. Progesterone priming is essential for the full expression of the positive feedback effect of estradiol in inducing the preovulatory gonadatropin-releasing hormone surge in the ewe. Neuroendocrinology. 140:165-170.

Castilla A, Garcia C, Cruz-Soto M, Martinez de la Escalera G, Thebault S, Clapp C. 2010. Prolactin in ovarian follicular fluid stimulates endothelial cell proliferation. J Vasc Res 47:45-53.

Chatfield A, Zhang L, Ramey J, Bowsher T, Loskutoff N, O’Neill K. 2006. Resolution of hyperprolactinemia in western lowland gorilla (Gorilla gorilla gorilla). J Zoo Wildl Med 37:565-566.

Clarke IJ, Cummins JT. 1989. Direct pituitary effects of estrogen and progesterone on gonadatropin secretion in the overiectomized ewe. Neuroendocrinol 39:267-274.

Cross DL. 1997. Fescue toxicosis in horses. In: Neotyphodium/Grass Interaction. Bacon CW, Hills NS (Eds). Plenum Press, New York and London. pp. 289-309.

de Villiers DJ, Skinner JD, Hall-Martin AJ. 1989. Circulating progesterone concentrations and ovarian functional anatomy in the African elephant (Loxodonta africana). J Reprod Fertil. 86:195-201.

Di Salle E, Ornati G, Briatico G. 1982. FCE 21336, a new ergoline derivative with a potent and long-acting lowering effect on prolactin secretion in rats. J Endocrinol Invest (Suppl 1) 6:6. Doppler W. 1994. Regulation of gene expression by prolactin. Rev Physiol Biochem Parmacol 124:92-130. 
Dow TL, Holásková I, Brown JL. 2011. Results of the third reproductive assessment survey of North American Asian (Elephas maximus) and African (Loxodonta africana) female elephants. Zoo Biol 29:1-13.

Dow TL, Brown JL. 2012. Evidence of hyperprolactinemia as a growing cause of infertility in female zoo African (Loxodonta africana) elephants. Reprod Fertil Devel. In Press.

Falk RJ. 1992. Isolated prolactin deficiency: a case report. Fertil Steril. 58:1160-1162.

Faust, L.J., Thompson, S.D., and Earnhardt, J.M. 2006. Is reversing the decline of Asian elephants in North American zoos possible? An individual-based modeling approach. Zoo Biol. 25:201218.

Ferrari, C., Paracchi, A., Mattei, A.M., de Vincentiis, S., D’Alberton, A., Crosignani, P. 1992. Cabergoline in the long-term therapy of hyperprolactinemic disorders. Acta Enddocrinol. 126:489494.

Gayton F, Morales C, Bellido C, Aguilar E, Sanchez-Criado JE. 1997. Role of prolactin in the regulation of macrophages and in proliferative activity of the vascular cells in newly formed and regressing rat corpora lutea. Biol Reprod. 57:478-486.

Gómez-Ochoa P, Castillo JA, Gascón M, Zarate JJ, Alvarez F, Couto CG. 2009. Use of domperidone in the treatment of canine visceral leishmaniasis: a clinical trial. Vet J. 179:259263.

Hanks J, Short RV. 1972. The formation and function of the corpus luteum in the African elephant (Loxodonta africana). J Reprod Fertil. 29:79-89.

Hermes R, Olson D, Goeritz F, Brown JL, Schmitt DL, Hagan D, Peterson JS, Fritsch G, Hildebrandt TB. 2000. Ultrasonography of the sexual cycle in female African elephants (Loxodonta africana). Zoo Bio. 19:369-382. 
Hildebrandt TB, Göritz F, Pratt NC, Brown JL, Montali RJ, Schmitt DL, Fritsch G, Hermes R. 2000. Ultrasonography of the urogenital tract in elephants (Loxodonta africana and Elephas maximus): An important tool for assessing female reproductive function. Zoo Biol 19:321-32.

Hodges JK, Heistermann M, Beard A, van Aarde RJ. 1997. Concentrations of progesterone and the 5- $\alpha$-reduced progestins, 5- $\alpha$-pregnane-3, 20-dione and 3- $\alpha$-hydroxy-5- $\alpha$-pregnan-20-one, in luteal tissue and circulating blood, and their relationship to luteal function in the African elephant. Biol Reprod. 56:640-646.

Hodges JK. 1998. Endocrinology of the ovarian cycle and pregnancy in the Asian (Elephas maximus) and African (Loxodonta africana) elephant. Anim Reprod Sci. 19:3-18.

Jones KL, King SS, Griswold KE, Cazac D, Cross DL. 2003. Domperidone can ameliorate deleterious reproductive effects and reduced weight gain associated with fescue toxicosis in heifers. J Anim Sci. 81:2568-2574.

Kapustin N, Critser JK, Olson D, Malven PV. 1996. Nonluteal estrous cycles of 3-week duration are initiated by anovulatory luteinizing hormone peaks in African elephants. Biol Reprod 55:11471154.

Kauppila A, Martikainen H, Puistola U, Reinila M, Ronnberg L. 1988. Hypoprolactinemia and ovarian function. Fertil Steril. 49:437-441.

Klopper A, Strong JA, Cook LR. 1957. Excretion of pregnanediol and adrenocortical activity. J Endocrinol. 15:180-189.

La Torre D, Falorni A. 2007. Pharmacological causes of hyperprolactinemia. Ther Clin Risk Manage 3:929-951.

Landolt AM, Osterwalder V, Landolt TA. 1985. Bromocriptine-induced removal of endoplasmic membranes from prolactinoma cells. Experientia 41:640-642.

Lawson DM, Haisenleder DJ, Marshall JC. 1993. A comparison of the temporal effects of estradiol and diethylstilbestrol on pituitary content of DNA, prolactin mRNA and prolactin and on serum prolactin levels in ovariectomized Holtzmen rats. Life Sci 53:1267-1272. 
Lebedeva IY, Denisenko VU, Lebedeva VA, Kuzmina TI. 1998. Prolactin in follicular fluid and intracellular store calcium in follicular cells are related to morphological signs of ovarian follicular atresia in cows: work in progress. Theriogenology 49:509-519.

Mah PM, Webster J. Hyperprolactinemia: etiology, diagnosis, and management. Semin Reprod Med 2002; 20:365-373.

Martikainen H, Rönnberg L, Puistola U, Tapanainen J, Orava M, Kauppila A. 1989. Prolactin suppression by bromocriptine stimulates aromatization of testosterone and estradiol in women. Fertil Steril. 52:51-54.

Martin MS, Glaeser SS, Finnegan M, Hunt K, Brown JL. 2011. Investigation of animal variability, synchronicity, and impact of life events on reproductive cycle dynamics through longitudinal serum progestagen monitoring of female Asian elephants (Elephas maximus) at the Oregon Zoo. Theriogenology In Review.

McNeilly AS. 2001. Lactational control of reproduction. Reprod Fertil Dev 13:583-590.

Melis GB, Gambacciani M, Paoletti AM, Mais V, Sqhedoni D, Fioretti P. 1989. Reduction in the size of prolactin-producing pituitary tumor after Cabergoline administration. Fertil Steril 52:412415.

Moore KE, Demarest KT. 1982. Effects of prolactin on central dopaminergic neurons. Prog Neurophychopharmacol Biol Psychiatry 6:645-650.

Mukherjee A, Murray RD, Columb B, Gleesib HK, Shalat SM. 2003. Acquired prolactin deficiency indicates severe hypopituitarism in patients with disease of the hypothalamic-pituitary axis. Clin Endocrinol. 59:743-748.

Neill JD, Nagy GM. 1994. Prolactin secretion and its control. In: The Physiology of Reproduction (Knobil E, Neill JD. eds.) pp. 1833-1860. Raven Press, New York.

Nissim M, Ambrosi B, Bernasconi V, Giannattasio G, Giovanelli MA, Bassetti M, Vaccari U, Moriondo P, Spada A, Travaglini P, Faglia G. 1982. Bromocriptine treatment of 
macroprolactinomas: studies on the time course of tumor shrinkage and morphology. J Endocrinol Invest 5:409-415.

Olson D, Wiese RJ. 2000. State of the North American African elephant population and projections for the future. Zoo Biol. 19:311-20.

Oxender WD, Noden PA, Hafs HD. 1977. Estrus, ovulation, and serum progesterone, estradiol, and LH concentrations in mares after an increased photoperiod during winter. Am J Vet Res. 38:203-207.

Plotka ED, Seal US, Zarembka FR, Simmons LG, Teare A, Phillips LG, Hinshaw KC, Wood, DG. 1988. Ovarian function in the elephant: luteinizing hormone and progesterone cycles in African and Asian elephants. Biol Reprod. 38:309-314.

Pontirolli AE, Falsetti L, Bottazzo G. 1987. Clinical, endocrine, roentgengraphic and immune characterization of hyperprolactinemic women. Int J Fertil. 32:81-85.

Prado-Oviedo N. 2011. Role of estrogens in hyperprolactinemia: Induced acyclicity in African female elephants. MS thesis, American University.

Proctor CM, Freeman EW, Brown JL. 2010. Results of a second survey to assess the reproductive status of female Asian and African elephants in North America. Zoo Biol 29(2):127-139.

Redmond LM, Cross DL, Strickland JR, Kennedy SW. 1992. Efficacy of domperidone and sulpiride as treatments for equine fescue toxicosis in gravid mares grazing endophyte-infected tall fescue. J Anim Sci 70 (Suppl 1):21.

Rengachary SS, Tomita T, Jefferies BF, Wantanabe I. 1982. Structural changes in human pituitary tumor with bromocriptine therapy. Neurosurgery 10:242-251.

Roberts CG, Ladenson PW. 2004. Hypothyroidism. Lancet 363:793-803.

Rolland R, Corbey RS. 1977. Hyperprolactinemia and hypogonadism in the human female. Eur J Obstet Gynecol Reprod Biol 7:337-348. 
Smith NS, Buss IO. 1975. Formation, function, and persistence of the copora lutea of the African elephant (Loxodonta africana). J Mammol. 56:30-43.

Strickland JR, Cross DL, Birrenkott GP, Grimes LW. 1994. Effects of ergovaline, loline, and dopamine antagonists on rat pituitary cell prolactin release in vitro. Am J Vet Res 55:716-721.

Tindall GT, Kovacs K, Horbath E, Thorner MO. 1982. Human prolactin-producing adenomas and bromocriptine: a histological, immunocytochemical, ultrastructural, morphometric study. J Clinical Endocrinol Metab 55:1178-1183.

Van Aken MO, Lamberts SW. 2005. Diagnosis and treatment of hypopituitarism: an update. Pituitary 8:183-191.

Wise T, Maurer RR. 1994. Follicular development, oocyte viability and recovery in relation to follicular steroids, prolactin and glycosaminoglycans throughout the estrous period in superovulated heifers with a normal LH surge, no detectable LH surge and progestin inhibition LH surge. Dom Anim Endocrinol 11:35-38.

Yoshimura Y, Nakamura Y, Yamada H, Ando M, Ubukata Y, Oda T, Suzuki M. 1991. Possible contribution of prolactin in the process of ovulation and oocyte maturation. Horm Res 1:22-32. Yu MC, Gerkins VR, Henderson BE, Brown JB, Pike MC. 1981. Elevated levels of prolactin in nullipaarous women. Br J Cancer. 43:826-831. 


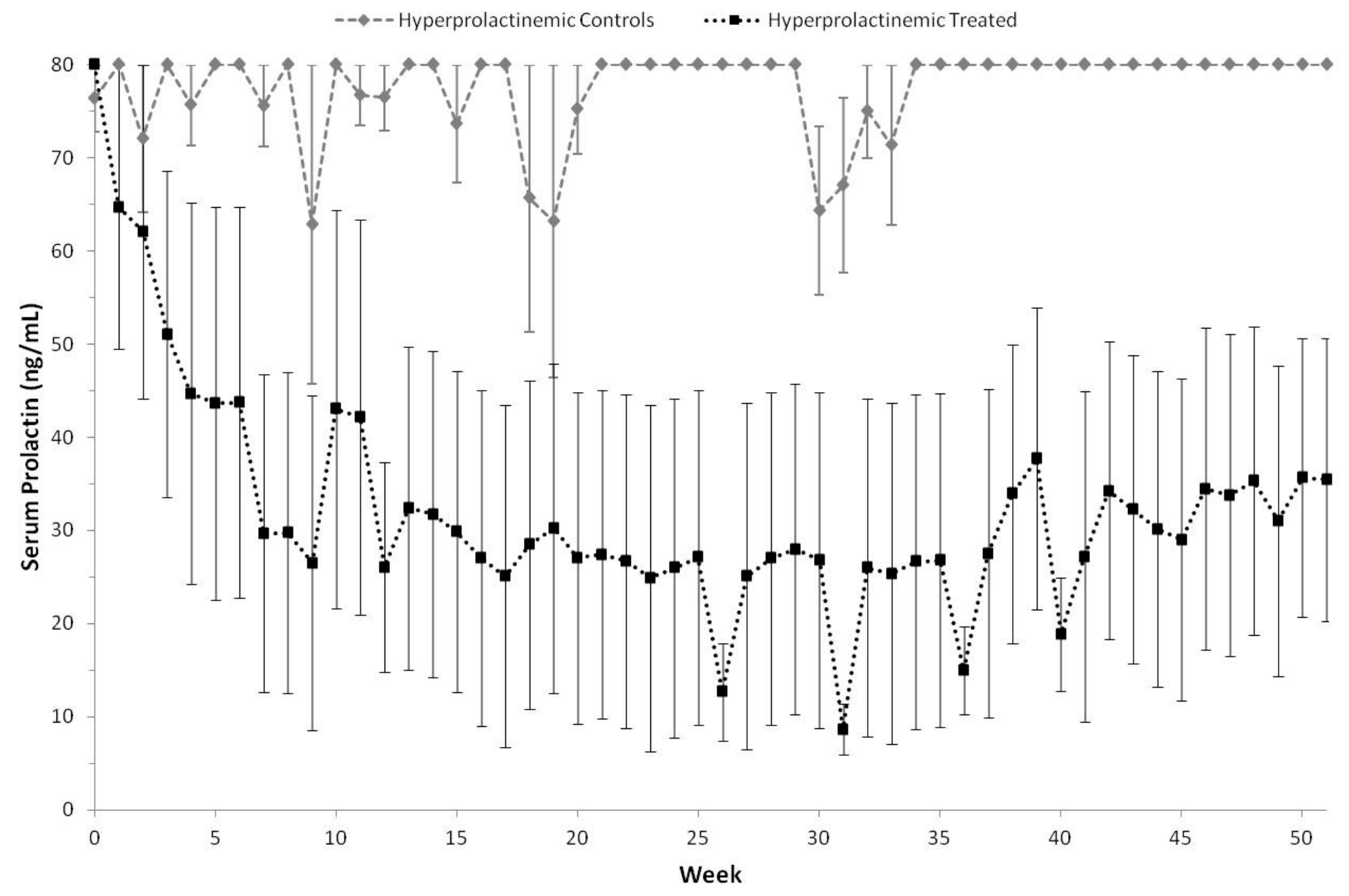

Figure 1. Serum prolactin concentrations in all Cabergoline treated $(n=4)$ and control $(n=4)$ hyperprolactinemic, acyclic female African elephants. 


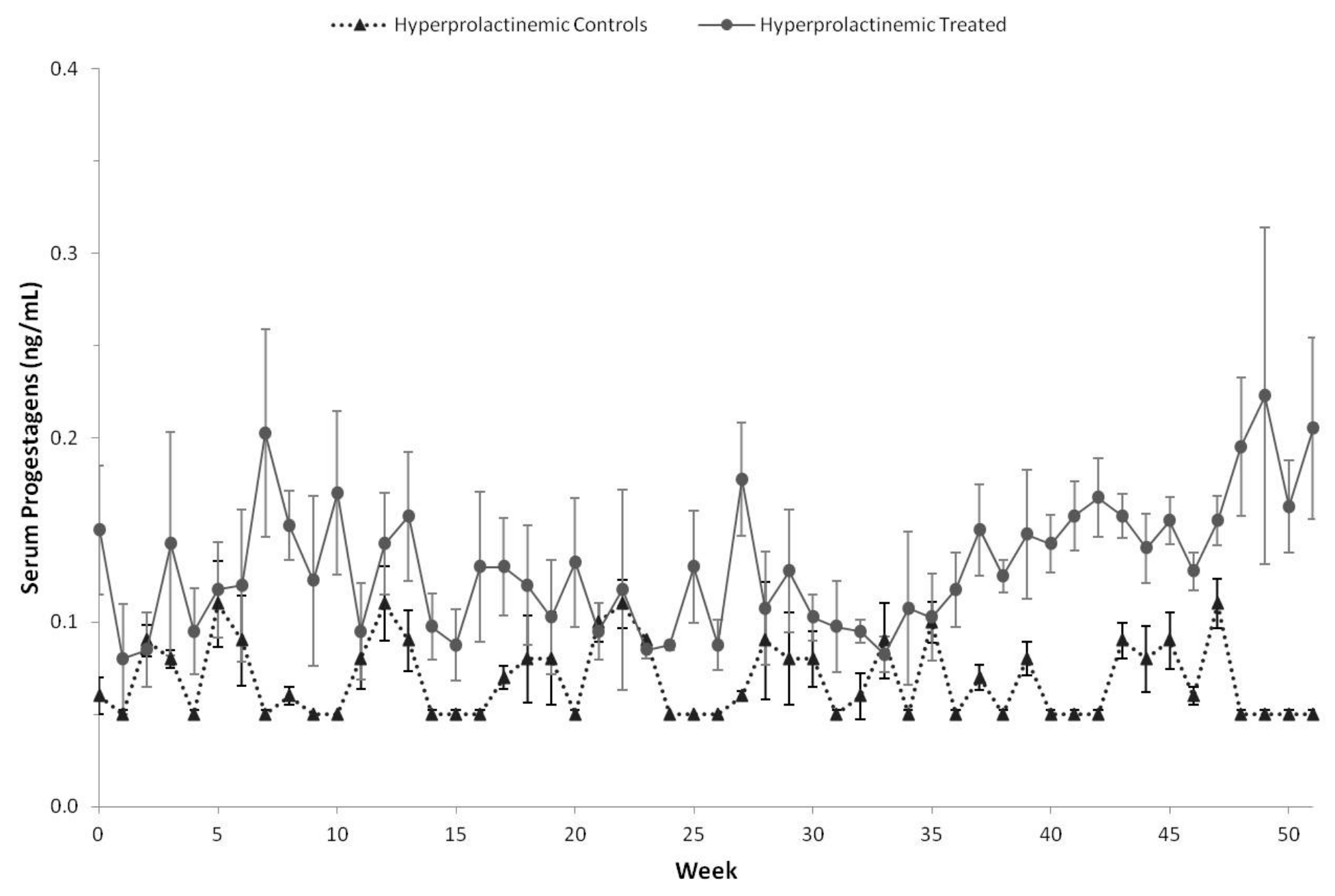

Figure 2. Serum progestagen concentrations in all Cabergoline treated $(n=4)$ and control $(n=4)$ hyperprolactinemic, acyclic female African elephants. 


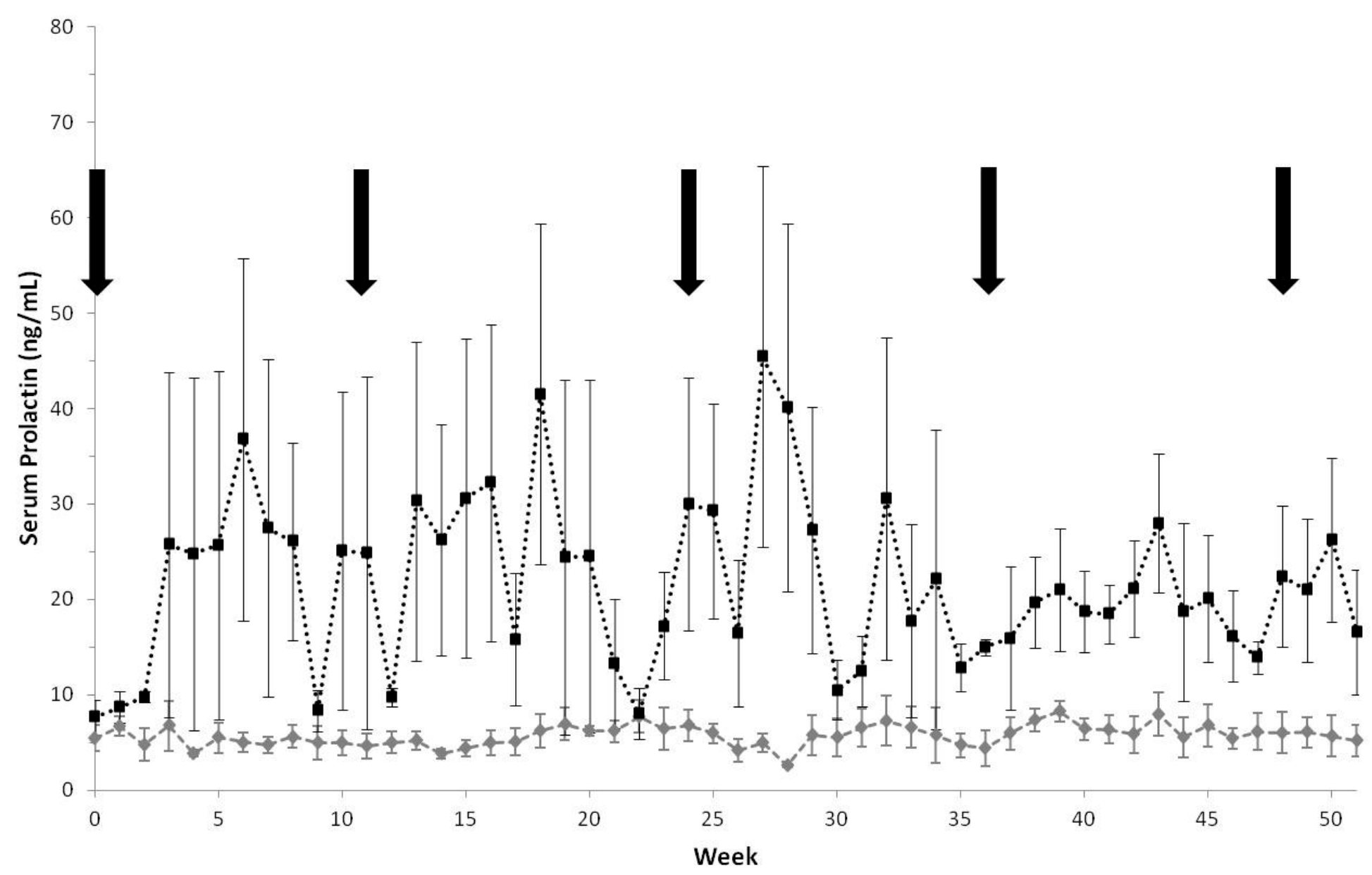

Figure 3. Serum prolactin concentrations in all domperidone treated $(n=4)$ and control $(n=4)$ prolactin deficient, acyclic female African elephants. Black areas designate treatment times (Week 0-3; 12-15; 24-27; 36-39; and 48-51). 

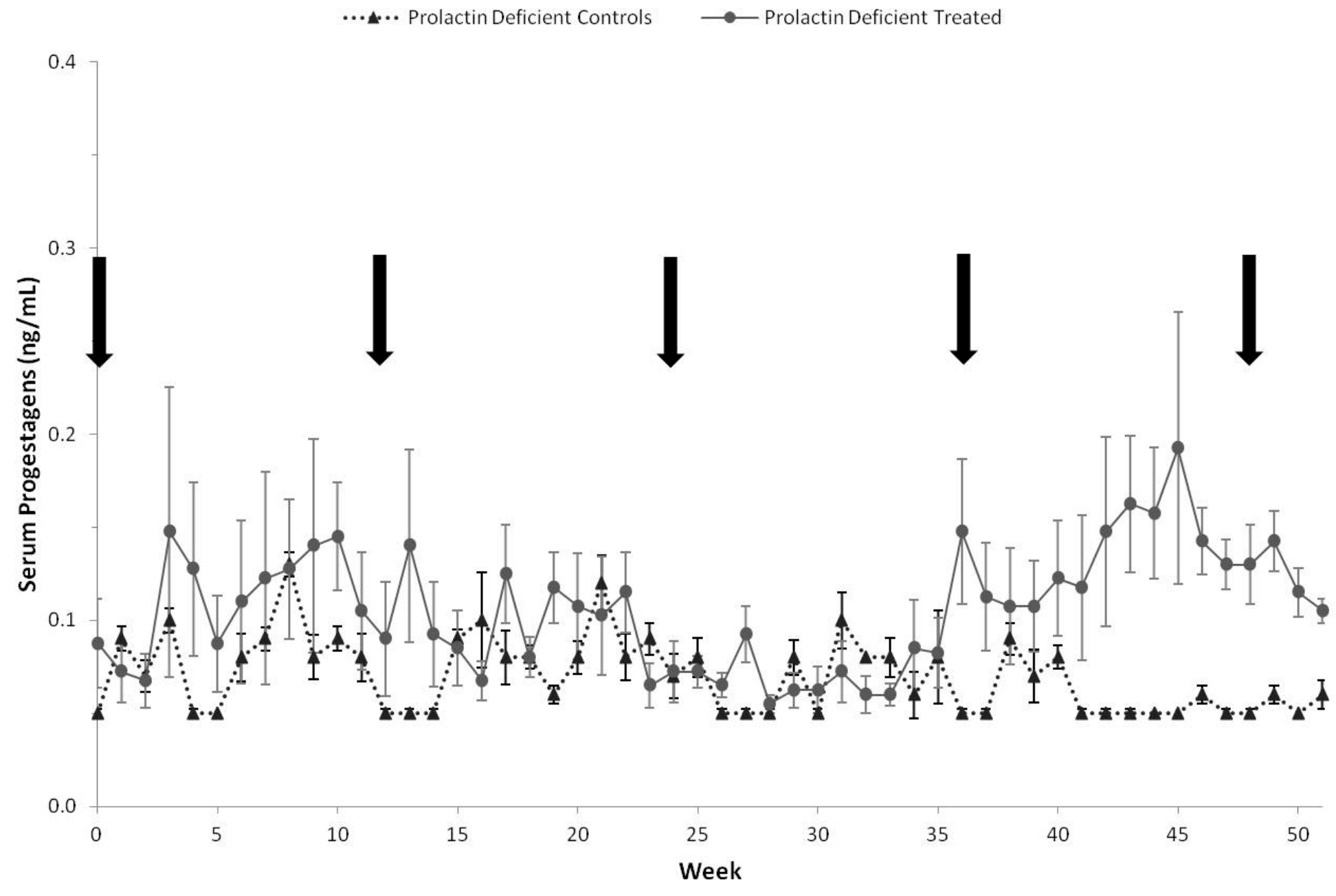

Figure 4. Serum progestagen concentrations in all domperidone treated $(n=4)$ and control $(n=4)$ prolactin deficient, acyclic female African elephants. Black areas designate treatment times (Week 0-3; 12-15; 24-27; 36-39; and 48-51). 


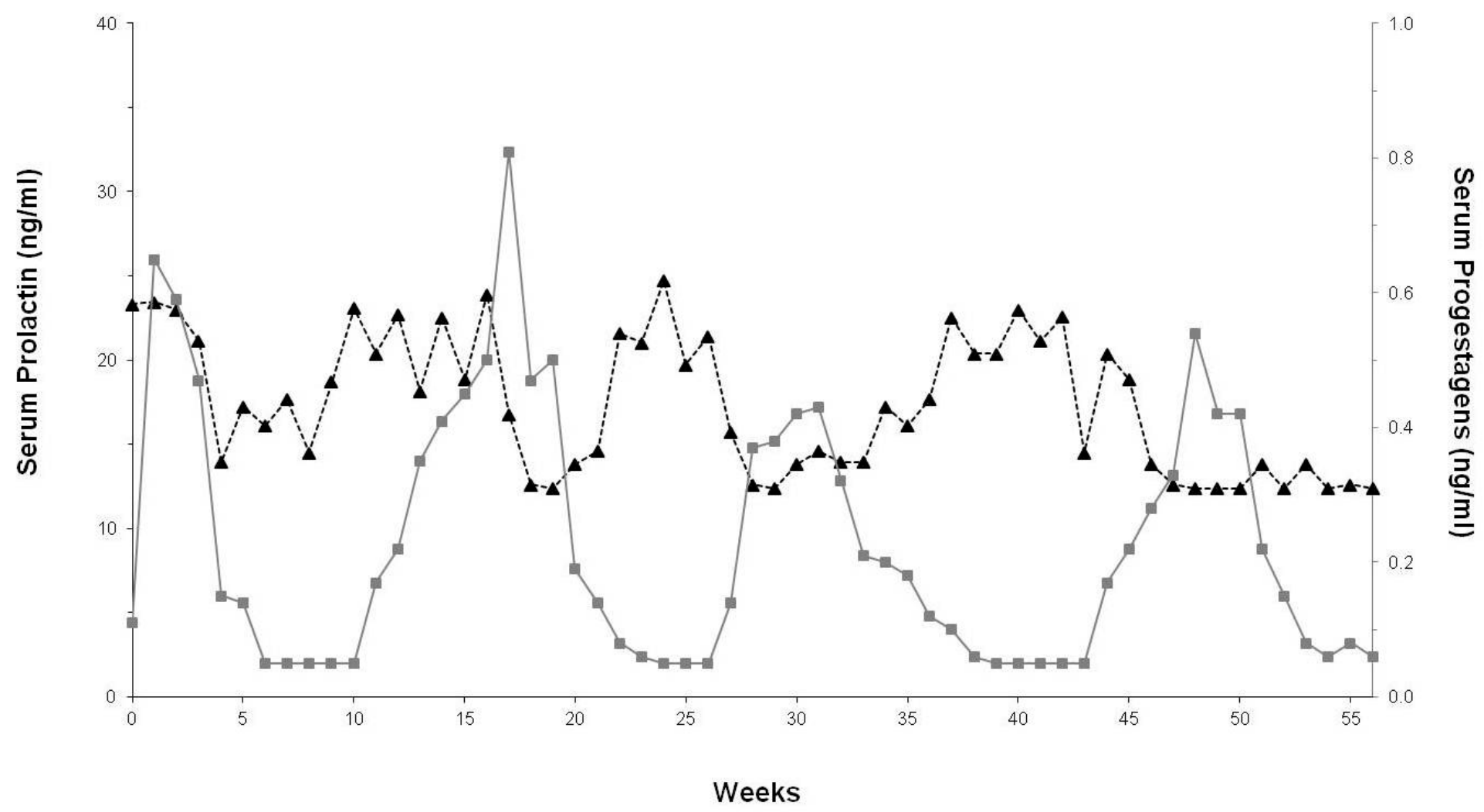

Figure. 5. Serum progestagen and prolactin concentrations in a single normal cycling female African elephant. Reprinted with permission from Dow and Brown (2012). 


\section{Summary and Conclusion}

Acyclicity in captive female African elephants is an increasing idiopathic reproductive

problem. Acyclicity is not indicative of permanent infertility wherein normal cycling and acyclic females have comparable serum anti-Müllerian hormone (AMH) concentration, which is used as a marker of fertility in a number of species. To date, several factors have been identified as possibly contributing to acyclicity; perturbations in serum prolactin concentration were consistent in all acyclic individuals. Although treatment protocols manipulating serum prolactin concentrations to within a normal range have been successful, no mechanism of action has yet been identified. Moreover, it is unknown if abnormal serum prolactin concentration is a cause or consequence of acyclicity in this species.

From the written survey the current reproductive status of all female elephants in North American zoological facilities was assessed. This survey showed that ovarian acyclicity, along with reproductive tract pathologies, is evident among all postpubertal age groups for both African and Asian elephants. Although overall rates of ovarian acyclicity did not change between 2005 and 2008, irregular cycles continued to increase, and in many females represent the transition from a cyclic to an acyclic state. Geographical location of a facility was not found to contribute to ovarian acyclicity, whereas management style, presence of a male within a facility, breeding opportunities, age, and presence of tract pathologies all had significant influences on estrous cyclicity status in female elephants. Moreover, there continues to be a species difference in the types and degree of reproductive problems, with African elephants apparently being more susceptible to factors affecting ovarian activity than Asian females.

Serum AMH concentrations in male and female Asian and African elephants were compared across age categories and between elephants of different reproductive status. No 
differences in mean AMH concentration between elephant species were significant. However, overall mean AMH concentrations were markedly higher in males than females. Anti-Müllerian hormone concentrations were highest in prepubertal individuals of both genders and decreased with age. However, AMH concentrations were not correlated with reproductive cyclicity status in female elephants, so the observation of high rates of ovarian inactivity in the captive population are likely not related to a loss of ovarian follicles.

Prolactin secretory patterns in acyclic verses normal and irregularly cycling female African elephants were significantly altered. Although the exact mechanism of prolactin action in elephants is still unclear, it appears that perturbations in prolactin synthesis, either too much (hyperprolactinemic) or too little (prolactin deficient), may be directly or indirectly involved in gonadal dysfunction. Most importantly, the frequency of hyperprolactinemia appears to have dramatically increased and is now observed in 71\% of acyclic females, up from the 37\% in 2004 . Logically, the next step is to determine if a loss in cyclical prolactin secretion during the nonluteal phase precedes acyclicity and whether it acts as a causative factor or if constant low prolactin synthesis is simply a consequence of the acyclic state. Because the captive African elephant population is not self-sustaining, it is imperative to have all reproductive-aged females cycling.

The oral administration of cabergoline, a dopamine receptor agonist that has been shown to temporarily decrease circulating prolactin concentration in hyperprolactinemic humans, or domperidone, dopamine receptor antagonist used to increase serum prolactin concentration in mares, have been proven to regulate prolactin concentrations in acyclic elephants. These experiments demonstrated that serum prolactin concentrations can be regulated by oral administration of cabergoline or domperidone in acyclic hyperprolactinemic or prolactin 
deficient female African elephants, respectively. Changes in prolactin concentrations are directly reflective of treatment administration regimen; however, what causes the observed change in concentration of progestagens is unknown. Currently, the North American captive African elephant population is not self-sustaining, thus it is crucial that all reproductive-aged females have normal estrous cyclicity. Although we now have potential treatment protocols for these types of acyclic females, we have nonetheless failed to define the mechanisms of action behind what causes these conditions. Moreover, it is yet to be determined if acyclicity is caused by or causes perturbations in prolactin synthesis.

In conclusion, acyclicity in captive African female elephants in North American zoological facilities is continuing to increase; all age categroeies of post-pubertal females are affected. Among acyclic females a common factor has been identified wherein serum prolactin concentration is either too high or deficient when compared to normal cycling elephants. Oral administration of either a dopamine agonist or antagonist, depending on prolactin synthesis abnormality, has shown to be effective in regulating serum prolactin concentration by restoring the profile to normal parameters. However, whether treatment reinitiates estrous cyclicity is yet to be determined. 


\section{Literature Cited}

Abbott, D. 1984. Behavioral and physiological suppression of fertility in subordinate marmoset monkeys. Am. J. Primatol. 6:169-186.

Abilay, T.A., Johnson, H.D., Madan, M. 1975. Influence of environmental heat onperipheral plasma progesterone and cortisol during the bovine estrous cycle.

Adams, G.P., Kastelic, J.P., Berfelt, D.R., Ginther, O.J. 1987. Effect of uterine inflammation and ultrasonically-detected uterine pathology on fertility in the mare. J. Reprod. Fertil., Suppl. 35:445-454.

Adams, J., Berg, J.K. 1980. Behavior of the African elephant (Loxodonta africana). Appl. Anim. Ethol. 6:257-276.

Agnew, D.W., Munson, L., Ramsey, E.C. 2004. Cystic endometrial hyperplasia in elephants. Vet. Pathol. 41:179-183.

Ajika, K., Krulich, L., Fawcett, C.P., McCann, S.M. 1972. Effects of estrogens on plasma and pituitary gonadotropins and prolactin, and on hypothalamic releasing and inhibiting factors. Neuroendocrinology 9:304-315.

Al-attar, L., Nöel, K., Dutertre, M., Belville, C., Forest, M.G., Burgoyne, P.S., et al. 1997. Hormonal and cellular regulation of Sertoli cell anti-Müllerian hormone production in the postnatal mouse. 100:1335-1343.

Allen, W.R. 2006. Ovulation, pregnancy, placentation and husbandry in the African elephant (Loxodonta africana). Philos. Trans. R. Soc. B. 361:821-834. 
Allen, W.R., Mathias, S., Wooding, F.B.P., van Aarde, R.J. 2003. Placentation in the African elephant (Loxodonta africana): II Morphological changes in the uterus and placenta throughout gestation. Placenta. 24:598-617.

Allrich, R.D. 2001. Cooperative Extension Service, Perdue University. Retrieved 22 April 2008, from http://www.ces.perdue.edu/extmedia/AS/AS-451.html.

Almaw G, Molla B. 2000. Prevalence and etiology of mastitis in camels (Camelus dromodarius) in Eastern Ethiopia. J Camel Pract Res. 7:97-100.

Alvarez, H. 2000. Grandmother hypothesis and primate life histories. Am. J. Phys. Anthropol. 113:435-450.

Ambrósio, C.E., Brolio, M.P., Martins, D.S., Morini, J.C., Carvalho, A.F., Miglino, M.A. 2011. Endometrial alterations, early placentation, and maternal fetal interaction in carnivores. Rev Bras Reprod Anim. 35:217-228.

Anderson, K.F., Eltringham, S.K. 1997. Some preliminary observation on possible stress in the elephants of Mikumi National Park, Tanzania. Af. J. Ecol. 35:278-282.

Ange, K., Crissey, S.D., Doyle, C., Lance, K., Hintz, H. 2001. A survey of African (Loxodonta africana) and Asian (Elephas maximus) elephant diets and measured body dimensions compared to their estimated nutrient requirements. Proc. Nut. Adv. Grp. 2001:5-14.

Appasamy, M., Muttukrishna, S., Pizzey, A.R., Groome, N.p., Serhal, P., Jauniaux, E. 2007. Relationship between male reproductive hormones, sperm DNA damage and markers of oxidative stress in infertility. Reprod Biomed Online. 14:159-65.

Archie, E.A., Morrison, T.A., Foley, C.A., Moss, C.J., Alberts, S.C. 2006. Dominance rank relationships among wild female African elephants, Loxodonta africana. Anim. Behav. 71:117-127. 
Asa, C.S., Robinson, J.A., Ginther, O.J. 1983. Changes in plasma cortisol concentrations during the ovulatory cycle of the mare. J. Endocrinol. 99:329-334.

Asa, C.S., Ginther, O.J. 1982. Glucocorticoid suppression of oestrus, follicles, LH, and ovulation in the mare. J. Reprod. Fertil., Suppl. 32:247-251.

Asdell, S.A., 1964. Patterns of Mammalian Reproduction. Cornell University Press, Ithaca, NY. Associattion of Zoos and Aquariums (AZA). 2003. Reproduction. In: Standards for Elephant Management and Care. Silver Spring, Maryland: AZA. pp 6.

Baarends, W.M., Uilenbroek, J.T., Kramer, P., Hoogerbrugge, J.W., van Leeuwen, E.C., Themmen, A.P., Grootegoed, J.A. 1995. Anti-Müllerian hormone and anti-Müllerian hormone type II receptor messenger ribonucleic acid expression in rat ovaries during post-natal development, estrous cycle, and gonadotropin-induced follicle growth. Endocrinology 136:4951-4962.

Bachelot, A., Binart, N. 2007. Reproductive role of prolactin. Reproduction 113:361-369.

Badawy, A., Elnashar, A. 2011. Treatment options for polycystic ovarian syndrome. Int. J. Womens Health 3:25-35.

Bagley, K.R. 2004. Chemosensory behavior and development of African male elephants (Loxodonta africana). MSc thesis, Georgia Southern University, Statesboro, GA.

Bagley, K.R., Goddwin, T.E., Rasmussen, L.E.L., Shulte, B.A. 2006. Male African elephant (Loxodonta africana) can distinguish oestrous status via urinary signals. Anim. Behav. $71: 1430-1445$.

Baker, H.W.G., Bangah, M.L., Burger, H.G., Kovacs, G.T., Summerball, D., Warnes, G.M. 1986. Timing of ovulation by determining of the urinary luteinizing hormone surge with 
an enzyme-linked monoclonal antibody dipstick (Ovustick). Aust. N. Z. J. Obstet. Gynaecol. 26:79-83.

Balfour, W.E., Comline, R.S., Short, R.V. 1957. Secretion of progesterone by the adrenal gland. Nature. 180:1480-1481.

Ball, R., Brown, J.L. 2006. Preliminary results of a cabergoline trial in captive elephants with hyperprolactinemia. In 'Proceedings, International Elephant Conservation and Research Symposium, Coppenhagen, 21 October 2006’. pp. 9. (International Elephant Foundation: USA.)

Balke, J.M.E., Boever, W.J., Ellersieck, M.R., Seal, U.S., Smith, D.A. 1988. Anatomy of the reproductive tract of the female African elephant (Loxodonta africana) with reference to development of techniques for artificial breeding. J. Reprod. Fertil. 84:485-492.

Barb, C.R., Kraeling, R.R., Rampacek, G.B., Fonda, E.S., Kiser, T.E. 1982. Inhibition of ovulation and LH secretion in the gilt after treatment with ACTH or hydrocortisone. 64:85-92.

Bast, J.D., Melampy, R.M. 1972. Luteinizing hormone, prolactin and ovarian $20 \alpha-$ hydroxysteroid dehydrogenase levels during pregnancy and pseudopregnancy in the rat. Endocrinology 91:1499-1505.

Bechert, U.S. 1998. Factors affecting prolactin secretion in the African elephant. Ph.D. Thesis, Oregon State University: Corvallis, Oregon.

Bechert, U.S., Swanson, L., Wasser, S.K., Hess, D.L., Stormshak, F. 1999. Serum prolactin concentrations in captive female African elephants (Loxodonta africana): Potential effects of season and steroid hormone interactions. Gen. Comp. Endocrinol. 114:269278. 
Bechert, U., Christensen, J.M., Nguyen, C., Neelkant, R., Bendas, E. 2008. Pharmacokinetics of orally administered phenylbutazone in African and Asian elephants (Loxodonta africana and Elephas maximus). J. Zoo Wildl. Med. 39:188-200.

Ben-Jonathan, N. 1994. Regulation of prolactin secretion. In: The Pituitary Gland. Imura, H. (Ed.) Raven Press, New York. pp 261-283.

Ben-Jonathan, N., Lapensee, C.R., Lapensee, E.W. 2008. What can we learn from rodents about prolactin in humans? Endocrine Rev. 29:1-41.

Benson CT. 2008. Prolactin deficiency. http://www.emedicine.com/med/topics1914.htm.

Bentley, G.R., Muttukrishna, S. 2007. Potential use of biomarkers for analyzing interpopulation and cross-cultural variability in reproductive aging. J. North Am. Menopause Soc. 14:668-679.

Benus, R.F., Koolhaas, J.M., van Oortmerssen, G.A. 1987. Individual differences in behavioral reaction to a changing environment in mice and rats. Behaviour 100:105-122.

Bergfelt, D.R., Mann, B.G., Schwartz, N.B., Ginther, O.J. 1991. Circulating concentrations of immunoreactive inhibin and FSH during the estrous cycle of mares. Equine Vet. Sci. 11:319-322.

Bergfelt, D.R., Ginther, O.J. 1992. Embryo loss following GnRH-induced ovulation in anovulatory mares. Theriogenology 38:33-43.

Besognet B, Hansen BS, Daels PF. 1996. Dopaminergic regulation of gonadotropin secretion in seasonally anoestrous mares. J Reprod Fertil. 108:55-61.

Besognet B, Hansen BS, Daels PF. 1997. Induction of reproductive function in anestrous mares using a dopamine antagonist. Theriogenology 47:467-480. 
Bierschwal, C.J., Garverick, H.A., Martin, C.E., Youngquist, R.S., Cantley, T.C., Brown, M.D. 1975. Clinical response of dairy cows with ovarian cysts to GnRH. J. Anim. Sci. 41:1660.

Bilezikijian, L.M., Blount, A.L., Leal, A.M., et al. 2004. Autocrine/paracrine regulation of pituitary function by activin, inhibin, and follistatin. Mol. Cell Endocrinol. 225:29-36.

Bilezikijian, L.M., Blount, A.L., Donaldson, C.J., et al. 2006. Pituitary actions of ligands of the TGF-beta family: activins and inhibins. Reproduction 132:207-215.

Biller, B.M. 1999. Hyperprolactinemia. Int. J. Fertil. 44:74-77.

Biller, B.M., Molitch, M.E., Vance, M.L., Cannistraro, K.V., Davis, K.R. 1996. Treatment of prolactin-secreting macroadenomas with the once-weekly dopamine antagonist cabergoline. J. Clin. Endocrinol. Metab. 81:2338-2343.

Billings, H.J.., Viguie, C., Karsch, F.J., Goodman, R.L., Connors, J.M., Anderson, G.M. 2002. Temporal requirements of thyroid hormones for seasonal changes in LH secretion. Endocrinology 143:2618-2625.

Blanc, J.J., Barnes, R.F.W., Craig, G.C., Dublin, H.T., Thouless, C.R., Douglas-Hamilton, I., Hart, J.A. 2007. African Elephant Status Report 2007. International Union for Conservation of Nature and Natural Resources, Switzerland.

Bonar, C.J., Lewandowski, A.H., Arafah, B., Capen, C.C. 2005. Pheochromocytoma in an aged African elephant (Loxodonta africana). J. Zoo Wildl. Med. 36:719-723.

Bosu, W.T.K., Sequin, B.E. 1998. Reproductive System. In: The Merck Veterinary Manual. Aiello, S.A., Mays, A. (eds.), Merck and Company, Inc. p 977-1048.

Bowman, L.A., Dilley, S.R., Keverne, E.B. 1978. Suppression of oestrogen-induced LH surges by social subordination in talapoin monkeys. Nature 275:56-58. 
Brennian, JD., Griffin, F., Papkoff, H., Terranova, P.F. 1988. Short and long phases of progesterone secretion during the oestrous cycle of the African elephant (Loxodonta africana). J. Reprod. Fertil. 84:357-365.

Brendemuehl, J.P., Cross, D.L. 2000. Influence of the dopamine antagonist domperidone on the vernal transition in seasonally anoestrous mares. J. Reprod. Fertil., Suppl. 56:185-193.

Broekmans, F., Visser, J., Laven, J., Broer, S., Themmen, A., Fauser, B. 1990. Anti-Müllerian hormone and ovarian dysfunction. Trends Endocrinol. Metab. 19:340-347.

Bronson, F.H. 1985. Mammalian reproduction: An ecological perspective. Biol. Reprod. 32:126.

Brown, J.L., Citino, S.B., Bush, M., Lehnhardt, J., Phillips, L.G. 1991. Cyclic patterns of luteinizing hormone, follicle-stimulating hormone, inhibin, and progesterone secretion in the Asian elephant (Elephas maximus). J. Zoo Wildl. Med. 1:49-57.

Brown, J.L., Bush, M., Wildt, D.E., Raath, J.R., de Vos, V., Howard, J.G. 1993. Effects of GnRH analogues on pituitary-testicular function in free-ranging African elephant (Loxodonta africana). J. Reprod. Fertil. 99:627-634.

Brown, J.L., Lehnhardt, J. 1995. Serum and urinary hormones during pregnancy and peri- and postpartum period in an Asian elephant (Elephas maximus). Zoo Biol. 14:555-564.

Brown, J.L., Wildt, D.E., Wielebnowski, N., Goodrowe, K.L., Graham, L.H., Wells, S., Howard, J.G. 1996. Reproductive activity in captive female cheetahs (Acinonyx jubatus) assessed by faecal steroids. J. Reprod. Fertil. 106:337-346.

Brown, J.L., Lehnhardt, J. 1997. Secretory patterns of serum prolactin in Asian (Elephas maximus) and African (Loxodonta africana) elephants during different reproductive 
states: comparison with concentrations in a noncycling African elephant. Zoo Biol. 16:149-159.

Brown, J.L., Schmitt, D.L., Bellum, A., Graham, L.H., Lehnhardt, J. 1999a. Hormone secretion in the Asian elephant (Elephas maximus): Characterization of ovulatory and anovulatory luteinizing hormone surges. Bio. Reprod. 61:1294-1299.

Brown, J.L., Hildebrandt, T.B., Theison, W., Neiffer, D. 1999b. Endocrine and ultrasound evaluation of a non-cycling African elephant: Identification of an ovarian follicular cyst. Zoo Biol. 18:223-232.

Brown, J.L. 2000. Reproductive endocrine monitoring of elephants: An essential tool for assessing captive management. Zoo Biol. 19:347-367.

Brown, J.L., Bellam, A.C., Fouraker, M., Wildt, D.E., Roth, T.L. 2001. Comparative analysis of gonadal and adrenal activity in the black and white rhinoceros in North America by noninvasive endocrine monitoring. Zoo Biol. 20:463-486.

Brown, J.L. Olson, D., Keele, M., Freeman, E.W. 2004a. Survey of the reproductive cyclicity status of Asian and African elephants in North America. Zoo Biol. 23:309-321.

Brown, J.L., Walker, S.L., Moeller, T. 2004b. Comparative endocrinology of cycling and noncycling Asian (Elephas maximus) and African (Loxodonta africana) elephants. Gen. Comp. Endocrinol. 136:360-370.

Brown, J.L. 2006. Reproductive Endocrinology. In: Biology, Medicine, and Surgery of Elephants, Fowler, M.E., Mikota, S.K. (eds). Blackwell Publishing. pp 377-387.

Brown, J.L., Somerville, M., Riddle, H.S., Keele, M., Duer, C.K., Freeman, E.W. 2007. Comparative endocrinology of testicular, adrenal, and thyroid function in captive Asian and African elephant bulls. Gen. Comp. Endocrinol. 151:153-162. 
Brown, J.L., Wielebnowski, N., Cheeran, J. 2008. Challenges with identifying and evaluating pain, distress, and suffering in elephants. In: Wemmer, C., Christian C. (eds). Elephants and Ethics. Baltimore, MD: John Hopkins University Press. pp 121-148.

Burger, H. 2008. The menopausal transition- Endocrinology. J. Sex. Med. 5:2266-2273.

Buss, I.O., Rasmussen, L.E., Smuts, G.L. 1976. The role of stress and individual recognition in the function of the African temporal gland. Mammalia 40:437-451.

Buss, I.O. 1990. Elephant Life: Fifteen Years of High Population Density. Iowa State University, Ames, Iowa.

Buttram, V.C. 1986. Uterine leiomyomata: aetiology, symptomatology, and management. Prog. Clin. Biol. Res. 225:275-296.

Cantley, T.C., Garverick, H.A., Bierschwal, C.J., Martin, C.E., Youngquist, R.S. 1975. Hormonal response of dairy cows with ovarian cysts to GnRH. J. Anim. Sci. 41:16661673.

Caraty, A., Skinner, D.C. 1999. Progesterone priming is essential for the full expression of the positive feedback effect of estradiol in inducing the preovulatory gonadatropin-releasing hormone surge in the ewe. Neuroendocrinology. 140:165-170.

Carden, M., Schmitt, D., Tomasi, T., Bradford, J., Moll, D., Brown, J.L. 1998. Utility of serum progesterone and prolactin analysis for assessing reproductive status in the Asian elephant (Elephas maximus). Anim. Reprod. Sci. 53:133-142.

Carlson, E., Giwercman, A., Keiding, N. 1992. Evidence for decreasing quality of semen during the past 50 years. BMJ. 305:609-13.

Carlson, E., Andersson, A.M., Peterson, J.H., Skakkebaek, N.E. 2003. History of febrile illness and variation in semen quality. Hum Reprod. 18:2089-2092. 
Carlstead, K., Mellen, J., Kleiman, D.G. 1999a. Black rhinoceros (Diceros bicornis) in U.S. zooz: I. Individual behavior profiles and their relationship to breeding success. 18:17-34.

Carlstead, K., Fraser, J., Bennett, C., Kleiman, D.G. 1999b. Black rhinoceros (Diceros bicornis) in U.S. zoos: II. Behavior, breeding success, and mortality in relation to housing facilities. 18:35-42.

Carnevale, E.M., Ginther, O.J. 1992. Relationships of age and uterine function and reproductive efficiency in mares. Theriogenology 37:1101-1115.

Carter, D.A., Pennington, J.M., Whitehead, S.A. 1982. In-vivo and in-vitro effects of domperidone on the release of prolactin and LH in male and female rats. J. Reprod. Fertil. 64:191-197.

Carvalho-Freitas, M.I., Anselmo-Franci, J.A., Teodorov, E., Nasello, A.G., Palermo-Neto, J., Felicio, L.F. 2007. Reproductive experience modifies dopaminergic function, serumlevels of prolactin, and macrophase activity in female rats. Life Sci. 81:128-136.

Casida, L.E., McShan, W.H., Meyer, R.K. 1944. Effects of an unfractionated pituitary extract upon cystic ovaries and nymphomania in cows. J. Anim. Sci. 3:273.

Castilla, A., Garcia, C., Cruz-Soto, M., Martinez de la Escalera, G., Thebault, S., Clapp, C. 2010. Prolactin in ovarian follicular fluid stimulates endothelial cell proliferation. J Vasc Res 47:45-53.

Chatfield, A., Zhang, L., Ramey, J., Bowsher, T., Loskutoff, N., O’Neill, K. 2006. Resolution of hyperprolactinemia in western lowland gorilla (Gorilla gorilla gorilla). J. Zoo Wildl. Med. 37:565-566.

Clarke IJ, Cummins JT. 1989. Direct pituitary effects of estrogen and progesterone on gonadatropin secretion in the overiectomized ewe. Neuroendocrinol 39:267-274. 
Clarkson, J., Herbison, A.E. 2006. Postnatal development of kisspeptin neurons in mouse hypothalamus: sexual dimorphism and projections to gonadotropin-releasing hormone neurons. Endocrinology 147:5817-5825.

Clarkson, J., d'Anglemont de Tassigny, X., Moreno, A.S., Colledge, W.H., Herison, A.E. 2008. Kisspeptin-GPR54 signaling is essential for preovulatory gonadotropin-releasing hormone activation and the luteinizing hormone surge. J. Neurosci. 28:8691-8697.

Chiaki, N. 1996. Seasonal variations in African elephant nutrition in Tsavo National Park, Kenya. MSc Thesis, Michigan State University, East Lansing, MI.

Chilton, B.S., Mani, S.K., Bullock, D.W. 1988. Servomechanism of prolactin and progesterone in regulating uterine gene experession. Mol. Cell. Endocrinol. 2:1169-1175.

Clauss, M., Löhlein, W., Kienzle, E., Wiesner, H. 2003a. Studies on feed digestibilities in captive Asian elephants (Elephas maximus). J. Anim. Phys. Anim. Nut. 87:160-173.

Clauss, M., Wang, Y., Ghebremeskel, K., Lendel, C.E., Streich, W.J. 2003b. Plasma and erythrocyte fatty acids in captive Asian (Elephas maximus) and African (Loxodonta africana) elephants. Vet. Rec. 153:54-58.

Clubb, R., Rowcliffe, M., Lee, P., Mar, K.U., Moss, C., Mason, G.J. 2009. Fecundity and population viability in female zoo elephants: Problems and possible solutions. Anim. Welfare 18:237-247.

Clubb, R., Rowcliffe, M., Lee, P., Mar, K.U., Moss, C., Mason, G.J. 2008. Compromised survivorship in zoo elephants. Science 322:1648-1651.

Codron, J., Lee-Thorp, J.A., Sponheimer, M., Codron, D., Grant, R.C., de Ruiter, D.J. 2006. Elephant (Loxodonta africana) diets in Kruger National Park, South Africa: Spatial and landscape differences. J. Mammal. 87:27-34. 
Cohen, J.P. 2006. Do elephants belong in zoos? BioScience 56:714-717.

Coleman, R.J., Anderson, R.M., Johnson, S.C., Kastman, E.K., Kosmatka, K.J., Beasley, T.M., Allison, D.B., Cruzen, C., Simmons, H.A., Kemnitz, J.W., Weindruch, R. 2009. Caloric restriction delays disease onset and mortality in Rhesus monkeys. Science 325:201-204.

Concannon, P.W., Hansel, W., Visek, W.J. 1975. The ovarian cycle of the bitch: plasma estrogen, LH, and progesterone. Biol. Reprod. 13:112-121.

Correa, H., Jocoby, J. 1978. Nutrition and fertility: Some iconoclastic results. Am. J. Clin. Nutr. 31:1431-1436.

Creel, S.R., Creel, N.M. 1991. Energetics, reproductive suppression, and obligate communal breeding in carnivores. Behav. Ecol. Sociobiol. 28:263-278.

Creel, S.R., Creel, N.M., Wildt, D.E., Monfort, S.L. 1992. Behavioural and endocrine mechanisms of reproductive suppression in Serengeti dwarf mongooses. Anim. Behav. 43:231-245.

Creel, S.R., Creel, N.M., Mills, M.G.L., Monfort, S.L. 1997. Rank and reproduction in cooperatively breeding African wild dogs: Behavioural and endocrine correlates. Anim. Behav. 8:298-306.

Cross, D.L., Ginther, O.J. 1987. The effect of estrogen, progesterone, and prostaglandin F2 $\alpha$ on uterine contractions in seasonally anovulatory mares. Dom. Anim. Endocrinol. 4:271278.

Cross, D.L. 1997. Fescue toxicosis in horses. In: Neotyphodium/Grass Interaction. (Bacon, C.W., Hills, N.S. (Eds.) Plenum Press, New York and London. pp 289-309.

Cross, D.L., Anas, K., Bridges, W.C., Chappell, J.H. 1999. Clinical effects of domperidone on fescue toxicosis in pregnant mares. AAEP Proc. 24:203-206. 
Czekala, N.M., MacDonald, E.A., Steinman, K., Walker, S., Garrigues, N.W., Olson, D., Brown, J.L. 2003. Estrogen and LH dynamics during follicular phase of the estrous cycle in the Asian elephant. Zoo Biol. 22:443-454.

Dasgupta, A., Rehamn, H.U. 2006. Neuroendocrinology of menopause. Minerva Ginecol. 58:25-33.

Davis, J.S., Weakland, L.L., Weiland, D.A., Farese, R.V., West, L.A. 1987. Prostaglandin F2 $\alpha$ stimulates phosphatidylinositol 4, 5-bisphosphate hydrolysis and mobilizes intracellular calcium in bovine luteal cells. Proc. Natl. Acad. Sci. 84:3728-3732.

De Bosschere, H., Ducatelle, R., Vermeirsch, H., Van Den Broeck, W., Coryn, M. 2001. Theriogenology 55:1509-1519.

de Oliveira, C.A., West, G.D., Houck, R., Leblanc, M. 2004. Control of musth in an Asian elephant bull (Elephas maximus) using leuprolide acetate. J. Zoo Wildl. Med. 35:70-76. de Villiers, D.J., Skinner, J.D., Hall Martin, A.J. 1989. Circulating progesterone concentrations and ovarian functional anatomy in the African elephant (Loxodonta africana). J. Reprod. Fertil. 86:195-201.

Deaver, D.R., Dailey, R.A. 1982. Effects of dopamine, norepinephrine and serotonin on plasma concentrations of luteinizing hormone and prolactin in ovariectomized anestrous ewes. Biol. Reprod. 27:624-632.

Dekkers, O.M., Lagro, J., Burman, P., Jørgensen, J.O., Romijn, J.A., and Pereira, A.M. 2010. Recurrence of hyperprolactinemia after withdraw of dopamine agonists: systemic review and meta-analysis. J Clin Endocrinol Metab. 95:43-51.

Derix, R., Van Hooff, J., de Vries, H., Wensing, J. 1993. Male and female matine competition in wolves: female suppression vs. male intervention. Behaviour 127:141-171. 
Di Salle, E., Ornati, G., Briatico, G. 1982. FCE 21336, a new ergoline derivative with a potent and long-acting lowering effect on prolactin secretion in rats. J Endocrinol Invest (Suppl 1) $6: 6$.

Dierenfeld, E.S., Dolensek, E.P. 1988. Circulating levels of vitamin E in captive Asian elephants (Elephas maximus). Zoo Bio. 7:165-172.

Dierenfeld, E.S. 1994. Nutrition. In: Medical Management of Elephants. Sargent, E.L., Ranglack, G.S., Mikota, S.K (Eds.). Indira Publishing House, West Bloomfeld. pp 6980.

Doi,O., Komatsumotot, M., Terazono, M., Wada, S., Akihisa, N., Sakamoto, H., Hamasaki, T., Yanagimoto, H., Nakano, K., Matsuoka, K., Ito, A., Kusunoki, H., Nakamura, T. 2000. Exfoliative cytology in vaginal vestibule of female Asian elephants: relation to circulating progesterone concentrations. Zool. Sci. 17:1303-1309.

Doknic, M., Pekic, S., Zarkovic, M., Medic-Stojanoska, M., Dieguez, C., Casanueva, F., and Popovic, V. 2002. Dopaminergic tone and obesity: an insight from prolactinomas treated with bromocriptine. Eur J Endocrinol. 147:77-84.

Doppler, W. 1994. Regulation of gene expression by prolactin. Rev Physiol Biochem Parmacol 124:92-130.

Dorflinger, L.J. Albert, P.J., Williams, A.T., Behrman, H.R. 1984. Calcium is an inhibitor of luteinizing hormone-sensitive adenylate cyclase in the luteal cell. Endocrinology 114:1208-1215.

Dougall, H.W., Sheldrick, D.L.W. 1964. The chemical composition of a daily diet of an elephant. E. Af. Wildl. J. 2:51-59. 
Douglas, R.H., Ginther, O.J. 1972. Effect of prostaglandin F2 $\alpha$ on length of diestrus in mares. Prostaglandins 2:265-268.

Douglas, R.H., Ginther, O.J. 1975. Route of prostaglandin F2 $\alpha$ injection and luteolysis in mares. Proc. Soc. Exp. Biol. Med. 148:263-269.

Douglas, R.H., Ginther, O.J. 1976. Effects of repeated daily injection of prostaglandin F2 $\alpha$. Prostaglandins 12:881-894.

Douglas, R.H., Del Campo, M.R., Ginther, O.J. 1976. Luteolysis following carotid or ovarian arterial injection of prostaglandin F2 $\alpha$ in mares. Biol. Reprod. 14:473-477.

Douglas, R.H., Ginther, O.J., Nuti, L. 1974. Induction of ovulation and multiple ovulations in seasonally anovulatory mares with equine pituitary fractions. Theriogenology. 2:133141.

Douglas-Hamilton, I. 1975. On the Ecology and Behaviour of the African Elephant. University of Oxford, Oxford.

Douglas-Hamilton, I. 1998. Tracking African elephants with a global positioning system (GPS) radio collar. Pacyderm 25:82-91.

Douglas-Hamilton, I., Douglas-Hamilton, O. 1975. Among the Elephants. The Viking Press, New York.

Dow, T.L., Holásková, I., and Brown, J.L. 2011a. Results of the third reproductive assessment survey of North American Asian (Elephas maximus) and African (Loxodonta africana) female elephants. Zoo Biol. 29:1-13.

Dow, T.L., Roudebush, W., Parker, F.N., Brown, J.L. 2011b. Influence of age and gender on secretion of anti-Müllerian hormone in Asian (Elephas maximus) and African (Loxodonta africana) elephants. Therio. 75:620-627. 
Dow, T.L., Brown, J.L. 2012. Evidence of hyperprolactinemia as a growing cause of infertility in female zoo African (Loxodonta africana) elephants. Reprod Fertil Devel. In Press.

Doyle, C., York, B., Whitely, A. 1999. A survey of Asian elephant births from 1962-1998. J Elephant Managers Assoc. 10:146-148.

Drago, F., Amir, S. 1984. Effects of hyperprolactinemia on core temperature of the rat. Brain Res. Bull. 12:355-358.

Drago, F., D’Agata, V., Iacona, T., Spadora, F., Grassi, M., Valerio, C., Raffaele, R., Astuto, C., Lauraia, N., Vitetta, M. 1989. Prolactin as a protective factor in stress-induced biological changes. J. Clin. Lab. Anal. 3:340-344.

Draincourt, M.A., Royere, D., Hedon, B., Levasseur, M.C. 1993. Oestrous and Menstrual Cycles. In: Reproduction in Mammals and Man. Thibault, C., Levasseur, M.C., Hunter, R.H.F. (Eds.). Ellipses, Paris. pp 281-305.

Drews, B., Hermes, R., Göritz, F., Gray, C., Kurz, J., Lueders, I., Hildebrandt, T.B. 2008. Early embryo development in the elephant assessed by serial ultrasound examinations. Theriogenology. 69:1120-1128.

Dublin, H.T. 1983. Cooperation and Reproductive Competition Among Female African Elephants. In: Social Behavior in Female Vertebrates. Wasser, S.K. (Ed.). Academic Press, New York. pp 291-313.

Durlinger, A.L., Kramer, P., Karels, B., de Jong, F.H., Uilenbroek, J.T., Grootegoed, J.A., et al. 1999. Control of primordial follicle recruitment by anti-Müllerian hormone in the mouse ovary. Endocrinol. 140:5789-96.

Ehrmann, D.A. 2005. Polycystic ovarian syndrome. N. Engl. J. Med. 352:1223-1236. 
Eisenburg, J.F., McKay, G.M., Jainudeen, M.R. 1971. Reproductive behavior of the Asiatic elephant (Elephas maximus maximus L.). Behaviour 38:193-225.

Elridge, H., Challis, J.R.G., Robinson, J.S., Roper, C., Thorburn, G.D. 1976. Influence of handling stress on plasma cortisol in Rhesus monkeys (Macaca mallatta). J. Endocrinol. 70:325-326.

Ensley, P.K., Anderson, M., Osburn, K., Bissonnette, S., Deftos, L.J. 1994. Osteodystrophy in an orphan Asian elephant (Elephas maximus indicus). Proc. Amer. Assoc. Zoo Vet., Pittsburgh, Pennsylvania. pp 142-143.

Epple, G., Katz, Y. 1984. Social influences on estrogen excretion and ovarian cyclicity in Saddle Back tamarins (Saguinus fusciocollis). Am. J. Primatol. 6:215-227.

Essawy, S.A., Benhaj, K.M., Cooke, R.G., Dobson, H. 1989. Effect of dose and route of administration of ACTH 1-24 on plasma cortisol concentrations in ewes. J. Vet. Pharmacol. Ther. 12:302-302.

Evans, T.J., Youngquist, R.S., Loch, W.E., Cross, D.L. 1999. A comparison of the relative efficacies of domperidone and reserpine in treating equine "Fescue Toxicosis." AAEP Pro. 45:207-209.

Falk, R.J. 1992. Isolated prolactin deficiency: a case report. Fertil Steril. 58:1160-1162.

Fanchin, R., Schonauer, L.M., Righini, C., Guibourdenche, J., Frydman, R., Taieb, J. 2003. Serum anti-Müllerian hormone is more strongly related to ovarian follicular status than serum inhibin-B, estradiol, FSH and LH on day 3. Hum Reprod. 18:323-327.

Faulkes, C.G., Abbott, D.H., Jarvis, J.U.M. 1990. Social suppression of ovarian cyclicity in captive and wild Naked mole-rats (Heterocephalus glaber). J. Reprod. Fertil. 88:559568. 
Faust, L.J., Thompson, S.D., Earnhardt, J.M. 2006. Is reversing the decline of Asian elephants in North American zoos possible? An individual-based modeling approach. Zoo Biol. 25:201-218.

Fayrer-Hosken, R.A., Grobler, D., Van Altena, J.J., Bertschinger, H.J., Kirkpatrick, L.F. 2000. Immunocontraception of African elephants. Nature 14:149.

Ferin, M. 1999. Stress and the reproductive cycle. J. Clin. Endocrinol. Metab. 84:1768-1774.

Ferrari, C., Paracchi, A., Mattei, A.M., de Vincentiis, S., D’Alberton, A., Crosignani, P. 1992. Cabergoline in the long-term therapy of hyperprolactinemic disorders. Acta Enddocrinol. 126:489-494.

Ferreira, J.C., Gastal, E.L., Ginther, O.J. 2008. Uterine blood flow and perfusion in mares with uterine cysts: Effect of the size of the cystic area and age. Reproduction. 135:541-550.

Ficicioglu, C., Kutlu, T., Baglam, E., Bakacak, Z. 2006. Early follicular anti-Müllerian hormone as an indicator of follicular reserve. Fertil. Steril. 85:592-596.

Field, C.R. 1976. The savanna ecology of Kidepo Valley National Park. E. Af. Wildl. J. 14:115.

Fitzpatrick, S.L., Richards, J.S. 1991. Regulation of cytochrome P450 aromatase messenger ribonucleic acid and activity by steroids and gonadotropins in rat granulosa cells. Endocrinology 129:1452-1462.

Fortune, J.E., Rivera, G.M., Yang, M.Y. 2004. Follicular development: the role of the follicular microenvironment in selection of the dominant follicle. Anim Reprod Sci. 82:109-126.

Fowler, C.W. 1981. Density dependence as related to life history strategy. Ecology. 62:602610. 
Franceschini, I., Lomet, D., Cateau, M., Delsol, G., Tillet, Y., Caraty, A. 2006. Kisspeptin immunoreactive cells of the ovine Preoptic area and arcuate nucleaus co-express estrogen receptor alpha. Neurosci Lett. 401:225-230.

Freedman, L.J., Garcia, M.C., Ginther, O.J. 1979. Influence of ovaries and photoperiod on reproductive function in the mare. J. Reprod. Fertil, Suppl. 27:79-86.

Freeman, E.W., Weiss, E., Brown, J.L. 2004. Examination of the interrelationships of behavior, dominance status, and ovarian activity in captive Asian (Elephas maximus) and African (Loxodonta africana) Elephants. Zoo Biol. 23:431-448.

Freeman, E.W., Guagnano, G., Olson, D., Keele, M., Brown, J.L. 2009a. Social factors influence ovarian acyclicity in captive African elephants (Loxodonta africana). Zoo Biol. 28:1-15.

Freeman, E.W., Whyte, I., Brown, J.L. 2009b. Reproductive evaluation of elephants culled in Kruger National Park, South Africa between 1975 and 1995. Af. J. Ecol. 47:192-210.

Freeman, E.W., Schulte, B.A., Brown, J.L. 2010. Investigating the impact of rank and ovarian activity on the social behavior of captive female African (Loxodonta africana) elephants. Zoo. Biol. 29:154-167.

Freeman, M.E., Kanyicska, B., Lerant, A., Nagy, G. 2000. Prolactin: structure, function and regulation of secretion. Physiol. Rev. 80:1523-1631.

Fried, J., Santhanakrishnan, T.S., Himizu, J., Lin, C.H., Rubin, B., Grigas, E.O. 1969. Prostaglandin antagonists: synthesis and smooth muscle activity. Nature 223:208-210.

Fujisawa, M., Yamsaki, T., Okada, H., Kamidono, S. 2002. The significance of anti-müllerian hormone concentration in seminal plasma for spermatogenesis. Hum Reprod. 17:968970. 
Funkenstein, B., Waterman, M.R., Simpson, E.R. 1984. Induction of synthesis of cholesterol side chain cleavage cytochrome P-450 and adrenodoxin by follicle-stimulating hormone, 8-bromo-cyclic AMP, and low density lipoprotein in cultured bovine granulosa cells. J. Biol. Chem. 259:8572-8577.

Ganswindt, A., Palme, R., Heistermann, M., Borragan, S., Hodges, J.K. 2003. Non-invasive assessment of adrenocortical function in the male African elephant (Loxodonta africana) and its relaation to musth. Gen. Comp. Endocrinol. 134:156-166.

Ganswindt, A., Heistermann, M., Hodges, K. 2005. Physical, physiological, and behavioral correlates of musth in captive African elephants (Loxodonta africana). Physiol. Biochem. Zool. 78:505-514.

Ganswindt, A., Rasmussen, H.B., Heistermann, M., Hodges, J.K. 2005. The sexually active states of free-ranging male African elephants (Loxodonta africana): defining musth and non-musth using endocrinology, physical signals, and behavior. Horm. Behav. 47:8391.

Garai, M.E. 1992. Special relationships between female Asian elephants (Elephas maximus) in zoological gardens. Ethology 92:187-205.

Garm, O. 1949. Astudy of bovine nymphomania. Acta. Endocrinol. 3(Suppl 3):1.

Gayton, F., Morales, C., Bellido, C., Aguilar, E., Sanchez-Criado, J.E. 1997. Role of prolactin in the regulation of macrophages and in proliferative activity of the vascular cells in newly formed and regressing rat corpora lutea. Biol Reprod. 57:478-486.

Geras, E., Rebecchi, M.J., Gershengorn, M.C. 1982. Evidence that stimulation of thyrotropin and prolactin secretion by thyrotropin-releasing hormone occurs via different calciummediated mechanisms: studies with verapamil. Endocrinol. 110:901-906. 
Ginther, O.J. 1974. Internal regulation of physiological processes through venoarterial pathways: a review. J. Anim. Sci. 39:550-564.

Ginther, O.J., Beg, M.A., Berfelt, D.R., Donadeu, F.X., Kot, K. 2001. Follicle selection in monovular species. Biol. Reprod. 65:638-647.

Gitay-Goren, H., Lindenbaum, E.S., and Kraiem, Z. 1989. Effects of prolactin on steroidogenesis and cAMP accumulation in rat luteal cell cultures. Mol Cell Endocrinol. 65:195-201.

Gobush, K.S., Mutayoba, B.M., Wasser, S.K. 2008. Long-term impacts of poaching on relatedness, stress, physiology, and reproductive output of adult female African (Loxodonta africana) elephants. Conserv. Biol. 22:1590-1599.

Gómez-Ochoa, P., Castillo, J.A., Gascón, M., Zarate, J.J., Alvarez, F., Couto, C.G. 2009. Use of domperidone in the treatment of canine visceral leishmaniasis: a clinical trial. Vet J. 179:259-263.

Goodman, R.L., Logan, S.L., Ryan, K.D., Foster, D.L., Karsch, F.J. 1980. Two effects of estradiol that normally contribute to the control of tonic LH secretion in the ewe. Biol. Reprod. 23:415-422.

Gross, T.S., Patton, M., Armstrong, D.L., Simmons, L.G. 1991. Estrus detection and synchronization in African elephants (Loxodonta africana): vaginal cytology and serum endocrine profiles. Biol. Reprod. 44:60.

Gumen, A., Sartori, R., Costa, F.M.J., Wiltbank, M.C. 2002. A gnRH/LH surge without subsequent progesterone exposure can induce development of follicular cysts. J. Dairy Sci. 85:43-50. 
Hale, G.E., Berger, H.G. 2009. Hormonal changes and biomarkers in late reproductive age, menopausal transition, and menopause. Best Pract. Res. Clin. Obstet. Gynaecol. 23:723.

Hall-Martin, A.J. 1987. Role of musth in the reproductive strategy of the African elephant (Loxodonta africana). S. Af. J. Sci. 83:616-620.

Hanks, J., Short, R.V. 1972. The formation and function of the corpus luteum in the African elephant (Loxodonta africana). J. Reprod. Fertil. 29:79-89.

Harder, J.D., Jackson, L.M. 2003. Male pheromone stimulates ovarian follicular development and body growth in juvenile female opposums (Monodelphis domestica). Reprod Bio Endocrinol. 1:21-30.

Harmon, B.G., Munday, J.S., Crane, M.M. 2004. Diffuse cystic endometrial hyperplasia and metastatic endometrial adenocarcinoma in a Vietnamese pot-bellied pig (Sus scrofa). J. Vet. Diagn. Invest. 16:587-589.

Hatt, J.M., Clauss, M. 2006. Feeding Asian and African elephants (Elephas maximus and Loxodonta africana) in captivity. Int. Zoo Yearbk. 40:88-95.

Hawkes, K., O’Connell, J.F., Blurton Jones, N.G., Alvarez, H., Charnov, E.L. 1998. Grandmothering, menopause, and the evolution of human life histories. PNAS. 95:13361339.

Hawkes, K. 2004. The grandmother effect. Nature. 428:128-129.

Heistermann, M., Trohorsch, B., Hodges, J.K. 1997. Assessment of ovarian function in the African elephant (Loxodonta africana) by measurement of 5- $\alpha$-reduced progesterone metabolites in serum and urine. Zoo Biol. 16:273-284. 
Hermes, R., Olson, D., Göritz, F., Brown, J.L., Schmitt, D.L., Hagen, D., Peterson, J.S., Fritsch, G., Hildebrandt, T.B. 2000. Ultrasonography of the estrous cycle in female African elephants (Loxodonta africana). Zoo Biol. 19:369-382.

Hermes, R., Hildebrandt, T.B., Göritz, F. 2004. Reproductive problems directly attributable to long-term captivity-asymmetric reproductive aging. Anim. Reprod. Sci. 82-83:49-60.

Hermes, R., Göritz, F., Streich, W.J., Hildebrandt, T.B. 2007. Assisted reproduction in female rhinoceros and elephants: current status and future perspective. Reprod. Dom. Anim., Suppl. 42:33-44.

Hess, D.L., Schmidt, A.M., Schmidt, M.J. 1983. The reproductive cycle of the Asian elephant (Elephas maximus) in captivity. Biol. Reprod. 28:767-773.

Hildebrandt, T.B., Göritz, F. 1995. Sonographic evidence of leiomyomas in female elephants. Ver. Ber. Erkrg. Zootiere. 36:59-67.

Hildebrandt, T.B., Göritz, F., Quandt, S., Pratt, N.C., Lehnhardt, J., Montali, R.J., Pitra, C. 1996. Ultrasonography as a way to evaluate the reproductive tract in female Asian (Elephas maximus) and African (Loxodonta africana) elephants. J. Ultrasound Med. Suppl 15:Abstract 59.

Hildbrandt, T.B., Göritz, F., Pratt, N.C., Scmitt, D.L., Lehnhardt, J., Hermes, R., Quandt, S., Raath, J., West, G., Montail, R.J. 1997. Assessment of health and reproductive status in African (Loxodonta africana) and Asian (Elephas maximus) elephants by transrectal ultrasonography. Proceedings of the American Association of Zoo Veterinarians Annual Meeting, October 26-30, Houston, TX. p 207-212.

Hildebrandt, T.B., Göritz, F., Pratt, N.C., Brown, J.L., Montali, R.J., Schmitt, D.L., Fritsch, G., Hermes, R. 2000a. Ultrasonography of the urogenital tract in elephants (Loxodonta 
africana and Elephas maximus): An important tool for assessing female reproductive function. Zoo. Biol. 19:321-332.

Hildebrandt, T.B., Hermes, R., Pratt, N.C., Fritsch, G., Blottner, S., Schmitt, D.L., Ratanakorn, P., Brown, J.L., Rietschel, W., Göritz, F. 2000b. Ultrasonography of the urogenital tract in elephants (Loxodonta africana and Elephas maximus): An important tool for assessing male reproductive function. Zoo. Biol. 19:333-345.

Hildebrandt, T.B., Brown, J.L., Hermes, R., Göritz, F. 2003. Ultrasound for the analysis of reproductive function in wildlife. In: Wildt, D.E., Holt, W.V., Pickard, A.R., Roger, J.C. (eds). Reproduction and Integrated Conservation Science. London: Zoological Society of London. p 166-182.

Hildebrandt, T.B. 2006. Reproductive and Diagnostic Ultrasonography. In: Biology, Medicine, and Surgery of Elephants. Fowler, M.E., Mikota, S.K. (eds.), Blackwell Publishing pp 357-376.

Hildebrandt, T.B., Göritz, F., Hermes, R., Reid, C., Dehnhard, M., Brown, J.L. 2006. Aspects of the reproductive biology and breeding management of Asian (Elephas maximus) and African (Loxodonta africana) elephants. Int. Zoo Yearbk. 40:20-40.

Hodges, J.K., Heistermann, M., Beard, A., van Aarde, R.J. 1997. Concentrations of progesterone and the 5- $\alpha$-reduced progestins, 5- $\alpha$-pregnane-3, 20-dione and 3- $\alpha$-hydroxy5- $\alpha$-pregnan-20-one, in luteal tissue and circulating blood, and their relationship to luteal function in the African elephant (Loxodonta africana). Biol. Reprod. 56:640-646.

Hodges, J.K. 1998. Endocrinology of the ovarian cycle and pregnancy in the Asian (Elephas maximus) and African (Loxodonta africana) elephant. Anim. Reprod. Sci. 19:3-18.

Holden, C. 2008. Post poaching stress disorder. Science 321:1613 
Ireland, J.L.H., Sheetz, D., Jimenez-Krassel, F., Themmen, A.P.N., Ward, F., Lonergan, P., Smith, G.W., Perez, G.I., Evans, A.C.O., Ireland, J.J. 2008. Antral follicle count reliably predicts number of morphologically healthy oocytes and follicles in ovaries of young adult cattle. Bio. Reprod. 79:1219-1225

Jainudeen, M.R., Eisenberg, M.R., Tilakertane, N. 1971. Oestrous cycle of the Asiatic elephant (Elephas maximus) in captivity. J. Reprod. Fertil. 27:321-328.

Jainudeen, M.R., Katongole, C.B., Short, R.V. 1972. Plasma testosterone levels in relation to musth and sexual activity in the male Asiatic elephant (Elephas maximus). J. Reprod. Fertil. 29:99-103.

Jones, E.E. 1989. Hyperprolactinemia and female infertility. J. Reprod. Med. 34:117-126.

Jones, K.L., King, S.S., Griswold, K.E., Cazac, D., Cross, D.L. 2003. Domperidone can ameliorate deleterious reproductive effects and reduced weight gain associated with fescue toxicosis in heifers. J Anim Sci. 81:2568-2574.

Jones, R.C., Rowlands, I.W., Skinner, J.D. 1974. Spermatozoa in the genital ducts of the African elephant (Loxodonta africana). J. Reprod. Fertil. 41:189-192.

Jost, A. Problems of fetal endocrinology: the gonadal and hypophyseal hormones. 1953. Recent Prog Horm Res. 8:379-418.

Joshi, H.S., Watson, D.J., Labhsetwar, A.P. 1973. Ovarian secretion of oestradiol, oesterone, 20-dihydroprogesterone during the oestrous cycle of the Guinea pig. J. Reprod. Fertil. 35:177-181.

Josso, N., Picard, J.Y., Rey, R., Clemente, N. 2006. Testicular anti-Müllerian hormone: history, genetics, regulation and clinical application. Pediatr Endocrinol Rev. 3:347-358.

Kahl, M.P., Santiapillai, C. 2004. A glossary of elephant terms. Gajah 23:1-36. 
Kamberi, I.A., Mical, R.S., Porter, J.C. 1972. Effects of melatonin and serotonin on the release of FSH and prolactin. Endocrinology 88:1288-1293.

Kaneko, H., Kishi, H., Wantanabe, G., Taya, K., sasamoto, S., Hasegawa, Y. 1995. Changes in plasma concentrations of immunoreactive inhibin, estradiol and FSH associated with follicular waves during the estrous cycle of the cow. J. Reprod. Dev. 41:311-320.

Kapustin, N., Critser, J.K., Olson, D., Malven, P.V. 1996. Nonluteal estrous cycles of 3-week duration are initated by anovulatory luteinizing hormone peaks in African elephants (Loxodonta africana). Biol. Reprod. 55:1147-1154.

Karsch, F.J., Battaglia, D.F., Breen, K.M., Debus, N., Harris, T.G. 2002. Mechanisms for ovarian cycle disruptions by immune/inflammatory stress. Stress. 5:101-112.

Katz, L.S., McDonald, T.J. 1992. Sexual behavior of farm animals. Therio. 38:239-53.

Kauppila, A., Martikainen, H., Puistola, U., Reinila, M., Ronnberg, L. 1988. Hypoprolactinemia and ovarian function. Fertil Steril. 49:437-441.

Keele, M., Ediger, N.D-E., (eds). 1997-2002. AZA Elephant Master Plan. AZA publication number 1999 10285.zooe. Portland, OR: Oregon Zoo.

Keele, M., Lewis, K., Owens, T. 2007. North American Regional Studbook for Asian Elephants (Elephas maximus). Oregon Zoo, Portland.

Kelly, M.A., Rubinstein, M., Asa, S.L., Zhang, G., Saez, C., Bunzow, J.R., Allen, R.G., Hnasko, R., Ben-Jonathan, N., Grandy, N.K., Low, M.J. 1997. Pituitary lactotroph hyperplasia and chronic hyperprolactinemia in dopamine D2 receptor-deficient mice. Neuron 19:103-113.

Kesler, D.J., Garverick, H.A. 1982. Ovarian cysts in Dairy cattle: a review. J Anim Sci. 55:1147-59. 
Kennedy, P.C., Cullen, J.M., Edwards, J.F., Goldschmidt, M.H., Larsen, S., Munson, L., Nielson, S. 1998. In: Histologic Classification of Tumors of the Genital System of Domestic Animals, Second Series. Armed Forces Institute of Pathology, Washington, D.C. pp 34-35.

Kerr, M.A. 1978. Reproduction of elephants in the Mana Pools National Park, Rhodesia. Arnoldia Rhod. 29:1-11.

Kevenaar, M.E., Meerasahib, M.F., Kramer, P., van de Lang-Born, B.M., de Jong, F.H., Groome, N.P., et al. 2006. Serum anti-Müllerian hormone levels reflect the size of the primordial follicle pool in mice. Endocrinol. 147:3228-34.

Kharlip, J., Salvatori, R., Yenokyan, G., Wand, G.S. 2009. Recurrance of hyperprolactinemia following withdraw of long-term Cabergoline therapy. J. Clin. Endocrinol. Metab. 94:2428-2436.

Kinder, J.E., Roberson, M.S., Wilfe, M.W., Stampf, T.T. 1994. Management factors affecting puberty in the heifer. In: Fields, M.J., Sands, R. (eds). Factors Affecting Calf Crops. Boca Raton, FL: CRC Press, Inc. pp 69-89.

Klopper, A., Strong, J.A., Cook, L.R. 1957. Excretion of pregnanediol and adrenocortical activity. J Endocrinol. 15:180-189.

Knauf, S., Blad-Stahl, J., Lawrenz, A., Wehrend, A. 2009. Plasma preparation and storage for African elephants (Loxodonta africana). J. Zoo Wildl. Med. 40:71-75.

LaMarca, A., Stabile, G., Carducci Artensisio, A., Volpe, A. 2006. Serum anti-Müllerian hormone throughout the human menstrual cycle. Hum Reprod. 21:3103-3107.

La Torre, D., Falorni, A. 2007. Pharmacological causes of hyperprolactinemia. Ther. Clin. Risk Manage. 3:929-951. 
Lahav, M., Freud, A., Lindner, H.R. 1976. Abrogation by prostaglandin F2 $\alpha$ of LH stimulated cyclic AMP accumulation in isolated rat corpora lutea of pregnancy. Biochem. Ciophys. Red. Commun. 68:1294-1299.

Lamprecht, S.A., Lindner, H.R., Strauss, J.F. 1969. Induction of 20a-hydroxysteroid dehydrogenase in rat corpora lutea by pharmacological blockage of pituitary prolactin secretion. Biochim. Biophys. Acta., Lipids Lipid. Metab. 187:133-143.

Landolt, A.M., Osterwalder, V., Landolt, T.A. 1985. Bromocriptine-induced removal of endoplasmic membranes from prolactinoma cells. Experientia 41:640-642.

Langbauer, W.R. 2000. Elephant communication. Zoo Biol. 19:425-445.

Langbauer, W.R., Payne, K.B., Charif, R., Thomas, E.M. 1989. Responses of captive African elephants (Loxodonta africana) to playback of low-frequency calls. Can. J. Zool. 67:2604-2607.

Larsen, J.L., Bhana, A., Odell, W.D. 1990. Prolactin inhibition of pregnant mare’s serum stimulated follicle development in the rat ovary. Endocrinol Res. 16:449-459.

Laws, R.M. 1969. Aspects of reproduction in the African elephant (Loxodonta africana). J. Reprod. Fert., Suppl. 6:193-217.

Lawson, D.M., Haisenleder, D.J., Marshall, J.C. 1993. A comparison of the temporal effects of estradiol and diethylstilbestrol on pituitary content of DNA, prolactin mRNA and prolactin and on serum prolactin levels in ovariectomized Holtzmen rats. Life Sci 53:1267-1272.

Lebedeva, I.Y., Denisenko, V.U., Leebedeva, V.A., Kuzmina, T.I. 1998. Prolactin in follicular fluid and intracellular store calcium in follicular cells are related to morphological signs of ovarian follicle atresia in cows: work in progress. Therio. 49:509-519. 
Lehman, M.N., Karsch, F.J. 1993. Do gonadotropin-releasing hormone, tyrosine hydroxylase, and beta-endorphine-immunoreactive neurons contain estrogen receptors? A doublelabeled immunocytochemical study in the Suffolk ewe. Endocrinology 133:887-895.

Lehman, M.N., Ebling, S.J., Moenter, S.M., Karsch, F.J. 1993. Distribution of estrogen receptor-immunoreactive cells in the sheep brain. Endocrinology 133:876-886.

Lee, P.C. 1987. Allomothering among African elephants. Anim. Behav. 35:278-291.

Lee, M.M., Donahoe, P.K. 1993. Müllerian inhibiting substance: a gonadal hormone with multiple functions. Endocr. Rev. 14:152-164.

Lees, C.M., Wilcken, J. 2009. Sustaining the ark: the challenges faced by zoos in maintaining viable populations. Int. Zoo Yearbk. 43:6-18.

Leong, K.M., Burks, K., Rizkalla, C.E., Savage, A. 2005. Effects of reproduction and social context on vocal communication in captive female African elephants (Loxodonta africana). Zoo Biol. 24:331-347.

Li, C.H., Chung, D., Bewley, T.A., Cabrera, C.M. 1987. Elephant prolactin: isolation and characterization. Int. J. Peptide Protein Res. 29:472-477.

Li, C.H., Oosthuizen, M.M.J., Chung, D. 1989. Primary Structure of elephant pituitary prolactin. Int. J. Peptide Protein Res. 33:67-69.

Li, W.L., Liu, Y., Yu, Y.C., Huang, Y.M., Liang, S.D., Shi, Z.D. 2011. Prolactin plays a stimulatory role in ovarian follicular development and egg laying in chicken hens. Domest Anim Endocrinol. 41:57-66.

Lieberman, M.E., Maurer, R.A., Gorski, J. 1978. Estrogen control of prolactin synthesis in vitro. Proc. Natl. Acad. Sci. U. S. A. 75:5946-5949. 
Lindsay, W.K. 1994. Feeding ecology and population demography of African elephants (Loxodonta africana) in Amboseli, Kenya. Ph.D. thesis, University of Cambridge, Cambridge, UK.

Line, S.W., Clarke, A.S., Markowitz, H. 1987. Plasma cortisol of female Rhesus monkeys in response to acute restraint. Lab. Prim. News. 26:1-4.

Liptrap, R.M. 1970. Effect of corticotrophin and corticosteroids on oestrus, ovulation and oestrogen excretion in the sow. J. Endocrinol. 47:197-205.

Liptrap, R.M. 1993. Stress and reproduction in domestic animals. Ann. N. Y. Acad. Sci. 697:275-284.

Lueders, I., Niemuller, C., Gray, C., Rich, P., Hildebrandt, T. 2010. Luteogenesis during the estrous cycle in Asian elephants (Elephas maximus). Reprod. 140:777-786.

Macleod, R.M., Lehmeyer, J.E. 1974. Studies on the mechanism of the dopamine-meidated inhibition of prolactin secretion. Endocrinol. 94:1077-1085.

Mah, P.M., Webster, J. 2002. Hyperprolactinemia: etiology, diagnosis, and management. Sem. Reprod. Med. 20:365-373.

Marsh, E.E., Bulun, S.E. 2006. Steroid hormones and leiomyomas. Obstet. Gynecol. Clin. North Am. 33:59-67.

Martel, C., Labrie, C., Couët, J., Dupont, E., Trudel, C., Luu-The, V., Takahashi, M., Pelletier, G., Labrie, F. 1990. Effects of human chorionic gonadotropin (hCG) and prolactin (PRL) on 3 beta-hydroxy-5-ene-steroid dehydrogenase/delta 5-delta 4 isomerase (3beta-HSD) expression and activity in the rat ovary. Mol Cell Endocrinol. 72:R7-13. 
Martikainen, H., Rönnberg, L., Puistola, U., Tapanainen, J., Orava, M., Kauppila, A. 1989. Prolactin suppression by bromocriptine stimulates aromatization of testosterone and estradiol in women. Fertil Steril. 52:51-54.

Martin, M.S., Glaeser, S.S., Finnegan, M., Hunt, K., Brown, J.L. 2011. Investigation of animal variability, synchronicity, and impact of life events on reproductive cycle dynamics through longitudinal serum progestagen monitoring of female Asian elephants (Elephas maximus) at the Oregon Zoo. Theriogenology In Review.

Matsuyama, S., Shiota, K., Takahashi, M. 1990. Possible role of transforming growth factor-beta as a mediator of luteotropic action of prolactin in rat luteal cell cultures. Endocrinology 127:1561-1567.

Mazuri. 2007. Mazuri elephant supplement. Retrieved 10 April 2008, from http://www.mazuri.com/PDF/5648-5M40.pdf.

McComb, K., Moss, C., Durant, S.M., Baker, L., Sayialel, S. 2001. Matriarchs as repositories of social knowledge in African elephants (Loxodonta africana). Science 292:491-494.

McCullagh, K.G. 1969. The growth and nutrition of the African elephant (Loxodonta africana). E. Af. Wildl. J. 7:91-97.

McCullagh, K.G. 1973. Are African elephants deficient in essential fatty acids? Nature 242:267-268.

McCracken, J.A., Carlson, J.C., Glew, M.E., Goding, J.R., Baird, D.T. 1972. Prostaglandin F2 $\alpha$ indentified as a luteolytic hormone in sheep. Nature New Biol. 238:129-34.

McCracken, J.A., Custer, E.E., Lamsa, J.C. 1999. Luteolysis: a neuroendocrine-mediated event. Physiol. Rev. 79:263-323. 
McFarlane, J.R., Carbera, C.M., Oosthuizen, M.M.J., Papkoff, H. 1990. Elephant pituitary gonadotropins. Gen. Comp. Endocrinol. 79:193-200.

McNeilly, A.S., Martin, R.D., Hodges, J.K., Smuts, G.L. 1983. Blood concentrations of gonadotropins, prolactin and gonadal steroids in males and in non-pregnant and pregnant female African elephants (Loxodonta africana). J. Reprod. Fert. 67:113-120.

McNeilly, A.S. 2001. Lactational control of reproduction. Reprod. Fertil. Dev. 13:583-590.

McTavish, K.J., Jimenez, M., Walters, K.A., Spaliviero, J., Groome, N.P., Themmen, A.P., Visser, J.A., Handelsman, D.J., Allan, C.M. 2007. Rising follicle-stimulating hormone levels in age accelerated female reproductive failure. Endocrinol. 148:4432-4439.

Meites, J., Lu, K.H., Wuttke, W., Welsch, C.W., Nagasawa, H., Quadri, S.K. 1972. Recent studies on functions and control of prolactin secretion in rats. Recent Prog. Horm. Res. 28:471-526.

Melis, G.B., Gambacciani, M., Paoletti, A.M., Mais, V., Sqhedoni, D., Fioretti, P. 1989. Reduction in the size of prolactin-producing pituitary tumor after Cabergoline administration. Fertil Steril 52:412-415.

Meyer, H.H.D., Jewgenow, K., Hodges, J.K. 1997. Binding activity of 5- $\alpha$-reduced gestagens to the progestin receptor from African elephants (Loxodonta africana). Gen. Comp. Endocrinol. 105:164-167.

Meyer, J.M., Ball, R., Brown, J.L. 2004. Why are so many elephants in captivity not cycling? Evidence of association between ovarian inactivity and hyperprolactinemia. JEMA. 15:9-15. 
Meyer, J.M., Goodwin, T.E., Schulte, D.A. 2008. Intrasexual chemical communication and social responses of captive female African elephants (Loxodonta africana). Anim. Behav. 76:163-174.

Miller, M., Chen, T.C., Holick, M.F., Mikta, S., Dierenfeld, E. 2009. Serum concentrations of calcium, phosphorus, and 25-hydroxyvitamin D in captive African elephants (Loxodonta africana). J. Zoo Wildl. Med. 40:302-305.

Miller-Schroeder, P., Paterson, J.D. 1989. Environmental influences on reproduction and maternal behavior in captive gorillas: results of a survey. In: Psychological Well-being of Primates. Edited by Segal, E. Noyes Publication, Park Ridge. pp 389-415.

Millspaugh, J.J., Burke, T., Van Dyk, G., Slotow, R., Washburn, B.E., Woods, R.J. 2007. Stress response of working African elephants (Loxodonta africana) to transportation and safari adventures. JWM. 71:1257-1260.

Moberg, G.P. 1985. Influence of stress on reproduction: measure of well being. In: Animal Stress. Edited by Moberg, G.P. American Physiological Society, Bethesda. pp 27-50. Moberg, G.P. 1987. Influence of the adrenal axis upon the gonads. In: Oxford Reviews of Reproductive Biology, Volume 9. Edited by Clarke, J.R. Clarendon Press, Oxford. pp 456-496.

Moberg, G.P. 1990. How behavioral stress disrupts the endocrine control of reproduction in domestic animals. J. Dairy Sci. 74:304-311.

Moeljono, M.P.E., Thatcher, W.W., Bazer, F.W., Frank, M., Owens, L.J., Wilcox, C.J. 1977. A study of prostaglandin F2 $\alpha$ as the luteolysin in swin: II. Characterization and comparison of prostaglandin F, estrogens and progestin concentration in utero-ovarian vein plasma of non-pregnant and pregnant gilts. Prostaglandins 14:543-555. 
Molitch ME. 2009. Prolactin in human reproduction. In: Yen and Jaffe’s Reproductive Endocrinology. Strauss, III, J.F., Barbieri, R.L (eds). Elsevier Health Science, New York. P. 93-123.

Montali, R.J., Hildebrandt, T., Göritz, F., Hermes, R., Ippen, R., Ramsey, E. 1997. Ultrasonography and pathology of genital tract leiomyomas in captive Asian elephants (Elephas maximus): Implications for reproductive soundness. Verh. Ber. Erkrg. Zootiere. 38:253-258.

Moore, K.E., Demarest, K.T. 1982. Effects of prolactin on central dopaminergic neurons. Prog. Neurophychopharmacol. Biol. Psychiatry. 6:645-650.

Moreira, N., Brown, J.L., Moraes, W., Swanson, W.F., Monteiro-Filho, E.L.A. 2007. Effect of housing and environmental enrichment on adrenocortical activity, behavior, and reproductive cyclicity in the female tigrina (Leopardus tigrinus) and Margay (Leopardus wiedii). Zoo Biol. 26:441-460.

Morishige, W.K., Rothchild, I. 1974. Temporal aspects of regulation of corpus luteum function by luteinizing hormone, prolactin, and placental luteotropin during the first half of pregnancy in the rat. Endocrinology 95:260-274.

Moss, C.J., Poole, J.H. 1983. Relationships and social structure of African elephants (Loxodonta africana). In: Primate Social Relationships: An Integrated Approach. Hinde, R.A. (Ed). Sinauer Associates, Inc., Sunderland. pp 315-324.

Moss, C.J. 1983. Oestrous behavior and female choice in the African elephant (Loxodonta africana). Behaviour 100:167-196.

Moss, C.J. 2001. The demography of an African elephant (Loxodonta africana) population in Amboseli, Kenya. J. Zool. 255:145-156. 
Mossman, H.W. 1987. Vertebrate Fetal Membranes. Rutgers University Press, New Brunswick. pp 263-266.

Mukherjee, A., Murray, R.D., Columb, B., Gleesib, H.K., Shalat, S.M. 2003. Acquired prolactin deficiency indicates severe hypopituitarism in patients with disease of the hypothalamic-pituitary axis. Clin Endocrinol. 59:743-748.

Napier, J.E., Murray, S., Garner, M.M., Viner, T., Murphy, H. 2005. Uterine leiomyomas in thre captive Eastern bongo (Tragelaphus eurycerus isaaci). J. Zoo Wildl. Med. 36:709711.

Neill, J.D., Nagy, G.M. 1994. Prolactin secretion and its control. In: The Physiology of Reproduction (Knobil, E., Neill, J.D. (Eds.) pp. 1833-1860. Raven Press, New York.

Nicoll, C.S. 1974. Physiological action of prolactin. In: Knobil, E., Sawyer, W.H. (Eds.) Handbook of Physiology. Section 7: Endocrinology. American Physiological Society, Washington, DC, pp 253-292.

Nicosia, S., Olivia, D., Giannattasio, G., Spada, A. 1983. The role of vasoactive intestinal polypeptide (VIP) as a hypothalamic neurohormone. J. Endocrinol. Invest. 6:235-240.

Nissim, M., Ambrosi, B., Bernasconi, V., Giannattasio, G., Giovanelli, M.A., Bassetti, M., Vaccari, U., Moriondo, P., Spada, A., Travaglini, P., Faglia, G. 1982. Bromocriptine treatment of macroprolactinomas: studies on the time course of tumor shrinkage and morphology. J Endocrinol Invest 5:409-415.

Niswender, G.D., Reimers, T.J., Diekman, M.A., Nett, T.M. 1976. Blood flow: a mediator of ovarian function. Biol. Reprod. 14:64-81.

Norman, R.J., Clark, A.M. 1998. Obesity and reproductive disorders: A review. Reprod. Fertil. Dev. 10:55-63. 
Oakley, A.E., Clifton, D.K., Steiner, R.A. 2009. Kisspeptin signaling in the brain. Endoc. Rev. 30:713-743.

Oerke, A.K., Heistermann, M., Hodges, J.K. 1999. Elephant service: non-invasive methods to monitor the reproductive status in the Asian (Elephas maximus) and African (Loxodonta africana) elephant. EEP Research Group Letter. 6:8.

Oliver, J.W. 1997. Physiological manifestations of endophyte toxicosis in ruminant and laboratory species. In: Neothyphdium/Grass Interactions, Bacon, C.W., Hill, N.S. (Eds.) Plenum Press, New York. pp 311-346.

Olson, D.J., Wiese, R.J. 2000. State of the North American African elephant population and projections for the future. Zoo Biol. 19:311-320.

Olson, D.J. 2008. North American Region Studbook for the African elephant (Loxodonta africana). Indianapolis Zoological Society, Indianapolis.

Ortolani, A., Leong, K., Graham, L., Savage, A. 2005. Behavioral indices of estrus in a group of captive African elephants (Loxodonta africana). Zoo Biol. 24:311-32.

Owens, M.J., Owens, D. 2009. Early age reproduction in female Savanna elephant (Loxodonta africana) after severe poaching. Af. J. Ecol. 47:214-222.

Oxender, W.D., Noden, P.A., Hafs, H.D. 1977. Estrus, ovulation, and serum progesterone, estradiol, and LH concentrations in mares after an increased photoperiod during winter. Am J Vet Res. 38:203-207.

Packard, J.M., Seal, U.S., Mech, L.D., Plotka, E.D. 1985. Causes of reproductive failure in two family groups of wolves. Zeits. Tierpsch. 68:24-40.

Packer, C., Tater, M., Collins, A. 1998. Reproductive cessation in female mammals. Nature. 392:807-811. 
Pate, J.L., Townson, D.H. 1994. Novel local regulators in luteal regression. J. Anim. Sci. 72(Suppl. 3):31-42.

Patton, M.L., Swaisgood, R.R., Czekala, N.M., White, A.M., Fetter, G.A., Montagne, J.P., Rieches, R.G., Lance, V.A. 1999. Reproductive cycle length and pregnancy in the Southern White rhinoceros (Ceratotherium simum simum) as determined by fecal pregnane analysis and observations of mating behavior. Zoo Biol. 18:111-127.

Payne, K.B., Langbauer Jr., W.R., Thomas, E.M. 1986. Infrasonic calls of the Asian elephant (Elephas maximus). Behav. Ecol. Soc. Biol. 18:297-301.

Perry, J.S. 1953. The reproduction of the African elephant (Loxodonta africana). Philos. Trans. R. Soc., B. 237:93-149.

Perry, J.S. 1974. Implantation, foetal membranes and early placentation of the African elephant (Loxodonta africana). Philos. Trans. R. Soc. Lond. Ser. B. 269:109-135.

Phifer, R.F., Midgley, A.R., Spicer, S.S. 1973. Immunohistologic and histologic evidence that follicle-stimulating hormone and luteinizing hormone are present in the same cell type in the human pars distalis. J. Clin. Endocrinol. Metab. 36:125-141.

Pielecka-Fortuna, J., Chu, Z., Moenter, SM. 2008. Kisspeptin acts directly and indirectly to increase gonadotropin-releasing hormone neuron activity and its effects are modulated by estradiol. Endocrinol. 149:1979-1986.

Piltonen, T., Morin-Papunen, L., Koinvunen, R., Perheentupa, A., Ruokonen, A., Tapanainen, J.S. 2005. Serum anti-Müllerian hormone levels remain high until late reproductive age and decrease during metaformin therapy in patients with polycystic ovarian syndrome. Hum. Reprod. 20:1820-1826. 
Plotka, E.D., Seal, U.S., Zarembka, F.R., Simmons, L.G., Teare, A., Phillips, L.G., Hinshaw, K.C., Wood, D.G. 1988. Ovarian function in the elephant: luteinizing hormone and progesterone cycles in African (Loxodonta africana) and Asian (Elephas maximus) elephants. Biol. Reprod. 38:309-314.

Pompolo, S., Pereora, A., Estrada, K.M., Clarke, I.J. 2006. Colocalization of kisspeptin and gonadotropin-releasing hormone in the ovine brain. Endocrinol. 147:804-810.

Pontirolli, A.E., Falsetti, L., Bottazzo, G. 1987. Clinical, endocrine, roentgengraphic and immune characterization of hyperprolactinemic women. Int. J. Fertil. 32:81-85.

Poole, J.H. 1987. Rutting behavior in African elephants: the phenomenon of musth. Behaviour 102:283-316.

Poole, J.H. 1989. Announcing intent: the aggressive state of musth in African elephants. Anim. Behav. 37:140-152.

Poole, J.H., Kasman, L.H., Ramsay, E.C., Lasley, B.L. 1984. Musth and urinary testosterone concentrations in African elephants (Loxodonta africana). J. Reprod. Fertil. 70:255-260.

Poole, J.H., Moss, C.J. 1981. Musth in the African elephant (Loxodonta africana). Nature 297:830-831.

Poole, J.H., Moss, C.J. 1989. Elephant mate searching: group dynamics and vocal and olfactory communication. Symp. Zool. Soc. Lon. 61:111-125.

Prado-Oviedo, N. 2011. Role of estrogens in hyperprolactinemia: Induced acyclicity in African female elephants (Loxodonta africana). MS. Thesis, American University: Washington, DC. 
Proctor, C.M., Freeman, E.W., Brown, J.L. 2010a. Results of a second survey to assess the reproductive status of female Asian (Elephas maximus) and African (Loxodonta africana) elephants in North America. Zoo Biol. 29:127-139.

Proctor, C.M., Freeman, E.W., Brown, J.L. 2010b. Influence of dominance status on adrenal activity and ovarian cyclicity status in captive African elephants (Loxodonta africana). Zoo Biol. 29:168-178.

Pryce, C.R., Schwarzenberger, F., Dobeli, M., Eller, K. 1995. Comparative study of oestrogen excretion in female New World monkeys: an overview of non-invasive ovarian monitoring and a new application in evolutionary biology. Folia Primatol. 64:107-123.

Radi, Z.A. 2005. Endometritis and cystic endometrial hyperplasia in a goat. J. Vet. Diagn. Invest. 17:393-395.

Rasmussen, L.E.L. 1998. Chemical communication: An integral part of functional Asian (Elephas maximus) elephant society. Ecoscience. 5:410-426.

Rasmussen, L.E.L. 2001. Source and cyclic release pattern of (Z)-7-Dodecenyl Acetate, the preovulatory pheromone of the female Asian elephant (Elephas maximus). Chem. Senses. 26:611-623.

Rasmussen, L.E.L., Buss, I.O., Hess, D.L., Schmidt, M.J. 1984. Testosterone and dihydrotestosterone concentrations in elephant serum and temporal gland secretions. Biol. Reprod. 30:352-363.

Rasmussen, L.E.L., Hall-Martin, A.J., Hess, D.L. 1996. Chemical profiles of male African elephants (Loxodonta africana): physiological and ecological implication. J. Mammal. 77:422-439. 
Rasmussen, L.E.L., Lee, T.D., Zhang, A., Roelofs, W.L., Daves Jr., G.D. 1997. Purification, identification, concentration and bioactivity of (Z)-7-Dodecen-1-yl Acetate: sex pheromone of the female Asian elephant (Elephas maximus). Chem. Senses 22:417-437.

Rasmussen, L.E.L., Schulte, B.A. 1998. Chemical signals in the reproduction of Asian (Elephas maximus) and African (Loxodonta africana) elephants. Anim. Reprod. Sci. 53:19-34.

Rasmussen, L.E.L., Greenwood, D.R. 2003. Frontalin: a chemical message of musth in Asian elephants (Elephas maximus). Chem Senses. 28:433-446.

Rasmussen, L.E.L., Krishnamurthy, V., Sukumar, R. 2005. Behavioural and chemical confirmation of the preovulatory hormone, (Z)-7-Dodecenyl Acetate, in wild Asian elephants (Elephas maximus): its relationship to musth. Behaviour 142:351-396.

Redmond, L.M., Cross, D.L., Strickland, J.R., Kennedy, S.W. 1992. Efficacy of domperidone and sulpiride as treatments for equine fescue toxicosis in gravid mares grazing endophyte-infected tall fescue. J Anim Sci 70 (Suppl 1):21.

Rees, P. 2009. The size of elephant groups in zoos: implication for elephant welfare. J. Appl. Anim. Welfare Sci. 12:44-60.

Reinhardt, V., Cowley, D., Scheffler, J., Vertein, R., Wegner, F. 1990. Cortisol response of female Rhesus monkeys to venapuncture in homecage verses venapuncture in restraint apparatus. J. Med. Primat. 19:601-606.

Rengachary, S.S., Tomita, T., Jefferies, B.F., Wantanabe, I. 1982. Structural changes in human pituitary tumor with bromocriptine therapy. Neurosurgery 10:242-251.

Resko, J.A., Koering, M.J., Goy, R.W., Phoeniz, C.H. 1975. Provulatory progestins: observations on their source in Rhesus monkeys. J. Clin. Endocrinol. Metab. 41:120125. 
Rey, R., Josso, N. 1996. Regulation of testicular anti-müllerian hormone secretion. Eur J Endocrinol. 135:144-152.

Rey, R.A., Belville, C., Nihoul-Fékété, C., Michel-Calemard, L., Forest, M.G., Lahlou, N., et al. 1999. Evaluation of gonadal function in 107 intersex patients by means of serum antiMüllerian hormone measurement. J. Clin. Endocrinol. Metab. 84:627-631.

Richards, J.S. 1980. Maturation of ovarian follicles: action and interactions of pituitary and ovarian hormones of follicular cell development. Recent Prog. Horm. Res. 32:477-527.

Richardson, S.J., Senikas, V., Nelson, J.F. 1987. Follicular depletion during the menopausal transition: evidence for accelerated loss and ultimate exhaustion. J. Clin. Endocrinol. Metab. 65:1231-1237.

Rillema, J.A. 1994. Development of the mammary gland and lactation. Trends Endocrinol. Metab 5:149-154.

Rillema, J.A. 1998. Actions of prolactin. In: Encyclopedia of Reproduction. Knobil, E., Neill, J. (Eds.) Vol. 4. Academia Press, London, pp 39-43.

Ringstrom, S.J., Schwartz, N.B. 1987. Differential effect of glucocorticoids on synthesis and secretion of luteinizing hormone (LH) and follicle stimulating hormone (FSH). J. Steroid Biochem. 27:625-630.

Roberts, C.G., Ladenson, P.W. 2004. Hypothyroidism. Lancet 363:793-803.

Roberts, M.S. 1989. A Survey and Analysis of Management Practice in the North American Red Panda SSP. In: Red Panda Biology. Edited by Glatston, A.R. SPB Academic Publishing, Hague. pp 129-151.

Roberts, S.J. 1971. Veterinary Obstetrics and Genital Diseases (2nd Ed.). Edward Brothers, Inc., Ann Arbor, MI. 
Roche, J.F. 2006. The effect of nutritional management of the dairy cow on reproductive efficiency. Anim. Reprod. Sci. 96:282-296.

Rock, J., Bartlett, M.K. 1937. Biopsy studies of the human endometrium: criteria of dating and information about amenorrhea, menorrhagia, and time of ovulation. J. Am. Med. Assoc. 108:2002-2028.

Rodgers, D.H., Elders, W.H. 1977. Movement of elephants in Luangua Valley, Zambia. J. Wildl. Manage. 41:56-62.

Roehrs, J.M., Brockway, C.R., Ross, D.V., Tiechard, T.A., Ullrey, D.E. 1989. Digestibility of timothy hay by African elephants (Loxodonta africana). Zoo Biol. 8:331-337.

Rolland, R., Corbey, R.S. 1977. Hyperprolactinemia and hypogonadism in the human female. Eur. J. Obstet. Gynecol. Reprod. Biol. 7:337-348.

Rota, A., Ballarin, C., Vigier, B., Cozzi, B., Rey, R. 2002. Age dependent changes in plasma anti-müllerian hormone concentrations in the bovine male, female, and freemartin from birth to puberty: relationship between testosterone production and influence on sex differentiation. Gen Comp Endocrinol. 129:39-44.

Roth, T.L. 2006. A review of the reproductive physiology of rhinoceros species in captivity. Intern. Zoo Yearbk. 40:130-143.

Roudebush, W.E., Wetzel, D.L., Breuel, K.F., Reynolds, J.E. 2009. Validation of an antiMüllerian hormone (AMH) ELISA for use in an endangered marine mammal, the West Indian Manatee (Trichechus manatus). Bio Reprod. 81:214.

Rüedi, D. 1995. Elefanten. In: Krankheiten der Zoound Wildtiere. Göltenboth, R., Klös, H.G. (Eds). Blackwell Wissenschafts-Verlag, Berlin, Germany. pp 156-189. 
Sadleir, R.M.F.S. 1969. The Ecology of Reproduction in Wild and Domestic Mammals. Methuan, London.

Salzert, W. 1976. Elefanten. In: Zootierkrankheiten. Klös, H.G., Laming, E.M. (eds). Verlag Paul Peray, Berlin, Germany. pp 133-149.

Sar, M., Meites, J. 1968. Effects of progesterone, testosterone, and cortisol on hypothalamic prolactin-inhibiting factor and pituitary content. Proc. Soc. Exp. Biol. Med. 127:426429.

Saragusty, J., Hermes, R., Göritz, F., Schmitt, D.L., Hildebrandt, T.B. 2009. Skewed birth sex ratio and premature mortality in elephants. Anim. Reprod. Sci. 115:247-254.

Schmidt, M.J. 1989. Zinc deficiency, presumptive secondary immune deficiency and hyperkeratosis in an Asian elephant (Elephas maximus): a case report. Proc. Amer. Assoc. Zoo Vet. 1989:23-31.

Schmitt, D.L., Hildebrandt, T.B. 1998. Manual collection and characterization of semen from Asian elephants (Elephas maximus). Anim Reprod Sci. 53:309-314.

Schmitt, D. 2006. Reproductive System. In: Biology, Medicine, and Surgery of Elephants. Fowler, M.E., Mikota, S.K. (Eds.), Blackwell Publishing. pp 347-356.

Schneyer, A.L., Fujiwara, T., Fox, J., Welt, C.K., Adams, J., Messerlian, G.M., Taylor, A.E. 2000. Dynamic changes in the intrafollicular inhibin/activin/follistatin axis during human follicular development: relationship to circulating hormone concentrations. J. Clin. Endocrinol. Metab. 85:3319-3330.

Schulte, B.A., Rasmussen, L.E.L. 1999. Signal-receiver interplay in the communication of male condition by Asian elephants (Elephas maximus). Anim. Behav. 57:1265-1274. 
Schulte, B.A., Feldman, E., Lambert, R., Oliver, R., Hess, D.L. 2000. Temporary ovarian inactivity in elephants: relationship to status and time outside. Physiol. Behav. 71:123131.

Schwarzenberger, F., Strauss, G., Hoppen, H.O., Schaftenaar, W., Dieleman, S.J., Zenker, W., Pagan, O. 1997. Evaluation of progesterone and 20-oxo-progestagens in the plasma of Asian (Elephas maximus) and African (Loxodonta africana) elephants. Zoo Biol. 16:403-413.

Senger, P.L. 2003. Pathways to Pregnancy and Parturition. Current Conceptions, Pullman.

Sharp III, D.C., Ginther, O.J. 1975. Stimulation of follicular activity and estrous behavior in anestrous mares with light and temperature. J. Anim. Sci. 41:1368-1372.

Shelton, M. 1960. Influence of the presence of a male goat on the initiation of Angora does. J Anim Sci. 19:368-375.

Shively, C.A. 2000. Effects of Social Stress on Reproduction. In: The Encyclopedia of Stress, Volume 3. Fink, G (Ed). Academic Press, New York. pp 360-366.

Short, R.V. 1966. Oestrous behaviour, ovulation and the formation of corpus luteum in the African elephant. Afr. J. Ecol. 4:56-68.

Sikes, S.K. 1971. The Natural History of the African Elephant (Loxodonta africana). American Elsevier Publishing, New York.

Silverman, A.J., Antunes, J.L., Ferin, M., Zimmerman, E.A. 1977. The distribution of luteinizing hormone-releasing hormone (LHRH) in the hypothalamus of the rhesus monkey. Light microscopic studies using immunoperoxidase technique. Endocrinol. 101:134-142. 
Slade-Cain, B.E., Rasmussen, L.E.L., Schulte, B.A. 2008. Estrous state influence on investigative, aggressive, and tail flicking behavior in captive female Asian elephants (Elephas maximus). Zoo Biol. 27:167-180.

Slaide, B.E., Schulte, B.A., Rasmussen, L.E.L. 2003. Oestrous state dynamics in chemical communication by captive female Asian elephants (Elephas maximus). Anim. Behav. 65:813-819.

Smith, J.G., Hanks, J., Short, R.V. 1969. Biochemical observations on the corpora lutea of the African elephant (Loxodonta africana). J. Reprod. Fertil. 20:111-117.

Smith, J.T., Popa, S.M., Clifton, D.K., Hoffman, G.E., Steiner, R.A. 2006. Kiss-1 neurons in the forebrain as central processors for generating the preovulatory luteinizing hormone surge. J. Neurosci. 26:6687-6694.

Smith, M.F., McIntush, E.W., Ricke, W.A., Kojima, F.N., Smith, G.W. 1999. Regulation of ovarian extracellular matrix remodeling by metalloproteases and their tissue inhibitors: effects on follicular development, ovulation, and luteal function. J Reprod Fertil Suppl. 54, 367-381.

Smith, N.S., Buss, I.O. 1975. Formation, function, and persistence of the copora lutea of the African elephant (Loxodonta africana). J Mammol. 56:30-43.

Smith, R.L., Read, B. 1992. Management parameters affecting the reproductive potential of captive female Black rhinoceros (Diceros bicornia). Zoo Biol. 11:375-383.

Smith, T.E., Faulkes, C.G., Abbott, D.H. 1997. Combined olfactory contact with the parent colony and direct contact with nonbreeding animals does not maintain suppression of ovulation in female Naked mole-rats (Heterocephalus glaber). Horm. Behav. 31:277288. 
Smuts, G.L. 1975. Reproduction and population characteristics of elephants in the Kruger National Park. J. S. Af. Wildl. Manage. Assoc. 5:1-10.

Snyder, D.A., Turner, D.D., Miller, K.F., Garcia, M.C., Ginther, O.J. 1979. Foolicular and gonadotrophic changes during transition from ovulatory to anovulatory seasons. J. Reprod. Fertil., Suppl. 27:95-101.

Sowers, M.F., Eyvazzadeh, A.D., McConnell, D., Yosef, M., Jannausch, M.L., Zhang, D., Harlow, S., Randolf, J.F. 2008. Anti-Müllerian hormone and Inhibin B in the definition of aging and the menopause transition. J. Clin. Endocrinol. Metab. 93:3478-3483.

Strickland, J.R., Cross, D.L., Birrenkott, G.P., Grimes, L.W. 1994. Effects of ergovaline, loline, and dopamine antagonists on rat pituitary cell prolactin release in vitro. Am J Vet Res 55:716-721.

Sukumar, R. 1994. Elephant Days and Nights: Ten Years with the Indian Elephant. Oxford University Press, New Delhi.

Sukumar, R. 2003. The Living Elephants. Oxford University Press. New York, USA.

Takreem, A., Danish, N., Razaq, S. 2009. Incidence of endometrial hyperplasia in 100 cases presenting with polymenorrhagia/menorrhagia in perimenopausal women. J. Ayub. Med. Coll. Abbottabad. 21:60-63.

Tashjian, A.H., Barowsky, N.J., Jensen, D.K. 1971. Thyrotropin-releasing hormone: direct evidence for stimulation of prolactin production by pituitary cells in culture. Biochem. Biophys. Res. Commun. 43:516-523.

Taya, K. 2007. Secretion of gonadal inhibin and steroid hormones in the elephant, EU-Asia Link Project Symposium: “Managing the Health and Reproduction of Elephant 
Populations in Asia.” Faculty of Veterinary Medicine, Kasetsart University, Bangkok, Thailand. pp 106-113.

Teixeira, J., Maheswaran, S., Donahoe, P.K. 2001. Müllerian inhibiting substance: an instructive developmental hormone with diagnostic and possible therapeutic applications. Endocr Rev. 22:657-674.

Thatcher, W.W., Chenault, J.R. 1976. Reproductive physiological responses of catte to exogenous prostaglandin F2 $\alpha$. J. Dairy Sci. 59:1366-1375.

Thitaram, C., Brown, J.L., Pongsopawijit, P., Chansitthiwet, S., Wongkalasin, W., Daram, P., Roongsri, R., Kalmapijit, A., Mahasawangkul, S., Rojansthien, S., Colenbrander, B., van der Weijden, G.C., van Eerdenburg, F.J.C.M. 2008. Seasonal effects on the endocrine pattern of semi-captive female Asian elephant (Elephas maximus): timing of the anovulatory luteinizing hormone surge determines the length of the estrous cycle. Theriogenology 69:237-244.

Thitaram, C., Chansitthiwet, S., Pongsopawijit, P., Brown, J.L., Wongkalasin, W., Daram, P., Roongsri, R., Kalmapijit, A., Mahasawangkul, S., Rojansthien, S., Colenbrander, B., van der Weijden, G.C., van Eerdenburg, F.J.C.M. 2008. Use of genital inspection and female urine test to detect oestrus in captive Asian elephants (Elephas maximus). Anim. Reprod. Sci. 115:267-278.

Thomas, B., Holland, J.D., Minot, E.O. 2008. Elephant (Loxodonta africana) home ranges in Sabi Sand Reserve and Kruger National Park: a five-year satellite tracking survey. Plos One 3:1-8.

Tilbrook, A.J., Turner, A.I., Clarke, I.J. 2000. Effects of stress on reproduction in non-rodent mammals: the role of glucocorticoids and sex differences. Rev. Reprod. 5:105-113. 
Tindall, G.T., Kovacs, K., Horbath, E., Thorner, M.O. 1982. Human prolactin-producing adenomas and bromocriptine: a histological, immunocytochemical, ultrastructural, morphometric study. J. Clinical. Endocrinol. Metab. 55:1178-1183.

Toledano, Y., Lubetsky, A., Shimon, I. 2007. Acquired prolactin deficiency in patients with disorders of the hypothalamic-pituitary axis. J. Endocrinol. Invest. 30:268-273.

Tsai-Morris, C.H., Ghosh, M., Hirshfield, A.N., Wise, P.M., Brodie, A.M. 1983. Inhibition of ovarian aromatase by prolactin in vivo. Biol. Reprod. 29:342-346.

Tüttelmann, F., Dykstra, N., Themmen, A.P.N., Visser, J.A., Nieschlag, E., Simoni, M. 2009. Anti-müllerian hormone in men with normal and reduced sperm concentration and men with maldescended testes. Fertil Steril. 91:1812-1819.

Udoff, L.C., Adashi, E.Y. 1998. Menopause. In: Encyclopedia of Reproduction. Knobil, E., Neill, J.D. (Eds.), Academic Press. pp 183-188.

Vale, W., Hsueh, A.J., Rivier, C., et al. 1990. The Inhibin/Activin Family of Growth Factors. In: Sporn, M.A., Roberts, A.B. (Eds). Peptide Growth Factors and Their Receptors, Handbook of Experimental Pharmacology. Heidelberg, Springer-Verlag, pp 211-248.

Vallar, L., Meldolesi, J. 1989. Mechanisms of signal transduction at the dopamine D2 receptor. Trends Pharmacol. Sci. 10:74-77.

Van Aken, M.O., Lamberts, S.W. 2005. Diagnosis and treatment of hypopituitarism: an update. Pituitary 8:183-191.

Van Rooij, I.A.J., Broekman, F.L.M., te Velde, E., Fauser, B., Bancsi, L., de Jong, F., Themmen, A. 2002. Serum anti-Müllerian hormone levels: a novel measure of ovarian reserve. Human Reprod. 17:3065-3071. 
van Rooij, I.A., Broekmans, F.J., Scheffer, G.J., Looman, C.W., Habbema, J.D., de Jong, F.H., et al. 2005. Serum anti-Müllerian hormone levels best reflect the reproductive decline with age in normal women with proven fertility: a longitudinal study. Fertil. Steril. 4:979-87.

Veasey, J. 2006. Concepts in the care and welfare of captive elephants. Intern. Zoo Yearbk. 40:63-79.

Visser, J.A., de Jong, F.H., Laven, J.S., Themmen, A.P. 2006. Anti-Müllerian hormone: a new marker for ovarian function. Reproduction 131:1-9.

Vom Saal, F.S., Finch, C.E. 1988. Reproductive senescence: phenomena and mechanisms in mammals and selected vertebrates. In: Physiology of Reproduction. Knobiel, E., Neill, J. (Eds.) Raven Press, New York. pp 2351-2399.

Wasser, S.K., Papageorge, S., Foley, C., Brown, J.L. 1996. Excretory fate of estradiol and progesterone in the African elephant (Loxodonta africana) and patterns of fecal steroid concentrations throughout the estrous cycle. Gen. Comp. Endocrinol. 102:255-262.

Webb, R., Woad, K.J., Armstrong, D.G. 2002. Corpus luteum (CL) function: local control mechanisms. Dom. Anim. Endocrinol. 23:277-285.

Webster, J., Scanlon, M.F. 1997. Prolactinomas. In: Sheaves, R., Jenkins, P.J., Wass, J.A. (Eds). Clincal Endocrine Oncology. Oxford, UK: Blackwell Science, pp 189-194.

Weenen, C., Laven, J., Von Bergh, A., Cranfield, M., Groome, N., Visser, J., et al. 2004. AntiMüllerian hormone expression pattern in the human ovary: potential implications for initial and cyclic follicle recruitment. Mol. Hum. Reprod. 10:77-83.

Weissenbock, N., Schwammer, H., Ruf, T. 2008. Estrous synchrony in a group of African elephants (Loxodonta africana) under human care. Anim. Reprod. Sci. 113:322-327. 
Whitehouse, A.M., Hall-Martin, A.J. 2000. Elephants in Addo elephant national park, South Africa: reconstruction of the population's history. Oryx. 34:46-55.

Wielebnowski, N.C., Ziegler, K., Wildt, D.E., Lukas, J., Brown, J.L. 2002. Impact of social management on reproduction, adrenal and behavioural activity in the cheetah (Acinonyx jubatus). Anim. Conserv. 5:291-301.

Wiese, R.J., Willis, K. 2004. Calculation of longevity and life expectancy in captive elephants. Zoo Biol. 23:365-373.

Wiese, R.J., Willis, K. 2006. Population management of zoo elephants. Intern. Zoo Yearbk. 40:80-87.

Williamson, B.R. 1976. Reproduction in female African elephants in the Wankie National Park, Rhodesia. S. Af. J. Wildl. Res. 6:89-93.

Wise, T., Maurer, R.R. 1994. Follicular development, oocyte viability and recovery in relation to follicular steroids, prolactin and glycosaminoglycans throughout the estrous period in superovulated heifers with a normal LH surge, no detectable LH surge and progestin inhibition LH surge. Dom Anim Endocrinol 11:35-38.

Wittemyer, G., Ganswindt, A., Hodges, K. 2007. The impact of ecological variability on the reproductive endocrinology of wild female African elephants. Horm. Behav. 51:346354.

Woolf, P.D. 1986. Differential diagnosis of hyperprolactinemia: physiological and pharmacological factors. In: Prolactinomas: Contempory Issues in Endocrinology and Metabolism. Robbins, R.J., Olefsky, J.M. (Eds.) Churchill Livingston, New York. pp 43-65. 
Yamamoto, Y., Yamamoto, T., Watanabe, G., Yuto, N., Keio, M., Narushima, E., Katayanagi, M., Nakao, R., Morikubo, S., Sakurai, Y., Kaneko, M., Kaewmanee, S., Taya, K.. 2010. Prolactin secretion and ovarian function in cycling and non-cycling African female elephants (Loxodonta africana). J. Vet. Med. Sci. 72:845-852.

Yazigi, R.A., Quintero, C.H., Salameh, W.A. 1997. Prolactin disorders. Fertil. Steril. 67:215225.

Yon, L., Kanchanapangks, S., Chaiyabutr, N., Stanczyk, F., Meepan, S., Lasley, B. 2007. A longitudinal study of LH, gonadal and adrenal steroids in four intact Asian bulls (Elephas maximus) and one castrate African bull (Loxodonta africana) during musth and nonmusth periods. Gen. Comp. Endocrinol. 151:241-245.

Yoshimura, Y., Tada, S., Oda, T., Nakamura, Y., Maruyama, K., Ichikawa, F., Ebihara, T., Hirota, Y., Sawada, T., Kawakami, S. 1989. Direct inhibitory ovarian effects of prolactin in the process of ovulation. Nippon Sanka Fujinka Gakhai Zasshi. 41:83-89.

Yoshimura, Y., Maruyana, K., Shiraki, M., Kawakami, S., Fukushima, M., Nakamura, Y. 1990. Prolactin inhibits plaminogen activator activity in the preovulatory follicles. Endocrinol. 126:631-636.

Yoshimura, Y., Nakamura, Y., Yamada, H., Ando, M., Ubukata, Y., Oda, T., Suzuki, M. 1991. Possible contribution of prolactin in the process of ovulation and oocyte maturation. Horm. Res. 35:22-32.

Yoshimura, Y., Nakamura, Y., Oda, T., Ando, M., Ubukata, Y., Koyama, N., Karube, M., Yamada, H. 1992. Effects of prolactin on ovarian plasmin generation in the process of ovulation. Biol. Reprod. 46:322-327. 
Young, K.H., Kraeling, R.R., Bazer, F.W. 1989. Effects of prolactin on conceptus survival and uterine secretory activity in pigs. J. Reprod. Fertil. 86:713-722.

Yu, M.C., Gerkins, V.R., Henderson, B.E., Brown, J.B., Pike, M.C. 1981. Elevated levels of prolactin in nullipaarous women. Br. J. Cancer. 43:826-831.

Zacur, H.A. 1999. Hyperprolactinemia. In: Encyclopedia of Reproduction. Knobil, E., Neill, J. (Eds.) Academic Press, New York. pp 423-427.

Zadworney, D., Shimada, K., Ishida, H., Sato, K. 1989. Gonadotropin-stimulated estradiol production in small ovarian follicles of the hen is suppressed by physiological concentrations of prolactin in vitro. Gen. Comp. Endocrinol. 74:468-473.

Zalata, A.A., Hassan, A.H., Nada, H.A., Bragais, F.M., Agarwal, A., Mostafa, T. 2008. Follicle-stimulating hormone receptor polymorphism and seminal anti-Müllerian hormone in fertile and infertile men. Andrologia. 40:392-397.

Zeleznik, A.J. 2001. Follicle selection in primates: “Many are called but few are chosen.” Biol. Reprod. 65:655-659.

Zhang, C., Bosch, M.A., Rønnekleiv, O.V., Kelly, M.J. 2009. Gamma-Aminobutyric acid B (GABA) receptor mediated inhibition of gonadotropin-releasing hormone neurons is suppressed by the kisspeptin G protein-coupled receptor 54 (GPR54) signaling. Endocrinol. 150:2388-2394.

Zuckerman, S. 1937. Cystic endometrial hyperplasia in a rhesus monkey. BJOG: Int. J. Obstet. Gynaecol. 44:494-499. 


\section{Appendix I.}

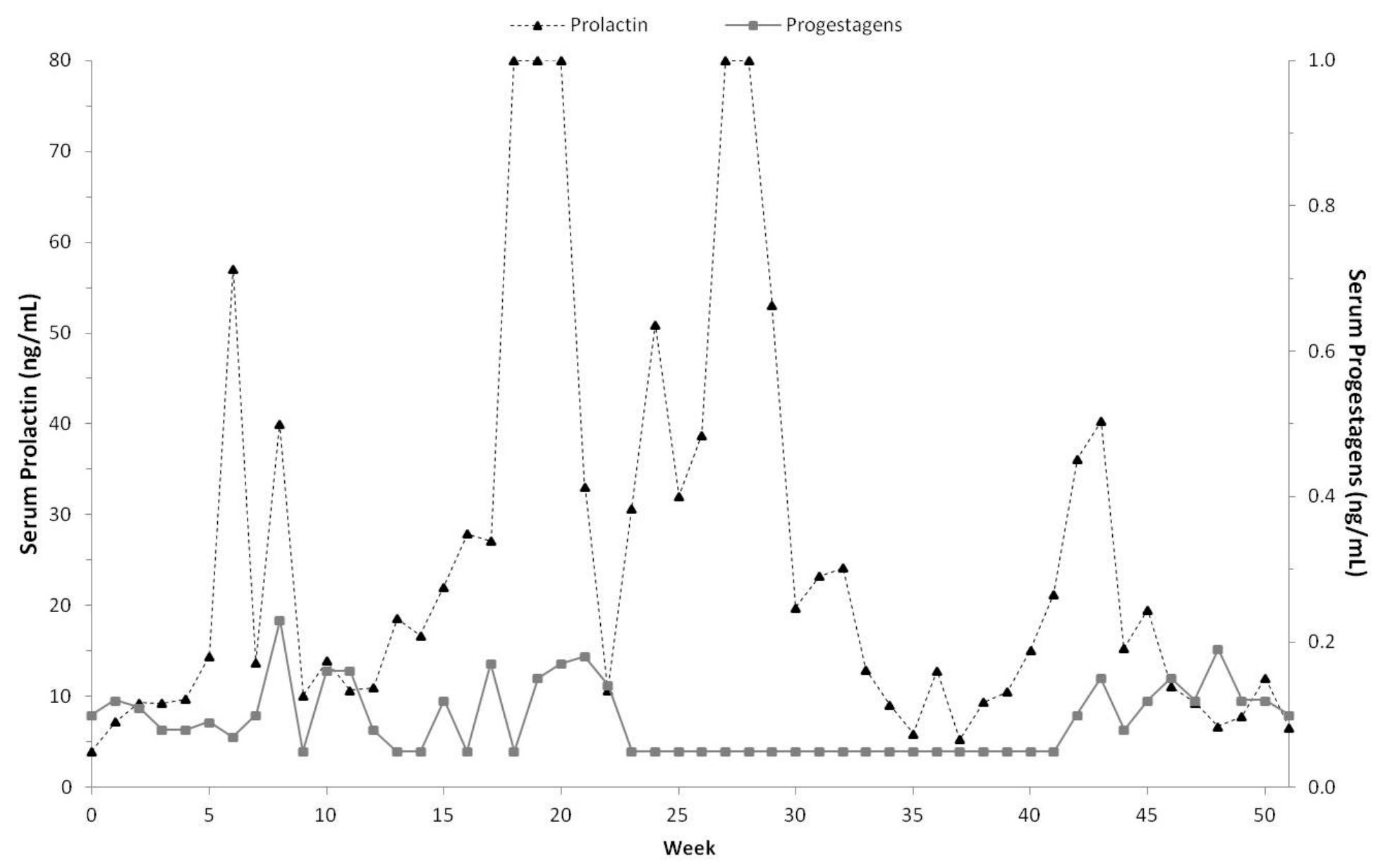

Figure 1. Elephant 1. Serum progestagen and prolactin concentrations in a domperidone treated prolactin deficient acyclic female African elephant. 


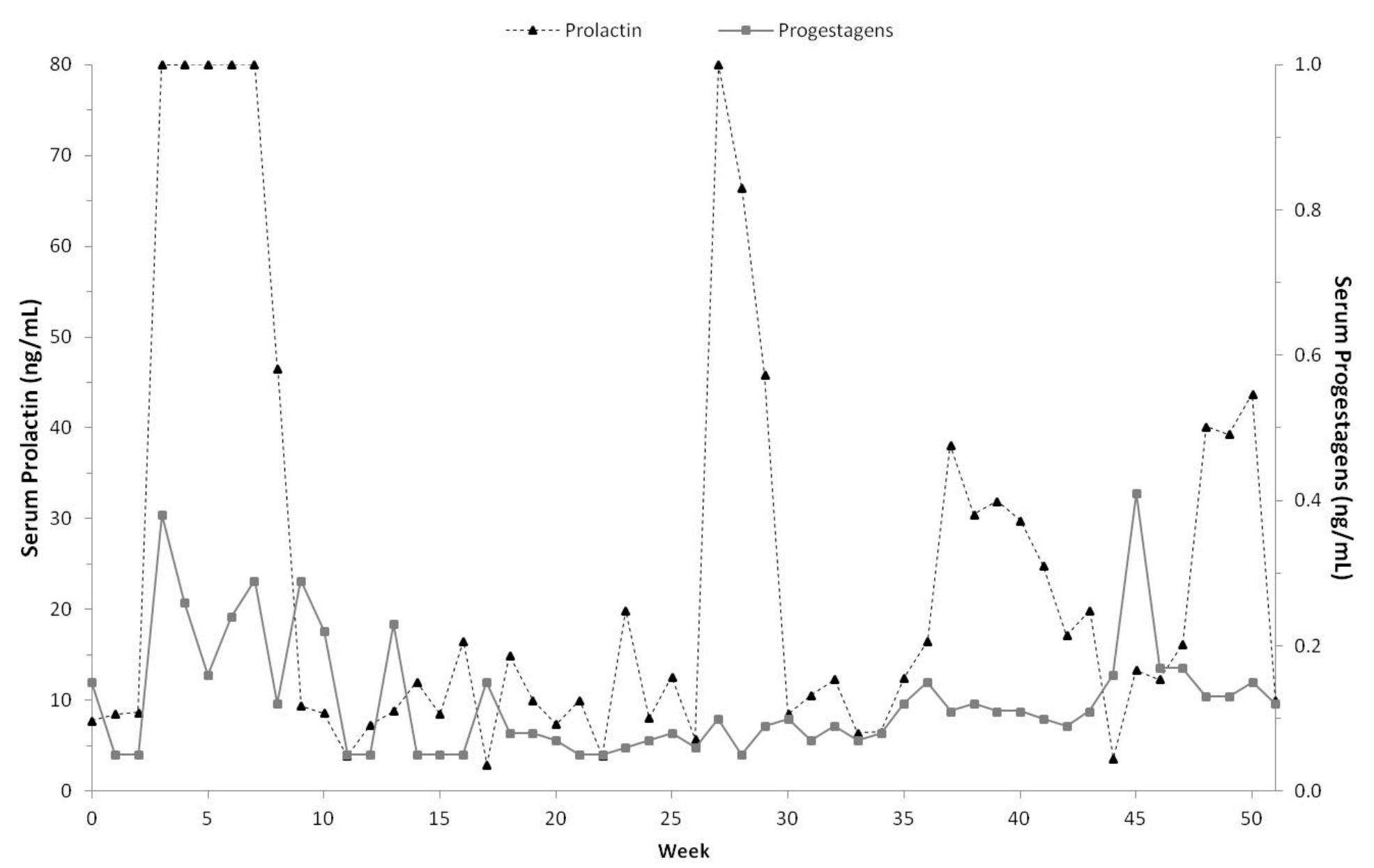

Figure 2. Elephant 2. Serum progestagen and prolactin concentrations in a domperidone treated prolactin deficient acyclic female African elephant. 


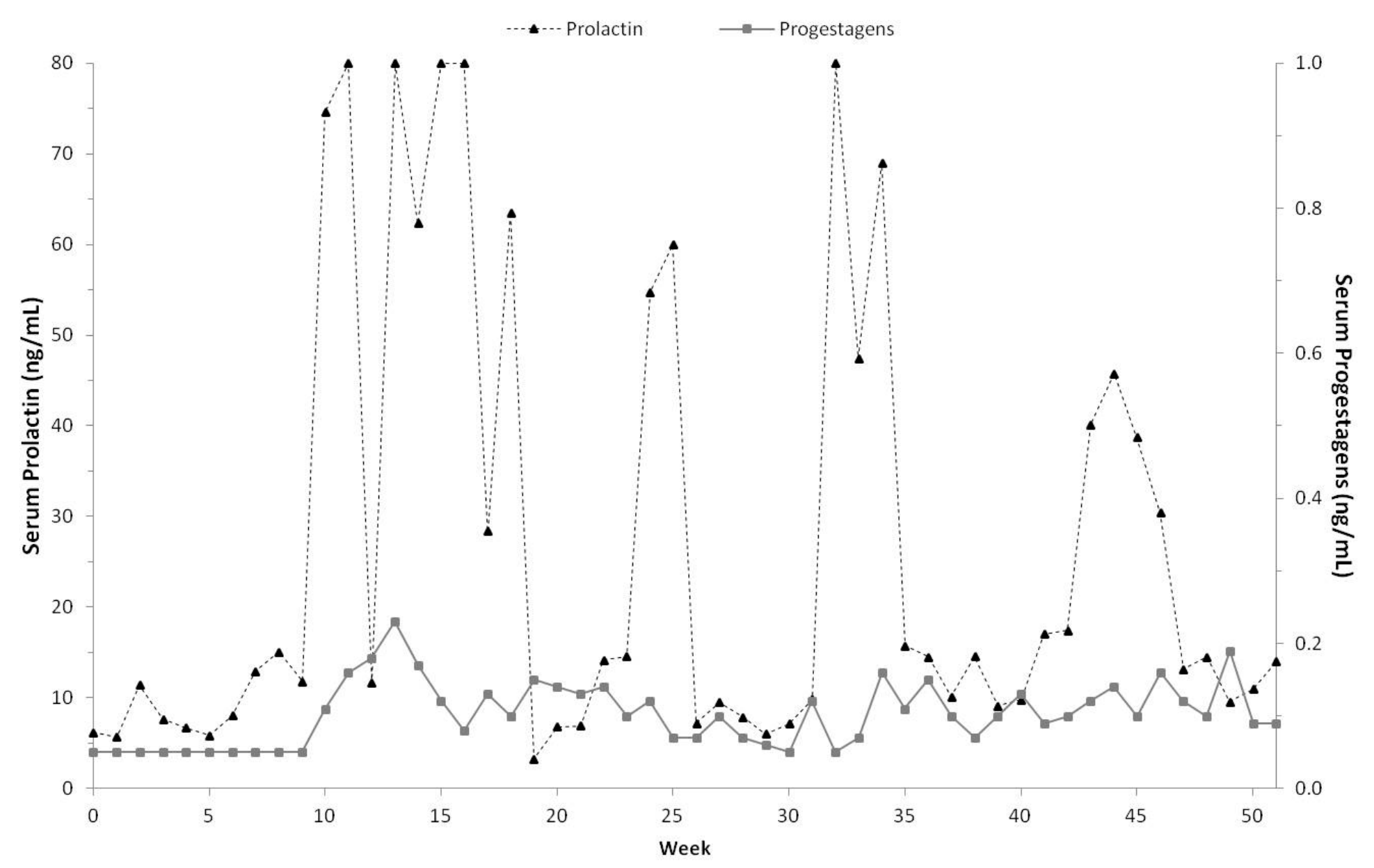

Figure 3. Elephant 3. Serum progestagen and prolactin concentrations in a domperidone treated prolactin deficient acyclic female African elephant. 


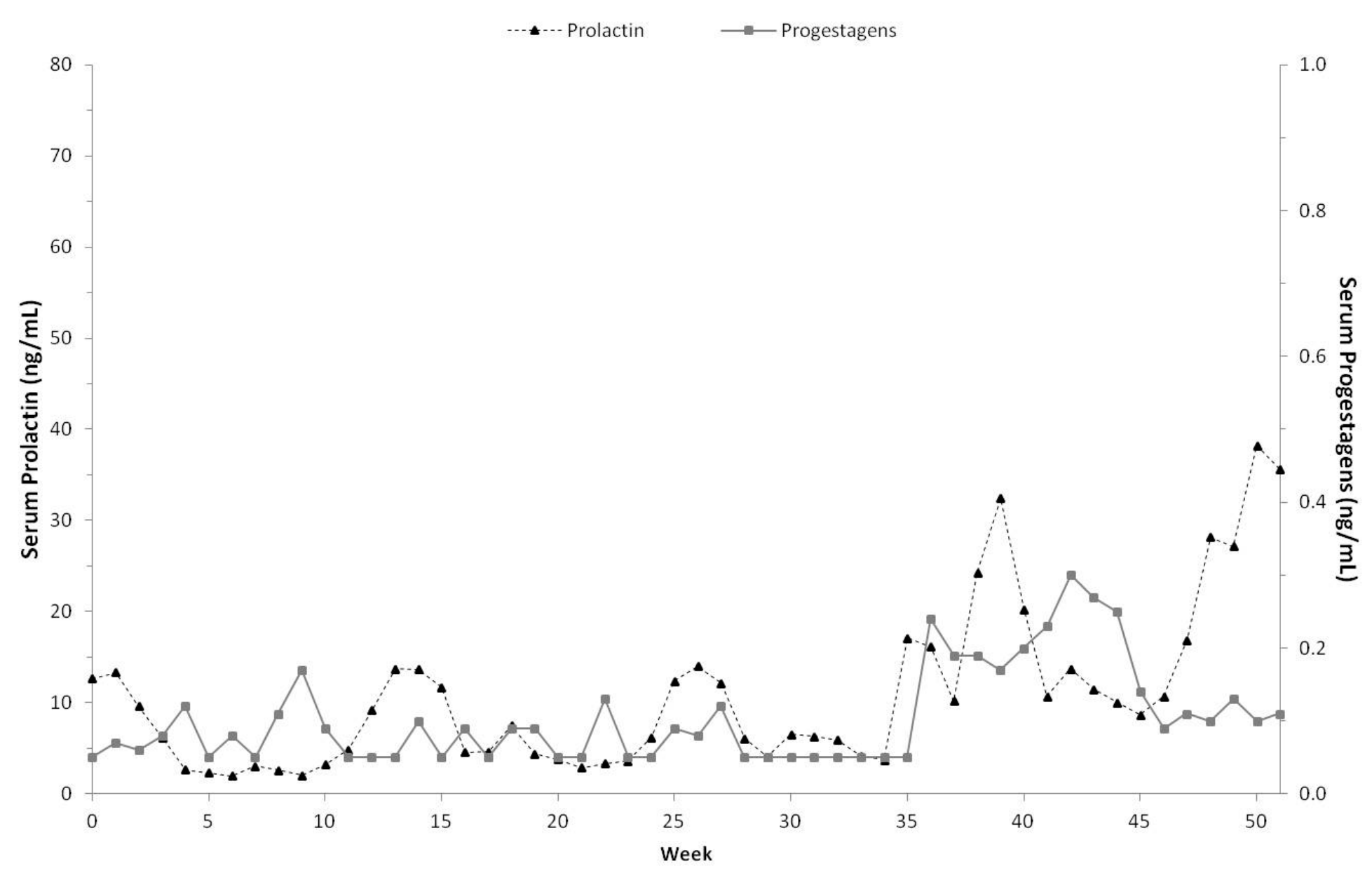

Figure 4. Elephant 4. Serum progestagen and prolactin concentrations in a domperidone treated prolactin deficient acyclic female African elephant. 


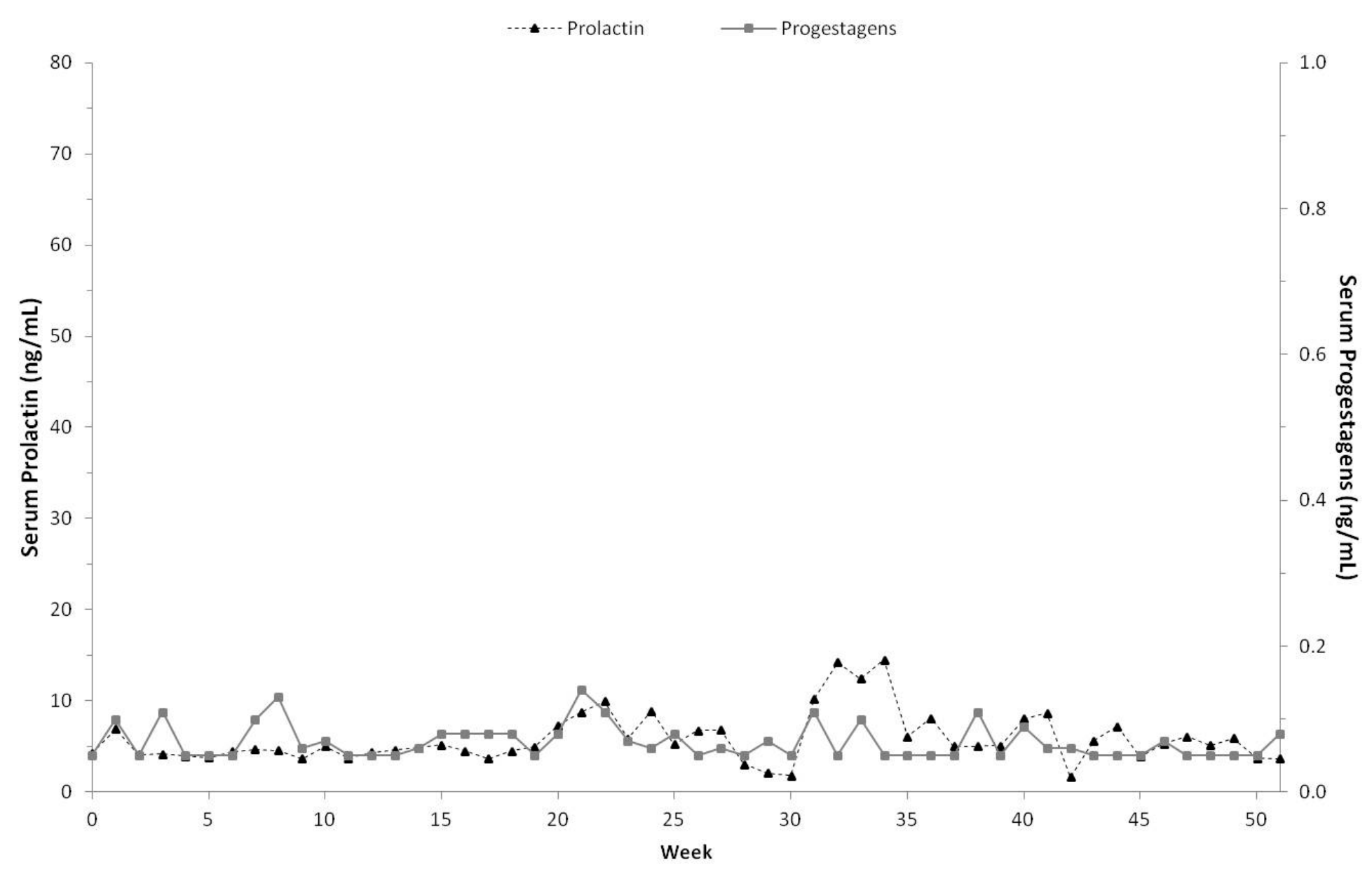

Figure 5. Elephant 5. Serum progestagen and prolactin concentrations in a domperidone control prolactin deficient acyclic female African elephant. 


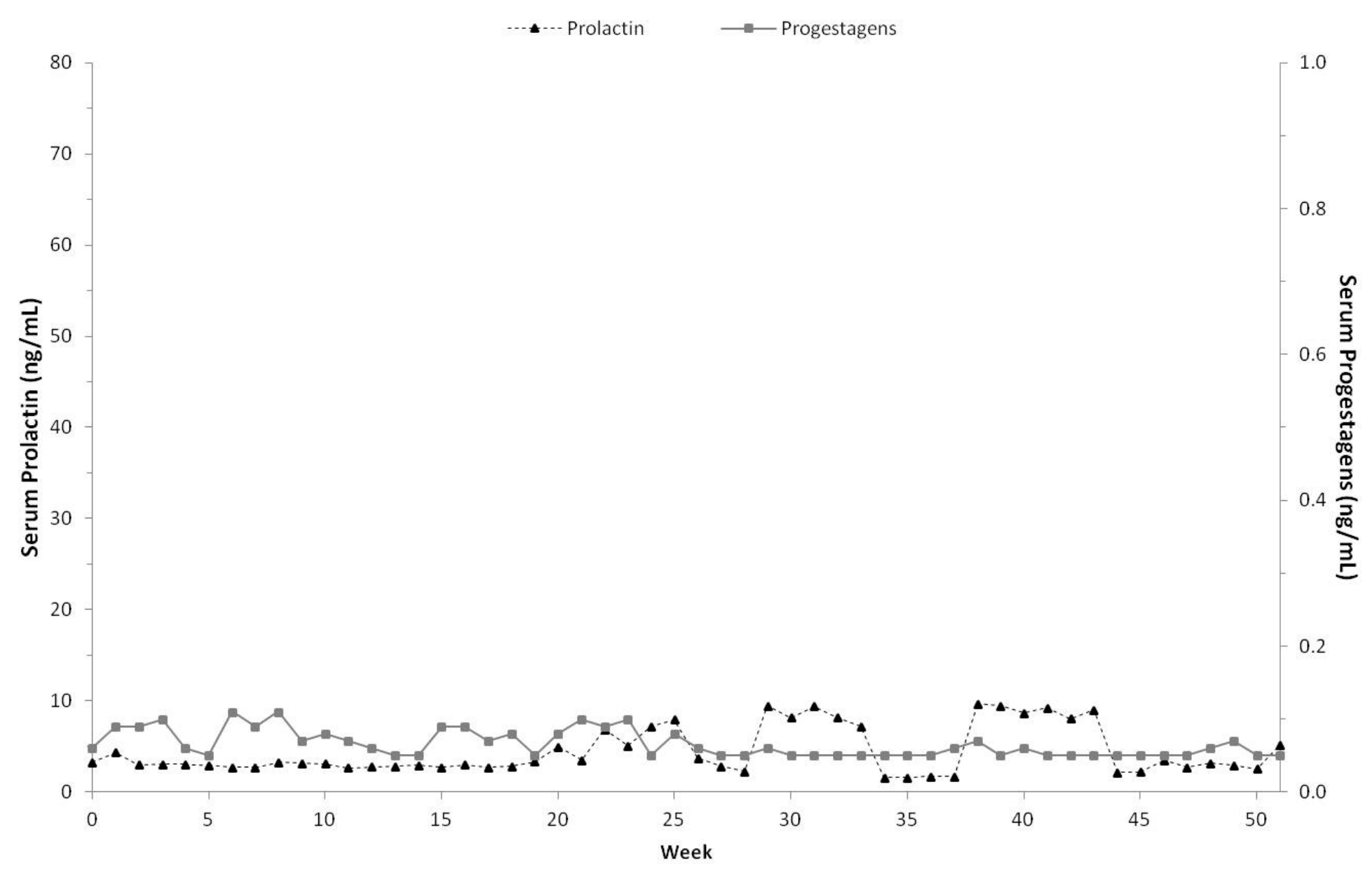

Figure 6. Elephant 6. Serum progestagen and prolactin concentrations in a domperidone control prolactin deficient acyclic female African elephant. 


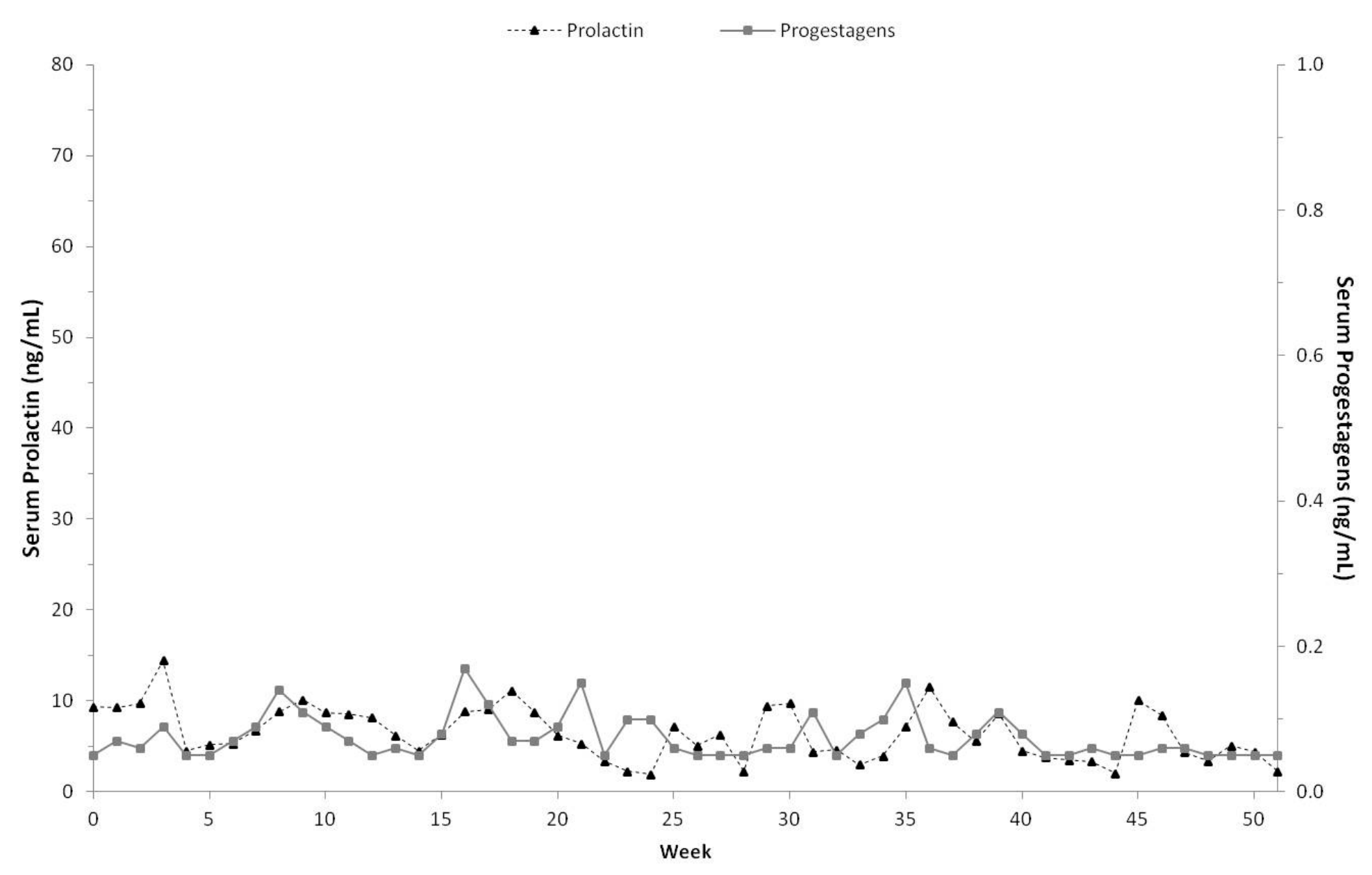

Figure 7. Elephant 7. Serum progestagen and prolactin concentrations in a domperidone control prolactin deficient acyclic female African elephant. 


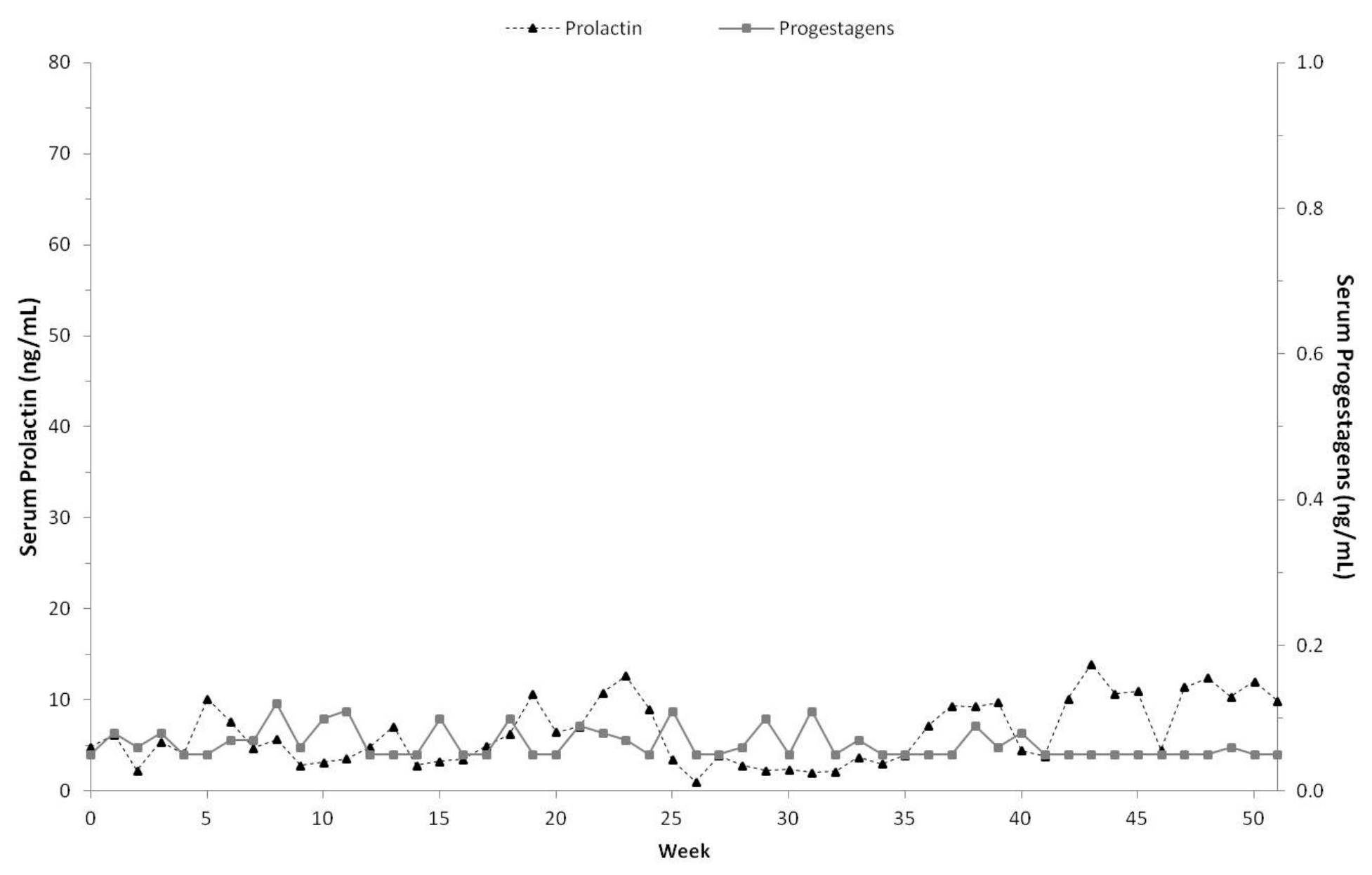

Figure 8. Elephant 8. Serum progestagen and prolactin concentrations in a domperidone control prolactin deficient acyclic female African elephant. 


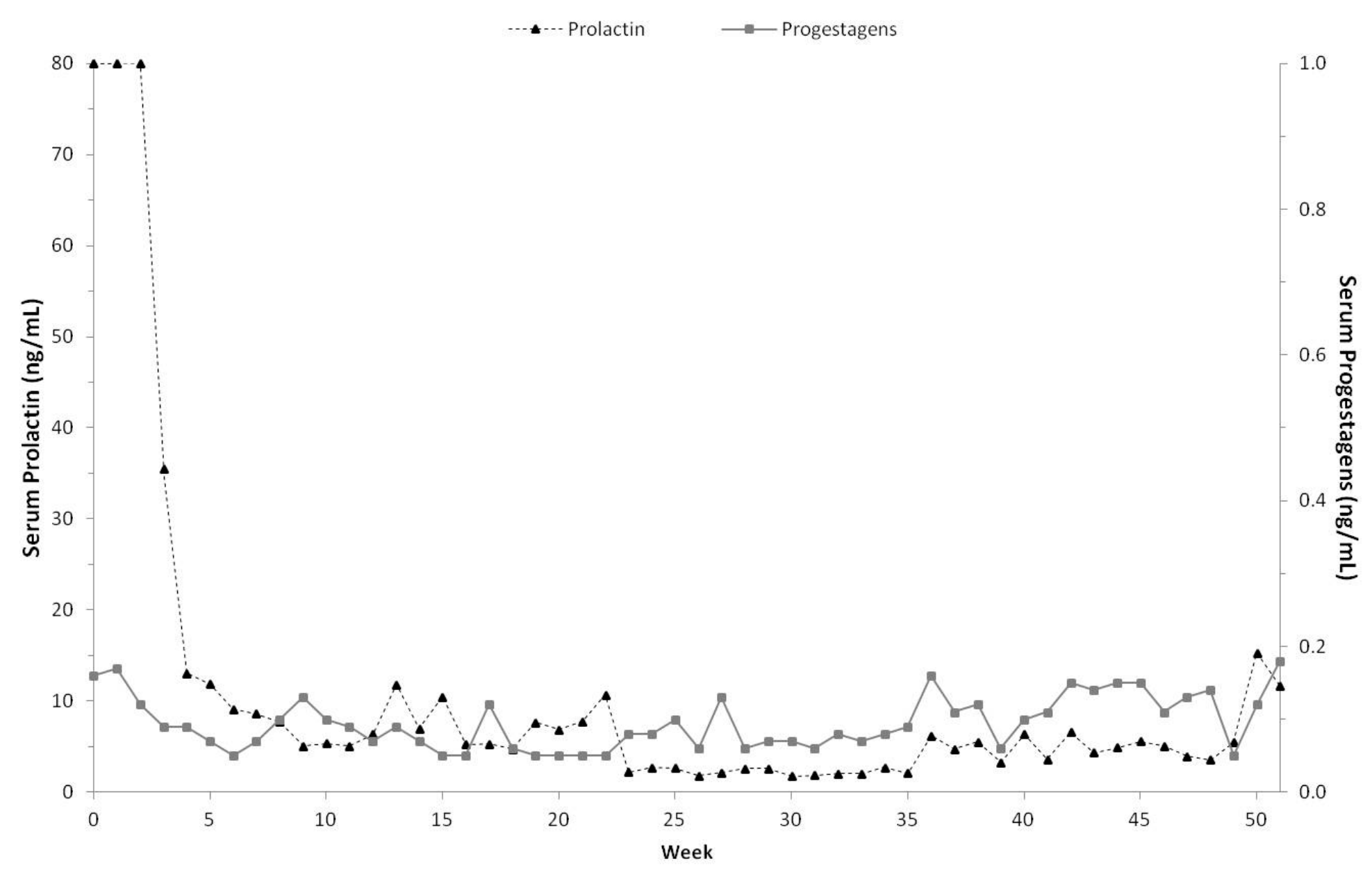

Figure 9. Elephant 9. Serum progestagen and prolactin concentrations in a Cabergoline treated hyperprolactinemic acyclic female African elephant. 


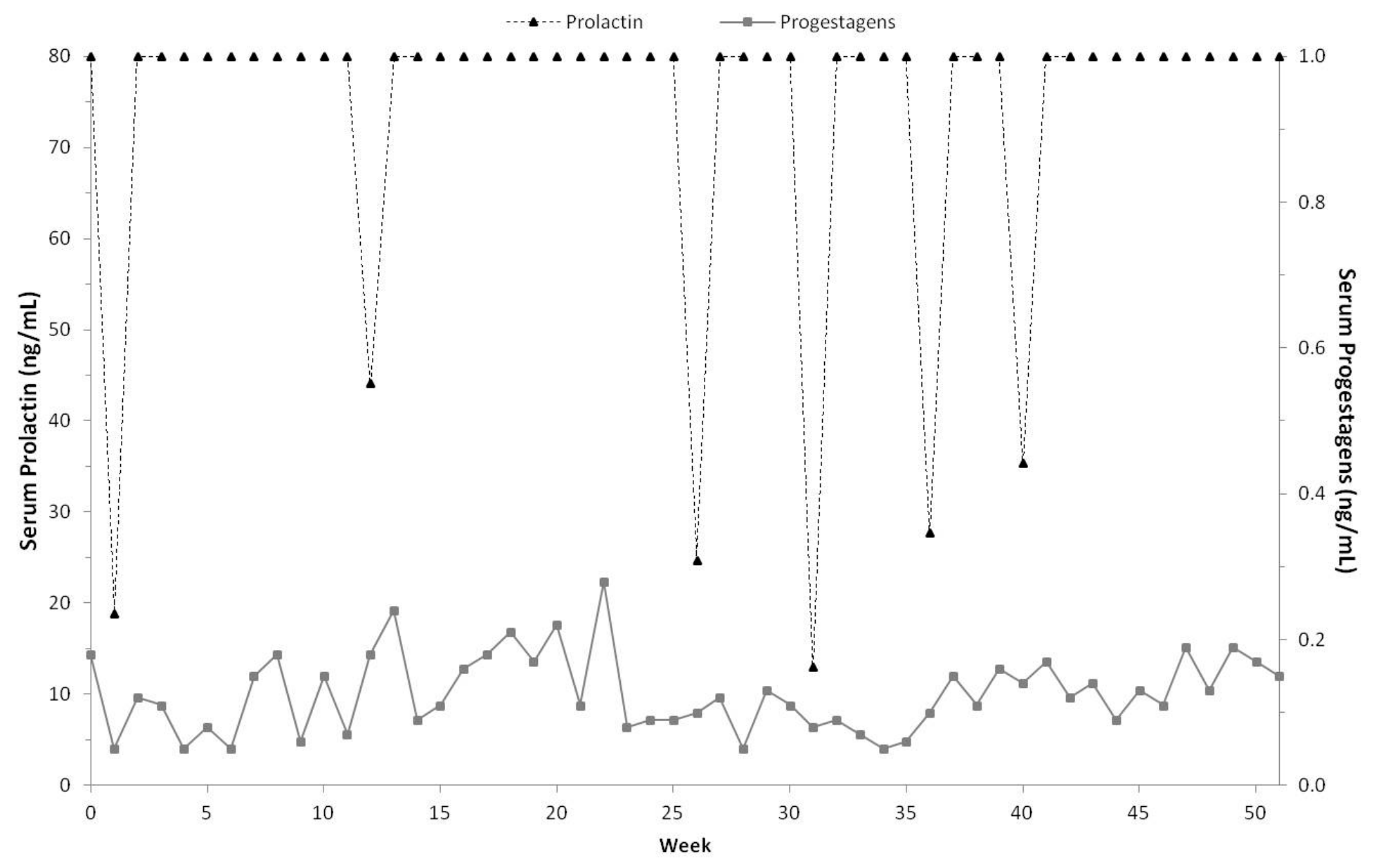

Figure 10. Elephant 10. Serum progestagen and prolactin concentrations in a Cabergoline treated hyperprolactinemic acyclic female African elephant. 


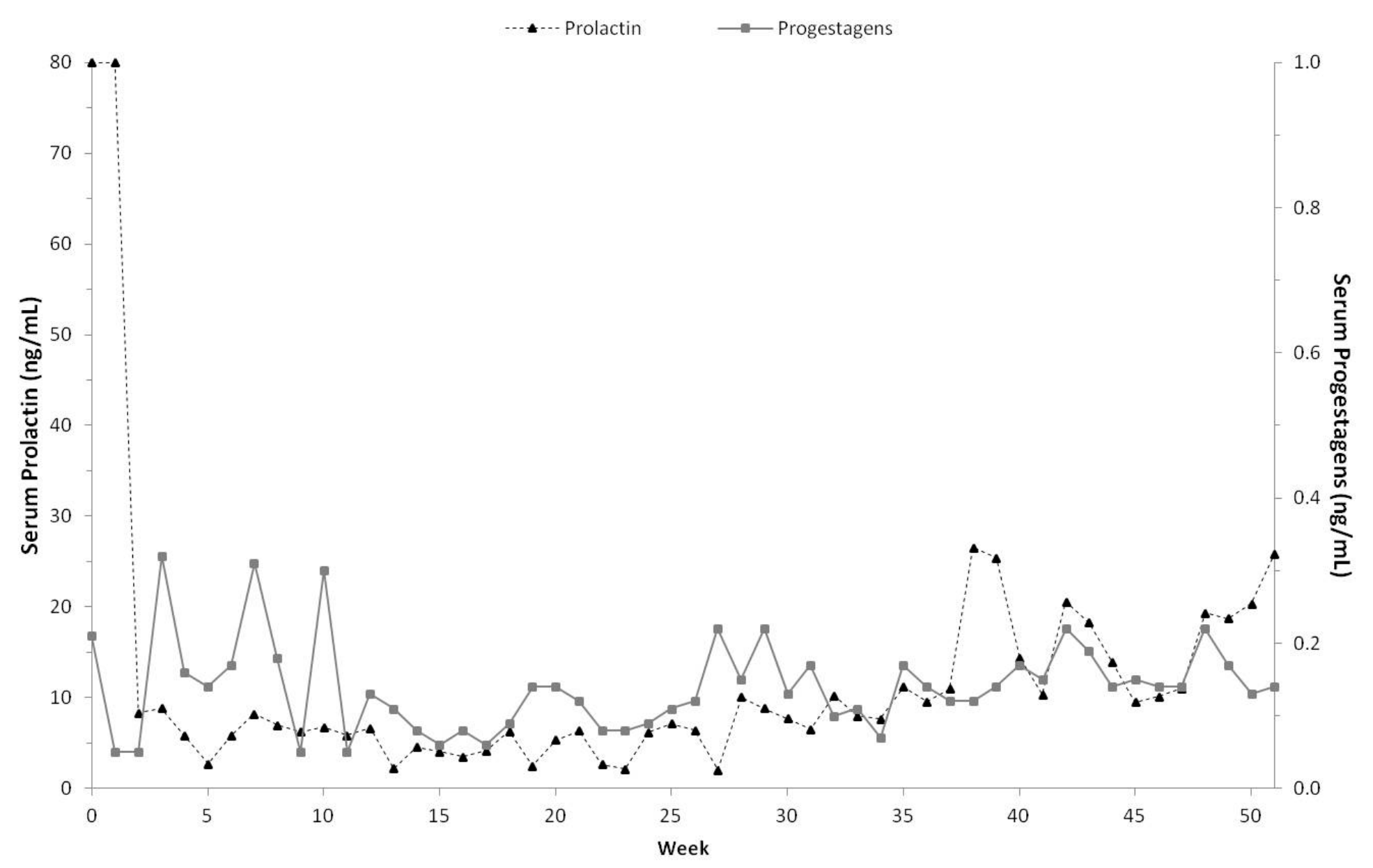

Figure 11. Elephant 11. Serum progestagen and prolactin concentrations in a Cabergoline treated hyperprolactinemic acyclic female African elephant. 


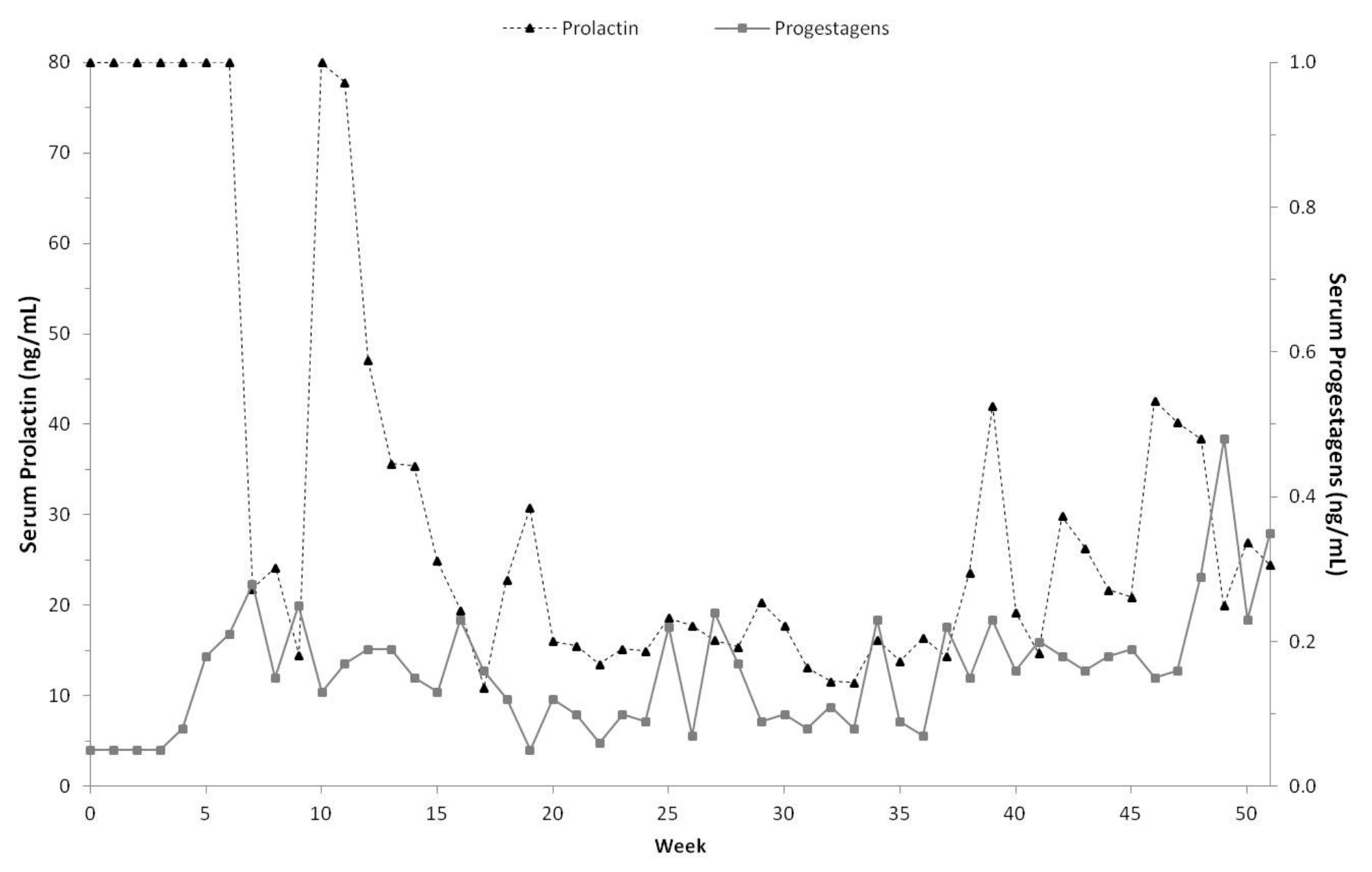

Figure 12. Elephant 12. Serum progestagen and prolactin concentrations in a Cabergoline treated hyperprolactinemic acyclic female African elephant. 


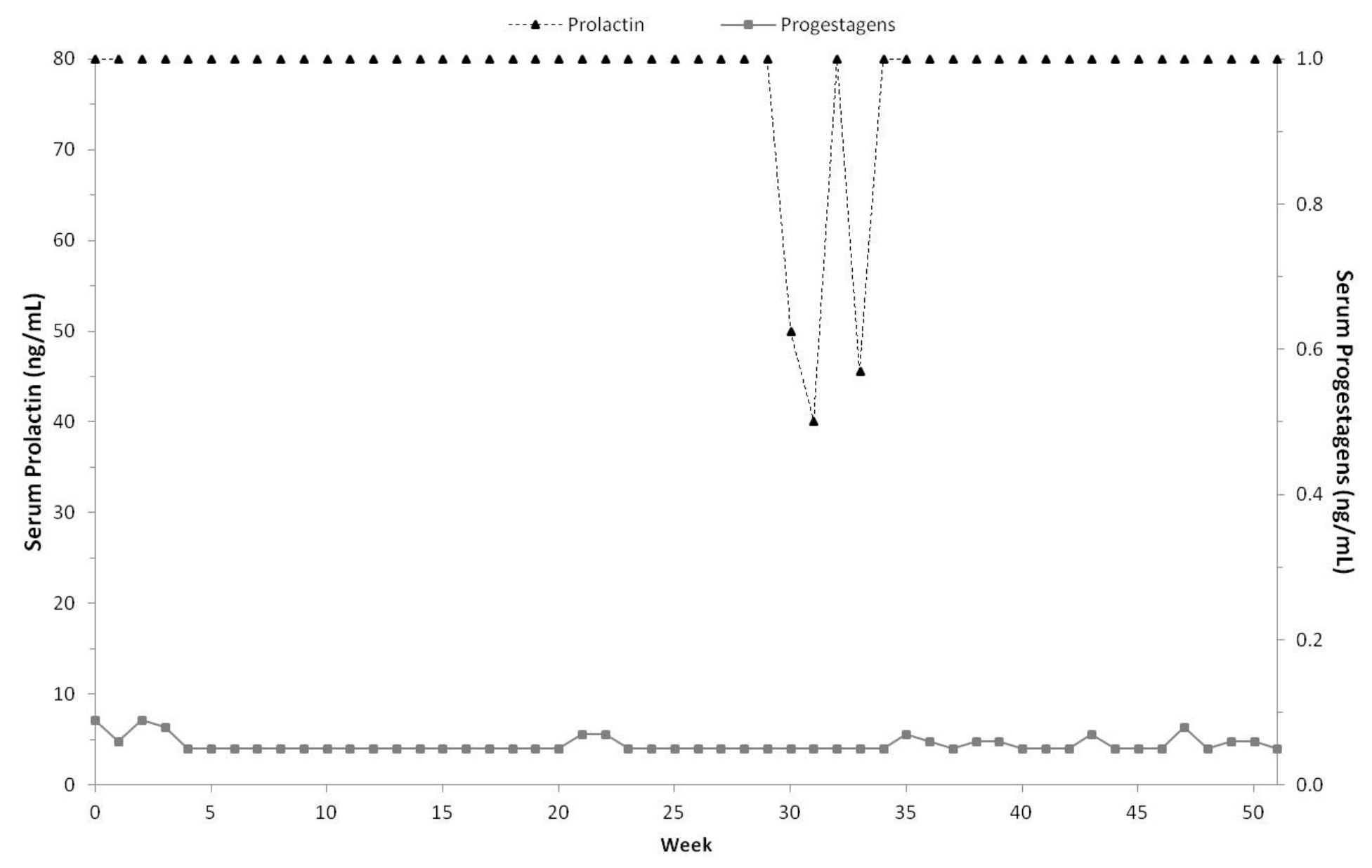

Figure 13. Elephant 13. Serum progestagen and prolactin concentrations in a Cabergoline control hyperprolactinemic acyclic female African elephant. 


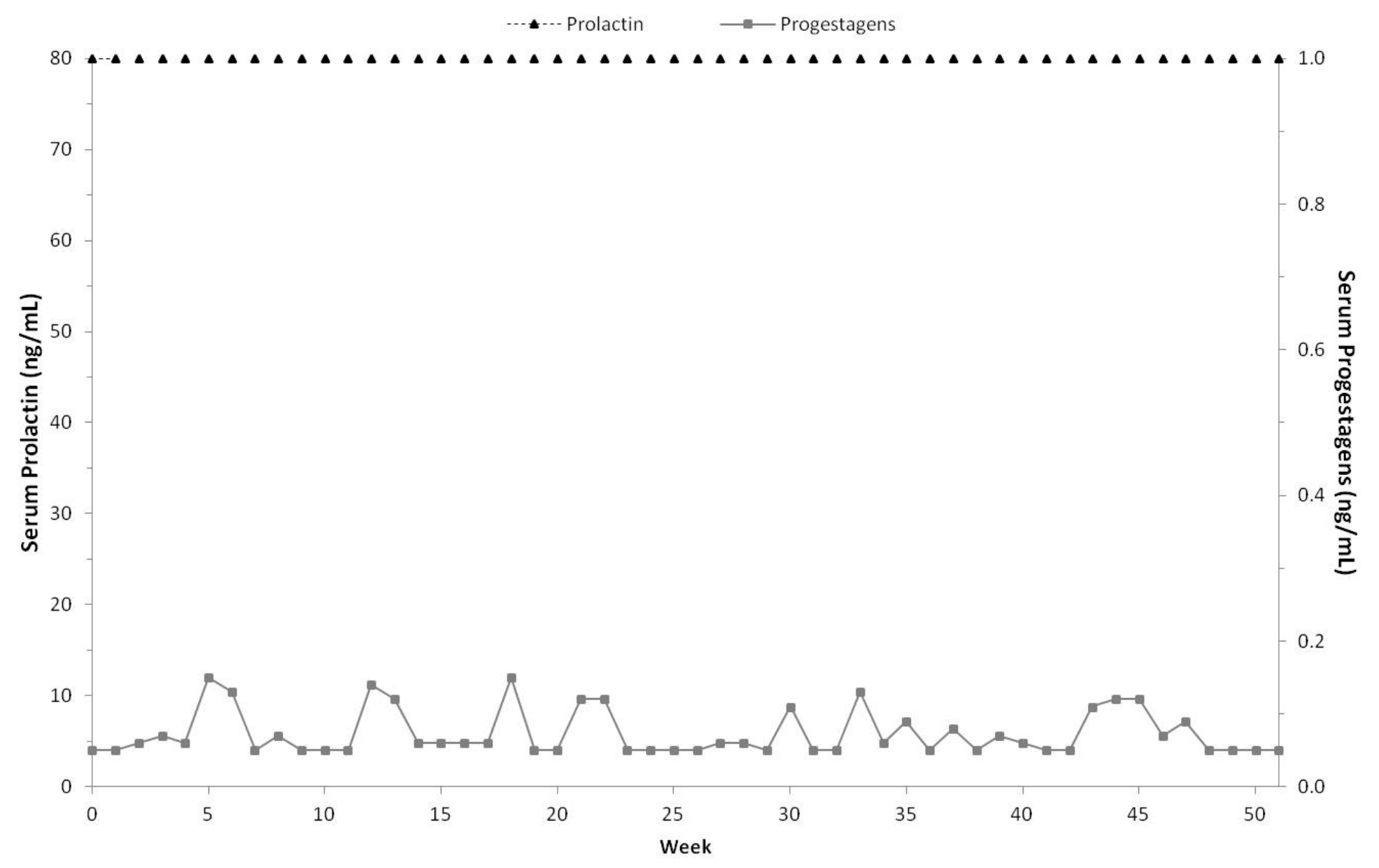

Figure 14. Elephant 14. Serum progestagen and prolactin concentrations in a Cabergoline control hyperprolactinemic acyclic female African elephant. 


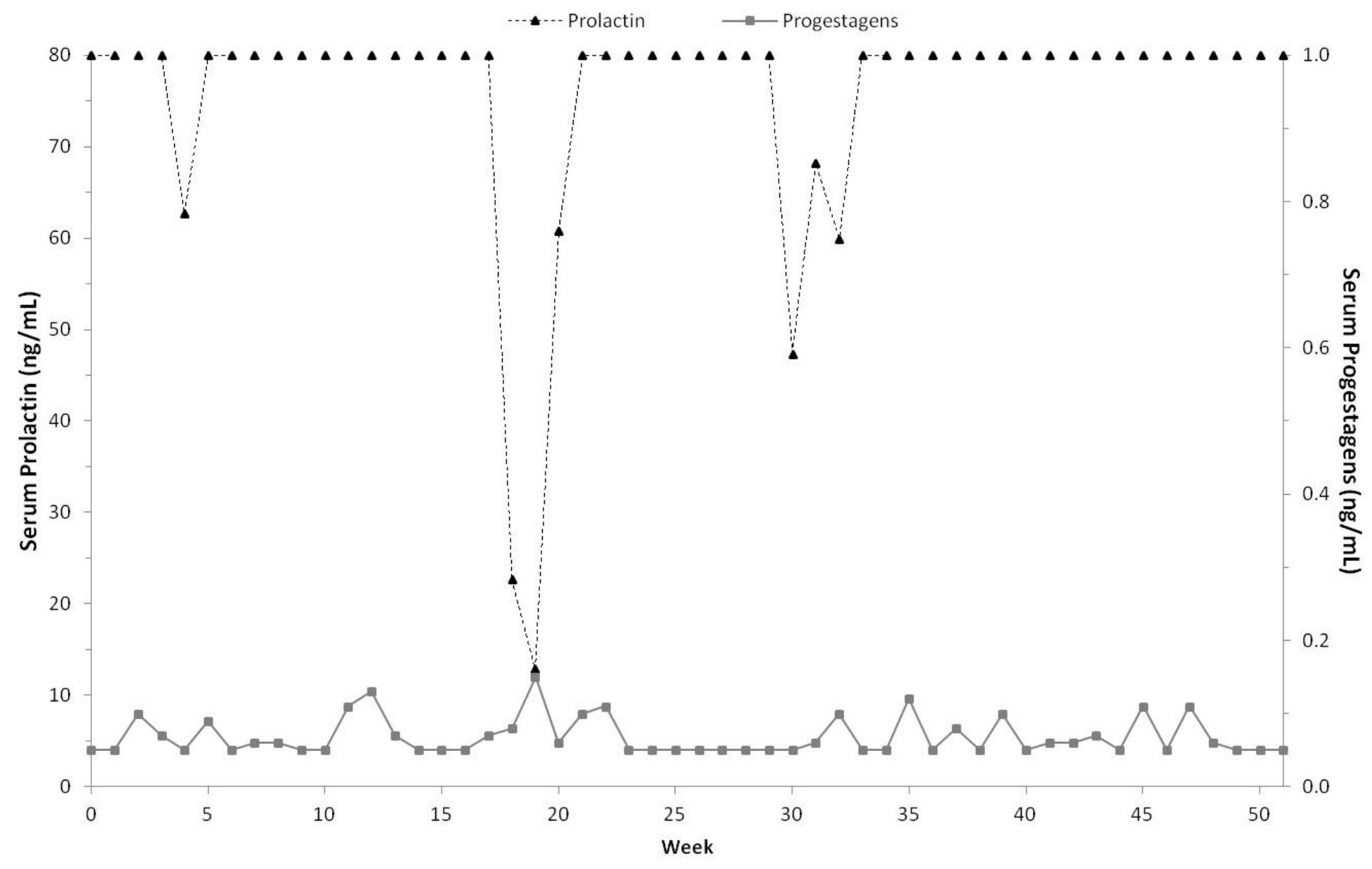

Figure 15. Elephant 15. Serum progestagen and prolactin concentrations in a Cabergoline control hyperprolactinemic acyclic female African elephant. 


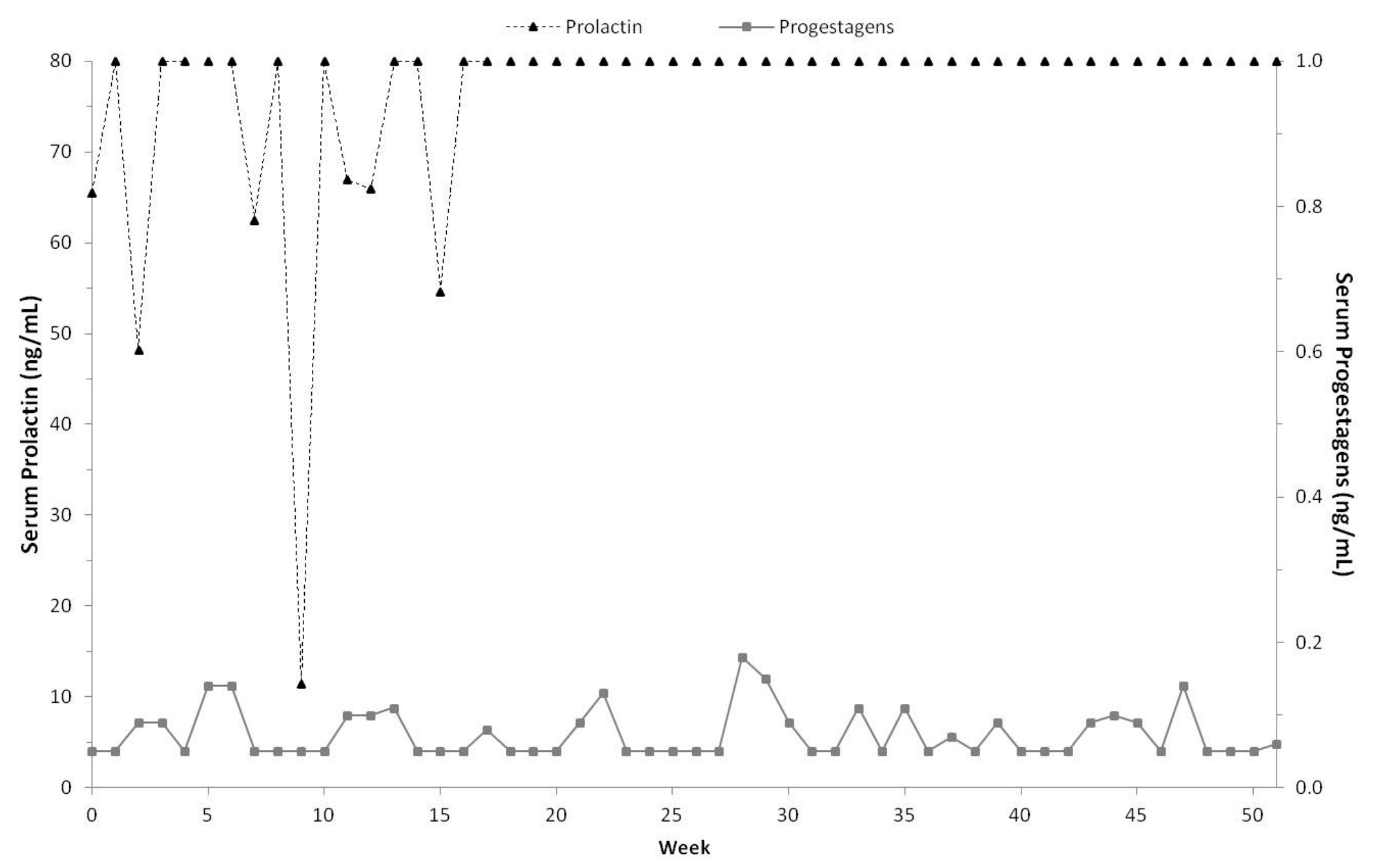

Figure 16. Elephant 16. Serum progestagen and prolactin concentrations in a Cabergoline control hyperprolactinemic acyclic female African elephant. 


\section{Vita}

Name:

Parents:

Date of Birth:

Place of Birth:

Schools Attended:

Flintstone High School

Flintstone, Maryland

West Virginia University

Morgantown, West Virginia

B.S. in Animal and Veterinary Science

West Virginia University

Morgantown, West Virginia

M.S. in Reproductive Physiology

West Virginia University

Morgantown, West Virginia

Ph.D. in Reproductive Physiology
Tina Lynn Dow

Thomas W. Grieves, Sr.

Shirley J. Grieves

December 11, 1976

Berkeley Springs, West Virginia

1990-1994

1999-2002

2006-2008

2008-2012 